3.

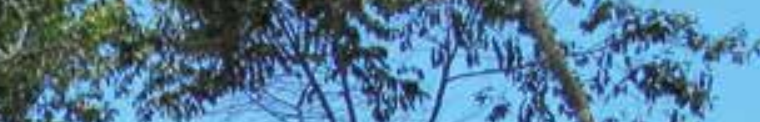

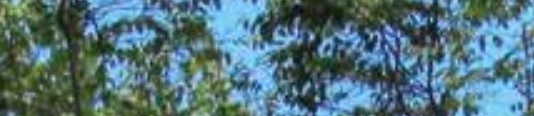

(3)

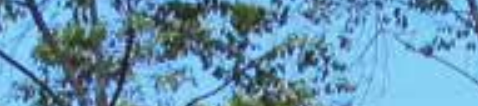

(1)

a.

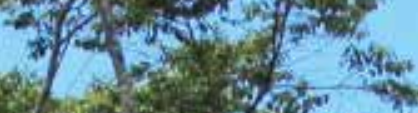

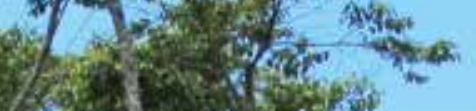
Q6)

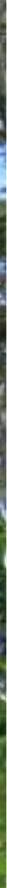
1,364085

\title{
Reformas en la tenencia forestal
}

Editores

Anne M. Larson y Ganga Ram Dahal

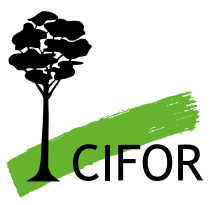





\section{Reformas en la tenencia forestal}

Editores

Anne M. Larson y Ganga Ram Dahal 


\section{Nota de los editores}

Esta colección de artículos fue traducida de la publicación original que apareció en la revista Conservation and Society 10(2) en el 2012. Allí se pueden encontrar tres estudios de caso adicionales (Ghana, Camerún y Kenia), disponibles en inglés, y que pueden ser descargados sin costo alguno, así como las versiones en inglés de todos los artículos, de la página web de la revista http://www.conservationandsociety.org/showBacklssue. asp?issn=0972-4923;year=2012; volume=10;issue=2;month=April-June

(C) 2013 Center for International Forestry Research

Todos los derechos reservados

ISBN: 978-602-8693-94-3

Larson, A.M y Dahal, G.R. (eds) 2013 Reformas en la tenencia forestal. Bogor, Indonesia.

Fotografías:

Portada por Peter Cronkleton; Parte 1-2 por Peter Cronkleton; Parte 3 por Anne M. Larson

CIFOR

Jl. CIFOR, Situ Gede

Bogor Barat 16115

Indonesia

$\mathrm{T}+62$ (251) 8622-622

$\mathrm{F}+62$ (251) 8622-100

E cifor@cgiar.org

\section{cifor.org}

Cualquier opinión vertida en este documento es de los autores. No refleja necesariamente las opiniones de CIFOR, de las instituciones para las que los autores trabajan o de los financiadores. 


\section{Índice}

Prefacio iv

Agradecimientos $\mathrm{V}$

Lista de autores $\quad$ vi

$\begin{array}{ll}\text { 1. Introducción } & 1\end{array}$

La reforma de la tenencia forestal: ¿Nuevos derechos sobre los recursos para las comunidades que viven en los bosques? 3

Anne M Larson y Ganga Ram Dahal

\section{Temas transversales}

La cogestión en la forestería comunitaria: Cómo la transferencia parcial de los derechos de manejo crea retos para las comunidades forestales

Peter Cronkleton, Juan M. Pulhin y Sushil Saigal

El fortalecimiento de las reformas de la tenencia forestal a través de regulaciones que respondan mejor a las necesidades de la población local

Anne M. Larson y Juan M. Pulhin

Condiciones que determinan la participación de los pequeños productores y las comunidades en los mercados de la madera en la América Latina tropical Pablo Pacheco

Organizaciones de segundo nivel y la democratización de la gobernanza forestal: Estudios de caso de Nepal y Guatemala

Naya Sharma Paudel, Iliana Monterroso y Peter Cronkleton

\section{Estudios de caso latinoamericanos}

La legitimidad de los derechos forestales: Los fundamentos de la reforma de tenencia forestal en las áreas protegidas de Petén, Guatemala Iliana Monterroso y Deborah Barry

De bosques comunales a áreas protegidas: Las implicaciones de los cambios de la tenencia en el manejo de los recursos naturales en Guatemala

Silvel Elías

Las reformas de las políticas públicas y la gobernanza forestal indígena:

El caso del pueblo Yuracaré en Bolivia

Rosario León, Patricia Uberhuaga, Jean Paul Benavides, Krister Andersson 


\section{Prefacio}

En muchos países en desarrollo, pero especialmente en América Latina, los derechos a cerca de 200 millones de hectáreas de bosque han sido reconocidos o transferidos legalmente a comunidades locales y grupos indígenas. Estos cambios en las políticas se han unido para formar lo que hoy entendemos por reformas en la tenencia forestal, similar a las grandes reformas agrarias que tuvieron lugar a mediados del siglo XX, con consecuencias igualmente importantes. Entender esta dinámica emergente exige el análisis sistemático y comparativo de los procesos y resultados asociados con estas reformas así como el desarrollo de marcos y enfoques que faciliten dicha comparación.

Esta colección presenta los resultados de una investigación preliminar, basado en tres años de estudio en diez países de tres regiones diferentes -América Latina, África y Asiafinanciado por el Centro Internacional de Investigaciones para el desarrollo (IDRC por sus siglas en inglés) y la Fundación Ford, con apoyo del Programa sobre Bosques (PROFOR) del Banco Mundial. El Centro para la Investigación Forestal Internacional (CIFOR) unió fuerzas con investigadores locales y nacionales para analizar los procesos de reforma en más de 30 lugares de investigación. La gran diversidad en los tipos de reforma permitió que el proyecto examinara la reforma en la tenencia forestal y el manejo comunitario en un gran número de contextos específicos, tanto a nivel nacional como local.

La introducción presenta un panorama general de la historia de la reforma y los principales resultados de la investigación. Los siguientes cuatro capítulos temáticos exploran, respectivamente, los problemas que enfrentan los acuerdos de cogestión, las regulaciones como barreras a los derechos, los desafíos de participar en los mercados de madera, y la experiencia y el potencial de las organizaciones de segundo nivel. Si bien algunos de estos temas fueron tratados en una publicación anterior sobre los resultados de la investigación, los artículos que aquí se presentan han profundizado el análisis así como su vínculo con la teoría.

A continuación siguen tres estudios de caso sobre lugares de investigación en América Latina: las concesiones forestales comunitarias del Petén, Guatemala, la tierras comunales del altiplano guatemalteco y un territorio indígena en Bolivia. El caso del Petén examina el rol de la legitimidad en el éxito de las reformas de derechos. El artículo referido al altiplano demuestra cómo las iniciativas de conservación en tierras comunales indígenas han socavado las instituciones locales. Por último, el caso de Bolivia analiza la gobernanza forestal indígena antes y después de las reformas. En la edición en inglés de esta colección, en la revista Conservation and Society 10(2), se pueden encontrar estudios de caso adicionales (Camerún, Ghana y Kenia).

Todos los artículos apuntan a uno de los hallazgos principales del estudio: obtener los derechos en papel no es mas que el punto de partida de un camino largo y difícil. 


\section{Agradecimientos}

Los editores quisieran agradecer a todos los autores por su constante apoyo durante el largo proceso, desde la investigación hasta la publicación en dos idiomas. Quisiéramos agradecer especialmente a Deborah Barry, quien tuvo a su cargo la coordinación del proyecto en sus fases iniciales y estuvo involucrada en la organización y edición preliminar de los artículos de esta colección. También quisiéramos expresar nuestra gratitud a los editores de Conservation and Society por su apoyo durante todo el proceso de revisión por pares y publicación en el idioma inglés, y por facilitarnos también el acceso a los archivos necesarios para la versión en español. Agradecemos al Equipo de Comunicaciones (ISG, por sus siglas en inglés) de CIFOR y al equipo de traductores por su apoyo, persistencia y paciencia en la producción de esta colección en español. La investigación CIFORRRI contó con el financiamiento del Centro Internacional de Investigaciones para el desarrollo (IDRC por sus siglas en inglés) y la Fundación Ford (para la investigación global), además del Programa sobre Bosques (PROFOR) del Banco Mundial para la investigación correspondiente a América Latina. Finalmente, esta publicación no hubiera sido posible sin el apoyo de docenas de organizaciones de base, y cientos líderes y miembros de las comunidades que amablemente nos concedieron su tiempo y energía. 


\section{Lista de autores}

Krister Andersson

Universidad de Colorado, Boulder,

Estados Unidos

anderssk@colorado.edu

Deborah Barry

Ministerio de Medio Ambiente y

Recursos Naturales, El Salvador

deborahabarryl@gmail.com

Jean Paul Benavides

Centro de Estudios de la Realidad

Económica y Social (CERES), Bolivia

jeanpaul.benavides@gmail.com

Peter Cronkleton

CIFOR, Perú

p.cronkleton@cgiar.org

\section{Ganga Ram Dahal}

Iniciativa para los Derechos y los

Recursos (RRI), Tailandia

ganga@recoftc.org

\section{Silvel Elias}

Universidad San Carlos, Guatemala

silvelelias@yahoo.com

Anne M. Larson

CIFOR, Perú

a.larson@cgiar.org
Rosario León

Centro de Estudios de la Realidad

Económica y Social (CERES), Bolivia

rleonceres@gmail.com

\section{Iliana Monterroso}

Iniciativa para los Derechos y los

Recursos (RRI), Guatemala

imonterroso@rightsandresources.org

Pablo Pacheco

CIFOR, Indonesia

p.pacheco@cgiar.org

Naya Sharma Paudel

ForestAction, Nepal

nsp@forestaction.wlink.com.np

Juan M. Pulhin

University de Filipinas Los Baños,

Filipinas

jmpulhin@uplb.edu.ph

Sushil Saigal

Programa Forest-PLUS, India

sushil@inspirenetwork.org

Patricia Uberhuaga

Universidad Mayor de San Simón, Bolivia uberhuaga.pat@gmail.com 


\section{Introducción}

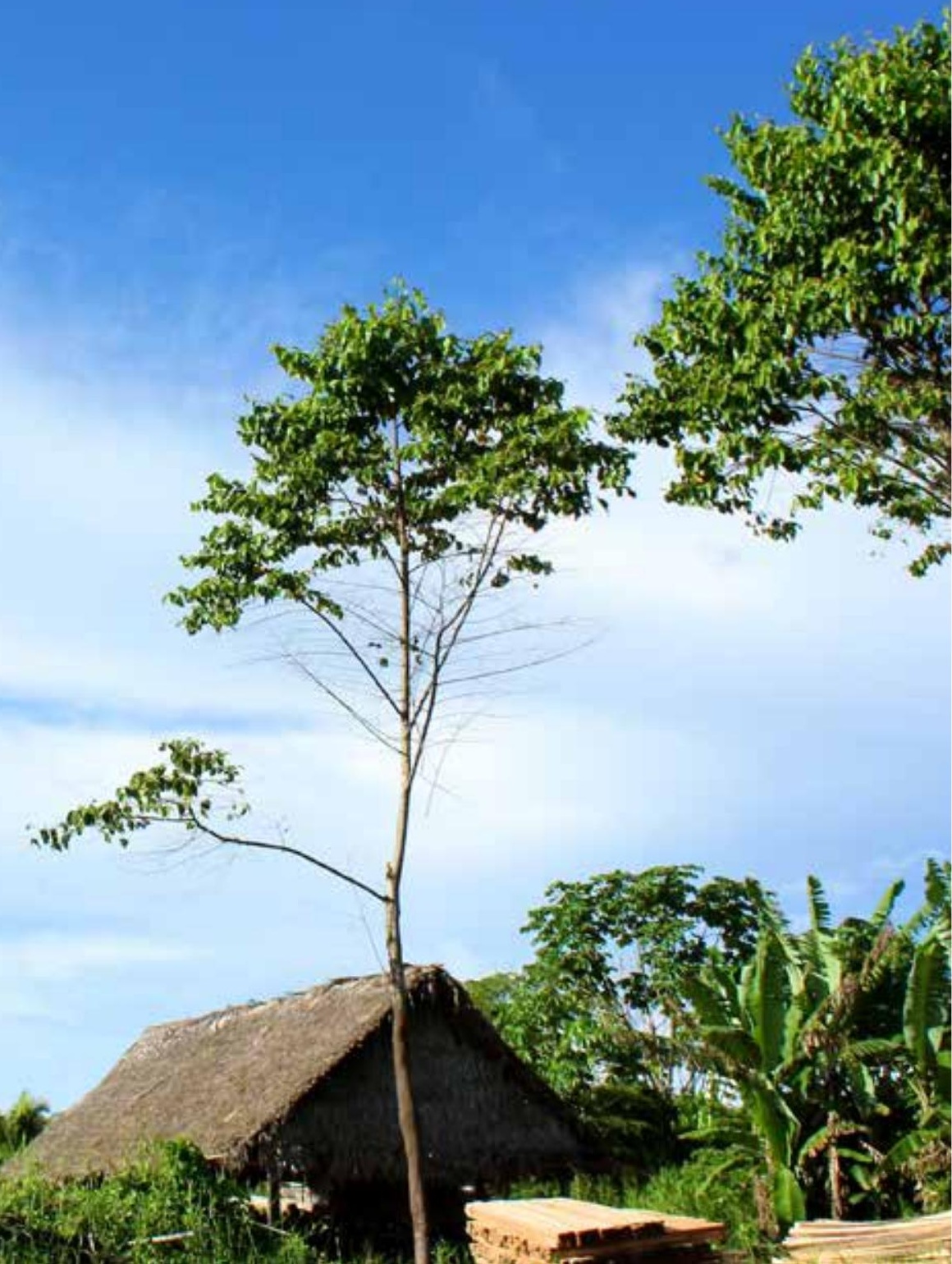





\title{
La reforma de la tenencia forestal
}

\author{
¿Nuevos derechos sobre los recursos para las comunidades que viven en \\ los bosques?!
}

Anne M Larsonii y Ganga Ram Dahaliii

\section{Introducción}

En Asia, África y América Latina, se ha producido un cambio importante en la tenencia de bosques a partir de 1985, debido al reconocimiento o a la transferencia legal de al menos 200 millones de hectáreas de bosque a comunidades locales y pueblos indígenas (White y Martin 2002). Aunque la porción de la superficie forestal mundial en propiedad de comunidades o administrada por estas sigue siendo pequeña — solo el 11,4\% en 2008—, los cambios son significativos, y datos recientes sugieren que la parte que corresponde a las comunidades sigue creciendo. En un estudio de 25 de los 30 países con más bosques, Sunderlin et al. (2008) determinaron que las tierras asignadas a las comunidades o de su propiedad habían aumentado en 15 países solo desde el año 2002. Además, el porcentaje de bosques en manos de comunidades en los países en desarrollo es mucho más alto: de $22 \%$ en 2002 aumentó a $27 \%$ en 2008 (Hatcher com. pers., basado en datos de Sunderlin et al. 2008).

Estos cambios en los derechos comunitarios sobre los bosques, examinados en los artículos de esta colección, no se han producido de la noche a la mañana. Las investigaciones sobre la devolución, la forestería comunitaria, los recursos de propiedad común, las iniciativas de conservación y desarrollo y, más recientemente, la descentralización forestal en el contexto del cambio climático han analizado diferentes aspectos de estas reformas. Lo nuevo aquí es el reconocimiento de que diversos cambios en las políticas y las concepciones se han unido para constituir lo que ahora se entiende por reforma de la tenencia forestal (Taylor et al. 2007; Pacheco et al. 2009), comparable a las amplias reformas agrarias de mediados del siglo XX con implicaciones igualmente importantes.

\footnotetext{
i Este artículo es una traducción del original, que apareció en inglés en la revista Conservation and Society, en la edición especial sobre Reformas de tenencia forestal (eds. Anne M. Larson y Ganga Ram Dahal). La cita original completa es: Larson, A.M. and Dahal, G.R. 2012 Forest Tenure Reform: New Resource Rights for Forest-based Communities? Conservation and Society 10 (2): 77-90. El artículo cuenta con una licencia de Creative Commons de Atribución 3.

ii Centro para la Investigación Forestal Internacional, Managua, Nicaragua - a.larson@cgiar.org.

iii La Iniciativa para los Derechos y Recursos (RRI), Centro para las Personas y los Bosques (RECOFTC), Bangkok, Tailandia.
} 
La reforma de la tenencia forestal es diferente de la reforma agraria. En lugar de redistribuir la tierra, implica, ante todo, el reconocimiento formal de los derechos y los beneficios forestales de las personas que ya viven en los bosques y alrededor de ellos; a menudo es impulsada por las reivindicaciones de los derechos ancestrales o consuetudinarios sobre la tierra. Además de responder a los intereses de los medios de vida, propone de forma explícita conservar los bosques, a diferencia de las políticas agrarias que muchas veces promovían la tala de bosques en el pasado (Larson et al. 2008). Las reformas se pueden originar tanto "desde arriba" como "desde abajo", y las fuerzas que dirigen y dan forma a estas reformas surgen de las comunidades, los pueblos indígenas y los movimientos sociales, los donantes internacionales o el Estado (Barry et al. 2010). Las reformas de la tenencia forestal tienen implicaciones tanto para las comunidades como para los bosques. Se basan, en parte, al menos en teoría, en la creencia de que las comunidades pueden ser buenas administradoras de los bosques. Sin embargo, en la práctica, esta posición no siempre parece guiar las decisiones de los responsables de la ejecución de estas reformas.

Para entender esta dinámica emergente como una reforma de la tenencia forestal es necesario llevar a cabo un análisis sistemático y comparativo de los procesos relacionados y de los resultados de estos cambios, — entre otras transiciones globales - y de la necesidad de desarrollar marcos y enfoques que puedan facilitar estas comparaciones. Esta sección especial representa los resultados de una investigación preliminar. Se analiza el origen, la naturaleza, los objetivos y los resultados de las políticas que reconocen o conceden, de manera formal, nuevos derechos comunitarios sobre los bosques, con especial énfasis en la comprensión de los desafíos enfrentados en su aplicación y el grado en el que, de hecho, representan una mejora en los medios de vida de las comunidades involucradas.

La mayoría de los artículos que son parte de esta colección se basan en investigaciones realizadas desde 2006 hasta 2008 por el Centro para la Investigación Forestal Internacional (CIFOR, por sus siglas en inglés), en coordinación con la Iniciativa para los Derechos y Recursos (RRI por sus siglas en inglés), en más de treinta sitios en diez países que han promovido, de alguna manera, mayores derechos locales sobre los bosques (Larson et al. 2010c). Los países del estudio se encuentran en Asia (India, Nepal y Filipinas), África (Burkina Faso, Camerún y Ghana) y América Latina (Bolivia, Brasil, Guatemala y Nicaragua). Se han ańadido a la colección dos artículos, de Kenia y Bolivia, basados en investigaciones de colegas que trabajan en temas similares. (No todos los artículos han sido traducidos para esta colección en español.)

Este artículo introductorio se organiza de la siguiente manera. La próxima sección presenta el proyecto de investigación, los métodos y los tipos de reformas estudiadas. La sección 3 revisa los aspectos clave del contexto internacional que condujeron a las reformas. La sección 4 presenta los casos incluidos en la investigación por país con una breve introducción de los dos casos adicionales. La sección 5 analiza brevemente algunas de las conclusiones centrales de la investigación, antes de cerrar con una presentación de cada uno de los artículos de esta colección. 


\section{El proyecto de investigación}

El proyecto de investigación CIFOR-RRI, "Improving equity and livelihoods in community forestry: A global action research initiative in support of a strategic partnership on rights and resources" (Mejora de la equidad y los medios de vida en la forestería comunitaria: Una iniciativa mundial de investigación y acción en apoyo a una alianza estratégica por los derechos y recursos), tuvo como objetivo estudiar y apoyar a la "forestería comunitaria", entendida en sentido amplio, como la gestión local o comunitaria de bosques ${ }^{1}$. Este proyecto se dirigió específicamente a examinar la ejecución y los resultados de las políticas de devolución de los recursos forestales a las comunidades y a los grupos de usuarios de los bosques, o las reformas de la tenencia forestal. El objetivo central fue generar información analítica, estratégica, y orientada a las políticas y la acción para fomentar a diferentes escalas políticas, instituciones y procesos en favor de los pobres y basadas en derechos. En la medida de lo posible, el trabajo se llevó a cabo en colaboración con socios locales en los países seleccionados.

Debido a que se dio prioridad a la investigación-política-acción, los países fueron seleccionados, en parte, con base en el posible impacto. Las regiones subnacionales y los sitios dentro de esas regiones se eligieron con el fin de abordar cuestiones que fueran útiles a las necesidades de los colaboradores nacionales para ayudar a impulsar y mejorar las reformas. Se proporcionó financiación específica para estos sondeos, lo que permitió un enfoque por fases para el desarrollo de las preguntas centrales de la investigación y los sitios de estudio.

Uno de los objetivos clave del estudio fue comprender el proceso de ejecución de la reforma, o la concesión de nuevos derechos a las comunidades en la práctica. La investigación se centró en el análisis de experiencias en las que se habían concedido derechos formales de tenencia forestal a las comunidades o en las que tales negociaciones estaban en curso y en la identificación de problemas e inquietudes desde la perspectiva de los grupos social y económicamente vulnerables que se suponía estaban beneficiándose con estas reformas. Las preguntas de investigación se organizaron en torno a varios temas: el efecto del cambio de tenencia en los derechos comunitarios de acceso a los bosques y en la toma de decisiones con respecto a ellos; el efecto de los marcos regulatorios, los mercados y la organización social en los procesos y resultados; y los efectos de las reformas en los medios de vida, los bosques y la equidad ${ }^{2}$. Los cuatro documentos temáticos de esta colección examinan, a su vez, diversos aspectos de los primeros cuatro temas: los cambios en los derechos de toma de decisiones y de acceso, los marcos regulatorios, los mercados y las organizaciones sociales. Muchos de los estudios de caso tratan sobre los efectos o resultados de las reformas, aunque con mayor énfasis en los temas de gobernanza y medios de vida que en los resultados ambientales o forestales, como se verá más adelante. 


\section{Metodología}

Por lo general, los sitios seleccionados para la investigación fueron una aldea o, más comúnmente, un grupo de aldeas o de personas de varias aldeas, en un país o una región del país donde se había producido o estaba en proceso algún tipo de reforma de la tenencia. Si la comunidad conformaba un grupo de aldeas en lugar de una sola aldea, por lo general estaba organizada, de alguna manera, alrededor de un bosque, y una o dos aldeas se seleccionaron para la verificación en el terreno y para recolectar ciertos tipos de datos (por ejemplo, datos sobre el impacto en los medios de vida). Se eligieron entre dos y cinco de estos sitios dentro de cada país o región con fines de comparación.

La variación entre los sitios dentro de los países se basó en las variables más relevantes para entender el tipo, el alcance o el resultado de las reformas de la tenencia de la tierra en el contexto nacional. En algunos casos, por lo tanto, los sitios de investigación seleccionados representaron diferentes tipos de reforma, mientras que en otros variaron sobre la base de características diferenciadoras clave, como la presencia o ausencia de un proyecto de forestería comunitaria, el tipo de organización social, el tipo de bosque o región ecológica, etcétera.

Se realizó un gran esfuerzo para contextualizar las reformas y los procesos de ejecución a múltiples escalas. Esto se consideró un elemento central no solo para la interpretación precisa de la información de los sitios, sino también para que los resultados fuesen tan útiles como fuera posible en el ámbito de las políticas y acciones. Por lo tanto, se recopiló información a todas las escalas consideradas relevantes, desde el pueblo o grupo (la "comunidad”), hasta la subregión y el país. Además, se elaboraron revisiones bibliográficas o bibliografías comentadas a escalas regionales para Asia, América Latina y África Occidental.

La combinación de objetivos de política-acción y de investigación tuvo ventajas y desventajas en el estudio comparativo global. Por un lado, los sitios, o incluso los tipos de reforma, no fueron elegidos para ser comparables en forma estricta, de modo que se dio prioridad a las evaluaciones cualitativas altamente contextualizadas por sobre los métodos cuantitativos. Por otro lado, debido al interés en promover el impacto de las políticas, los socios y las comunidades estuvieron a menudo muy involucrados en la investigación, y fue extenso el acceso a las ideas y las percepciones de los actores interesados a diversas escalas, lo que permitió una comprensión más profunda de los procesos involucrados.

Con respecto a los resultados de la reforma, todos los estudios combinaron las evaluaciones cualitativas y cuantitativas de los medios de vida, los ingresos, la condición del bosque y la equidad, pero, nuevamente, las evaluaciones cuantitativas no fueron estandarizadas en todos los sitios. Por ejemplo, no fue posible ni siquiera medir el cambio de la cubierta de bosque de manera significativa a través de métodos comparables, como por imágenes satelitales. Esto es, en parte, porque muchas de las reformas están aún en proceso y, en parte, porque no hay datos "anteriores" que se puedan comparar y no se dispuso de financiación suficiente para hacer frente a estas deficiencias ${ }^{3}$. Por lo tanto, los artículos de esta colección se centran principalmente en la política y la economía de la gobernanza y los medios de vida. 
Toda la investigación se llevó a cabo a partir del mismo conjunto de preguntas centrales de investigación, lecturas clave sobre teoría y antecedentes, hipótesis y definiciones de términos clave, aunque los métodos específicos que se utilizaron para obtener información variaron. En casi todos los casos, dirigieron la investigación organizaciones asociadas o investigadores de los países en vías de desarrollo, y todos los investigadores principales tenían una amplia experiencia en los países estudiados.

\section{Tipos de reformas estudiadas}

La investigación examinó una amplia gama de formas en las que se reconocieron derechos formales a los bosques o se otorgaron nuevos derechos a las comunidades. Entre estos se encuentran la titulación de grandes territorios, como en las tierras indígenas de Nicaragua y Bolivia, o de áreas más pequeñas en Filipinas; la titulación a nombre de personas con extensiones comunes de bosques, como en las comunidades de colonos de Brasil; la titulación de las comunidades agroextractivas del norte de Bolivia; la concesión de los bosques comunitarios a perpetuidad en Nepal; el establecimiento de una reserva agroextractiva (RESEX) en Brasil ${ }^{4}$; las concesiones forestales comunitarias de Guatemala y Burkina Faso; los arrendamientos renovables para el manejo de tierras "baldías" a través de cooperativas en las tierras comunales de la India; varios tipos de cogestión, manejo colaborativo o acuerdos de forestería comunitaria a través de contratos en Camerún, Ghana, Burkina Faso y Filipinas; contratos individuales para la siembra de árboles, cuyos ingresos en el futuro serán compartidos por los individuos y la comunidad en Ghana; el reconocimiento de "tierras comunales" en la legislación guatemalteca; y la participación de la comunidad en los beneficios del aprovechamiento de la madera en Ghana.

¿Quiénes son los beneficiarios? Algunas de las reformas responden específicamente a las reivindicaciones de los derechos ancestrales, y estas son las que, en nuestro estudio, parecen tener más probabilidades de proporcionar títulos de propiedad ${ }^{5}$. En todos nuestros casos, esto ocurre en las antiguas colonias españolas (América Latina y Filipinas). Otras reformas, la gran mayoría, tienen el objetivo específico de beneficiar a las comunidades que tradicionalmente han vivido en los bosques o cerca de ellos, o que han utilizado los recursos forestales, aunque no se las consideren necesariamente "pueblos indígenas". Este es el caso de los grupos de usuarios de los bosques de Nepal, las cooperativas de aldeas en la India, la reserva agroextractiva en Brasil y las comunidades agroextractivas en el norte de Bolivia, la mayoría de los casos africanos, las comunidades en Filipinas que se benefician de los acuerdos de manejo comunitario de los recursos naturales y de cogestión, algunas comunidades del altiplano guatemalteco y otras de las que se benefician de las concesiones de Petén, en Guatemala. Por último, algunas reformas han beneficiado a colonos más recientes, en particular, a las comunidades de colonos de Brasil y muchas de las concesiones de Petén, en Guatemala. Todos los casos presentan beneficios colectivos, aunque algunos también tienen un elemento individual, como los contratos de siembra de árboles de Ghana y las comunidades de colonos de Brasil. 
Las reformas más amplias en términos de los derechos concedidos son las que otorgan derechos permanentes y seguros sobre los bosques a perpetuidad. Entre estas se incluyen los títulos de propiedad, por ejemplo, de los territorios indígenas de Nicaragua, Bolivia y Filipinas o la concesión de derechos sobre los bosques a perpetuidad a las comunidades de Nepal (aunque los activistas estaban tratando de obtener también garantías constitucionales; Paudel com. pers.). Lo que se les permite hacer a las comunidades con esos bosques está, por supuesto, siempre sujeto a la normatividad nacional, pero también puede estar supeditado a otras reglas y regulaciones (Larson y Pulhin en esta colección). En la mayoría de los otros casos, los derechos son o bien menos seguros, o bien menos permanentes; con frecuencia vinculan a las comunidades con normas y obligaciones específicas (Cronkleton et al. en esta colección). Este "conjunto de derechos" se describirá más adelante.

\section{Contexto internacional de las reformas}

Durante los últimos 30 años, numerosos estudios sobre la devolución, la descentralización y la forestería comunitaria han examinado casos en los que se han concedido a la población local derechos —o responsabilidades — sobre los bosques donde viven. Juntos, han demostrado un amplio grado de variación en las políticas, las metas, las estrategias de aplicación y los resultados y han constatado que, hasta la fecha, ninguna experiencia en particular constituye una panacea para lograr los objetivos relacionados tanto con los medios de vida como con el manejo forestal sostenible.

Algunos de los primeros casos documentados provienen de Asia, en particular de Nepal y la India. El primer experimento de Nepal con bosques comunitarios consistió en el desarrollo de plantaciones en las colinas en tierras yermas, bajo el control del Gobierno local (panchayats), a partir de 1978. Sin embargo, estas solo tuvieron éxito en algunos distritos donde los bosques se encontraban gravemente reducidos (Gilmour 2003).

En la India, la forestería social se desarrolló en 1976 explícitamente como una política para reducir la presión sobre los bosques de producción proporcionando áreas sin bosques y áreas forestales degradadas a los habitantes. Como ha señalado el Gobierno de la India:

\footnotetext{
"Uno de los principales objetivos de la forestería social es hacer que sea posible cumplir las necesidades [de las poblaciones rurales] en su totalidad con las áreas de fácil acceso, y con ello aligerar la carga cada vez mayor sobre la producción forestal. Estas necesidades se deben satisfacer con la forestería de pequeńa escala, la extensión forestal, y mediante la rehabilitación de bosques de matorrales y bosques degradados" (GOI 1976: 25, citado en Saxena 1997).
}

Al igual que en Nepal y Filipinas, la estrategia se basó en el supuesto de que las personas locales invertirían su trabajo voluntariamente en estos modelos impuestos por el Gobierno, con poco conocimiento de cómo estas ya utilizaban y manejaban los bosques.

Estos primeros ejemplos de forestería comunitaria no se basaron en el reconocimiento de los derechos de las comunidades sobre los bosques. De hecho, en estos casos era evidente que se consideraba que eran las comunidades las que habían destruido los bosques y que, 
hasta cierto punto, tenían la obligación de generar nuevos recursos. Por ejemplo, el mismo documento del Gobierno de la India también declaró: "Después de haber sobreexplotado los recursos, [los pobladores rurales] no pueden, con toda justicia, esperar que alguien se tome la molestia de proporcionarles productos forestales de forma gratuita” (GOI 1976: 25, citado en Saxena 1997). La información relativa a los derechos de acceso y uso de los recursos forestales que la gente tenía, de hecho, les fue ocultada "en parte debido al temor de que se agravara la degradación y debido a la cultura administrativa [del Departamento Forestal] de mantener a la gente en la ignorancia” (Saxena 1997).

Lo que estos primeros casos sugieren es que la población local tenía ciertos derechos legales sobre el acceso al bosque y su uso (aunque tal vez en contra de la voluntad de la administración forestal); sin embargo, las iniciativas de transferencia o de forestería comunitaria no se basaban en una ampliación de esos derechos ni, aún menos, en el reconocimiento de ningún tipo de derecho consuetudinario o preexistente sobre los bosques. Una serie de factores empezó a cambiar esta situación.

\section{La documentación del manejo forestal comunitario endógeno}

En la década de 1980 en Nepal, forestales e investigadores comenzaron a documentar las formas en que la población local de las colinas ya administraba los bosques a través de instituciones locales informales. Esto tuvo un impacto importante sobre el terreno, ya que estos profesionales empezaron, al mismo tiempo, a desarrollar y probar "modalidades de planificación y ejecución de la forestería comunitaria” durante este período. Su investigación llevó a un cambio en la política nacional tendiente a un modelo basado en los grupos de usuarios de los bosques a principios de los noventa (Gilmour 2003).

\section{Conocimientos sobre los bienes comunes}

La documentación de las prácticas locales de manejo forestal se apoyó, en particular, en la creciente literatura sobre instituciones de propiedad común, desarrollada por Elinor Ostrom y sus colegas. Ostrom (1990) demostró que grupos de personas pueden reunirse para el manejo compartido de los recursos y desarrolló un conjunto de principios de diseño que "parecen compartir todas las instituciones de recursos comunes que perduran” y son exitosas (Mwangi 2010). En una revisión de la contribución de Ostrom al conocimiento sobre los bosques, Mwangi (2010) concluye que "el número y el alcance de los estudios en el sector forestal que derivan directamente del trabajo fundacional de Ostrom es abrumador".

\section{Cuestionamientos al discurso que culpa a las comunidades}

Varios investigadores comenzaron a cuestionar las suposiciones detrás de declaraciones y políticas, como las del Gobierno de la India ya mencionadas, que acusaban a las personas que viven en los bosques de ser los principales culpables de la deforestación y la degradación. Por ejemplo, Fairhead y Leach $(1996,1998)$ han escrito mucho sobre las interpretaciones externas del cambio del medio ambiente que predominan en los discursos sobre desarrollo, en particular en África occidental, y concluyeron que estas interpretaciones no solo eran inexactas, sino que diferían considerablemente de las 
perspectivas locales. La bibliografía sobre la agricultura itinerante y el uso del fuego demostró que podía ser un uso racional y productivo de los bosques (Dove 1983) y que la represión de estas prácticas puede ser una cortina de humo para cubrir otros intereses (Kull 2004).

\section{El fracaso de los bosques estatales}

Otro factor importante del cambio fue que, según se verificó, numerosos bosques estatales estaban en malas condiciones después de haber sido controlados por el Estado durante décadas (Poffenberger 2001). La gestión centralizada del Estado, tanto de las áreas protegidas (Hecht y Cockburn 1989, Rao y Geisler 1990) como del aprovechamiento de la madera (Brunner et al. 1999, Poffenberger 2006), había sido en gran medida incapaz de controlar la deforestación y la degradación de los bosques. Poffenberger (2006) escribe:

"Por lo general, el auge de las agencias estatales y empresas privadas como responsables del manejo forestal ha coincidido con una pérdida acelerada de bosques naturales en toda la región de Asia durante la época posterior a la Segunda Guerra Mundial. En el Sudeste Asiático, las selvas tropicales han disminuido de 250 millones de hectáreas en 1900 a menos de 60 millones de hectáreas en 1989”.

Una evaluación del Banco Mundial determinó que donde antes había sistemas tradicionales o indígenas, los Estados no pudieron reemplazarlos con instituciones más eficaces (Bromley y Cernea 1989).

\section{El movimiento internacional por los derechos de los indígenas}

El movimiento por el reconocimiento de los derechos de los indígenas surgió en el escenario mundial entre los años ochenta y noventa. Obtuvo en ese ámbito las victorias que las organizaciones indígenas no habían podido lograr a escala nacional, como el Convenio no 169 de 1989 sobre Pueblos Indígenas y Tribales, de la Organización Internacional del Trabajo (OIT). El artículo 14 garantiza que deberá reconocerse "a los pueblos interesados el derecho de propiedad y de posesión sobre las tierras que tradicionalmente ocupan". El artículo 15 protege sus derechos "a los recursos naturales existentes en sus tierras [y] el derecho [...] a participar en la utilización, administración y conservación de dichos recursos".

\section{El encuentro de la conservación y el desarrollo}

En 1987, la Comisión Brundtland pidió un nuevo enfoque sobre "desarrollo sostenible", y en 1992, la Declaración de Río sobre el Medio Ambiente y Desarrollo declaró que "los seres humanos constituyen el centro de las preocupaciones relacionadas con el desarrollo sostenible". Roe (2008) escribe que las políticas de conservación y desarrollo desde la década de los ochenta hasta mediados de los noventa se formaron en torno a estas ideas de desarrollo sostenible, a través de políticas que promueven la descentralización y la participación local. Uno de los resultados fue que las políticas y proyectos de conservación promovieron con más frecuencia la participación de la población local en lugar de, por ejemplo, su traslado fuera de las áreas protegidas. 
Estos son algunos de los principales factores que han favorecido un mayor reconocimiento de los derechos de las comunidades sobre los bosques a través de las políticas de devolución, descentralización y forestería comunitaria. Hay otros, sin duda, y en ocasiones las causas y los efectos no son claros ${ }^{6}$. Pero todas estas dinámicas han contribuido a una mayor aceptación de la idea de que las personas que viven en los bosques podrían ser buenos administradores forestales o que pueden tener derechos legítimos sobre ellos.

Se han publicado cientos de artículos sobre experiencias locales de manejo forestal; sin embargo, se han aprendido relativamente pocas lecciones generales. Algunos han declarado que la forestería comunitaria es un fracaso (por ejemplo, Blaikie 2006), otros dicen que es un éxito. Varios autores han identificado conjuntos de variables biofísicas, socioeconómicas e institucionales que son relevantes para el éxito, como el tamaño y los límites de los bosques, el tamaño y la homogeneidad de los grupos, la naturaleza y el diseño de las reglas, y la estabilidad de las condiciones externas (véase Agrawal y Chhatre 2007 para una lista de variables y fuentes específicas). Un metaanálisis de 69 casos identificó 43 variables independientes y se determinó que las más importantes para el éxito eran: derechos de propiedad bien definidos, mecanismos institucionales eficaces y los intereses e incentivos de la comunidad (Pagdee et al. 2006).

Un problema importante para comprender los patrones es que los resultados son muy específicos, dependiendo de los contextos, tanto locales como nacionales, ecológicos, sociales y económicos, las políticas, la gobernanza e historia (Pagdee et al. 2006; Charnley y Poe 2007). En su estudio de la cubierta de bosque a través del tiempo, Dietz et al. (2003) determinaron que los tres tipos principales de instituciones de gobierno — públicas, privadas y comunitarias - están a veces asociados a la reducción, ausencia de cambios y la mejora de la cubierta. Agrawal y Chhatre (2006: 164), en su estudio de 95 casos de gobernanza forestal de base comunitaria en Himachal Pradesh, India, concluyeron que "tal vez sea imposible identificar un conjunto de condiciones necesarias y suficientes que constituyan una teoría [...] de la gobernanza de los recursos locales y los bienes comunes".

¿Los fracasos del manejo comunitario de los recursos obedecen a las políticas, a su aplicación o a la capacidad de la población local? Con respecto a las políticas de descentralización, Ribot (2004) argumenta que la descentralización democrática en realidad no se ha puesto en práctica, por lo tanto, lo que estamos analizando son, como mucho, los resultados de descentralizaciones parciales. Del mismo modo, la "forestería comunitaria" consiste en diferentes políticas bajo diversos nombres. ¿Cómo puede la investigación proporcionar mejores maneras para entender las políticas y las prácticas?

\section{Los países y los casos estudiados}

Esta sección ofrece una breve presentación de los casos estudiados; sin embargo, no todos ellos se desarrollan en los artículos de esta colección, y de la colección en inglés, no se tradujeron todos los artículos al español. También, en parte por azar y en parte por elección ${ }^{7}$, los artículos temáticos tienden a tomar casos de América Latina y Asia con fines comparativos, mientras que los artículos sobre estudios de caso abarcan dos de 
los países africanos estudiados (Ghana y Camerún), y dos condiciones y regiones muy diferentes de Guatemala (los grandes bosques tropicales de las tierras bajas de Petén y los bosques fragmentados de pinos del altiplano). Los dos artículos de estudios de caso que no formaron parte del proyecto de investigación del CIFOR-RRI analizan un territorio indígena en Bolivia (uno diferente del que abarca este proyecto) y el manejo forestal participativo en Kenia, un país que no se incluyó en la investigación. En esta sección se revisarán los diversos casos por región y por país Figura 1. [Nota: Los tres estudios de caso en África están disponibles en inglés en la siguiente página web: www. conservationandsociety.org/showBackIssue. asp?issn=0972-4923; ;ear=2012; volum $\mathrm{e}=10$;issue $=2$; month=April-June]
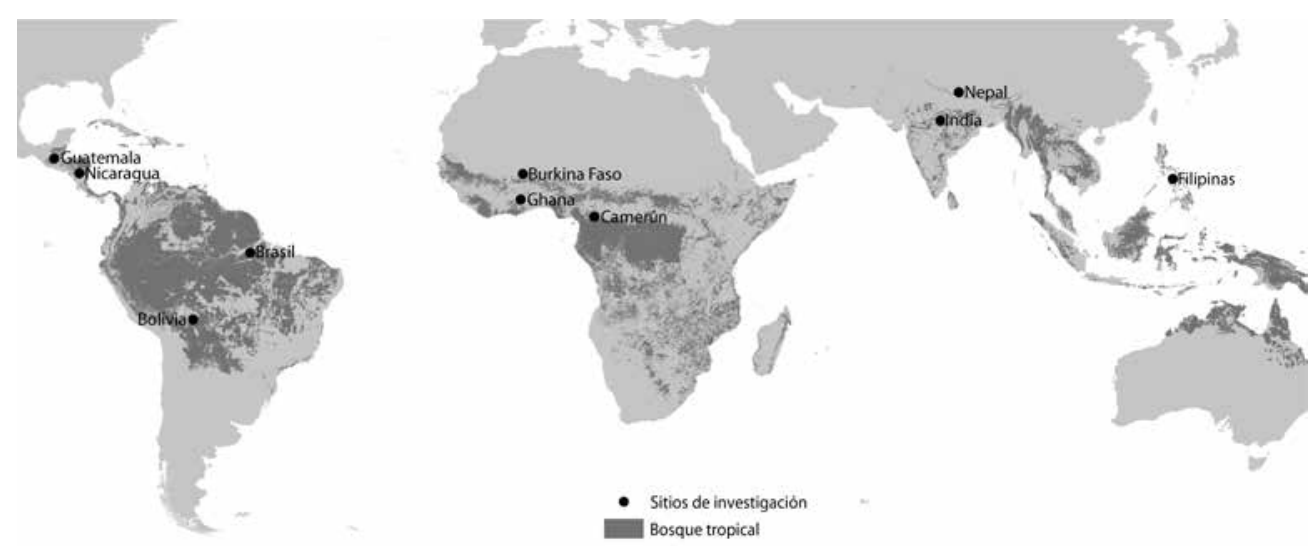

Figura 1. Mapa de los países estudiados

Fuente: Adaptado de Larson et al. 2010c

\section{Asia}

Las reformas de Asia se encuentran entre las más antiguas y, como se mencionó anteriormente, en sus primeros años, tendían a concentrarse en la obtención de mano de obra comunitaria para las plantaciones forestales y la protección de la regeneración natural. Surgieron nuevas iniciativas basadas en las lecciones aprendidas de esas experiencias tempranas, y con frecuencia estas han llegado mucho más lejos en la concesión de derechos, como también de responsabilidades, a las comunidades forestales. Hoy en día, el 68\% de los bosques de Asia y el Pacífico pertenecen a los Gobiernos y son administrados por ellos, el $25 \%$ son propiedad de comunidades y pueblos indígenas, el 3\% son propiedad de los Gobiernos - pero designados para ser utilizados por comunidades y pueblos indígenas - y $4 \%$ son propiedad de individuos y empresas (RRI y OIMT 2009).

Los casos de Nepal representan una de las reformas estudiadas más importantes, con una política forestal comunitaria que ha surgido de las experiencias de los años setenta y 
ochenta mencionadas anteriormente. La forestería comunitaria "ha evolucionado desde una modalidad de manejo forestal de pequeña escala, localizado y exploratorio hasta un programa nacional importante que involucra a alrededor del 40\% de la población total”. El Plan Maestro de 25 ańos para el Sector Forestal, aprobado en 1989, legalizó el uso de los bosques locales y reconoció a los grupos de usuarios de bosques comunitarios "como la institución clave en el manejo de los bosques". Al momento del estudio, se habían entregado alrededor del 21\% (1,2 millones de hectáreas) de los bosques de Nepal a comunidades locales organizadas en más de 15000 grupos (Paudel et al. 2009).

Los bosques transferidos han sido otorgados a las comunidades supuestamente a perpetuidad, pero la burocracia forestal del Estado puede disolver el comité ejecutivo de un grupo de usuarios de bosques comunitarios y convocar a nuevas elecciones (Paudel com. pers.) y, en general, juega un papel importante en el control del aprovechamiento de los productos forestales, en particular de la madera. Los estudios de caso se centraron en cuatro grupos de usuarios con planes operativos aprobados en cuatro regiones geográficas diferentes: las tierras bajas, las colinas (una rural y otra periurbana) y la región montañosa de gran altitud. La organización de segundo nivel que surge de estos grupos, la Federación de Usuarios de Bosques Comunitarios de Nepal (Federation of Community Forest Users, FECOFUN), ha desempeñado un papel central en la ampliación de los derechos de la comunidad y en la negociación con la burocracia forestal a nivel nacional. En los artículos de esta colección, se puede encontrar información sobre el estudio de Nepal en Paudel et al. (véase también Paudel et al. 2009).

Filipinas es otro país con una historia relativamente larga de reformas de tenencia forestal en favor de comunidades de tierras altas. Después de los programas de forestería social (que se iniciaron en la década de los setenta bajo la dictadura de Marcos), los cuales eran mucho más limitados en su alcance, la más reciente y amplia de estas reformas acompańó el retorno a la democracia y la caída de Marcos en 1986. Al igual que en Nepal, estas nuevas políticas "se basaron en el supuesto de que la supervivencia de los bosques de Filipinas se encuentra en manos de los pequeños productores". Al momento del presente estudio, en casi 6 millones de hectáreas —ya que el 38\% de las tierras del país están clasificadas como bosques- se aplican acuerdos de manejo forestal comunitario, que abarcan cerca de 700000 hogares (Pulhin et al. 2008). Este régimen de manejo forestal no otorga derechos a perpetuidad, sino que los derechos son condicionales y temporales, y están basados en acuerdos renovables por períodos de 25 ańos. Dos de los sitios de investigación comprendieron comunidades con acuerdos de manejo forestal comunitario. Un tercer sitio abarcó un acuerdo de cogestión entre el Gobierno local y una comunidad. En esta colección, uno de los casos de manejo forestal comunitario está incluido en Cronkleton et al. (véase también Pulhin et al. 2008).

Un tipo diferente de reforma implica el reconocimiento de las reivindicaciones de las tierras ancestrales de las comunidades indígenas a perpetuidad, un derecho otorgado a través de la Ley de Derechos de los Pueblos Indígenas de 1997. Estas reivindicaciones son reconocidas a través de un proceso largo y burocrático que da como resultado la concesión plena del título de propiedad por medio de un Certificado de Título de 
Dominio Ancestral. El cuarto estudio de caso, Filipinas, examina la reserva forestal de Ikalahan, una de las primeras de estas áreas tituladas. Este caso no se utiliza en los análisis que se encuentran en esta colección (para obtener más información sobre el caso del dominio ancestral, véase Larson et al. 2010d).

En la India, la evolución de las políticas es similar, con una participación formal de la comunidad en el sector forestal, establecida a través de la forestería social en la década de 1970 (como se describió anteriormente) y después de 1990 a través de otras políticas, como el Manejo Forestal Conjunto ${ }^{8}$. La Política Forestal de 1988 fue radicalmente diferente de las políticas anteriores, ya que cambió el enfoque de la actividad forestal de la industria a los medios de vida locales y sentó las bases para una mayor participación comunitaria en el manejo forestal (Saxena 1997). Sin embargo, esta forma de manejo todavía no reconoce los derechos de tenencia más allá de los derechos de usufructo. El resultado fue una creciente desilusión debido a las demandas insatisfechas de los pueblos dependientes de los bosques. Esas reivindicaciones llegaron a su punto culminante en el año 2002, en respuesta a una directiva sin precedentes de la Corte Suprema que estipulaba desalojar a todos los ocupantes ilegales de los bosques en un período de cuatro meses; "el tumulto que siguió radicalizó y reunió a los movimientos populares, y la nueva causa común fue reconocida entre los grupos dependientes de los bosques en todo el país" (Springate-Baginski et al. 2009:18).

La Ley de Derechos sobre el Bosque9, aprobada en 2006, finalmente reconoció los derechos a las tierras forestales de los pueblos "registrados" (scheduled peoples) y otros habitantes tradicionales del bosque. Sin embargo, al igual que muchos de los otros casos de este estudio (véase también Larson 2010a), la ejecución ha estado plagada de conflictos y ha requerido una movilización permanente para superar la lentitud, la burocracia y la oposición (Ramdas 2009; Springate-Baginski et al. 2009; CSD 2010). Siguiendo con este proceso dinámico y en desarrollo, el Consejo Consultivo Nacional del Gobierno de la India ha publicado recientemente una serie de directrices para fortalecer su aplicación (The Hindu 27 de febrero de 2011).

La presente investigación se centró en uno de los pocos casos de derechos de tenencia más importantes que comenzaron antes de esta última serie de reformas. Este programa, conocido como la Sociedad Cooperativa de Cultivadores de Árboles (TGCS, por sus siglas en inglés), creó cooperativas para establecer y administrar las plantaciones de árboles en las tierras comunales legalmente clasificadas como tierras baldías. Este programa fue seleccionado porque "está, sin duda, entre los modelos institucionales más sólidos probados en el sector forestal de la India”; por ejemplo, a diferencia del Manejo Forestal Conjunto, creó un órgano formalmente registrado con "una identidad jurídica independiente del proyecto", y la transferencia de tierras se hace a través de un contrato formal de arrendamiento (Saigal et al. 2009: 20). El programa ha existido desde la década del ochenta, y en los sitios estudiados, las cooperativas creadas en el marco de la TGCS habían trabajado durante más de diez años sin ningún tipo de apoyo externo significativo. En 2007, había 548 cooperativas de cultivadores de árboles. El estudio 
examinó tres sitios de TGCS en Rajastán, en la misma provincia y región ecológica. Las tres aldeas habían obtenido contratos de arrendamiento por 25 ańos, renovables por períodos de 10 años cada vez, de tierras del Estado clasificadas como "tierras baldías del Gobierno" (revenue wasteland). Los casos correspondientes a la India se presentan en esta colección en Cronkleton et al. (véase también Saigal et al. 2009).

\section{África}

En su gran mayoría, los bosques africanos todavía pertenecen formalmente al Estado, mientras que las instituciones tradicionales tienen derechos defacto, y a veces el control sobre los recursos forestales. Cerca del $98 \%$ son propiedad del Gobierno y están administrados formalmente por este (RRI y OIMT 2009). Las reformas han sido más recientes que en Asia, puesto que comenzaron en la década del noventa. Una característica singular de los casos africanos es la importancia de las autoridades e instituciones consuetudinarias en el contexto de los derechos forestales.

Ghana ha aplicado diversas políticas desde 1994 bajo el nombre de Manejo Forestal Colaborativo, después de que la Política Forestal y de Vida Silvestre sentara las bases para una mayor participación de la comunidad. La tenencia de la tierra y los derechos sobre los árboles en Ghana son extremadamente complejos, dado que los derechos varían, entre otras cosas, sobre la base de la tenencia de la tierra (por ejemplo, familiar o comunitaria, dentro o fuera de las reservas), el origen del árbol (plantado o silvestre) y el uso del árbol o de su producto (doméstico o comercial). Además, desde la promulgación de la Ley de Concesiones de 1962, la tenencia de los árboles recae oficialmente en el Presidente, quien administra todos los árboles de Ghana en nombre de las autoridades tradicionales (chiefs), que son los propietarios de las tierras. Sin embargo, una importante reforma de 1997 impide al Estado otorgar una concesión maderera en tierras privadas o agrícolas, sin el permiso escrito de su propietario (Marfo 2009).

El manejo forestal colaborativo está dirigido a aumentar la participación comunitaria en el manejo, principalmente en la mejora de la producción forestal, pero sin modificar los derechos de tenencia subyacentes. La investigación se centró en dos casos muy diferentes. El primero abarcó tres comunidades que utilizan el Sistema Taungya Modificado, el cual aumenta los derechos sobre los árboles plantados como parte del sistema Taungya, introducido en la década de 1920. En el antiguo sistema, se les concedía a los agricultores tierras para la agricultura a cambio de la plantación de árboles, que luego utilizaban por dos o tres años, hasta que la sombra impidiera el cultivo; es decir, no tenían ningún derecho a los árboles. En el nuevo sistema, se proporciona a los agricultores una participación en las ganancias por las futuras ventas de árboles, pero podría mejorar aún más la seguridad de los medios de vida a través de una mayor confianza y transparencia, la firma de contratos, y la autorización del uso de planes de crédito contra futuras ganancias (Marfo 2009). El segundo caso es una situación única, en la que un grupo de comunidades solicitaron el apoyo del Estado para proteger un área de bosque que se está degradando. 
La investigación de Ghana prestó especial atención al tema de la representación y la autoridad, sobre la base de acuerdos de beneficios compartidos de los ingresos procedentes de la madera que se establecieron en la Constitución de 1992. Aunque esto no fue específicamente parte del trabajo de campo, fue una preocupación central en la revisión y el análisis de la bibliografía utilizada. Estos acuerdos de beneficios compartidos se establecieron de manera que los ingresos volvieran a las comunidades de las cuales procedían los árboles vendidos, en lugar de enriquecer solo al Gobierno central. Sin embargo, los fondos rara vez llegan a los productores debido a la limitada rendición de cuentas de las autoridades tradicionales. El estudio de caso sobre Ghana se centra principalmente en el tema de la distribución de los beneficios (el artículo está disponible en inglés en la página web mencionada arriba; para obtener más información sobre los estudios de caso, véase Marfo 2009).

En la década del ochenta una grave crisis económica en Camerún llevó, entre otras cosas, a demandas de participación comunitaria en el manejo forestal y a una nueva Ley Forestal en 1994. La Constitución de 1996 reconoció los derechos históricos de las comunidades locales a los beneficios derivados de la explotación de los recursos naturales. Una de las principales formas en las que se dio este reconocimiento fue a través de la concesión de bosques comunitarios. Al momento de la investigación, se habían establecido alrededor de 167 de ellos, sin embargo, la obtención del reconocimiento de un bosque comunitario es un proceso muy burocrático, lento y caro. De los 167 , solo se administraban y explotaban 47 al momento del estudio. Además, la presencia de bosques comunitarios solo se permite en la zona forestal no permanente o en las plantaciones agroforestales de baja calidad situadas en tierras consuetudinarias cercanas a los pueblos; no se autoriza en los bosques estatales de mayor calidad, donde se encuentran los bosques de producción (Oyono et al. 2009).

La investigación se llevó a cabo en cuatro sitios que abarcaron aldeas organizadas alrededor de 13 bosques comunitarios. Un quinto sitio empleaba un mecanismo de participación diferente en el que los ingresos forestales se compartían con las comunidades locales. En todos los casos, el manejo de los bosques y los ingresos derivados de ellos eran administrados por comités que representan a las comunidades — generalmente grupos de elite con escasa rendición de cuentas. En el quinto sitio, la gestión de los fondos estaba en manos del consejo rural y otras autoridades administrativas, con poco conocimiento o aporte de la comunidad. El control de la explotación de los bosques solo es fuerte en una comunidad, donde las instituciones tradicionales de manejo forestal siguen siendo sólidas. El caso de Camerún se presenta en Oyono et al. en inglés en la página web mencionada arriba.

La Constitución de 1991 en Burkina Faso reconoció los derechos de la comunidad a participar en la administración de las tierras colectivas, y clasifica los recursos naturales como propiedad común de la aldea. El sistema de tenencia de la tierra todavía se rige en gran parte por prácticas y costumbres indígenas, pero la ley de tierras vigente mantiene el principio de que el Estado es propietario de todas las tierras, excepto en los casos en que alguna persona haya reivindicado derechos exclusivos de propiedad. Si una aldea quiere 
obtener derechos de manejo forestal, las reglas varían según la legislación: el Código Forestal de 1997 se refiere a las organizaciones de pobladores locales, mientras que la ley agraria se refiere a los comités de manejo de tierras de las aldeas. En la práctica, los contratos de concesión son la principal forma a través de la cual se transfieren los derechos a las comunidades de los bosques "administrados" oficialmente, y los pobladores deben formar asociaciones privadas o cooperativas para obtener un contrato. Los consejos de desarrollo rural elegidos tienen la autoridad sobre los bosques "no administrados" (Kante 2009).

Los casos estudiados incluyeron una variedad de formas. Tres casos constituían concesiones: una en un bosque y reserva de vida silvestre, y dos con manejo para la producción comercial de leña. Estos dos últimos se encontraban en bosques "catalogados", uno administrado por el Gobierno central y el otro por el local. El cuarto caso se trató de una asociación local que administraba una zona de regeneración de bosque. La investigación y análisis en Burkina Faso hizo especial hincapié en el uso y la evolución de las instituciones consuetudinarias de acceso al bosque, y en los problemas entre estas instituciones y las legales. En las áreas de nuestro estudio, las comunidades podían hacer uso de prácticas tradicionales, siempre que no contradijeran la ley. En general, las comunidades solo tienen derechos de uso, mientras que las agencias forestales estatales son las que toman las decisiones importantes de manejo (Kante 2009). El caso de Burkina Faso no está incluido en esta colección.

Kenia no formó parte de la investigación CIFOR-RRI, pero Mogoi et al. presentan un estudio de caso en la colección en inglés (ver página web). Como en los otros casos de África, las reformas de descentralización han dado lugar al desarrollo de iniciativas de apoyo a la participación comunitaria en el manejo forestal. En el caso de Kenia, el impulso principal fue la rápida deforestación en la década del noventa, y la participación de las comunidades locales se institucionalizó recién en 2005 con la nueva Ley Forestal. La participación implica la creación de las Asociaciones de Bosques Comunitarios (CFA, por sus siglas en inglés), las cuales pueden firmar acuerdos con el Servicio Forestal de Kenia (Kenya Forest Service) estableciendo tanto derechos como responsabilidades para acceder a los bosques.

\section{América Latina}

La devolución de los derechos forestales en América Latina tiene una historia un poco diferente de la de las otras dos regiones. Sus orígenes están más vinculados a la tierra que a los bosques y, en especial, a las luchas de los pueblos indígenas de la región por los derechos a las tierras, aunque muchas comunidades ya se han beneficiado con las reformas desde entonces. Las zonas sobre las que se están reconociendo derechos locales también tienden a ser mucho más grandes que en la mayoría de los países de Asia o de África y cuentan con superficies de mayor tamaño per cápita. Por ejemplo, casi 110 millones de hectáreas de bosques son propiedad de pueblos y comunidades indígenas en Brasil; 40 millones, en México; 28 millones, en Colombia (RRI y OIMT 2009) ${ }^{10}$. Con respecto a la superficie per cápita, en nuestros sitios de estudio, los bosques concedidos a grupos de usuarios de 
bosques comunitarios en Nepal son de 100 a 635 ha, a veces menos de 1 ha por persona. Mientras tanto, una de las concesiones en Petén, Guatemala, abarca 65000 ha, es decir 190 ha por miembro y la titulación en Pando, Bolivia, concedió suficientes tierras para que cada familia tenga 500 ha con el fin de promover la extracción sostenible de castańa (Dahal et al. 2010).

En general, el porcentaje de los bosques que son propiedad de las comunidades en América Latina es similar al de Asia, pero el de las tierras forestales cuyos propietarios son personas y empresas es mucho más elevado. Solo el $36 \%$ de los bosques son propiedad de los Gobiernos de la región y son administrados por ellos, el $25 \%$ pertenecen a las comunidades y los pueblos indígenas, el $7 \%$ son de propiedad estatal — pero designados para el uso de comunidades y pueblos indígenas- y el 32\% son propiedad de personas y empresas (RRI y OIMT 2009).

En Nicaragua, el cambio más significativo de los derechos forestales locales está directamente relacionado con el reconocimiento de los derechos territoriales indígenas. En 1987, como parte de las negociaciones de paz que hubo entre el Gobierno y los grupos disidentes que apoyaron a las fuerzas contrarrevolucionarias durante la guerra de la década del ochenta, se crearon por ley dos regiones autónomas, donde se encuentra la gran mayoría de los bosques y las poblaciones indígenas del país. Ese mismo año, la nueva Constitución reconoció los derechos de los pueblos indígenas y las comunidades étnicas a su identidad cultural, a sus formas de organización y a su propiedad, así como a la explotación de sus aguas y bosques. Más de 15 años después, en 2003, se aprobó finalmente la Ley del Régimen de Propiedad Comunal ${ }^{11}$, que estableció el marco institucional para la demarcación y titulación de tierras.

Desde 2007, los líderes indígenas han promovido de forma activa la formación de grandes territorios indígenas con el apoyo del Gobierno central. Varios de esos territorios ahora están titulados. La investigación del estudio de caso se centró en dos grupos de comunidades: Tasba Raya, donde existen títulos individuales de propiedad y algunos bosques comunales sin titular, y Layasiksa, donde solo hay tierras comunes sin titular. Ninguna tenía los títulos territoriales en el momento del estudio, aunque Tasba Raya se tituló en 2010 como parte de un territorio más grande. El análisis se centró en los conflictos políticos que hubo detrás del proceso de formación de los territorios (Larson y Mendoza-Lewis 2009; Larson 2010b). Layasiksa tenía la iniciativa de forestería comunitaria más avanzada del país, y Pacheco analiza este caso en la presente colección.

En Bolivia, una combinación de reformas importantes mejoró de muchas formas el acceso comunitario a los bosques en la década de los noventa. La Ley Forestal de 1996 transfirió derechos sobre los bosques a una amplia gama de partes interesadas, lo que permitió que las comunidades indígenas y los pequeños propietarios no indígenas adquirieran el derecho a administrar los bosques y al aprovechamiento de la madera con un plan de manejo aprobado. Ese mismo año la Ley de Reforma Agraria reconoció las tierras colectivas y un tipo de propiedad comunal para los pueblos indígenas llamado Tierra Comunitaria de Origen (TCO). El énfasis en estos tipos de propiedades surgió 
"en parte como respuesta al creciente activismo indígena, en particular en las tierras bajas del oriente, donde las necesidades territoriales de los pequeños productores indígenas y campesinos han quedado sin resolver o se ignoran" (Larson et al. 2008:18).

La investigación examinó dos regiones diferentes ${ }^{12}$ : una TCO en la provincia de Guarayos y la titulación de las comunidades agroextractivas de Pando. En el caso de los grupos indígenas, el Viceministerio de Asuntos Indígenas y Pueblos Originarios (VAIPO) realiza un análisis de las necesidades para evaluar las reivindicaciones de la TCO y determina el tamaño y la forma de la misma, luego el Instituto Nacional de Reforma Agraria (INRA) "inmoviliza" la zona y prohíbe la presentación de nuevas reivindicaciones dentro de los límites. La demarcación y la titulación implican un largo proceso de evaluación de todas las demandas presentadas. El caso de Guarayos muestra muchas de las dificultades de este proceso, así como el papel de las iniciativas de manejo forestal. En esta colección, Cronkleton et al. estudian el caso de Guarayos, y el artículo de Pacheco describe una de las comunidades específicas estudiadas, donde se realiza la explotación comercial de madera. Aunque el caso de Yucararé, que se presenta en León et al. en esta colección, no formaba parte de la investigación CIFOR-RRI, también se refiere a la experiencia de una TCO y se centra en las condiciones institucionales de la gobernanza forestal antes y después de la aplicación de la reforma de la tenencia.

El estudio de Pando abarcó la titulación de grandes extensiones a comunidades agroextractivas, en particular de bosques que se utilizan principalmente para la extracción de castaña. Las políticas de descentralización de la década de los noventa establecieron un proceso para que las comunidades rurales obtuvieran personería jurídica con el fin de participar en los procesos de gobernanza municipal. Estas organizaciones, conocidas como Organizaciones Territoriales de Base (OTB), se convirtieron en el eje de las reivindicaciones de tierras de la comunidad. Sus principales competidores fueron los antiguos propietarios de las tierras forestales, los barraqueros, quienes, durante el proceso de titulación, intentaron recuperar el control sobre la región que habían abandonado en gran medida cuando cayó el precio de los productos forestales no maderables (PFNM) en la década de los ochenta. Sin embargo, "la respuesta colectiva de las organizaciones de productores indígenas y campesinos de la región inclinó la reforma agraria en favor de las comunidades" (Larson et al. 2008: 41), y la experiencia general ha tenido mucho éxito. El caso de Pando no está incluido en esta colección (para obtener más información, consulte Cronkleton et al. 2009).

En Guatemala, la investigación comprendió dos regiones muy diferentes: las concesiones comunitarias de la Reserva de la Biosfera Maya (RBM) y los pequeños bosques comunales del altiplano. La RBM se creó en 1990 para proteger los diversos recursos naturales y culturales ubicados en la región norte del Petén. Varios factores condujeron al desarrollo de las concesiones comunitarias en la parte de la RBM conocida como la Zona de Uso Múltiple, incluidas las malas condiciones resultantes de las concesiones madereras privadas y una alianza entre organizaciones conservacionistas y las comunidades que viven en la región (Monterroso y Barry 2009). Los contratos de concesión otorgan el derecho de uso exclusivo de la zona delimitada y de sus recursos a las concesiones comunitarias 
por 25 años. A diferencia de las concesiones industriales, estas permiten el uso y la administración tanto de la madera como de los productos forestales no maderables. Los contratos de concesión requieren que toda la extracción de recursos esté organizada de forma colectiva y basada en planes de manejo aprobados por el Consejo Nacional de Áreas Protegidas (CONAP). La investigación se centró en dos concesiones de un total de 12: una otorgada a una comunidad que vive dentro de la reserva y cuya subsistencia en el pasado se basaba en productos forestales no maderables, y la otra concedida a una organización formada por miembros de nueve pueblos más urbanos. En la presente colección, las concesiones se describen con más detalle en Monterroso y Barry; el estudio de Petén también se utiliza con fines de comparación en dos de los estudios temáticos, Cronkleton et al. y Paudel et al.

El estudio de las tierras forestales en el altiplano de Guatemala implicó una reforma de la tenencia mucho más atenuada. De hecho, de todas las reformas estudiadas, es probablemente la más incipiente y, por lo tanto, la de menor aplicación. El objetivo fue examinar el reconocimiento en el derecho, por primera vez, de la existencia de tierras comunales y los resultados de las políticas de fomento del manejo forestal comunitario en el altiplano. En el momento del estudio, sin embargo, todavía había considerables obstáculos administrativos y de otra índole para la aplicación de la reforma catastral, que se suponía iba a permitir la titulación de las tierras comunales.

Hay cientos de bosques comunales en el altiplano de Guatemala, los cuales abarcan una variedad de tipos oficiales de tenencia de la tierra, en particular los ejidos municipales y numerosos sistemas de propiedad conjunta (Elías et al. 2009). El estudio abarcó un análisis regional, así como estudios de caso en cuatro comunidades, cada uno de los cuales muestra las diferentes formas en que las comunidades obtienen y mantienen sus bienes comunes. Una comunidad era propietaria de sus tierras y bosques a través de un acuerdo de copropiedad entre todos los propietarios individuales; las otras tres estaban oficialmente en tierras municipales. De estas tres últimas, una comunidad había luchado y ganado el reconocimiento, por parte del Gobierno municipal, de sus derechos sobre un bosque de 50 ha que históricamente había sido comunal. Otra había reivindicado la propiedad de una zona que había sido abandonada por su dueño y que la comunidad había administrado como bosque comunal desde 1992. La última comunidad está sujeta a las decisiones del Gobierno municipal, y la declaración de un área protegida condujo a restricciones de uso, divisiones en la comunidad y el temor a que la comunidad perdiera el control sobre la tierra. El artículo de Elías que forma parte de esta colección se basa más en el análisis regional que en los estudios de caso individuales (para obtener más información sobre los casos, véase Elías et al. 2009).

Desde hace mucho tiempo, el enfoque de Brasil con respecto a los derechos de propiedad en la región amazónica ha fomentado la ocupación y el desarrollo, incluidos intentos de colonización masiva para establecerse en lo que antes era visto como una frontera "vacía". Como resultado de los movimientos de base y la presión de las organizaciones no gubernamentales (ONG), se dieron nuevas formas de asentamiento y el reconocimiento de los derechos de los pueblos que ya vivían en la Amazonia. Una de las iniciativas 
más importantes fue la creación del Consejo Nacional de Recolectores de Caucho, la primera organización nacional capaz de representar los intereses de los caucheros y otros trabajadores forestales en la Amazonia con eficacia (Schmink y Wood 1992). Esto llevó a la creación de nuevos modelos para el reconocimiento de los asentamientos agroextractivos, incluyendo las reservas extractivas (RESEX), competencia del Instituto Brasileño de Medio Ambiente y Recursos Naturales Renovables (IBAMA). Otros modelos de asentamiento siguen siendo competencia del Instituto de Reforma Agraria, pero con nuevos modelos que incluyen los derechos colectivos e individuales, tales como los Proyectos de Desarrollo Sostenible (PDS) que están destinados a promover la conservación de los bosques a través de la gestión colectiva.

La investigación se centró en dos asentamientos comunitarios en el límite de una RESEX en Porto de Moz y dos asentamientos de colonización en diferentes etapas de evolución en la región transamazónica, que están tituladas según el modelo de los PDS. Los artículos de esta colección incluyen una breve descripción de la RESEX en Larson y Pulhin, y de uno de los asentamientos en su frontera, donde se realizan actividades de aprovechamiento de la madera en Pacheco. Los casos Transamazónicos no se incluyen aquí (para obtener más información, véase Larson et al. 2008 y Pacheco et al. 2008).

\section{Principales resultados de la investigación}

Esta investigación analizó casos alrededor del mundo, desde la perspectiva de aquellos que reivindican, exigen o que aparentemente obtienen el reconocimiento de sus derechos. Una cuestión central para la comparación fue el cambio en los patrones de derechos y propiedad: ¿hasta qué punto las políticas aumentaron los derechos en las leyes y, lo que es más importante, en la práctica?

Se utilizó el concepto de conjunto de derechos con el fin de dividir los derechos de tenencia en sus diferentes componentes y, en particular, para separar los derechos relativos al uso de aquellos correspondientes a la toma de decisiones. Este conjunto (Schlager y Ostrom 1992; Meinzen-Dick y Knox 1999; Agrawal y Ostrom 2001) incluye el derecho a entrar en el área (derecho de acceso); a utilizar la tierra y retirar recursos (derecho de uso); a administrar el paisaje y planificar el uso futuro, con la siembra de árboles o el manejo de la madera por ejemplo (derecho de manejo); a determinar quién puede y quién no puede utilizar los recursos (derecho de exclusión); y a vender o transferir estos derechos a terceros (derecho de enajenación). En las tierras que son formalmente de propiedad pública o estatal, que a menudo es el caso de los bosques, las personas o los grupos pueden tener uno o más de estos derechos. Los derechos pueden ser ratificados de forma oficial por el Estado o pueden ser aprobados por otros medios, como a través de los dominios ancestrales o las reivindicaciones consuetudinarias.

En la Cuadro 1 se presenta un resumen parcial de los resultados concernientes a los cambios de los derechos en la práctica (la explicación completa de los métodos que derivaron en esta tabla se puede encontrar en Dahal et al. 2010). La aplicación efectiva 


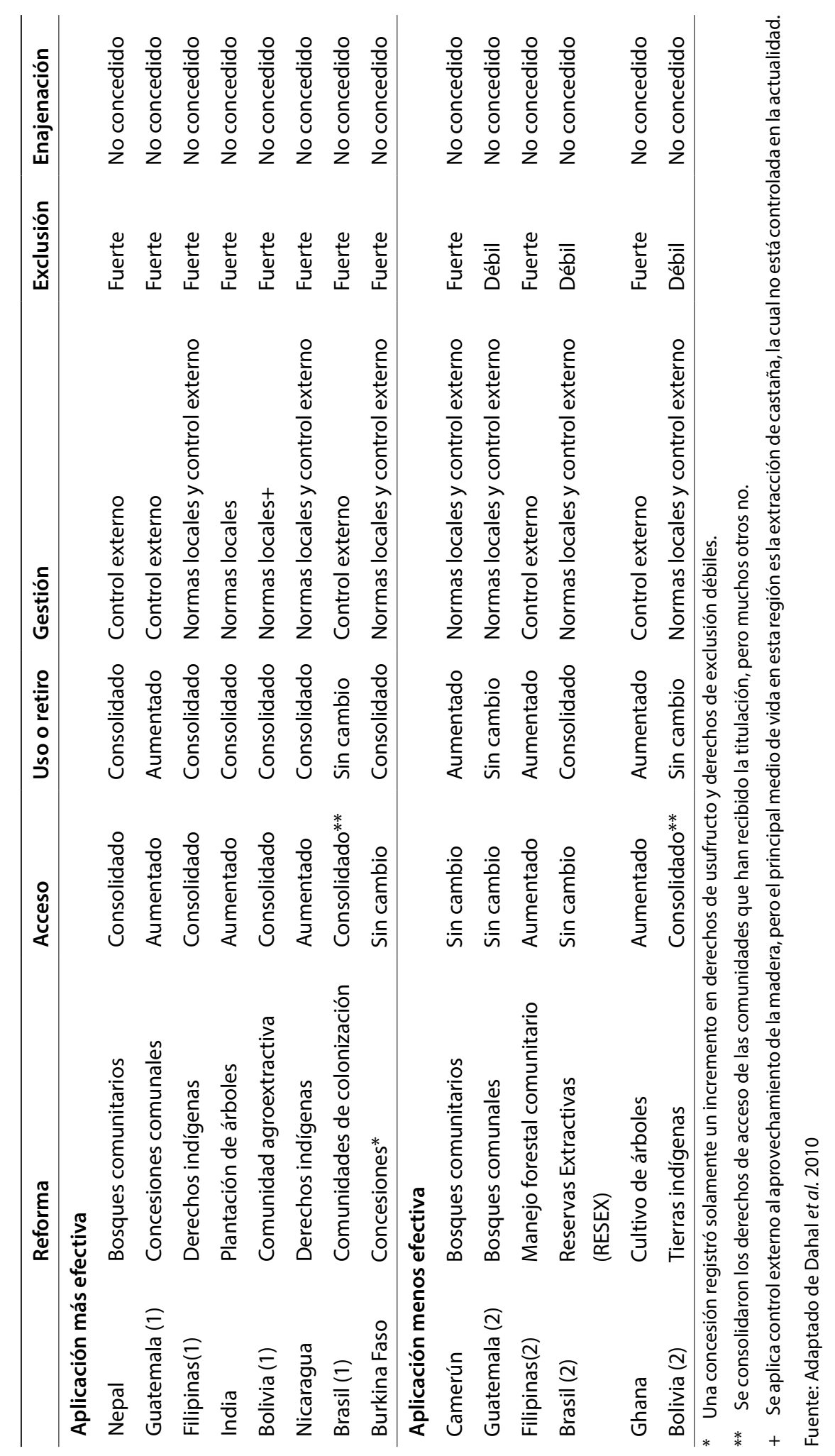


se refiere al establecimiento de una política, así como leyes y reglamentaciones asociadas a un "progreso demostrado a través de pasos identificables hacia el cumplimiento de los objetivos de la reforma". La tabla clasifica los derechos de acceso y uso como: "sin cambio", "aumentado" o "consolidado". Los derechos de gestión o bien permiten la aplicación de las normas locales, o bien se rigen por controles externos, más allá de regulaciones directas (Larson y Pulhin en esta colección). Los derechos de exclusión se clasifican como débiles o fuertes.

Uno de los hallazgos más importantes es que, a pesar de que ha habido un cambio importante en el discurso y un aumento claro en las políticas que otorgan nuevos derechos a las comunidades locales en los bosques, los cambios significativos en los derechos de toma de decisiones a menudo son bastante limitados. La tabla muestra un claro aumento en los derechos de acceso y de uso, pero en lo que respecta a la toma de decisiones sobre el manejo, con frecuencia hay un control externo significativo. Cuando existen normas locales, estas por lo general solo se aplican a los productos de bajo valor o de usos no comerciales. Los derechos de exclusión son fuertes en los casos en que la ley ha sido implementada efectivamente, aunque en algunos casos no se otorgan por ley, sino que los mantienen las poderosas autoridades locales (por ejemplo, en Burkina Faso). En ninguno de los casos se han concedido derechos de enajenación.

La parte más compleja del conjunto se refiere a los derechos de manejo. Como se puede ver en la tabla, se hace difícil diferenciar entre los casos y se necesita hacer mucho para detallar tal complejidad. Este tema se trata en el artículo de Cronkleton et al. en la presente colección. Cuando los bosques son "concedidos" a las comunidades o los derechos de la comunidad son "reconocidos", los derechos siguen estando vinculados a obligaciones o limitados por las normas y regulaciones del Estado. Este tema se aborda en el artículo de Larson y Pulhin en la presente colección.

Por lo tanto, en lo que respecta a los derechos, no es suficiente analizar solo "el conjunto" de estos cinco derechos para distinguir entre los tipos de reformas. Además de una mayor comprensión de los derechos y regulaciones asociados con el manejo, el análisis requiere una dimensión de tiempo y otra de seguridad. El tiempo se refiere a la vigencia del derecho concedido, por ejemplo, a través de un proyecto o contrato temporal, o de una reforma legal permanente.

La seguridad es un tema particularmente complejo. Se mide de muchas maneras, aunque Sjaastad y Bromley (2000) sostienen que debería referirse solo a la garantía de los derechos o al riesgo de perderlos. La seguridad en la teoría y en la práctica son dos cuestiones diferentes, y la segunda requiere una profunda comprensión del contexto. La seguridad en la práctica se relaciona con la cuestión de los derechos de exclusión, como se observa en la tabla, pero puede cambiar en cualquier momento debido a amenazas nuevas. Otro resultado clave de la investigación, por lo tanto, fue la medida en que las reformas y su aplicación afrontan constantes desafíos provocados por actores con diferentes intereses (Larson et al. 2010a; Larson 2010a). De ahí la importancia de los movimientos sociales en la defensa de los derechos. Este tema se analiza en el artículo de Paudel et al. en la presente colección. 
Otro hallazgo importante de la investigación se refiere a los resultados de las reformas: a no ser que se hagan grandes esfuerzos para nivelar el campo de juego y mejorar las opciones de medios de vida, es difícil que las comunidades obtengan grandes ganancias de sus nuevos derechos. En esta colección, el cuarto y último artículo temático de Pacheco examina un aspecto de los resultados de las reformas: la participación en los mercados de la madera ${ }^{13}$.

Una serie de preguntas quedan por abordar en futuras investigaciones. Algunas se relacionan con la profundidad de los derechos. El conjunto de derechos se refiere solo a qué derechos se conceden pero no a por qué son concedidos o a cuál es la base subyacente de la reivindicación. ¿Cuándo tienen las comunidades la base para reclamar derechos independientemente de las normas y regulaciones sobre bosques, y cuándo deben estar vinculadas a las obligaciones forestales? ¿Cómo afecta su aplicación el origen de las reivindicaciones? ¿En qué condiciones avanzan las reformas más significativas, superando la resistencia política? Se necesitan más detalles comparativos sobre la estructura de las políticas de reforma.

Es necesario un mayor entendimiento de la seguridad de los derechos. La seguridad de la tenencia es mucho más compleja que la legalidad. ¿Cuáles son los factores que influencian y definen la seguridad, y cuándo las reformas se traducen en derechos más seguros? ¿Cómo pueden las comunidades y sus partidarios defender los derechos frente a los desafíos actuales de los actores poderosos (por ejemplo, los intereses de la minería, el petróleo, los biocombustibles, las áreas protegidas, el comercio de carbono, etc.)?

Otra área importante de investigación y política es el nivel y el tipo de controly obligaciones apropiados. ¿Por qué las comunidades deben tener obligaciones adicionales o diferentes de las del titular de una propiedad privada o de una empresa maderera? ¿Cómo pueden los marcos regulatorios facilitar la participación comunitaria en los mercados y basarse en instituciones locales en lugar de sustituirlas, especialmente frente a las burocracias arraigadas? ¿Cómo se puede apoyar el manejo y los modelos de "desarrollo" locales? ¿Cómo debe apoyarse la estructura institucional y la gobernanza (y cómo se deben superar los problemas) en los territorios compuestos por múltiples comunidades o en las instituciones consuetudinarias?

Por último, los métodos de investigación deben ir más allá del estudio de caso exhaustivo ${ }^{14}$ y combinar los métodos comparativos, cuantitativos y cualitativos. A medida que pasa el tiempo, también debería ser posible llevar a cabo más estudios que permitan la comparación en el tiempo, antes y después de las reformas, en particular en relación a los resultados de las reformas para los bosques, los medios de vida y la equidad.

\section{Breve presentación de los artículos}

Todos los artículos se enfocan en una de las conclusiones centrales de la investigación: que las comunidades tienen por delante un camino muy largo y difícil desde que ganan los derechos por escrito hasta que logran su aplicación, ejercen los derechos en la práctica y mejoran los medios de vida. Aunque a veces la búsqueda de un equilibrio adecuado entre 
esta mejora y la conservación de los bosques puede ser la causa de tensión, en ocasiones muchos otros intereses contrapuestos inhiben la aplicación total de las reformas. Además, las comunidades se enfrentan a retos internos, tales como problemas de gobernanza, incluyendo la representación, la rendición de cuentas y la capacidad. Por último, las reformas —o la formalización de los derechos_ pueden establecer una serie de reglas y obligaciones formales sobre las instituciones locales de gobernanza forestal existentes (que posiblemente sean más eficaces), con implicaciones para la cultura y los bosques.

En cada artículo se presentan los principales retos o las maneras en que estos se han superado. Los cuatro primeros artículos realizan una serie de comparaciones entre sitios y describen algunos de los principales aspectos transversales de las reformas. Los restantes seis artículos, tres de los cuales están incluidos en esta colección en español, examinan otras cuestiones a través de estudios de caso en un país o en una región de un país.

El primer artículo temático, de Peter Cronkleton, Juan Pulhin y Sushil Saigal, compara cuatro casos de reforma - en Bolivia, Filipinas, India y Guatemala- y analiza en qué medida se han otorgado derechos a las comunidades. Se centra en el papel fundamental que desempeñan los derechos de manejo en la distribución de los diferentes aspectos del conjunto de derechos de tenencia y la manera en que son, con frecuencia, retenidos por el Estado. Aunque la reforma de la tenencia ha abierto mayores oportunidades para el manejo forestal local, la transferencia de derechos a las comunidades forestales es a menudo incompleta, lo que da como resultado sistemas de cogestión en los que las comunidades y las agencias estatales comparten las responsabilidades y los beneficios del manejo forestal. Estos sistemas suelen colocar una carga mayor sobre los actores a nivel de comunidad y carecen de la flexibilidad para responder a la diversidad local o permitir la adaptación.

El artículo de Anne Larson y Juan Pulhin examina varios tipos de regulaciones que comúnmente acompañan a las reformas y que, al igual que los acuerdos de cogestión, limitan en gran medida el alcance de las mismas. Sobre la base de una serie de estudios de caso, analiza tanto las normas que limitan las áreas disponibles para las comunidades locales como aquellas que delimitan las áreas de conservación e imponen límites sobre el uso, y los requisitos burocráticos para los permisos y planes de gestión, que restringen el uso comercial y la comercialización de productos forestales valiosos. Se analizan las formas de promover regulaciones adecuadas para la conservación de bosques, pero que sean más sensibles a las comunidades.

El artículo de Pablo Pacheco examina cómo las diferentes formas de participación en el mercado de la madera, en el contexto de las reformas de tenencia, inciden en los beneficios para los pequeños productores y las comunidades. Se argumenta que los beneficios que las comunidades obtienen de los recursos forestales dependen de varios riesgos y oportunidades, en los que median dos tipos de factores: las condiciones específicas del mercado y las capacidades de la comunidad para la interacción con el mercado. El artículo analiza cuatro casos de comunidades forestales de Bolivia, Brasil y Nicaragua, y hace un llamado a respuestas de políticas públicas diferenciadas en función de las formas de interacción. 
El cuarto y último artículo temático, escrito por Naya Sharma Paudel, Iliana Monterroso y Peter Cronkleton, muestra el papel que desempeñan las organizaciones de segundo nivel para superar los tipos de obstáculos que se presentan en los tres artículos anteriores, y mejorar así la aplicación de las reformas y sus resultados en lo concerniente a los medios de vida. Los autores analizan cómo ha surgido en los últimos años la acción colectiva para la gobernanza forestal a través de organizaciones de segundo nivel. Sobre la base de la experiencia de la Federación de Usuarios de Bosques Comunitarios (FECOFUN), en Nepal, y la Asociación de Comunidades Forestales de Petén (ACOFOP), en Guatemala, el artículo muestra cómo estas organizaciones han contribuido a fortalecer la aplicación de las reformas de tenencia forestal, así como a mejorar los beneficios del manejo para las comunidades dependientes de los bosques.

Los seis artículos siguientes presentan estudios de caso en Petén, Guatemala, el altiplano de Guatemala, Ghana, Camerún, Kenia y un territorio indígena en Bolivia, respectivamente (solo los tres sobre América Latina han sido traducidos al español). El primer estudio de caso, realizado por Iliana Monterroso y Deborah Barry, analiza la importancia de la legitimidad para el mantenimiento o la defensa de los derechos en las concesiones comunitarias de Petén, en Guatemala. Las concesiones forestales comunitarias muestran efectos positivos en los medios de vida locales y las condiciones del bosque, sin embargo, al ser concesiones, su futuro continuamente depende de su legitimidad. Conflictos de intereses y valores cambiantes en el mismo paisaje forestal ejercen presión constante sobre las concesiones para repensar los términos futuros de sus derechos de tenencia. Este artículo analiza los elementos que definen la legitimidad (por ejemplo, a nivel interno, a través de la distribución de beneficios, y, externamente, a través del cumplimiento de las normas legales) y cómo esta condiciona el futuro de los bosques de Guatemala.

El artículo sobre el altiplano de Guatemala, escrito por Silvel Elías, analiza los discursos y los riesgos relacionados con la creación de áreas protegidas en los bosques comunales, la mayoría de las cuales son administradas por comunidades indígenas. Elías analiza los efectos que la conversión de bosques comunales a áreas protegidas ha tenido en las formas tradicionales de gobernanza forestal en los bosques de las zonas montañosas de Guatemala. El artículo destaca la importancia de las nuevas reglas de acceso y exclusión respecto a los recursos forestales, el aumento de los conflictos entre los usos formales e informales de los bosques y el protagonismo de nuevos actores sociales que están redefiniendo los sistemas ecológicos en el altiplano de Guatemala.

El artículo de Emmanuel Marfo se basa en la experiencia de las reformas de tenencia en Ghana para examinar cómo las comunidades pueden beneficiarse de las oportunidades ofrecidas por los esquemas de mitigación de carbono, tales como el Mecanismo de Desarrollo Limpio y la Reducción de Emisiones de la Deforestación y la Degradación de los Bosques (REDD). Marfo sostiene que las dos limitaciones principales de la distribución de beneficios en Ghana son: los débiles derechos de tenencia de las comunidades —y la inseguridad que resulta de ellos- y la falta de rendición de cuentas por parte de la autoridad, lo que lleva al usufructo de beneficios por una élite. Si no se presta atención para superar estos problemas, los beneficios no llegarán a la población local, y entonces es improbable que estos esfuerzos puedan mejorar el manejo de los bosques y los árboles. 
El artículo sobre Camerún de Phil René Oyono, Martin Blaise Biyong y Serge Kombo Samba examina los resultados de las iniciativas forestales comunitarias en cuatro sitios de investigación. Los autores demuestran que la forestería comunitaria no ha mejorado los activos o ingresos básicos en los hogares, sino que, más bien, han aumentado las amenazas a los recursos naturales debido a acuerdos institucionales y estrategias de manejo deficientes. Los autores sostienen que el Estado y las comunidades están en conflicto por los derechos y que la tenencia segura es un primer paso esencial para una reforma eficaz.

Jephine Mogoi, Emily Obonyo, Paul Ongugo, Vincent Oeba y Esther Mwangi examinan los avances y desafíos en la formación de las Asociaciones de Bosques Comunitarios (CFA), en el marco de las políticas de descentralización en Kenia. La investigación compara las CFA en 12 bosques de Kenia en un período de 10 años. Aunque el Servicio Forestal de Kenia sigue controlando las decisiones clave y los recursos, las CFA también tienen importantes responsabilidades de manejo y toman decisiones autónomas con respecto a las normas de manejo, los líderes y la resolución de conflictos. La investigación estudia su capacidad, así como las limitaciones y los desafíos que enfrentan, en vista de los crecientes conflictos de interés con el Servicio Forestal de Kenia, mientras que los aspectos importantes relativos a la distribución de competencias y beneficios aún no se han definido.

El último artículo, escrito por Rosario León, Patricia Uberhuaga, Jean-Paul Benavides y Krister Andersson, analiza cómo los esfuerzos para reformar la gobernanza forestal, tanto a través de la descentralización como de las reformas de tenencia, han incidido en un territorio indígena, sus habitantes y sus esfuerzos por gobernar sus recursos forestales. Este artículo examina específicamente los efectos de las reformas de tenencia sobre las condiciones institucionales para el manejo de los recursos forestales, analizando el uso del bosque en el pueblo Yuracaré en las tierras bajas bolivianas, tanto antes como después de la reforma.

En resumen, los artículos de esta colección abordan una amplia gama de países, casos y temas relacionados con la reforma de la tenencia forestal. Juntos, proporcionan una visión bastante exhaustiva de los principales retos - y oportunidades- para el futuro.

\section{Notas}

1. En esta investigación, la "comunidad" no se refiere necesariamente a un grupo de personas que viven en un solo pueblo, sino que más bien se define como aquellos que tienen un interés o un fin común en un bosque en particular y comparten recursos comunes. De ahí que la comunidad (o pueblo) residente se puede superponer con la comunidad de interés o ser un subconjunto de esta, o viceversa. También puede haber pequeñas "comunidades" que forman parte de comunidades más grandes.

2. Aunque se tenía previsto que la investigación reuniera más datos comparativos sobre los resultados a nivel mundial, los fondos no fueron suficientes para recopilar el tipo de datos forestales de calidad que hubieran podido ser útiles, y no se disponía de datos de referencia para realizar un estudio riguroso de los resultados de medios de vida. Por lo tanto, este análisis fue principalmente cualitativo (Larson et al. 2010b; Dahal et al. 2010). 
3. Una evaluación analítica transversal de estos resultados se puede encontrar en Dahal et al. (2010) y Larson et al. (2010b).

4. Por razones logísticas, el trabajo de campo se centró en dos comunidades aledañas a la reserva. Allí se utilizaron las dinámicas para la comparación con la información disponible sobre la RESEX.

5. Pero no a las comunidades indígenas en el altiplano de Guatemala.

6. Por ejemplo, las políticas de transferencia y descentralización están claramente apoyadas por otras fuerzas, como las políticas y el discurso de democratización (Ribot 2002), sobre todo en Estados poscoloniales en África o después de la caída de las dictaduras, guerras civiles o regímenes revolucionarios en numerosos países de África, Asia y América Latina (Barry et al. 2010).

7. Por ejemplo, los casos de Ghana son muy distintos y serían difíciles de comparar, pero la forestería comunitaria en Camerún podría haberse incluido en el análisis de la cogestión o el mercado de la madera. Sin embargo, el énfasis de los investigadores fue diferente; el caso de Camerún se centró menos en el papel del Estado y más en el papel de las elites. Del mismo modo, los casos de Burkina Faso podrían haberse incluido en el análisis de cogestión. En el artículo sobre oportunidades de mercado, todos los casos fueron seleccionados de América Latina debido a que se disponía de fondos para la coordinación entre los investigadores de América Latina, lo cual no estaba disponible en las demás regiones, y debido a la familiaridad del autor con la región. Al mismo tiempo, las dos organizaciones secundarias que se compararon (de Nepal y Guatemala) fueron seleccionadas por su importancia. El artículo sobre regulaciones se refiere a casi todos los casos; sin embargo, una vez más, los casos de Ghana eran muy diferentes, y la información sobre las regulaciones de Burkina Faso era limitada.

8. Véase Guha (2001) para obtener más información sobre los derechos forestales a principios de siglo.

9. Ley de Las Tribus Registradas y Otros Habitantes Tradicionales de los Bosques, 2006.

10. Algunos países de Asia y el Pacífico muestran cifras similares. En China, 100 millones de hectáreas son propiedad de las comunidades y pueblos indígenas; en Papúa Nueva Guinea, 26 millones; en Australia, 21 millones (RRI y OIMT 2009). La distribución per cápita no se encuentra disponible.

11. Ley del Régimen de Propiedad Comunal de los Pueblos Indígenas y Comunidades Étnicas de las Regiones Autónomas de la Costa Átlantica de Nicaragua y de los Ríos Coco, Bocay, Índio y Maíz.

12. En el artículo de Pacheco de esta colección se presenta el caso de una tercera región, que fue incluido después de que este proyecto haya terminado.

13. Para obtener más resultados y conclusiones de las reformas, véase Larson 2010a; Larson et al. 2008, 2010a, b; www.cifor.cgiar.org/tenure-reform

14. Gracias a Krister Andersson por su contribución a los conocimientos sobre las preguntas sin respuestas y sobre métodos de investigación. 


\section{Agradecimientos}

Los autores quieren agradecer a los editores de Conservation and Society por sus comentarios sobre una versión anterior de esta introducción. La investigación CIFORRRI fue financiada por la Fundación Ford, el CIID y el Programa Forestal (PROFOR) del Banco Mundial.

\section{Referencias}

Agrawal, A. y A. Chhatre. 2006. Explaining success on the commons: Community forest governance in the Indian Himalaya. World Development 34(1): 149-166.

Agrawal, A. y A. Chhatre. 2007. State involvement and forest co-governance: Evidence from the Indian Himalayas. Studies in Comparative International Development 42(1/2): 67-86.

Agrawal, A. y E. Ostrom. 2001. Collective action, property rights, and decentralization in resource use in India and Nepal. Politics and Society 29(4): 485-514.

Barry, D., A.M. Larson y C.J.P. Colfer. 2010. Forest tenure reform: An orphan with many uncles. En: Forests for people: Community rights and forest tenure reform (eds. Larson, A.M., D. Barry, G.R. Dahal y C.J.P. Colfer). Londres: Earthscan.

Blaikie, P. 2006. Is small really beautiful? Community-based natural resource management in Malawi and Botswana. World Development 34(11): 1942-1957.

Bromley, D.W. y M.M. Cernea. 1989. The management of common property natural resources. World Bank Discussion Paper No. 57. Washington D.C.: Banco Mundial.

Brunner, J., F. Seymour, N. Badenoch y B. Ratner. 1999. Forest problems and law enforcement in Southeast Asia: The role of local communities. Resources Policy Brief. Washington D.C.: Instituto de Recursos Mundiales.

Charnley, S. y M.R. Poe. 2007. Community forestry in theory and practice: Where are we now? Annual Review of Anthropology 36: 301-336.

Council for Social Development (CSD). 2010. Summary report on implementation of the Forest Rights Act. Nueva Delhi, http://www.forestrightsact.com/component/ $\mathrm{k} 2 /$ item/15. Visitado el 14 de abril de 2011.

Cronkleton, P., P. Pacheco, R. Ibarguen y M.A. Albornoz. 2009. Reformas en la tenencia de la tierra y los bosques: La gestión comunal en las tierras bajas de Bolivia. La Paz, Bolivia: Centro para la Investigación Forestal Internacional; y Centro de Estudios para el Desarrollo Laboral y Agrario.

Dahal, G.R., A. Larson y P. Pacheco. 2010. Outcomes of reforms for livelihoods, forest condition and equity. En: Forests for people: Community rights and forest tenure reform (eds. Larson, A.M., D. Barry, G.R. Dahaly C.J.P. Colfer). Pp. 183-209. Londres: Earthscan.

Dove, M.R. 1983. Theories of swidden agriculture, and the political economy of ignorance. Agroforestry Systems 1(2): 85-99. 
Elías, S., A.M. Larson y J. Mendoza. 2009. Tenencia de la tierra, bosques y medios de vida en el Altiplano Occidental de Guatemala. Guatemala: Centro para la Investigación Forestal Internacional y Facultad de Agronomía (Universidad de San Carlos).

Fairhead, J. y M. Leach. 1996. Misreading the African landscape: Society and ecology in a forest-savanna mosaic. Cambridge y Nueva York: Cambridge University Press.

Fairhead, J. y M. Leach. 1998. Reframing deforestation: Global analyses and local realitiesStudies in West Africa. Londres: Routledge.

Gilmour, D. 2003. Retrospective and prospective view of community forestry in Nepal. Journal of Forest and Livelihoods 2(2): 5-7.

Guha, R. 2001. The prehistory of community forestry in India. Environmental History 6(2): 213-238.

Hecht, S. y Cockburn, A. 1989. The fate of the forest. Londres: Verso.

Rights and Resources Initiative e International Tropical Timber Organization (RRI and ITTO). 2009. Tropical forest tenure assessment: Trends, challenges and opportunities. Prepared for the International conference on forest tenure, governance and enterprise: New opportunities for Central \& West Africa. Hôtel Mont Fébé, Yaundé, Camerún. Del 25 al 29 de mayo de 2009.

Kante, B. 2009. Amélioration de l'équité et des moyens de subsistance dans la foresteriac ommunautaire au Burkina Faso. Informe de país. Centro para la Investigación Forestal Internacional. Inédito.

Kull, C.A. 2004. Isle of fire: The political ecology of landscape burning in Madagascar. Chicago, IL: University of Chicago Press.

Larson, A.M. 2009. Recognizing community rights: The potential and challenges of forest tenure reform. Infobrief No. 22. Bogor: Centro para la Investigación Forestal Internacional.

Larson, A.M. 2010a. Forest tenure reform in the age of climate change: Lessons for REDD+. Global Environmental Change 21: 540-549. doi:10.1016/j. gloenvcha.2010.11.008.

Larson, A.M. 2010b. Making the 'rules of the game': Constituting territory and authority in Nicaragua's indigenous communities. Land Use Policy 27: 1143-1152.

Larson, A.M. y J. Mendoza-Lewis. 2009. Desafios en la tenencia comunitaria de bosques en la RAAN de Nicaragua. Managua: Centro para la Investigación Forestal Internacional, Universidad de las Regiones Autónomas de la Costa Caribe Nicaragüense y Iniciativa para los Derechos y Recursos.

Larson, A.M., D. Barry y G.R. Dahal. 2010a. Conclusions and reflections for the future of forest tenure reform. En: Forests for people: Community rights and forest tenure reform (eds. Larson, A.M., D. Barry, G.R. Dahal y C.J.P. Colfer). Pp. 210-223. Londres: Earthscan.

Larson, A.M., D. Barry y G.R. Dahal. 2010b. New rights for forest based communities: Understanding processes of forest tenure reform. International Forestry Review 12(1): 78-96. 
Larson, A.M., D. Barry, G.R. Dahal y C.J.P. Colfer (eds.). 2010c. Forests for people: Community rights and forest tenure reform. Londres: Earthscan.

Larson, A.M., E. Marfo, P. Cronkleton y J. Pulhin. 2010d. Authority relations under new forest tenure arrangements. En: Forests for people: Community rights and forest tenure reform (eds. Larson, A.M., D. Barry, G.R. Dahal y C.J.P. Colfer). Pp. 93-115. Londres: Earthscan.

Larson, A.M., P. Cronkleton, D. Barry y P. Pacheco. 2008. Tenure rights and beyond: Community access to forest resources in Latin America. Bogor: Centro para la Investigación Forestal Internacional, Occasional Paper No. 50.

Marfo, E. 2009. Security of tenure reforms and community benefits under collaborative forest management arrangements in Ghana. Accra: Centro para la Investigación Forestal Internacional y Forestry Research Institute of Ghana.

Meinzen-Dick, R. y A. Knox. 1999. Collective action, property rights, and devolution of natural resource management: A conceptual framework. Artículo presentado en el International workshop on collective action, property rights and devolution of natural resource management, exchange of knowledge and implications for policy. Filipinas. Del 21 al 25 de junio de 1999.

Monterroso, I. y D. Barry. 2009. Tenencia de la tierra, bosques y medios de vida en la reserva de la biosfera maya en Guatemala: Sistema de concesiones forestales comunitarias. Guatemala: Centro para la Investigación Forestal Internacional y Facultad Latinoamericana de Ciencias Sociales.

Mwangi, E. 2010. The struggle to understand: Elinor Ostrom and institutions for the governance of forests. Publicación especial de International Association for the Study of the Commons. The Commons Digest 9 (Spring): 11-13.

Ostrom, E. 1990. Governing the commons. Nueva York, NY: Cambridge University Press.

Oyono, P.R., S.S. Kombo y M.B. Biyong. 2009. Les nouvelles niches de droitsforestierscommunautaires au Cameroun: Effetscumulatifssur les moyens de subsistance et les formes locales de vulnérabilité. Yaoundé: Centro para la Investigación Forestal Internacional.

Pacheco, P., D. Barry, A. Larson y P. Cronkleton. 2009. From agrarian to forest tenure reform: The recognition of forest rights in Latin America. Artículo presentado en el $13^{\text {er }}$ Congreso Forestal Mundial. Buenos Aires, Argentina. Del 18 al 23 de octubre de 2009.

Pacheco, P., W. Nunes, C. Rocha, I. Vieira, J. Herrera, K. Alves, T. Feitosa y G. Cayres. 2008. Acesso à terra e meios de vida: Examinando suas interaçôes em três locais no Estado do Pará. Santa Cruz, Bolivia: Centro para la Investigación Forestal Internacional, Laboratório Agroecológico da Transamazonica, y Assessoria Comunitária e Ambiental.

Pagdee, A., Y. Kim y P.J. Daugherty. 2006. What makes community forest management successful: A meta-study from community forests throughout the world. Society and Natural Resources 19(1): 33-52. 
Paudel, N.S., M. Banjade y G.R. Dahal. 2009. Improving equity and livelihoods in community forestry. Informe de país, Nepal. Forest Action y Centro para la Investigación Forestal Internacional, Katmandú, Nepal.

Pulhin, J.M., J.T. Dizon, R.V.O. Cruz, D.T. Gevana y G.R. Dahal. 2008. Tenure reform on Philippine forest lands: Assessment of socio-economic and environmental impacts. Los Baños: College of Forestry and Natural Resources, University of Philippines.

Poffenberger, M. 2001. Communities and forest management in Southeast Asia. Gland, Suiza: Unión Internacional para la Conservación de la Naturaleza.

Poffenberger, M. 2006. People in the forest: Community forestry experiences from Southeast Asia. International Journal of Environment and Sustainable Development 5(1): 57-69.

Ramdas, S.R. 2009. Women, forest spaces and the law: Transgressing the boundaries. Review of Women's Studies, Economic and Political Weekly 44: 65-73.

Rao, K. y C. Geisler. 1990. The social consequences of protected areas development for resident populations. Society and Natural Resources 3(1): 19-32.

Ribot, J.C. 2002. Democratic decentralization of natural resources: Institutionalizing popular participation. Washington D.C.: Instituto de Recursos Mundiales.

Ribot, J.C. 2004. Waiting for democracy: The politics of choice in natural resource decentralization. Washington D.C.: Instituto de Recursos Mundiales.

Roe, D. 2008. The origins and evolution of the conservation-poverty debate: A review of key literature, events ad policy processes. Oryx 42(4): 491-503.

Saigal, S., G.R. Dahal y B. Vira. 2009. Cooperation in forestry: Analysis of forestry cooperatives in Rajasthan, India. Cambridge: Iniciativa para los Derechos y Recursos, Centro para la Investigación Forestal Internacional y Universidad de Cambridge.

Saxena, N.C. 1997. The saga of participatory forest management in India. Special Publication. Bogor: Centro para la Investigación Forestal Internacional.

Schlager, E. y E. Ostrom. 1992. Property rights regimes and natural resources: A conceptual analysis. Land Economics 68(3): 249-262.

Schmink, M. y C. Wood. 1992. Contested frontiers in Amazonia. Nueva York: Columbia University Press.

Sjaastad, E. y D.W. Bromley. 2000. The prejudices of property rights: On individualism, specificity, and security in property regimes. Development Policy Review 18(4): 365-389.

Springate-Baginski, O., M. Sarin, S. Ghosh, P. Dasgupta, I. Bose, A. Banerjee, K. Sarap, et al. 2009. Redressing 'historical injustice' through the Indian Forest Rights Act 2006. Discussion paper series 27. IPPG, Mánchester, Reino Unido. www.ippg.org. uk. Consultado el 19 de marzo de 2012.

Sunderlin, W., J. Hatcher y M. Liddle. 2008. From exclusion to ownership? Challenges and opportunities in advancing forest tenure reform. Washington D.C.: Iniciativa para los Derechos y Recursos. 
Taylor, P.L., A. Larson y S. Stone. 2007. Forest tenure and poverty in Latin America: A preliminary scoping exercise. Centro para la Investigación Forestal Internacional e Iniciativa para los Derechos y Recursos. Informe inédito. 18 de agosto de 2007.

The Hindu. 2011. Strengthen Forest Rights Act, says National Advisory Committee.http:// www.thehindu.com/2011/02/27/stories/2011022765121400.htm. Consultado el 18 de abril de 2011.

White, A. y A. Martin. 2002. Who owns the world's forests? Washington D.C.: Forest Trends. 



\section{Temas transversales}

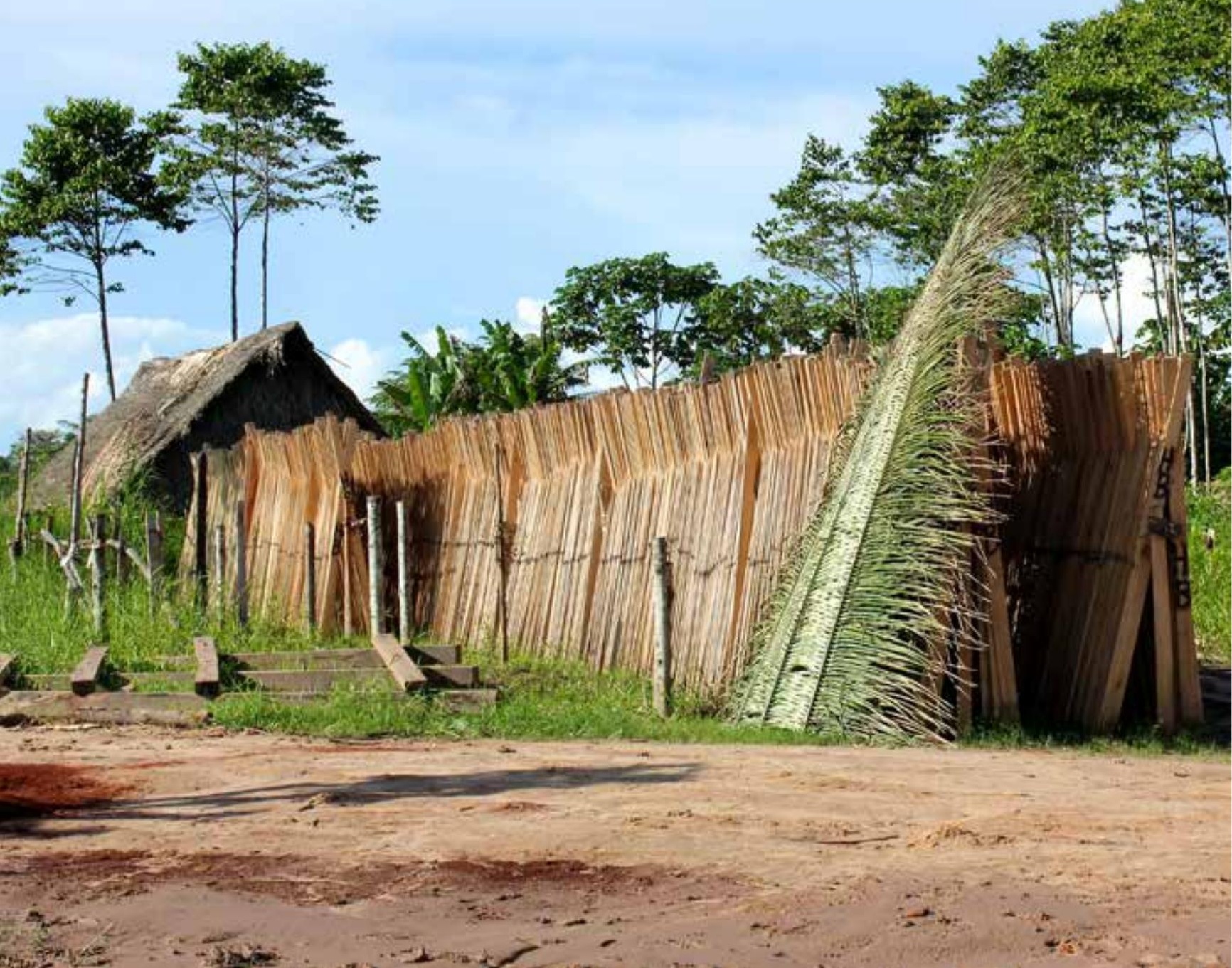





\title{
La cogestión en la forestería comunitaria
}

\author{
Cómo la transferencia parcial de los derechos de manejo crea retos para las \\ comunidades forestales ${ }^{i}$
}

Peter Cronkletonii, Juan M. Pulhiniii y Sushil Saigaliv

\section{Resumen}

La reforma de la tenencia forestal ha creado oportunidades económicas y de medios de vida para el manejo forestal comunitario a través de la devolución de los derechos de manejo, en el marco de amplias reformas de descentralización. Sin embargo, la transferencia a las comunidades forestales de los derechos y del poder que estos otorgan suele ser parcial. La propiedad entendida como "conjunto de derechos" permite la desagregación de los derechos transferidos del Gobierno a la población local. En la práctica, es frecuente que los derechos de los usuarios de recursos naturales abarquen solo una parte del conjunto de derechos. Esta transferencia parcial de los derechos lleva a la creación de instituciones de forestería comunitaria y tiene un impacto en la manera en que funcionan. Cuando las comunidades y las agencias estatales comparten las responsabilidades y los beneficios del manejo forestal, ellas están colaborando dentro de sistemas de cogestión. Los sistemas de cogestión son atractivos para los Gobiernos porque permiten la participación local en la gobernanza de los recursos y una distribución más equitativa de los beneficios, a la vez que mantienen cierto nivel de control estatal. Sin embargo, los sistemas de cogestión pueden imponer una carga mayor a los actores de las comunidades, sin proporcionar los beneficios correspondientes. Como resultado, es posible que la cogestión no cumpla con las expectativas. Por ello, el fomento de la forestería comunitaria puede requerir un mayor énfasis en el ajuste de los marcos regulatorios, las instituciones y las agencias forestales, a fin de que los actores de las comunidades tengan más libertad en el desarrollo de sistemas de manejo forestal.

i Este artículo es una traducción del original, que apareció en inglés en la revista Conservation and Society, en la edición especial sobre Reformas de tenencia forestal (eds. Anne M. Larson y Ganga Ram Dahal). La cita original completa es: Cronkleton, P., Pulhin, J.M. and Saigal, S. 2012 Co-management in Community Forestry: How the Partial Devolution of Management Rights Creates Challenges for Forest Communities. Conservation and Society 10(2): 91-102. El artículo cuenta con una licencia de Creative Commons de Atribución 3.

ii Centro para la Investigación Forestal Internacional (CIFOR), Lima, Perú - pcronkleton@cgiar.org.

iii Universidad de Filipinas Los Baños, Filipinas.

iv Universidad de Cambridge, Cambridge, Reino Unido. 


\section{Introducción}

Durante varias décadas, las reformas legales relacionadas con la descentralización y la reforma de la tenencia forestal en el trópico han tratado de promover condiciones que lleven a un manejo forestal sostenible por parte de actores locales en las comunidades (Larson et al. 2010b). Aunque diversos factores impulsaron esta tendencia, entre los intereses comunes que subyacen a estos esfuerzos se incluyen tanto las cuestiones ambientales como las de equidad. Por un lado, con frecuencia se atribuye la deforestación y la degradación a derechos de propiedad mal definidos o contradictorios, la falta de seguridad de la tenencia y a marcos jurídicos débiles o mal aplicados (Brown y Pearce 1994; Kaimowitz y Angelsen 1998). Por otro lado, el proporcionar a las personas que dependen de los bosques un libre acceso a los recursos forestales y oportunidades para explotarlos legalmente, incentiva el mantenimiento de la cobertura forestal (Eliasch 2008). Estas reformas forestales dirigidas a las comunidades y organizaciones comunitarias son parte de un proceso más amplio conocido como "descentralización democrática", es decir, la transferencia de competencias y recursos a las autoridades representativas responsables ante las poblaciones locales (Ribot 2002).

A pesar de tener objetivos aparentemente claros, las reformas forestales y de la tenencia lideradas por el Gobierno han enfrentado desafíos complejos para determinar cómo asignar los derechos y también para asegurar que aquellos que reciban los derechos administren los recursos de manera sostenible. Por ello, los Gobiernos suelen transferir los derechos de manejo forestal solo parcialmente, ya que conservan facultades clave para sí mismos, una situación que crea sistemas de cogestión. En los sistemas de cogestión, múltiples actores negocian y comparten importantes funciones, derechos y responsabilidades de manejo sobre un área o recurso (Borrini-Feyerabend 2000). En situaciones de forestería comunitaria, se concede a los actores de nivel comunitario ciertas facultades para la toma de decisiones sobre el manejo, así como oportunidades para obtener beneficios en marcos definidos y aplicados por las agencias estatales. Los residentes de la comunidad pueden trabajar en el bosque y explotar los recursos para su sustento económico, pero el Estado mantiene un papel importante en la supervisión, vigilancia y evaluación de cómo estas personas utilizan los recursos forestales. Aunque la cogestión es potencialmente prometedora para conservar los bosques y mejorar el bienestar humano, en la práctica, las estrategias y acciones adoptadas por los actores estatales a menudo crean sistemas de cogestión defectuosos, lo que disminuye su eficacia y limita su impacto.

Este artículo examina los derechos de manejo forestal y la forma en que se transfieren de los Gobiernos a las organizaciones comunitarias. El artículo utiliza el concepto de "conjunto de derechos" para desagregar los derechos que son transferidos a las comunidades locales y analiza la naturaleza de los sistemas de cogestión en que se basan las iniciativas de forestería comunitaria resultantes. El análisis se basa en un estudio comparativo global sobre la reforma de la tenencia forestal llevado a cabo por el Centro para la Investigación Forestal Internacional (CIFOR por sus siglas en inglés) y la Iniciativa para los Derechos y Recursos (RRI por sus siglas en inglés) (véase Larson y Dahal en esta colección; también Larson et al. 2010a, b). El proyecto global CIFOR-RRI ha adoptado un enfoque basado 
en derechos (Nyamu-Musembi y Cornwall 2004) para analizar estudios de caso a escalas múltiples en países donde la reforma de la tenencia forestal estaba en marcha y donde ya existía el potencial para influir en las decisiones de políticas. Este trabajo se basa en casos de Bolivia, Filipinas, India y Guatemala, seleccionados con el objetivo explícito de ilustrar una amplia variedad de reformas innovadoras que intentaron transferir los derechos de manejo sobre los bosques a las comunidades, para brindarles oportunidades económicas. Aunque no se pretende que sean una muestra representativa, los casos revelan cómo pueden surgir problemas similares de cogestión en iniciativas que están geográficamente dispersas, que involucran diferentes tipos de organizaciones que administran bosques de varios tamaños, para el aprovechamiento de diferentes recursos y que poseen diferentes marcos jurídicos.

Si bien la transferencia parcial de los derechos de manejo a las comunidades crea sistemas de responsabilidad compartida sobre los recursos forestales entre los administradores de las comunidades locales y los organismos reguladores estatales, la manera en que esas agencias operan en el marco regulatorio tiene importantes implicaciones para la forma en que funciona la forestería comunitaria (Pulhin et al. 2010). Este artículo sostiene que la transferencia de poder a los grupos locales es, muchas veces, restringida y con demasiada frecuencia los enfoques utilizados por el Gobierno obstaculizan las ventajas potenciales que se podrían obtener de los sistemas de cogestión. Con una mayor reflexión por parte de los responsables políticos, un diálogo con los administradores de la comunidad y un ajuste de los procesos de supervisión, se podría mejorar la eficiencia de estos esquemas, simplificar los procesos de regulación y posiblemente aumentar los beneficios para la población rural y los bosques que manejan.

El artículo está dividido en cinco secciones, incluyendo esta introducción. La segunda sección ofrece un panorama general de los derechos de propiedad, su transferencia en el marco de la reforma de la tenencia forestal, y explica cómo la transferencia parcial de derechos de manejo conduce a sistemas de cogestión. En la tercera sección se presentan estudios de caso en los que comunidades de Bolivia, Filipinas, India y Guatemala han luchado por aprovechar las oportunidades comerciales del manejo forestal comunitario en los marcos de cogestión. La cuarta sección analiza tres problemas fundamentales observados en los estudios de caso que dificultan la cogestión: altos costos iniciales para las comunidades, la distribución desigual de responsabilidades y marcos regulatorios uniformes y rígidos. La sección final sugiere la revaluación de los derechos y de los mecanismos que forman parte de la cogestión de los bosques comunitarios para mejorar su potencial.

\section{La asignación de derechos en paisajes forestales complejos: el papel de la cogestión}

Antes de examinar cómo ha funcionado la asignación de los derechos sobre los recursos forestales a las comunidades en la teoría y la práctica, es necesario revisar algunos conceptos básicos acerca de los derechos de propiedad sobre los recursos naturales. Las reformas de 
la tenencia forestal se llevan a cabo en un contexto más amplio de descentralización, es decir, la transferencia de poder desde el Gobierno central a las entidades administrativas o territoriales en los niveles inferiores (Ribot 2002). Los problemas principales de la descentralización son: si se transfiere un poder seguro y si este se otorga "a autoridades que representan a las poblaciones locales y que son responsables ante ellas” (Ribot 2004: 9). Aunque se considera un medio para mejorar la eficiencia del manejo y la administración, y para aumentar la equidad y la participación, muchos Gobiernos se resisten a transferir competencias adecuadas y suficientes a los actores locales (Ribot 2002). Hay varias razones que pueden explicar este fenómeno: una genuina preocupación para asegurar el uso sostenible de los recursos naturales (Larson et al. 2010b), intereses en mantener la apropiación por parte de la elite o el rentismo (Adams 2004; Larson y Ribot 2007; Larson y Pulhin en este volumen) y también la inflexibilidad causada por la inercia burocrática. En el contexto de la reforma de la tenencia forestal, la reticencia de los Gobiernos a apoyar plenamente y defender las propiedades forestales que están siendo reconocidas para los actores de las comunidades ha significado que muy a menudo los derechos de tenencia han sido insuficientes para garantizar la seguridad (Larson et al. 2008).

El análisis de cómo se produce la transferencia en el marco de la reforma de la tenencia forestal requiere un examen más detallado de los conceptos de propiedad. La propiedad suele conceptualizarse en el marco de uno de los tres sistemas de tenencia: propiedad pública, comunitaria y privada. Sin embargo, estos sistemas tienden a superponerse, en lugar de ser unidades claras e independientes (Feeny et al. 1990). Las tierras comunitarias son a menudo mosaicos de áreas públicas, comunes y de propiedad privada y con frecuencia conllevan "redes de intereses" que combinan los derechos públicos, colectivos e individuales sobre los recursos (Meinzen-Dick y Mwangi 2008). En realidad, los derechos con frecuencia no tienen como titular un único individuo o entidad, sino que a menudo se comparten entre los grupos, y diferentes derechos pueden ser ejercidos por distintos individuos. Un ejemplo sería un sistema colectivo en el que los derechos pueden ser ejercidos por una autoridad comunal, que determina la asignación de los derechos de acceso, pero el uso de los recursos se lleva a cabo a nivel individual o del hogar, más que de la comunidad, todo lo cual es evaluado y aprobado por las agencias estatales.

La reforma de la tenencia forestal se lleva a cabo en paisajes que muchas veces están compuestos de múltiples actores, grupos de interés competidores y distintas agencias públicas con derechos, que reclaman el control sobre las tierras y los recursos forestales, y con diferentes niveles de poder para hacer cumplir sus derechos. La transferencia de los derechos de tenencia se complica aún más debido a que estos derechos tienen muchas facetas. Es decir, abarcan diferentes tipos de sistemas de tenencia y conjuntos de derechos específicos sobre los recursos, como los sistemas consuetudinarios de "tenencia de árboles" (Fortmann et al. 1985). Con frecuencia, los derechos de tenencia dependen del recurso, por ejemplo, los bosques y los recursos del subsuelo se pueden separar de los derechos sobre la tierra y pueden ser ejercidos por el Estado como propiedad pública, independientemente de si se encuentran dentro de propiedades comunales o privadas.

Un enfoque influyente que permite desagregar los derechos incorporados en la propiedad es considerar los derechos de tenencia no como un derecho de propiedad único y general, 
sino como un "conjunto de derechos" (Schlager y Ostrom 1992; Agrawal y Ostrom 2001; véase también Oyono et al. en este volumen para observar el uso de este concepto en el caso de Camerún). Desde esta perspectiva, el conjunto consta de derechos de acceso, extracción, manejo, exclusión y enajenación. Cada derecho otorga diferentes poderes de decisión y acción al titular de los derechos y todos están definidos por normas. Algunos derechos, como el de manejo, el de exclusión y el de enajenación, ofrecen facultades notablemente mayores que los demás derechos. Estos se consideran como "derechos de elección colectiva" o derechos de decisión, ya que permiten al titular de los derechos definir las reglas y normas para el ejercicio del poder, tales como la decisión respecto de quién tiene acceso al recurso o cómo debe extraerse un recurso (Schlager y Ostrom 1992). Debido a que estos derechos permiten al titular de los derechos establecer nuevas normas o ajustar las existentes, son cruciales para permitir que los usuarios de los recursos se adapten a las condiciones cambiantes que inciden en los recursos o sus medios de vida.

Para entender cómo funciona el manejo forestal comunitario es fundamental examinar qué partes del conjunto de derechos se han transferido a las comunidades. Aunque los derechos de manejo y extracción son similares, la principal diferencia radica en el poder de decisión. El titular de los derechos de extracción puede explotar los recursos dentro de parámetros definidos, pero sin poder para definir cómo, cuándo o qué uso de los recursos se llevará a cabo en el futuro, y con poco control sobre otras personas que comparten los derechos de extracción. Con los derechos de manejo, el titular de los derechos puede tomar tales decisiones. El manejo es "el derecho a regular los patrones de uso interno o transformar el recurso" (Agrawal y Ostrom 2001: 489). El manejo de los recursos - a diferencia de su uso- debe entenderse como un conjunto de decisiones, prácticas y conceptos que implican la toma de decisiones más allá de la utilización inmediata de recursos y con intenciones futuras. Los derechos de manejo están estrechamente vinculados a los derechos de exclusión (es decir, el derecho a no dejar entrar a otros). El aprovechamiento de los derechos de manejo implica inversiones en el uso de recursos en el futuro. Sin embargo, para asegurar que las inversiones valgan la pena y que el titular de los derechos consiga los beneficios en el futuro, el administrador necesita la autoridad y la capacidad para excluir a terceros y a otros que no cumplan con las normas de manejo.

El hecho de que la descentralización es a menudo incompleta se manifiesta en los derechos (del conjunto) sobre los bosques que son transferidos a los actores locales. En la práctica, la transferencia de todo el conjunto de derechos es poco frecuente. En cambio, algunos derechos son conservados por el Estado o no se ofrecen sin la supervisión o el control oficial. Una tendencia común en los bosques tropicales es que el Estado mantiene o limita los derechos de enajenación (es decir, el derecho de vender tierras o transferir derechos a otros), pero reconoce otros derechos de los pueblos indígenas o tradicionales de los bosques (Barry et al. 2010). Aun cuando los derechos de propiedad colectiva e individual son reconocidos, estos a menudo están sujetos a reivindicaciones estatales de autoridad, sobre todo en relación con los recursos del subsuelo o del bosque. Cuando se trata de los recursos forestales, el Estado generalmente mantiene el control a través de la supervisión o impone restricciones a los actores de la comunidad en cuanto al uso y beneficio de estos recursos. Por lo general, los derechos de manejo otorgados por el Estado sobre los bosques representan una transferencia parcial del poder de decisión. Por 
ejemplo, una comunidad a la que se le ha dado el derecho de manejo comercial de la madera, puede elegir qué parte de su bosque manejar, qué árboles extraer y cómo llevar a cabo la explotación. Sin embargo, sus decisiones deben ser aprobadas y deben cumplir con las normas de manejo establecidas por el Estado.

Debido a la transferencia parcial de los derechos de manejo en la reforma de la tenencia forestal, el proceso suele producir modelos de forestería comunitaria que implican sistemas de cogestión. La cogestión es "una situación en la que dos o más actores sociales negocian, definen y garantizan entre ellos un reparto equitativo de las funciones de manejo, derechos y responsabilidades de un determinado territorio, área o conjunto de recursos naturales" (Borrini-Feyerabend 2000). Por lo general, esto implica la división del poder y de la responsabilidad entre el Gobierno y los pobladores locales en relación con el uso y la conservación de los recursos naturales (Berkes et al. 1991, citado en Carlsson y Berkes 2005), y ha sido una característica común de los programas gubernamentales dirigidos a promover la forestería comunitaria (Fisher 1995). La cogestión debe entenderse "como un proceso en el que continuamente se reajustan las partes y su respectiva influencia, posiciones y actividades" (Carlsson y Berkes 2005). Debe ser un proceso adaptable que consiste en la negociación, el regateo o la mediación, y es un espacio para la resolución de problemas y el aprendizaje. Lo ideal es que combina los puntos fuertes y mitiga los puntos débiles de cada uno de los socios participantes (Singleton 1998).

Los sistemas de cogestión son el resultado del conocimiento de que la población local tiene un papel que desempeñar en el manejo de los recursos, la conservación y el desarrollo, pero también del hecho de que las personas que dependen de los bosques han exigido el reconocimiento de sus derechos y han sido cada vez más difíciles de excluir (Cronkleton $e t$ al. 2008). Además, la transferencia de derechos a los actores de las comunidades permite el acceso a conocimientos locales detallados, necesarios para tomar decisiones de manejo correctas e involucra a grupos de interés locales que podrían hacer un mejor trabajo que los burócratas forestales que toman decisiones estandarizadas en oficinas distantes. En teoría, así es como debería funcionar la cogestión; en la práctica, puede ser un reto encontrar el equilibrio adecuado para compartir los derechos, las responsabilidades y los poderes asociados para obtener beneficios mutuos.

Los sistemas de cogestión pueden producir consecuencias no deseadas y no estar a la altura de sus promesas de compartir las responsabilidades y los beneficios. Las restricciones onerosas al uso de los recursos por parte de las agencias gubernamentales pueden desalentar la participación en el sector formal, reprimir la innovación o incluso excluir a algunos grupos de interés. El hecho de compartir la toma de decisiones no elimina el desequilibrio de poder inherente a los procedimientos de supervisión verticalista de los organismos forestales. Por lo general, los procedimientos requieren que los pobladores locales obtengan la aprobación del Estado, sean objeto de inspecciones sobre el terreno y acepten las restricciones al transporte de recursos forestales o sufran sanciones por incumplimiento. Además, los mecanismos institucionales establecidos para asignar y controlar los derechos de manejo por parte del Estado pueden ser muy complejos e 
implican altos costos de transacción tanto para las comunidades como para los Gobiernos. De hecho, demasiada dependencia por parte de los gobiernos en esquemas de mando y control puede limitar la adaptación, que es la clave para la resiliencia, y podría mermar los objetivos de conservación (Armitage et al. 2009). Por último, el Estado no es una entidad única, y los diferentes sectores o agencias del Gobierno pueden tener autoridad sobre los mismos territorios mediante la regulación, por ejemplo, de los recursos naturales, de la agricultura y del comercio. En estas condiciones, los intentos de cogestión pueden verse afectados cuando los organismos que interactúan con las comunidades tienen políticas contradictorias y no coordinan sus actividades. La eficacia de los sistemas de cogestión es muy variable y depende de los poderes de decisión que son concedidos o conservados por el Estado y de si las responsabilidades y los beneficios se han distribuido equitativamente entre los diferentes actores. Por desgracia, es muy común que, debido a sistemas de cogestión disfuncionales, se restrinjan las oportunidades y los beneficios que ofrece la forestería comunitaria. Para entender cómo funcionan los sistemas de forestería comunitaria, es primordial aclarar la naturaleza de los derechos y las facultades que se transfieren y la manera en que influyen en el funcionamiento de los sistemas de cogestión. En la siguiente sección se ilustran estos temas con estudios de caso de forestería comunitaria en el marco de las reformas de la tenencia forestal.

\section{La cogestión después de las reformas forestales y de la tenencia}

La manera en que se crean sistemas de cogestión a través de la transferencia parcial de los derechos de propiedad influye fuertemente en cómo funciona el sistema de forestería comunitaria resultante, qué tan accesibles son las oportunidades para la población local y cuánto se benefician. Para estudiar la cogestión de los bosques comunitarios, este artículo examina estudios de casos de forestería comunitaria, que forman parte de un estudio más amplio de la reforma de la tenencia forestal a lo largo de varios años (véase Larson y Dahal en esta colección; Larson et al. 2010a y b para obtener una descripción completa del proyecto). Los casos, que no deben considerarse una muestra representativa, se seleccionaron para proporcionar una amplia variedad de ejemplos de reformas de la tenencia forestal que tenían como objetivo beneficiar a grupos comunitarios con oportunidades económicas. Se los utilizará para examinar la reforma de la tenencia forestal y sus impactos en cuatro tipos de actores a nivel comunitario: una asociación de manejo forestal indígena de las tierras bajas de Bolivia, una cooperativa de desarrollo forestal del sur de Filipinas, concesiones forestales comunitarias del Petén guatemalteco y una cooperativa de cultivadores de árboles del noroeste de la India.

Estos sistemas de cogestión tienen varios aspectos comunes. En todos los casos, el Estado mantiene la propiedad y un control sustancial sobre los bosques (es decir, conserva completamente los derechos de enajenación y un papel parcial con respecto a otros derechos). Los derechos para las operaciones de manejo se conceden de forma condicional, y se requiere el cumplimiento de las normas. A los titulares de derechos se les otorga el poder de decisión, pero las decisiones deben estar dentro de los parámetros establecidos 
por el Estado. Aunque están geográficamente dispersos y constituyen diferentes contextos sociopolíticos, se observan problemas comunes entre ellos, pero también es evidente una impresionante capacidad de recuperación para responder a las restricciones por parte de los miembros de la comunidad y las organizaciones.

\section{Bolivia: la cogestión forestal con asociaciones indígenas forestales}

El primer estudio de caso describe el debilitamiento de la transferencia de los derechos de propiedad y los derechos exclusivos de manejo sobre los bosques en propiedades tituladas debido a reglamentaciones costosas, organismos ineficientes y la estrategia de titulación adoptada. Asimismo, examina el desarrollo de las iniciativas forestales comunitarias con las poblaciones indígenas de la región de las tierras bajas de Guarayos en Bolivia. Este sistema de cogestión tiene su origen en una serie de reformas de descentralización emprendidas en la década de 1990 que cambiaron el conjunto de derechos de tenencia a disposición de los pueblos indígenas de Bolivia (Pacheco 2005). En 1996 se ratificó una ley de reforma de la tenencia (popularmente conocida como "ley INRA", por la agencia que la creó, el Instituto Nacional de Reforma Agraria, INRA). La ley INRA reconoció un tipo de propiedad comunal llamada Tierra Comunitaria de Origen (TCO) que dio derechos comunales y poder de decisión a las poblaciones indígenas, quienes, como dueños de la propiedad, tenían el derecho de excluir a otros. Según la definición de la ley INRA, una Tierra Comunitaria de Origen es una propiedad comunal que abarca las tierras tradicionalmente ocupadas y utilizadas por las poblaciones indígenas. Las TCO son inalienables, indivisibles, irreversibles, colectivas, no hipotecables y exentas de impuestos. Dentro de estas propiedades comunales, la distribución interna y el uso de los recursos están determinados por el uso consuetudinario de los residentes, aunque están obligados a cumplir las normas agrarias y forestales de todos modos.

El mismo año en que la Ley INRA fue ratificada, una nueva ley forestal creó un marco normativo en el cual los pueblos indígenas finalmente podían demandar derechos de manejo forestal. Estas reformas abrieron oportunidades de manejo forestal que podrían proporcionar nuevas fuentes de ingresos para los pueblos indígenas. En el marco de la nueva ley forestal, los derechos de manejo forestal para el uso de recursos de subsistencia fueron transferidos casi en su totalidad, lo cual también fue definido por la práctica consuetudinaria con poca participación de las agencias estatales. Sin embargo, para el uso comercial de los recursos forestales, los derechos de manejo fueron asignados solamente con la aprobación de la Superintendencia Forestal del Estado para los planes de manejo con normas específicas para las tierras indígenas.

Un lugar donde tanto el INRA como las leyes forestales han cambiado drásticamente la dinámica de los derechos de propiedad y el uso de los bosques es la provincia de Guarayos, en el norte de Santa Cruz. La región era conocida por sus ricos bosques, que atrajeron a empresas madereras, agroindustrias y colonos desde la década de 1980. Después de que la demanda de la TCO de Guarayos fue presentada en 1996, el Gobierno determinó que la propiedad debía abarcar 1,3 millones de hectáreas (VAIPO 1999). Sin embargo, la titulación ha sido lenta e incluso, después de una década, todavía no está completa. En 
la última década la población se ha vuelto étnicamente mixta; la población indígena va desde solo el 36\% hasta el 93\% en los tres municipios en la provincia (UDAPE 2003). Con la llegada de extraños, los pueblos indígenas han luchado por mantener un control seguro sobre su propiedad consuetudinaria (Cronkleton et al. 2009).

La estrategia del INRA para la titulación de las TCO se centró primero en las zonas lejanas, que no estaban en disputa, lo que permitió un rápido progreso en áreas grandes. Sin embargo, no es en estas áreas donde vive la mayor parte del pueblo guarayo, así que fue poco consuelo para los pueblos indígenas, cuyas reivindicaciones de tierras se encontraban bajo presión de otros actores (Cronkleton et al. 2009). La mayor parte de la población se concentra cerca de una carretera interdepartamental que cruzaba la TCO, donde hay más disputas sobre propiedades y donde las reclamaciones sobre tierras indígenas son, con frecuencia, impugnadas. En respuesta al largo proceso y para hacer frente a los problemas de seguridad de las tierras que rodean sus pueblos, los grupos guarayos han adoptado planes de manejo forestal como una estrategia para controlar los bosques comunales, excluir a los extraños y ofrecer otra oportunidad de generar ingresos.

Aunque los bosques de la TCO estaban en tierras de propiedad del pueblo guarayo, por ley el bosque todavía pertenecía al Estado. El manejo comercial requiere autorización previa de la Superintendencia Forestal, que, a su vez, controla las operaciones de aprovechamiento para asegurar el cumplimiento de las normas técnicas. La aprobación por parte del Estado de los derechos de manejo fue un proceso lento y costoso. Para la aprobación de los derechos de manejo, los pueblos indígenas debieron formar organizaciones de manejo y documentar su control indisputable sobre la unidad de manejo forestal designada, con la aprobación de la Central de Organizaciones de Pueblos Nativos Guarayos (COPNAG). También tenían que llevar a cabo inventarios y desarrollar un plan de manejo que se ajustara a las normas técnicas del Gobierno. Llegar a la etapa de aprobación podía tomar años. Por ejemplo, la comunidad de Cururú esperó más de dos años para la aprobación de su plan de manejo, desde la planificación inicial hasta la aprobación final de la Superintendencia Forestal. Una vez que un plan es aprobado, las organizaciones de comunidades indígenas tienen que presentar planes operativos anuales basados en un censo de madera comercial en la unidad de extracción y luego, al final de la temporada, presentar un informe anual de extracción preparado y firmado por un forestal registrado. La elaboración de un plan de manejo es compleja y costosa, así que las comunidades de Guarayos tuvieron que solicitar la ayuda de ONG que pudieran proporcionar apoyo técnico y subvencionar los costos de preparación de los planes de manejo y los planes operativos anuales.

Desde el año 2008, siete comunidades han obtenido la aprobación de planes generales de manejo forestal en Guarayos que abarcan unas 150000 ha de bosque (Cronkleton $e t$ al. 2009), lo cual constituye al rededor del $11 \%$ de la TCO propuesta. Los planes benefician a unas 250 familias indígenas, directamente con trabajo asalariado y con beneficios de la venta de madera. A pesar de que las empresas madereras ya han extraído la madera de calidad superior, todavía queda un volumen significativo de especies alternativas con valor comercial. Cuando estas comunidades extraen y venden la madera, pueden 
potencialmente generar decenas de miles de dólares en ingresos brutos. Sin embargo, muchas veces esto no es posible debido a los retrasos para obtener de la aprobación, a conflictos internos provocados a menudo por los madereros y a la dificultad de mantener sus bosques libres de extraños.

Los sistemas de cogestión con el Gobierno han creado desincentivos para los grupos de manejo forestal comunitario. Aunque las ONG subvencionaron las inversiones iniciales, las comunidades asumen una alta proporción de los riesgos y costos de transacción del sistema. Para las comunidades que controlaban las áreas forestales pequeñas o degradadas, atraer el apoyo de las ONG era difícil, así que no fue fácil justificar el costo y el esfuerzo necesario para obtener la aprobación para el manejo comercial de sus bosques.

Las agencias gubernamentales no han cumplido plenamente con sus responsabilidades de apoyar los derechos de la comunidad en Guarayos. La Superintendencia Forestal de Bolivia tenía pocos fondos y personal insuficiente, lo que provocó retrasos en las autorizaciones. La falta de personal y de fondos también implicó que la Superintendencia Forestal fuera menos eficaz para restringir la extracción de madera ilegal y no sostenible. De los siete proyectos comunitarios de manejo forestal de Guarayos, tres comunidades cercanas a la carretera han tenido problemas de ocupaciones por parte de extraños. Solicitaron la asistencia del INRA y la Superintendencia Forestal para defender sus unidades de manejo y reafirmar sus derechos de exclusión, pero no obtuvieron respuesta (Cronkleton et al. 2009).

Como ilustra el estudio de caso de Guarayos, se hicieron grandes esfuerzos para reconocer los derechos de los pueblos indígenas a controlar sus territorios y manejar sus bosques. Sin embargo, una estrategia equivocada de titulación, marcos regulatorios onerosos e ineficiencias de las agencias gubernamentales crearon cuellos de botella en los sistemas de cogestión. Como resultado, los beneficios no han sido tan amplios como se esperaba y algunos pueblos indígenas interesados en un manejo forestal comercial no han podido participar.

\section{Filipinas: la cogestión forestal en una cooperativa de desarrollo forestal}

El caso de Filipinas examina los resultados de un cambio en la política gubernamental, de un sistema en el que los derechos sobre los recursos forestales se otorgaban a grandes industrias a uno en el que los derechos se transferían a organizaciones comunitarias para llevar a cabo el manejo forestal. En este caso, el sistema de cogestión se encuentra limitado porque las regulaciones habituales son costosas, no se ajustan a los diferentes niveles de capacidad de las organizaciones comunitarias y no dan suficiente ayuda a los nuevos grupos de manejo comunitario.

En Filipinas, los terrenos forestales son propiedad del Estado, y la principal agencia responsable de su administración y manejo es el Ministerio de Medio Ambiente y Recursos Naturales (Department of Environment and Natural Resources, DENR). En 1989, el 
DENR estableció un programa forestal comunitario para proporcionar acuerdos de manejo forestal a organizaciones calificadas de la comunidad por 25 ańos, renovables por el mismo período. En 1995, el Gobierno cambió la estrategia forestal nacional para dar prioridad al programa comunitario de manejo forestal (Pulhin y Ramírez 2008). El Gobierno concedió a las organizaciones comunitarias el derecho a ocupar y manejar ciertos bosques y terrenos forestales que anteriormente habían estado en poder de la industria.

Una de estas organizaciones es la Cooperativa de Desarrollo de Recursos Forestales Ngan Panansalan Pagsabangan, situada en la isla filipina sureña de Mindanao (Pulhin y Dressler 2009). Esta cooperativa administra el segundo proyecto comunitario más importante de manejo forestal en Filipinas. Los bosques de la cooperativa eran administrados por una empresa maderera, Maderas Valderrama, pero el acuerdo de licencia de la compañía expiró en 1994. Preocupado por el hecho de que el bosque se convirtiera en una zona de acceso libre y sin una organización comunitaria fuerte para canalizar el uso local y los beneficios de los bosques, el DENR, con el apoyo de la Agencia de los Estados Unidos para el Desarrollo Internacional, presentó en 1995 la idea de formar una cooperativa (Pulhin y Ramírez 2008). Se presentó una propuesta a los Gobiernos locales en la antigua área de concesión. Aunque los miembros de los pueblos indígenas Mansaka-Mandaya dudaban al principio, finalmente aceptaron la idea. Se permitió a los trabajadores migrantes que habían sido empleados por la empresa convertirse en miembros de la cooperativa. Esta se creó y registró ante el Gobierno en 1996. Más tarde, ese mismo año, se le otorgó un contrato de manejo que abarca 14800 ha de bosques fuera de las ciudades de Compostela y New Bataan. De los 324 miembros de la cooperativa, los primeros migrantes representan el $60 \%$ de los miembros, y los pueblos indígenas locales Mansaka-Mandaya, el resto (Pulhin y Ramírez 2008).

En el marco del manejo forestal comunitario, la cooperativa puede extraer la madera, siempre que tenga un plan de manejo, prepare un plan a mediano plazo con proyecciones del volumen de madera que se extraerá a lo largo de cinco años y solicite un permiso anual para el uso de los recursos. Sin embargo, el proceso de solicitud de permisos es tedioso e implica altos costos de transacción, ya que la aprobación puede llevar fácilmente más de seis meses y cuesta cerca de 5000 dólares estadounidenses (Pulhin y Dressler 2009).

La cooperativa tiene básicamente los mismos derechos que la empresa tenía antes, pero no tiene el mismo poder político y económico para ejercer influencia en la burocracia gubernamental. En la práctica, la situación es más difícil. A pesar de que la forestería comunitaria era una prioridad del Gobierno, la burocracia estatal no estaba preparada para el cambio de paradigma, y la mayoría de la personal antiguo ha tenido dificultades para adoptar su nueva función (Pulhin y Ramírez 2008). La toma de decisiones se ha mantenido centralizada. Además, las políticas del Gobierno nacional tienden a restringir a la cooperativa, en lugar de ayudarla.

Los sistemas descritos por Pulhin y Dressler (2009) no facilitan las operaciones comunitarias. A pesar del largo y costoso proceso de desarrollar un plan de manejo para 
solicitar los permisos de uso de los recursos, estos tienen una validez de solo un año, contado a partir del final del anterior. Debido a estos retrasos, un permiso aprobado podría terminar siendo válido por solo seis meses en el momento en que lo recibe la cooperativa. Además, tres veces entre 1998 y 2006, el DENR emitió suspensiones nacionales de los permisos para el uso de recursos debido a denuncias de incumplimiento $\mathrm{o}$ infracciones por parte de las organizaciones comunitarias. Las suspensiones se aplicaron de manera uniforme, incluso a las organizaciones comunitarias bien administradas. A pesar de que la Cooperativa de Desarrollo de Recursos Forestales Ngan Panansalan Pagsabangan tenía certificación de SmartWood, sus permisos se suspendieron junto con todos los demás. Asimismo, el DENR no tuvo en cuenta las suspensiones y demoras para ajustar los objetivos de desarrollo de la cooperativa en el plan de manejo, lo que puso mayor presión sobre la cooperativa.

La cooperativa carecía del poder y la influencia de la empresa maderera y ahora tenía que lidiar con varios otros grupos que reclamaban derechos sobre la zona de manejo forestal de la cooperativa, incluidos el ejército y el Nuevo Ejército del Pueblo, un grupo rebelde que considera al bosque como su base. De vez en cuando, la cooperativa debe negociar con el ejército, el grupo rebelde y el DENR para garantizar el paso seguro de la madera y para evitar retrasos en el transporte. Debido a que la cooperativa no tiene el dinero necesario para contratar a personal de vigilancia, esto atrajo madereros ilegales al lugar, especialmente durante el período en que se cancelaron los permisos de uso de recursos. Estos madereros acosan al personal de la cooperativa y en algunos casos han utilizado amenazas de violencia para intimidar a la cooperativa.

Aunque la política forestal nacional de Filipinas está supuestamente destinada a promover el manejo comunitario, en la práctica, las acciones de las agencias del Gobierno reducen o limitan los beneficios de estos programas. Los derechos fueron transferidos de la industria para priorizar a los grupos comunitarios, pero no se han hecho suficientes esfuerzos para dar cabida a las capacidades de la comunidad. En general, en el caso de la Cooperativa de Desarrollo de Recursos Forestales Ngan Panansalan Pagsabangan, las suspensiones y los conflictos han erosionado, entre los miembros de la comunidad, la motivación y el compromiso de proteger y manejar sus bosques (Guiang y Castillo 2007).

\section{La cogestión en cooperativas de cultivadores de árboles en la India}

El siguiente caso examina el programa de la Sociedad Cooperativa de Cultivadores de Árboles (TGCS, por sus siglas en inglés) en el noroeste de la India, un modelo de cooperativa creado para establecer y manejar plantaciones de árboles en tierras degradadas. El programa de la TGCS surgió en la década de 1980 por iniciativa de agencias gubernamentales de la India que estaban preocupadas por la escasez de leña y forraje, y por la creciente degradación de la tierra (Saigal et al. 2008). En el marco del modelo de la TGCS, se proporcionó a las cooperativas arrendamientos a largo plazo sobre tierras comunales de propiedad estatal (oficialmente, "tierras baldías del Gobierno") para el desarrollo de plantaciones de árboles y el aumento de la producción de forraje. 
Sin embargo, los contratos de arrendamiento son para parcelas de tierras muy pequeñas y degradadas. Los contratos de arrendamiento, por lo general, abarcaban unas 40 ha, eran válidos por 25 años y podían ser renovados por otros 10 años, a condición de que no hubiera incumplimiento de las condiciones de arrendamiento. La membresía de cada cooperativa estaba limitada generalmente a un pueblo, aunque en la práctica otros pobladores también podían participar; se trató de involucrar a tantas familias como fuese posible. Había un miembro por familia, y cada uno pagaba una cuota nominal. Las cooperativas establecieron plantaciones para obtener leńa y forraje en las tierras arrendadas y contrataron guardias locales para proteger las plantaciones contra actividades ilícitas de pastoreo, la tala de árboles y la recolección de diversos productos forestales. Se esperaba que este modelo de cooperativa para plantaciones de árboles fuera una alternativa institucional prometedora al programa de forestería social existente, y se lo puso en marcha con un importante financiamiento de una agencia del Gobierno de la India, así como de donantes extranjeros (Saxena 1996; NTGCF 1997; Misra 2002; IRMA 2006).

Las actividades del programa estuvieron a cargo de una organización que se conoció como la Federación Nacional de Cooperativas de Cultivadores de Árboles (NTGCF, por sus siglas en inglés). El costo total de la plantación fue asumido por la NTGCF, que, durante los primeros cinco ańos, prestó apoyo técnico y programático a través de los equipos de campo con sede en la región (NTGCF 1997; IRMA 2006). Para el año 2007, había 548 cooperativas de cultivadores de árboles (FES 2007). Sin embargo, el apoyo financiero externo había terminado y no había ningún proyecto específico de apoyo a las cooperativas (Saigal et al. 2008). No obstante, las concesiones arrendadas siguieron funcionando.

El estudio de caso de la TGCS se centró en tres pueblos en el estado de Rajastán, en el noroeste de la India (Saigal et al. 2008). Rajastán es el estado más grande de la India, y constituye el 10\% de la superficie del país (GoI 2008). Aunque el $9 \%$ se clasifica como terrenos forestales, la cobertura de bosque real es de solo el 5\% (FSI 2003). La mayor parte de la región (el 61\%) es desértica o semidesértica (GoR 2007), y hasta un 30\% del estado se clasifica como "tierras baldías" (MoRD y NRSA 2005). Las tierras estatales clasificadas como "tierras baldías del Gobierno" se incluyen en el total de tierras baldías y son tratadas como tierras comunales por los habitantes, pero suelen ser "de acceso abierto" de facto, de manera que provocan una mayor degradación.

Los tres pueblos estudiados se registraron como organizaciones de la TGCS entre 1991 y 1992 (Saigal et al. 2008). Sus poblaciones tenían entre 82 y 220 hogares, y los territorios se extendían desde 490 ha hasta 1716 ha. Las tierras de los pueblos se componían de tres tipos de propiedad: las tierras privadas (en las que se realizaban, principalmente, actividades de agricultura, tanto de secano como de regadío), las tierras del consejo del pueblo (tierras comunales que se utilizaban para el pastoreo) y las tierras del Gobierno. Las "tierras baldías del Gobierno" generalmente eran consideradas como bienes comunes de facto y eran utilizadas, en realidad, como áreas "de acceso abierto", degradadas y desérticas debido al pastoreo excesivo y a la recolección de leña. 
Algunas de las tierras baldías del Gobierno habían sido privatizadas de manera ilegal por los pobladores locales, y en los tres casos, los miembros de la TGCS eliminaron las ocupaciones ilegales antes de comenzar las plantaciones. Las zonas arrendadas se cerraron durante varios años para permitir que crecieran los árboles y las gramíneas, y se abrieron para el pastoreo recién cuando los árboles estaban más altos que la altura de ramoneo.

Aunque ya han pasado más de 10 años desde que terminó el apoyo externo a las tres cooperativas, las plantaciones en los tres sitios se han mantenido y están creciendo (Saigal et al. 2008). Las cooperativas están dispuestas a renovar sus contratos de arrendamiento de las tierras asignadas. La tenencia relativamente segura ha alentado a los miembros a invertir en la tierra y proteger las plantaciones, incluso después de que el apoyo financiero y técnico fue retirado, cinco años tras su establecimiento. Las tres cooperativas mantuvieron los guardas en sus plantaciones, incluso después de que el proyecto dejó de pagarles. Fuera de las concesiones de la TGCS, las demás tierras comunales de los pueblos se están privatizando poco a poco.

En el sistema de cogestión, los contratos de arrendamiento otorgaron a las cooperativas derechos temporales de manejoy exclusión. Seconcedióa las cooperativas la responsabilidad del manejo a cambio de inversiones, el apoyo de la NTGCF y la posibilidad de obtener beneficios. Aunque se esperaba que impidieran las ocupaciones y que cumplieran con las normas relacionadas con la administración de la cooperativa, se les dio una considerable libertad en la toma de decisiones de manejo, incluyendo la forma de extraer y distribuir los recursos y la forma de organizar las actividades de manejo. A diferencia de los otros casos, el Gobierno jugó un papel muy pasivo en la supervisión de las tierras arrendadas, probablemente debido al pequeño tamaño y al alto grado de degradación antes de comenzar el programa. Las cooperativas recibieron apoyo financiero y técnico de la NTGCF, e invirtieron considerable esfuerzo y dinero para preparar los sitios, llevando a cabo trabajos de conservación del suelo y del agua, estableciendo plantaciones de árboles para obtener leña y forraje, irrigando los plantones y protegiendo los sitios de actividades ilícitas de pastoreo y de extracción de productos forestales.

El sistema solamente ha tenido un impacto marginal en los medios de vida locales. Una de las razones del bajo impacto es el límite de 40 ha en los contratos de arrendamiento, independientemente del tamaño de la población. Unas parcelas tan pequeñas no pueden generar beneficios significativos en los medios de vida y los ingresos para todos los hogares del pueblo. Por otra parte, la mayoría de las tierras arrendadas eran de mala calidad y se encontraban muy degradadas cuando se les entregó a las cooperativas. Continuas sequías en los últimos años limitaron el crecimiento de gramíneas forrajeras, y el sistema de pastoreo - una importante fuente de ingresos monetarios para las cooperativas - había sido suspendido en los tres sitios. La producción de gramíneas forrajeras ha caído y, como resultado, en el momento del estudio, las cooperativas han abandonado la práctica antigua de restringir el acceso del ganado del pueblo a sus plantaciones durante la temporada del monzón para permitir la regeneración de los pastos (Saigal et al. 2008).

Las cooperativas tenían la obligación de seguir las regulaciones habituales, pero, debido a la débil supervisión del Gobierno, los grupos se han vuelto menos democráticos. La 
elección de líderes no se lleva a cabo con regularidad, y las decisiones importantes son tomadas por un comité administrador, en lugar de una asamblea general. Por ejemplo, en un caso, los líderes de la cooperativa decidieron ofrecer las existencias anuales de forraje y leña de la plantación entera a través de subastas (Saigal et al. 2008). El mejor postor paga por adelantado y luego puede revender los productos en parcelas más pequeñas a otros. Esta práctica reduce los costos de transacción para las cooperativas, pero está claro que infringe los principios de cooperación, ya que las ganancias van a los que pueden pagar, mientras que los pobres se enfrentan a precios más altos. El mejor postor ni siquiera necesita ser un miembro de la cooperativa. Aparte del apoyo estatal inadecuado, una de las principales razones por las que se realiza esta práctica es la falta de conciencia y la apatía de los miembros, quienes permanecen pasivos.

\section{La cogestión en el Petén guatemalteco}

El último estudio de caso examina un modelo de concesión forestal comunitaria desarrollado en el Petén guatemalteco. A lo largo de la historia, el Gobierno de Guatemala ha tenido una presencia débil en Petén, y sus políticas son a menudo ambiguas o contradictorias. En 1989, la creación del Consejo Nacional de Áreas Protegidas (CONAP) marcó el movimiento de una agenda ambiental a la vanguardia de la política estatal en Petén. En 1990, gran parte del norte de Petén se convirtió en la Reserva de la Biosfera Maya (RBM).

El esquema territorial original de la RBM abarcaba 2,1 millones de hectáreas, con una zona núcleo de conservación estricta, una gran zona de uso múltiple (donde se permitía la extracción sostenible de la madera y de productos no maderables) y una zona de amortiguamiento para aliviar la presión sobre la reserva. El mandato del CONAP era acabar con la tala ilegal, poner freno a la conversión de bosques para la agricultura y la ganadería, detener el saqueo de sitios arqueológicos y poner fin al tráfico ilícito de drogas, fauna, y trabajadores migrantes (Nittler y Tschinkel 2005). Las políticas restrictivas iniciales de la reserva ocasionaron serios conflictos con la población local. Como los grupos de intereses encontrados se resistieron, fue más difícil para el Gobierno hacer cumplir las políticas de conservación que conllevaban a la exclusión de actores forestales importantes (Monterroso y Barry 2008).

La principal fuente de oposición local provino de una organización fundada en 1995 por grupos comunitarios con el fin de conseguir derechos de manejo forestal, que se conoció como la Asociación de Comunidades Forestales de Petén (ACOFOP). En respuesta a esta resistencia, la política del Gobierno adoptó un modelo de cogestión en el que se otorgaron concesiones de manejo forestal a algunas comunidades por un período de 25 años. Con este plan, se dieron concesiones a seis comunidades de la zona de uso múltiple, seis comunidades aledañas a esta área y dos industrias madereras locales, que abarcan 426000 ha de terrenos forestales (Monterroso y Barry 2008). Las organizaciones comunitarias estaban obligadas a registrarse ante las agencias estatales, desarrollar planes de manejo, cumplir las normas técnicas y certificar sus operaciones de manejo de la madera. Cada grupo tenía la obligación de certificar sus operaciones de acuerdo con las normas internacionales de terceros, como las del Consejo de Administración 
Forestal, para mantener su autorización para extraer madera. Además, las organizaciones de los concesiones comunitarias tenían que controlar otros usuarios de los bosques que eran titulares de derechos consuetudinarios de extracción de productos forestales no maderables. Para superar estos costos, los grupos internacionales de conservación financiados en gran medida por la Agencia de los Estados Unidos para el Desarrollo Internacional proporcionaron un importante apoyo financiero y asistencia técnica para asegurarse de que las organizaciones comunitarias reunieran los requisitos y siguieran cumpliendo con las nuevas regulaciones para las concesiones. Para el año 2005, ACOFOP tenía 22 comunidades y organizaciones miembros, lo que representaba 14000 personas en 30 comunidades (Nittler y Tschinkel 2005).

Con el sistema de cogestión en Petén, los costos de transacción aumentaron de forma considerable, no solo en términos de las necesidades financieras para participar y obtener la aprobación, sino también en función del tiempo que les lleva a las comunidades participar en estos procesos burocráticos. El cumplimiento se complica por la limitada experiencia organizativa y técnica de algunos grupos de la concesión comunitaria. Asimismo, la toma de decisiones en las comunidades puede ser lenta y conflictiva. Con este ritmo puede resultar difícil reaccionar ante los cambios o responder a las peticiones de los Gobiernos.

Sin duda, las concesiones comunitarias de Petén hacen frente a graves obstáculos, especialmente las operaciones con las organizaciones más débiles y bosques de menor valor comercial (Nittler y Tschinkel 2005). En algunos casos, ciertas personas que han tratado de apoderarse de las tierras de la concesión como propiedad privada. Las organizaciones enfrentan el escepticismo y la abierta oposición de la industria y de algunas ONG (Gómez y Méndez 2005; Trópico Verde 2005). Además, en una región con una población creciente y con una gran falta de tierras, las organizaciones concesionarias afrontan posibles amenazas de grupos que cuestionan la asignación de áreas tan extensas a un pequeño número de organizaciones comunitarias. El CONAP no es la única institución gubernamental con influencia en Petén y la RBM. El Ministerio de Cultura y Deportes y la Secretaría de Turismo de Guatemala, por ejemplo, tienen competencias superpuestas en cuanto al manejo de los recursos en la región. Se han sugerido políticas alternativas que han incluido esfuerzos para crear una nueva área de conservación que anularía los derechos de concesión forestal. El Gobierno también ha otorgado concesiones para la explotación petrolera que coinciden con las áreas de manejo de madera.

Las organizaciones comunitarias y ACOFOP han aumentado su capacidad y fortalecido sus instituciones. Las agencias gubernamentales, como el CONAP, a pesar de ser débiles y contar con fondos insuficientes, proporcionan ayuda con los procedimientos legales y un cierto apoyo en el campo. Sin embargo, se necesitaron inversiones significativas de donantes externos para desarrollar planes de manejo, establecer aserraderos y capacitar a las comunidades en materia de comercio y de normas de certificación, inversiones que permitieron a los grupos comunitarios convertir los nuevos derechos en mejoras en los medios de vida y en los ingresos (Mollinedo et al. 2002). 


\section{Discusión}

En teoría, la transferencia parcial de los derechos de manejo, que crea sistemas de cogestión, no debería ser problemática y podría ofrecer beneficios derivados de una mejor producción, gobernanza forestal e ingresos rurales. Los sistemas de cogestión viables deben consistir en responsabilidades y beneficios compartidos, tanto por los organismos gubernamentales de supervisión como por las comunidades forestales, y lo ideal es combinar las fortalezas de ambas partes. Por ejemplo, las agencias gubernamentales con recursos limitados podrían transferir los derechos de manejo a los habitantes de los bosques, los cuales tendrían más poder para controlar y gobernar los terrenos forestales, y excluir a otros que estén degradando el recurso. A cambio, las comunidades, fortalecidas por este reconocimiento formal, podrían aprovechar mejor los beneficios del manejo y mantener sus medios de vida forestales. Los sistemas bien diseñados incluirían procesos de negociación y de interacción para adaptar los sistemas según sea necesario. Sin embargo, como han demostrado estos casos, la creación de sistemas de cogestión no ha sido tan armoniosa o tan equilibrada como se esperaba.

En los cuatro casos, el Estado conservó la propiedad de los bosques (es decir, los derechos de enajenación) y ofreció algunos derechos de manejo, pero siempre desempeñó algún papel en el proceso e impuso responsabilidades significativas sobre los grupos comunitarios. En cada caso, para poder ejercer los derechos de manejo, los actores de las comunidades debieron llevar a cabo tareas específicas para obtener la autorización. El Estado mantuvo el control del manejo imponiendo formatos de planificación, normas técnicas, modelos de organización y procedimientos administrativos. Los derechos de manejo otorgados eran condicionales y, en tres casos, temporales. El incumplimiento del sistema significaba un riesgo de perder los derechos. No obstante, en estos sistemas de cogestión, algunos poderes y responsabilidades fueron transferidos a los actores locales. Todos los grupos pudieron o no tomar decisiones operativas sobre su uso de los bosques, sin embargo, se les pidió a todos mantenerse dentro de los parámetros establecidos.

Si bien todos los casos ilustraron intentos innovadores para transferir los derechos, responsabilidades y beneficios a las comunidades forestales, los marcos de cogestión se vieron muy afectados por tres tipos de problemas: onerosos marcos que impusieron altos costos iniciales y obstáculos para la participación; la distribución desequilibrada de responsabilidades para el cumplimiento, que se asignaron en mayor medida a las comunidades; y marcos uniformes e inflexibles que fueron difíciles de adaptar e influenciar. En la siguiente sección se trata en mayor detalle cada uno de estos puntos.

\section{Costos iniciales elevados que crean obstáculos para la participación}

En los casos observados, los marcos jurídicos y los acuerdos institucionales del sistema de cogestión crearon costos iniciales elevados que se convirtieron en obstáculos para algunos segmentos de la población. En los cuatro casos estudiados, el proceso incluyó 
requisitos de aprobación complejos, que incluían dificultades técnicas y administrativas, e inversiones de capital fuera del alcance de las comunidades rurales típicas. Los trámites con la burocracia gubernamental añadieron costos adicionales para las comunidades a través de requisitos previos, tales como el uso de documentos de identidad para los miembros, la incorporación legal de la organización que efectúa el manejo y los costos legales para defender los derechos de propiedad contra los demás. En los casos en que se administraba madera, los acuerdos generalmente requerían inventarios forestales de miles de hectáreas. Estas actividades implicaban dirigir la mano de obra de la comunidad, las habilidades logísticas y el capital para el suministro de alimentos y equipos para mantener a los trabajadores en el bosque. El desarrollo de planes de manejo requiere conocimientos forestales técnicos, cartografía y conocimientos de informática que no se encuentran en la mayoría de las comunidades rurales, lo que fomenta la dependencia del apoyo técnico externo. En algunos casos, como en Bolivia, las comunidades tenían la obligación legal de contratar a expertos profesionales, lo cual puede ser costoso. En el caso guatemalteco se sumó también el costo de la certificación.

Estos costos iniciales para la preparación de un plan de manejo forestal podrían superarse en los sitios donde hay grandes volúmenes de madera o predominan las especies valiosas disponibles para la extracción. Sin embargo, no es frecuente que se concedan estos bosques a las comunidades. A menudo se les otorga derechos sobre bosques que están degradados o que, cuando menos, ya han sido talados por empresas madereras. En esos casos, es un desafío generar suficientes ingresos para recuperar los costos iniciales de inversión en un plan de manejo si no son subvencionados por terceros.

El resultado final es que solo algunos actores de la comunidad pueden participar en los programas forestales comunitarios. En los cuatro casos, las comunidades que pudieron participar fueron los grupos que habían recibido una importante asistencia de entidades externas, principalmente las ONG con financiamiento externo. Estas subvenciones crean riesgos de dependencia del apoyo de terceros y del desarrollo de modelos de organización forestal que no se pueden sostener por sí mismos de manera viable. Los grupos locales que no tuvieron acceso a la ayuda o que no cumplieron los criterios utilizados por los técnicos externos para identificar los sitios que deben recibir apoyo fueron abandonados a su suerte.

Hay varias maneras de ajustar los enfoques de cogestión para hacerlos más accesibles a más comunidades. Una manera en que los sistemas de cogestión podrían promover un mejor manejo comunitario sería reduciendo los obstáculos provocados por los marcos técnicos y las regulaciones. Las normas técnicas que se utilizan para que las comunidades manejen la madera son, a menudo, copiadas de normas estrictas usadas para regular el sector de la industria maderera y, por lo tanto, implican altos niveles de capital y experiencia técnica. Algunos grupos de la comunidad tienen los recursos, la capacidad y el interés para desarrollar operaciones forestales que requieren una gran cantidad de capital, pero no todas las comunidades quieren o pueden trabajar en esa escala o intensidad. Una estrategia podría consistir en sustituir los instrumentos detallados de planificación por 
un enfoque de "normas mínimas" que asegure un buen manejo ambiental a la vez que permita independencia en la toma de decisiones de los actores locales (Ribot 2002). La simplificación de los requisitos podría reducir los costos y facilitar la participación.

\section{La distribución desigual de costos y responsabilidades}

La supervisión estatal del manejo forestal en general se centra en los usos comerciales de los recursos forestales en un esfuerzo para asegurar el uso sostenible. Con ello se pretende evitar la sobreexplotación de los recursos forestales valiosos por parte de los dueńos de las propiedades, cuando tienen oportunidad de obtener beneficios económicos. También podría haber una preocupación de que los pobres sean vulnerables a manipulaciones de terceros sin la supervisión del Gobierno. A pesar de que se puede justificar que este mantenga el papel de árbitro neutral, es un reto proporcionar esta vigilancia y apoyo de forma tal que no se obstaculicen otros aspectos del sistema de cogestión. Cuando la ayuda externa termina, existe el riesgo de que fracasen los proyectos, al no poder hacer frente a los costos de cumplimiento sin subvenciones. Entre los casos, el ejemplo de la India es una excepción. Varios años después de concluido el financiamiento externo, las cooperativas continúan manejando sus concesiones, aunque a un nivel muy bajo de actividad y con costos mínimos de cumplimiento.

Mientras que las comunidades tienen la obligación de realizar altas inversiones iniciales, no hay un compromiso similar de los organismos gubernamentales para cumplir con sus obligaciones hacia los grupos comunitarios. Por ejemplo, a menudo hay retrasos significativos antes de que las comunidades reciban beneficios después de su inversión. Generar la información necesaria para un plan de manejo o un permiso de aprovechamiento puede tardar meses. La espera de una respuesta por parte de las agencias gubernamentales puede tomar aún más tiempo y depende del ritmo de las burocracias nacionales. En el caso de algunas de las comunidades de Guarayos, en Bolivia, el proceso para obtener la aprobación de sus planes de manejo forestal duró dos ańos (Cronkleton et al. 2009).

Incluso después de que los planes de manejo son aprobados, los administradores de la comunidad deben documentar continuamente las actividades para mantener la aprobación. Solo en un caso, el de la India, el Estado asumió mayor responsabilidad por los costos de transacción durante el proyecto, pero esto sucedió en zonas pequeñas y degradadas. En los tres casos relacionados con la madera, los requisitos incluyeron planes operativos anuales e informes posteriores a la extracción, que debían presentarse a tiempo en el formato adecuado para que se otorgara la autorización para la extracción y la venta. A menudo, los controles legales intentan detener el uso insostenible o ilegal de los recursos, pero la carga de estas medidas, por lo general, recae desproporcionadamente sobre los grupos comunitarios que tratan de cumplir con la ley. Los madereros ilegales, por definición, tienen incentivos para evitar los controles gubernamentales, mientras que los grupos de la comunidad que quieren mantener la aprobación deben perseguir al Gobierno para demostrar el cumplimiento. 
Cuando los grupos de la comunidad obtienen la aprobación, en general esta es solo temporal, por lo que deben esforzarse constantemente para prolongar sus derechos. Los permisos de extracción tienen una validez limitada (por ejemplo, de un año en Filipinas, de tres ańos en Bolivia), de modo que si las comunidades no usan la autorización, la pierden. Una desventaja de los sistemas de concesión (de Guatemala, Filipinas y la India) es que los derechos de manejo, en general, tienen períodos limitados de tiempo. Esto puede producir incertidumbre y desalentar la toma de decisiones sostenible y a largo plazo.

Aunque las organizaciones comunitarias están sujetas a normas estrictas, con demasiada frecuencia las agencias estatales no cumplen con sus obligaciones. Irónicamente, los grupos comunitarios se enfrentan a sanciones si los trámites se atrasan, pero tienen pocos recursos si los retrasos son causados por las burocracias gubernamentales. Los problemas producidos porque las agencias estatales no se hacen cargo de su parte del acuerdo de cogestión se pueden ilustrar con claridad con el ejemplo de los grupos comunitarios que tratan de defender sus derechos de exclusión (en Bolivia, Filipinas y Guatemala). En estos casos, mientras los grupos comunitarios luchaban por cumplir con las normas de manejo forestal para satisfacer el cumplimiento del manejo, se encontraron con que sus unidades forestales habían sido invadidas por otros grupos o madereros ilegales. Las agencias estatales no respondieron a las solicitudes de ayuda o adoptaron medidas ineficaces. Este problema se observa con claridad en Filipinas, donde la cooperativa carecía del poder económico y político de la empresa maderera para defender sus intereses, por lo que realizó grandes esfuerzos para pagar los sobornos necesarios, excluir madereros ilegales y pagar dinero en concepto de protección a los rebeldes.

Los programas de asistencia técnica para apoyar las iniciativas de forestería sostenible con las comunidades pueden desempeñar un papel crucial en asegurar que la población local no esté sobrecargada en el sistema de cogestión. Las alianzas comunitarias y asociaciones con la industria u otros actores, como las ONG, podrían brindar beneficios mutuos. Sin embargo, estas disposiciones requieren un cierto nivel de supervisión y regulación estatales (es decir, un árbitro neutral para el cumplimiento de los contratos) para asegurar que no se explote a las comunidades y que se les trate con justicia. Además, debe haber una interacción reflexiva dentro del sistema para asegurar que las subvenciones otorgadas a través de los programas de asistencia no encubran iniciativas que no sean viables y que fracasen cuando la asistencia termine.

\section{Marcos jurídicos uniformes e inflexibles}

Hasta cierto punto, es comprensible por qué los Gobiernos optan por modelos de manejo uniformes. Estos ofrecen un sistema general, con normas coherentes que deberían ser relativamente transparentes. Los sistemas uniformes evitan que surjan situaciones que requieran negaciones caso por caso, lo cual sería aún más caótico y propenso a la corrupción. Sin embargo, los modelos uniformes son solo apropiados para algunos grupos y algunos tipos de gestión. En cada uno de los sistemas de cogestión tratados aquí, el marco jurídico creó modelos de forestería comunitaria que eran uniformes e inflexibles, 
diseñados por los Gobiernos como una solución única. En los casos de Bolivia, Filipinas y Guatemala los modelos se elaboraron para el manejo de madera industrial a gran escala (técnicamente complejos, que requieren grandes capitales y extensas áreas forestales). No se adaptaban a las necesidades y condiciones heterogéneas en las que se encontraban las comunidades de estos países. Estos modelos eran menos aplicables a los grupos que manejaban los PFNM en vez de madera, que manejaban madera a pequeña escala con una tecnología rústica o los que tenían bosques degradados que no generaban ingresos económicos altos.

Se pueden ver ejemplos específicos de los problemas de los marcos uniformes en cada uno de los casos. En las cooperativas de cultivadores de árboles de la India, el límite único de tamaño para las concesiones — sin tomar en consideración el número de miembros de la cooperativa o la disponibilidad de tierra estatales adecuadas - con seguridad disminuyó el nivel de beneficios para algunas cooperativas más grandes y limitó el impacto potencial del programa para rehabilitar tierras degradadas. En el caso de Filipinas, la cooperativa era más accesible a los migrantes que habían trabajado para la empresa maderera que a la población indígena local que carecía de las habilidades necesarias para la explotación industrial y tenía diferentes estrategias para manejar el bosque. En Guarayos, Bolivia, solo las comunidades que controlaban grandes parcelas (de varios miles de hectáreas) de reserva forestal que contienen madera comercial podían justificar la inversión (o al menos atraer el interés de las ONG para que brindaran apoyo). En el modelo de concesión de Guatemala, las operaciones con madera eran menos viables para los grupos de la comunidad que recibieron concesiones más pequeñas y más degradadas, por lo que estos realizaron grandes esfuerzos para mantener las operaciones y defender sus bosques.

Una forma de ajustar el sistema y equilibrar mejor las responsabilidades podría ser que las agencias estatales consideren diferentes niveles de control para los distintos grupos. Por ejemplo, algunos tipos de supervisión serían convenientes para aquellos que están iniciando sus planes de manejo. Lo ideal sería considerar la supervisión como una oportunidad para facilitar el aprendizaje y la interacción, y no de hacer cumplir la ley, con el fin de ayudar a los grupos a adaptarse al sistema. Cuando una organización de manejo tiene un historial de cumplimiento, es posible reducir los niveles de supervisión. Se podría permitir que los grupos que hayan obtenido la certificación de terceros estén sujetos a una menor fiscalización por parte de las agencias estatales. En las zonas en que los bosques están degradados, se podría alentar a las comunidades a invertir en la recuperación de estos bosques mediante la reducción de los requisitos para recibir los derechos de manejo y de los costos de cumplimiento. Si son elevados los costos de participación en el manejo, esto podría ser un desincentivo importante para mantener bosques degradados que proporcionan bajos beneficios económicos. Además, se puede permitir a los grupos con organizaciones sociales más fuertes una mayor autorregulación. $\mathrm{Si}$ las autoridades tradicionales locales pudieran proporcionar supervisión, habría una menor carga para las agencias gubernamentales, que podrían verificar el cumplimiento solo periódicamente. Como resultado, la supervisión podría cambiar su énfasis de modo de asegurar que todos los residentes interesados en el manejo estén autorizados a participar y que los beneficios se distribuyan de manera equitativa. 
La cogestión debe concebirse como un proceso de negociación y diálogo entre los actores gubernamentales y comunitarios. Se requiere el seguimiento y la reflexión para actualizar y mejorar el sistema de forma permanente. Las burocracias forestales estatales suelen ser rígidas o no estar dispuestas a evaluar o ajustar los marcos reglulatorios, pero la flexibilidad es necesaria. Constituye un reto equilibrar la necesidad de abordar los contextos locales sin que los marcos políticos se diluyan en un sinfín de normas locales específicas.

\section{Conclusiones}

En la reforma de la tenencia forestal, la transferencia del conjunto de derechos a los actores a nivel comunitario suele ser incompleta. La cesión parcial de derechos de manejo crea situaciones de cogestión en las que las comunidades y las agencias estatales no solo comparten las responsabilidades y los costos, sino también los beneficios del manejo de los recursos. En teoría, la cogestión puede ser una forma muy eficaz de equilibrar los puntos fuertes de los diferentes actores, y el diálogo y la interacción entre los actores deberían dar lugar a sistemas que tengan flexibilidad para adaptarse a las necesidades y condiciones cambiantes de ambas partes. Sin embargo, en la práctica, la manera en que tiene lugar la transferencia parcial de los derechos genera sistemas de cogestión defectuosos. Estos esquemas excluyen a algunos participantes potenciales debido a los altos costos iniciales, imponen cargas y responsabilidades desiguales en los actores comunitarios que pueden participar y se basan en marcos uniformes e inflexibles que limitan la negación, la innovación y la adaptación.

En el caso de la forestería comunitaria tratado aquí, la transferencia parcial de los derechos de manejo a través de los sistemas de cogestión tuvo varias ventajas y desventajas. $\mathrm{Al}$ renunciar a parte del control legal sobre las decisiones de uso de los recursos, el Gobierno obtuvo una mayor cooperación por parte de los actores locales. Como las partes interesadas a nivel comunitario obtienen beneficios mediante el cumplimiento de las normas y directrices oficiales, ellas son más propensas a tener un mayor interés en el mantenimiento de los recursos forestales. En casos como el de Guatemala, las concesiones han aliviado un poco el conflicto sobre los recursos y han fortalecido la zona de amortiguamiento de la RBM. En Guarayos, las opciones de manejo forestal comunitario ayudaron a algunas comunidades a mantener los bosques en zonas que presentan altas tasas de deforestación (aunque esto dependió del nivel de presión externa y no fue el caso en todas las comunidades). El aumento de los beneficios para los grupos comunitarios conlleva mayores responsabilidades y obligaciones. En algunos casos, la carga de las nuevas normas y la intrusión por parte del Gobierno son mayores que los beneficios de participación para los pobladores locales. En cada uno de los casos, el modelo de cogestión solo ayudó a algunos segmentos de la población rural de la región.

Una conclusión central de este trabajo es que la transferencia parcial de los derechos de manejo por parte del Estado crea obstáculos persistentes y significativos para la adopción de la forestería comunitaria, y, en algunos casos, los beneficios son solo para los participantes locales. En los peores casos, las regulaciones estatales introducidas para guiar las decisiones se convierten en marcos rígidos que dificultan las operaciones de 
manejo de las comunidades y excluyen a muchos otros grupos comunitarios. Se necesitan mecanismos que faciliten el diálogo entre las agencias estatales y las comunidades a fin de que más aportes locales contribuyan a la elaboración y revisión de las normas de los sistemas de cogestión.

Los esquemas de cogestión de los que forma parte la forestería comunitaria podrían proporcionar mecanismos para conservar los bosques y aumentar el bienestar de la población local. Sin embargo, estos fines requieren que se adapte la forma en que funcionan los esquemas. Es necesario simplificar los marcos jurídicos que sustentan los sistemas de cogestión, posiblemente con base en normas mínimas para facilitar una mayor participación. Los sistemas utilizados por el Estado para la regulación y el control del manejo deben distribuir mejor las responsabilidades y disminuir las cargas de los grupos que intentan, de buena fe, usar los recursos de manera sostenible. Además, es preciso equilibrar los esfuerzos de control por parte de los Gobiernos, con una mayor asistencia técnica o programas, como el crédito rural, para promover la participación de las comunidades. Por último, los procesos políticos deben ser más inclusivos para dar cabida a un mayor número de partes interesadas, incluir mecanismos de interacción y alentar el cambio adaptable para que la cogestión pueda lograr su potencial.

\section{Referencias}

Adams, W.M. 2004. Against extinction: The story of conservation. Londres: Earthscan.

Agrawal, A. y E. Ostrom. 2001. Collective action, property rights, and decentralization in resource use in India and Nepal. Politics and Society 29(4): 485-514.

Armitage, D.R., R. Plummer, F. Berkes, R. Arthur, A. Charles, I. Davidson-Hunt, A. Diduck, et al. 2009. Adaptive co-management for social-ecological complexity. Frontiers in Ecology and Environment 7(2): 95-102.

Barry, D., A. Larson y C.J.P. Colfer. 2010. Forest tenure reform: An orphan with only uncles. En: Forests for people: community rights and forest tenure reform (eds. Larson, A., D. Barry, G.R. Dahaly C.J.P. Colfer). Pp. 19-40. Earthscan, Londres.

Berkes, F., P. George y R. Preston. 1991. Co-management: the evolution of the theory and practice of joint administration of living resources. Alternatives 18(2): 12-18.

Borrini-Feyerabend, G. 2000. Co-management of natural resources: Organising, negotiating and learning by doing. Yaundé, Camerún: Unión Internacional para la Conservación de la Naturaleza (UICN).

Brown, K. y D. Pearce (eds.). 1994. The causes of tropical deforestation. Londres: University College London Press.

Carlsson, L. y F. Berkes. 2005. Co-management: Concepts and methodological implications. Journal of Environmental Management 75: 65-76.

Cronkleton, P., P.L. Taylor, D. Barry, S. Stone-Jovicichy y M. Schmink. 2008. Environmental governance and the emergence of forest-based social movements. CIFOR Occasional Paper No. 49. Bogor, Indonesia: Centro para la Investigación Forestal Internacional (CIFOR). 
Cronkleton, P., P. Pacheco, R. Ibarguen y M. Albornoz. 2009. Reformas en la tenencia de la tierra y los bosques: La gestión comunal en las tierras bajas de Bolivia. La Paz: Centro para la Investigación Forestal Internacional (CIFOR) y Centro de Estudios para el Desarrollo Laboral y Agrario (CEDLA).

Eliasch, J. 2008. Climate change: Financing global forests. The Eliasch Review. Londres: Oficina de Cambio Climático del Reino Unido.

Feeny, D., F. Berkes, B. McCay y J. Acheson. 1990. The tragedy of the commons: Twenty-two years later. Human Ecology 18(1): 1-19.

Fisher, R. 1995. Collaborative management of forests for conservation and development. Gland, Suiza: Unión Internacional para la Conservación de la Naturaleza (UICN) y Fondo Mundial para la Naturaleza (WWF).

Fortmann, L., J. Riddell, J. Bruce, A. Fraser, N. Garcia-Pardoy y R. Labelle. 1985. Trees and tenure: An annotated bibliography for agroforesters and others. Madison, Estados Unidos: Land Tenure Centre, University of Wisconsin.

Forest Survey of India (FSI). 2003. The State of Forest Report. Dehradun: FSI.

Foundation for Ecological Security (FES). 2007. Annual report 2006-2007. Anand: FES.

Gobierno de la India (GoI). 2008. India 2008: a reference manual. Nueva Delhi: GoI, Ministry of Information and Broadcasting.

Gobierno de Rajastán (GoR). 2007. Economic Review 2006-07. Jaipur: GoR, Directorate of Economics and Statistics.

Gómez, I. y E. Méndez. 2005. Análisis de contexto: el caso de la organización de comunidades forestales de Petén (ACOFOP). El Salvador: PRISMA.

Guiang, E.S. y G. Castillo. 2007. Trends in forest ownership, forest resources, tenure and institutional arrangements in the Philippines: Are they contributing to better forest management and poverty reduction? En: Understanding forest tenure in South and Southeast Asia. Forestry Policy and Institutions Working Paper No. 14. Roma: Organización de las Naciones Unidas para la Alimentación y la Agricultura (FAO).

Institute of Rural Management (IRMA). 2006. NTGCF: 'Anand pattern' in natural resources management. Disponible en: http://www.irma.ac.in/about/ntgcf.html Consultado el 25 de noviembre del 2006.

Kaimowitz, D. y A. Angelsen. 1998. Economic models of tropical deforestation: a review. Bogor, Indonesia: Centro para la Investigación Forestal Internacional (CIFOR).

Larson, A., D. Barry, P. Cronkleton y P. Pacheco. 2008. Tenure rights and beyond: community access to forest resources in Latin America. Occasional Paper No. 50, Bogor, Indonesia: Centro para la Investigación Forestal Internacional (CIFOR).

Larson, A., D. Barry y G.R. Dahal (eds.). 2010a. Forests for People: Community Rights and Forest Tenure Reform. Londres: Earthscan.

Larson, A., Barry, D. y Dahal, G.R. 2010b. New rights for forest-based communities? Understanding processes of forest tenure reform. International Forestry Review 12(1): 78-96.

Larson, A. y J.C. Ribot. 2007. The poverty of forestry policy: double standards on an uneven playing field. Sustainability Science 2(2): 189-204. 
Meinzen-Dick, R. y E. Mwangi. 2008. Cutting the web of interests: Pitfalls of formalizing property Rights. Land Use Policy 26: 36-43.

Misra, V.K. 2002. Greening of wastelands: experiences from the Tree Growers' Cooperative Project. En: Institutionalizing Common Pool Resources (ed. Marothia, D.K.). Pp. 334-354. Nueva Delhi: Concept Publishing.

Mollinedo, A. del C., J.J. Campos, M. Kanninen y M. Gómez. 2002. Beneficios sociales y rentabilidad financiera del manejo forestal comunitario en la Reserva de la Biósfera Maya, Guatemala. Serie Técnica. Informe Técnico No 327. Turrialba, Costa Rica: Centro Agronómico Tropical de Investigación y Enseñanza (CATIE).

Monterroso, I. y D. Barry. 2008. Sistema de Concesiones Forestales Comunitarias: Tenencia de la Tierra, Bosques y Medios de Vida en la Reserva de la Biosfera Maya en Guatemala. Ciudad de Guatemala, Guatemala: Centro parala Investigación Forestal Internacional (CIFOR) y Facultad Latinoamericana de Ciencias Sociales (FLACSO).

Ministry of Rural Development, India, (MoRD) y National Remote Sensing Agency, India, (NRSA). 2005. Wastelands Atlas of India. Nueva Delhi y Hyderabad, India: MoRD y NRSA.

National Tree Growers' Cooperative Federation Limited (NTGCF). 1997. Annual Report 1996-97. Anand, India: NTGCF.

Nittler, J. y H. Tschinkel. 2005. Manejo comunitario del bosque en la RBM de Guatemala: Protección mediante ganancias. Athens, Estados Unidos: Sustainable Agriculture and Natural Resources Management; Collaborative Research Support Program: 32.

Nyamu-Musembi, C. y A. Cornwall. 2004. What is the 'rights-based approach' about? Perspectives from international development agencies. IDS Working Paper 234. Sussex, Reino Unido: Institute of Development Studies (IDS).

Pacheco, P. 2005. Decentralization of forest management in Bolivia: Who benefits and why? En: The politics of decentralization: forests, people and power (eds. Colfer C. y D. Capistrano). Pp. 166-183. Londres: Earthscan.

Pulhin, J.M. y W.H. Dressler. 2009. People, power and timber: The politics of communitybased forest management. Journal of Environmental Management 91: 206-214.

Pulhin, J. y M. Ramirez. 2008. Improving equity and livelihoods in community forestry: The case of Ngan, Panansalan, Pagsabangan Forest Resources Development Cooperative, Inc. (NPPFRDC), Compostela Valley, Southern Philippines. Bogor, Indonesia: Centro para la Investigación Forestal Internacional (CIFOR) e Iniciativa para los Derechos y Recursos (RRI).

Pulhin, J., A.M. Larson y P. Pacheco. 2010. Regulations as barriers to community benefits in tenure reform. En: Forests for people: community rights and forest tenure reform (eds. Larson, A., D. Barry, G.R. Dahaly C.J.P. Colfer). Pp. 139-159. Londres: Earthscan.

Ribot, J.C. 2002. Democratic decentralization of natural resources: institutionalizing popular participation. Washington D.C.: Instituto de Recursos Mundiales (WRI).

Ribot, J.C. 2004. Waiting for democracy: the politics of choice in natural resource decentralization. Washington D.C.: Instituto de Recursos Mundiales (WRI). 
Saigal, S., G.R. Dahal y B. Vira. 2008. Cooperation in forestry: Analysis of forestry cooperatives in Rajasthan, India. Bogor, Indonesia: Centro para la Investigación Forestal Internacional (CIFOR) e Iniciativa para los Derechos y Recursos (RRI).

Saxena, R. 1996. 'The Vatra Tree Growers' Cooperative Society. En: Cooperative management of natural resources. (eds. Singh, K. y V. Ballabh). Pp. 39-58. Nueva Delhi: Sage Publications.

Schlager, E. y E. Ostrom. 1992. Property rights regimes and natural resources: a conceptual analysis. Land Economics 68(3): 249-262.

Singleton, S. 1998. Constructing cooperation: The evolution of institutions of comanagement. Ann Arbor, Estados Unidos: University of Michigan Press.

Trópico Verde. 2005. El proyecto turístico Cuenca del Mirador y las concesiones forestales en la zona de uso múltiple de la Reserva de la Biosfera Maya. Flores, Guatemala: Trópico Verde.

Unidad de Análisis de Política Económica (UDAPE). 2003. Pobreza y desigualdad en municipios de Bolivia: Estimación del gasto de consumo combinando el Censo 2001 y las Encuestas de hogares. La Paz: UDAPE.

Viceministerio de Asuntos Indígenas y Pueblos Originarios (VAIPO). 1999. Identificación de Necesidades Espaciales TCO Guaraya. La Paz: VAIPO. 


\title{
El fortalecimiento de las reformas de la tenencia forestal a través de regulaciones que respondan mejor a las necesidades de la población locali
}

\author{
Anne M. Larsonii y Juan M. Pulhiniii
}

\section{Resumen}

Las reformas de la tenencia forestal han abierto nuevas oportunidades para que las comunidades obtengan derechos formales sobre sus bosques y sobre los beneficios que derivan de ellos, pero al mismo tiempo, se aplican una serie de restricciones a las opciones de medios de vida. En este artículo presentamos varios estudios de caso de reformas realizadas en África, Asia y América Latina para analizar las regulaciones que acompañan dichas reformas. Identificamos tres tipos de regulaciones, específicamente las que limitan el área disponible para las comunidades locales; las que delimitan las áreas de conservación e imponen restricciones al uso de recursos; y los requisitos burocráticos para la obtención de permisos y planes de manejo, que restringen el uso comercial y la comercialización de valiosos productos forestales. Analizamos los problemas asociados a estas regulaciones y proponemos un marco simple que permita identificar maneras de promover regulaciones que funcionen para la conservación forestal, pero que, al mismo tiempo, respondan mejor a las necesidades de las comunidades y los bosques.

\section{Introducción}

Las reformas de la tenencia forestal en Asia, África y América Latina han abierto nuevas oportunidades para que las comunidades obtengan derechos formales sobre sus bosques y recursos forestales (para obtener un resumen sobre este tema, véase la introducción de esta colección de Larson y Dahal). En muchos aspectos, estas reformas han tenido también efectos positivos sobre los medios de vida, como el otorgamiento a las comunidades de acceso seguro y a largo plazo a los recursos, el derecho de excluir a terceros (como las concesiones madereras indeseadas) y la participación en mercados para nuevos productos

\footnotetext{
i Este artículo es una traducción del original, que apareció en inglés en la revista Conservation and Society, en la edición especial sobre Reformas de tenencia forestal (eds. Anne M. Larson y Ganga Ram Dahal). La cita original completa es: Larson, A.M. and Pulhin, J.M. 2012 Enhancing Forest Tenure Reforms Through More Responsive Regulations. Conservation and Society 10(2): 103-113. El artículo cuenta con una licencia de Creative Commons de Atribución 3.

ii Centro para la Investigación Forestal Internacional (CIFOR), Managua, Nicaragua - a.larson@cgiar.org.

iii Departamento de Forestería Social y Gobernanza Forestal, Facultad de Forestería y Recursos Naturales, Universidad de Filipinas Los Baños, Filipinas.
} 
(Dahal et al. 2010). No obstante, en muchos casos, es evidente que las comunidades podrían obtener mayores beneficios si no se les impusieran serias limitaciones sobre sus opciones.

Estas limitaciones asumen diferentes formas. Basándose en una investigación sobre reformas de la tenencia forestal llevada a cabo en 10 países, este artículo examina tres tipos diferentes de regulaciones: las que limitan el área disponible para las comunidades locales, las que delimitan áreas de conservación e imponen restricciones al uso de recursos, y los requisitos burocráticos para la obtención de permisos y planes de manejo, que restringen el uso comercial y la comercialización de valiosos productos forestales (véase también Pulhin et al. 2010). Estas regulaciones no están desvinculadas de las reformas de la tenencia, sino que, más bien, forman parte integral de estas y sugieren una percepción limitada por parte del Estado sobre lo que constituyen los "derechos" comunitarios (véase Larson y Dahal en esta colección, y Cronkleton en esta colección).

Aunque se reconoce ampliamente que es necesario contar con cierto tipo de regulaciones para garantizar el futuro de los bosques mundiales, es evidente que muchas de ellas no tienen objetivos tan nobles, como el deseo de mantener empleos y autoridad en el seno del gobierno y favorecer los intereses de la elite (Silva et al. 2002; Larson y Ribot 2007) o el rentismo y la corrupción (Kolstad y Soreide 2009). Este artículo analiza brevemente los métodos de investigación y la historia de la burocracia forestal antes de presentar ejemplos de estos tres tipos de regulaciones. La sección final analiza los resultados del estudio y sugiere un marco para repensar el rol del Estado en la regulación de las comunidades, basado en los motores de la deforestación y el grado de dependencia de los bosques a nivel local.

\section{Metodología}

Los estudios de caso analizados en este artículo forman parte de un proyecto de investigación-acción llevado a cabo en 10 países durante el período 2006-2008. El proyecto, liderado por el Centro para la Investigación Forestal Internacional (CIFOR, por sus siglas en inglés) en coordinación con la Iniciativa para los Derechos y Recursos (RRI, por sus siglas en inglés), tenía como objetivo entender el origen, la naturaleza y los resultados iniciales de las reformas de la tenencia forestal llevadas a cabo en Asia (India, Nepal y Filipinas), África (Burkina Faso, Camerún y Ghana) y América Latina (Bolivia, Brasil, Guatemala y Nicaragua). Las reformas varían considerablemente y contemplan desde acuerdos de distribución de beneficios hasta la titulación completa, pero todas ellas involucran la transferencia o el reconocimiento de nuevos derechos estatutarios a las comunidades que viven en los bosques.

Los sitios de investigación a nivel de país y a nivel subregional se eligieron no solo para analizar los cambios en los sistemas de tenencia, sino también partiendo de la conclusión (a través de sondeos con socios) de que existía la posibilidad de mejorar los derechos o influir en las decisiones sobre políticas. La elección específica de los territorios o comunidades estudiadas en estos sitios se basó en una evaluación de aquellos que permitirían entender mejor la reforma o el proceso de reforma, dependiendo de cada contexto nacional. 
Toda la investigación se basó en el mismo grupo de preguntas centrales, lecturas fundamentales de teoría y antecedentes, hipótesis y definiciones de conceptos clave, aunque la metodología utilizada para obtener la información varió en función del país. Los investigadores principales pertenecían a los países donde se llevaba a cabo el trabajo y, por lo general, la organización y realización del trabajo de campo estuvo a cargo de organismos no gubernamentales, nacionales o subnacionales, o universidades bajo la supervisión de CIFOR (para obtener más información sobre la metodología utilizada, véase Larson y Dahal en esta colección).

Teniendo en cuenta los objetivos orientados a las políticas así como las prioridades de investigación y acción, los investigadores y las comunidades se dedicaron con frecuencia a promover las reformas y mejorar los resultados. Por ello, una de las principales variables estudiadas fue el rol de las regulaciones promoviendo u obstaculizando la capacidad de las comunidades para obtener beneficios adicionales de medios de vida relacionados con sus nuevos derechos estatutarios. En el diseño de la investigación, el tema de las regulaciones se concibió únicamente desde el punto de vista del tercer tipo mencionado anteriormente: los requisitos burocráticos para obtener permisos y planes de manejo. Los otros dos tipos de regulaciones surgieron del análisis posterior de los casos.

\section{Origen de las regulaciones gubernamentales en materia forestal}

Las burocracias forestales surgen de una tradición de regulaciones que empezó con la organización de las tierras y los recursos en un proceso descrito por Vandergeest y Peluso (1995: 387-388) como “territorialización”. La territorialización involucra la división del territorio y la creación de "regulaciones que establecen cómo y quiénes pueden utilizar estas áreas”, incluyendo el uso de los recursos naturales dentro de su perímetro.

El concepto de territorialización, tal como se aplica a los bosques, tiene sus orígenes en la antigüedad. El primer registro probablemente proviene de Asiria, donde en el año 700 a. C. se establecieron por decreto reservas para las cacerías reales (Dixon y Sherman 1991). En la Europa medieval, los bosques se demarcaban como un dominio particular en la silva (literalmente, un lugar donde crecen árboles), reservada para las actividades de caza de la clase dominante de terratenientes (Fay y Michon 2003). La aplicación de las regulaciones forestales se convirtió en responsabilidad de los administradores forestales, quienes tenían la misión específica de proteger el dominio forestal contra ocupaciones. En Europa, el primer grupo real de administradores forestales (más tarde llamados forestales), se creó en 1290 para "defender los derechos reales de caza y justicia” y, más tarde, para restringir los derechos de usufructo de los campesinos (Fay y Michon 2003: 6). Este grupo de administradores veló por los intereses económicos de la elite. Por lo tanto, el rey y la nobleza usaban las regulaciones forestales no solo para proteger sus exclusivas áreas reservadas para actividades de caza, sino también para asegurar oportunidades económicas (Peluso 1992), aunque probablemente la creación de las reservas forestales respondió también a cálculos referidos a la necesidad de contar con productos y servicios forestales a largo plazo. 
Por lo tanto, la tendencia de los forestales (más conocidos como ingenieros forestales en español) a excluir de los bosques a la población local tiene una larga historia que se remonta a la interacción de la profesión forestal con las autoridades terratenientes. Este sesgo se reprodujo fácilmente en su participación en la privatización de tierras comunales en Europa, especialmente en los siglos XVIII y XIX y también se adaptó fácilmente al estilo poco democrático y jerárquico de las autoridades coloniales.

Con el tiempo, la administración de los bosques adoptó la misión más compleja de regular, administrar, conservar y gestionar el dominio forestal, a medida que el diseño y la armonización de prácticas silvícolas, para garantizar una producción sostenible, se iban convirtiendo en una de las preocupaciones principales (Fay y Michon 2003). Por ejemplo, en 1661, Luis XIV de Francia y su ministro de hacienda, Colbert, introdujeron reformas en la administración y legislación forestal con el propósito de revertir la reducción de la cobertura forestal causada por la explotación indiscriminada de la misma (Elliott 1996).

El desarrollo de la "forestería científica", desde alrededor de 1765 hasta 1800, principalmente en Prusia y Sajonia, legitimó la territorialización y con ello la aplicación de regulaciones forestales para racionalizar el manejo forestal. De allí que su nacimiento puede comprenderse mejor dentro del contexto de las iniciativas centralizadas de la época, que tenían como objetivo la construcción del Estado (Scott 1995). El primer concepto de manejo forestal científico fue captado mejor que nadie por Le Roy, el responsable de los jardines del Palacio de Versalles, en la Enciclopedia de Diderot de 1766:

"En todos los tiempos se ha sentido la importancia de preservar los bosques; estos siempre se han considerado propiedad del Estado y han sido administrados en su nombre. Incluso la religión misma había consagrado a los bosques, sin duda para proteger, mediante la veneración, aquello que debía conservarse para el bien público [...] Nuestros robles ya no profieren oráculos [...] debemos sustituir este culto con la atención solícita, y cualquiera sea la ventaja que haya podido encontrarse antes en el respeto por los bosques, cabe esperar mayor éxito aún de la vigilancia y economía [...] Si se explotan los bosques para atender las necesidades presentes, también hay que conservarlos y hacer planes con antelación para las generaciones futuras [...] Es necesario, por consiguiente, que aquellos a quienes el Estado ha encargado supervisar y mantener los bosques tengan mucha experiencia [...] y deben conocer los mecanismos de la naturaleza” (Le Roy, citado en Harrison 1992: 117-118).

La cita anterior propone las bases filosóficas para el diseño y aplicación de las regulaciones forestales del Estado. En primer lugar, los bosques son propiedad del Estado y deben ser administrados en su nombre para el bien público. Por lo tanto, es necesario crear una entidad forestal estatal que tenga a su cargo el control de los terrenos y recursos forestales para el bien público, responsabilidad que llevará a cabo mediante regulaciones. En segundo lugar, los bosques pueden ser aprovechados para satisfacer las necesidades presentes, pero también se los debe conservar para las generaciones futuras. Por ello, en su calidad de propietario, la entidad forestal estatal es tanto una empresa forestal como una institución de conservación, roles que pueden entrar en conflicto (Peluso 1992). De allí que sea necesario elaborar regulaciones forestales para equilibrar los objetivos económicos 
y de conservación del manejo forestal del Estado. En tercer lugar, aquellos a quienes el Estado ha encomendado la supervisión del mantenimiento de los bosques deben tener experiencia y conocer "los mecanismos de la naturaleza". Esto legitimó la misión de los forestales y estableció la exclusividad de los profesionales forestales en la administración y la gestión forestal (Fay y Michon 2003). Cuando estos últimos se desempeñan en sus funciones, sus acciones - llevadas a cabo a nombre del bien público- están guiadas y legitimadas por las regulaciones forestales.

El primer programa universitario de capacitación para promover el manejo forestal científico se creó en la Universidad de Friburgo, en Friburgo, Alemania. En 1824 se fundó la Escuela Nacional Forestal en Nancy, Francia (Mantel 1964), la que atrajo estudiantes de toda Europa y Estados Unidos (Peluso 1992). Cuando los ingenieros forestales retornaban a sus países o viajaban a las colonias en Asia y África o a América Latina, llevaban consigo la filosofía de un manejo forestal tecnocrático controlado por el Estado (Fernow 1991).

El fundador del Servicio Forestal de los Estados Unidos, Gifford Pinchot, estudió en Nancy y se lo considera el primer impulsor de una "conservación moderna de los recursos naturales" (Eckersley 1992). Pinchot opinaba que la conservación y el desarrollo eran complementarios: los bosques, decía, deberían ser gestionados para "proporcionar el mayor bienestar al mayor número de personas durante el mayor tiempo posible" (Dana y Fairfax 1980: 72). Como resultado, "en la actualidad, el concepto de conservación forestal puede significar muchas cosas, desde la producción intensiva de madera hasta la preservación total" (Elliott 1996).

Tanto el punto de vista utilitario de los bosques, como fuente de ingresos para el Estado (el uso de los bosques para proporcionar el mayor bien al mayor número de personas), como la actitud más preservacionista defendida por algunos conservacionistas han justificado el control absoluto del Estado sobre los recursos forestales y la aplicación de estrictas regulaciones para su uso. La delimitación actual de vastas extensiones de terrenos forestales como áreas de producción y protección por parte de los Gobiernos de muchos países en desarrollo pone de manifiesto la persistencia del paradigma de conservación de recursos propuesto por Pinchot. Este mismo paradigma permite que los ingenieros forestales desarrollen su ciencia según los intereses del Estado, aunque rara vez consideran que sus políticas o la aplicación de estas representan actos políticos. En la actualidad, las ciencias forestales se refieren tanto a la tradición alemana — plantaciones organizadas con poca diversidad y la sabiduría de los forestales para obtener una producción sostenidacomo al concepto más moderno de manejo profesional planificado, sostenible y orientado a la conservación (Tim Synnott com. pers.).

Los pueblos indígenas o tribales, así como otras comunidades locales, obtienen muy pocos beneficios de la territorialización o centralización del control de los bosques, a no ser el empleo temporal como trabajadores calificados o no calificados en tierras que muy posiblemente controlaron en el pasado (Peluso 1992). A pesar de la promesa de que las 
burocracias forestales gestionarían los recursos forestales con sabiduría, su desempeño en muchos países en desarrollo con frecuencia ha perpetuado o incluso exacerbado la degradación de la tierra y la pobreza rural (Blaikie 1985).

El interés en el valor de los bosques ha aumentado recientemente a la luz de las estrategias de mitigación del cambio climático, como la Reducción de Emisiones de la Deforestación y la Degradación de los Bosques (REDD o REDD+). REDD es un mecanismo basado en el desempeño, a través del cual se utilizarán fondos para compensar a los países en desarrollo por la reducción de emisiones de carbono con respecto a una línea de base nacional; el signo "+" se refiere a la inclusión del aumento de las reservas de carbono. Es muy probable que este mecanismo incluya fondos y mercados de cumplimiento, y podría, potencialmente, involucrar grandes sumas de dinero, aunque las expectativas de un acuerdo global en el corto plazo se han reducido recientemente (Berglund 2010). Las estrategias de REDD+ proporcionan a los Gobiernos un producto forestal nuevo potencialmente de alto valor en carbono, necesitan un sistema de supervisión centralizado para evitar las fugas y probablemente requieran considerable experiencia científica en las actividades de monitoreo de carbono (Angelsen 2009). Por ello, ha causado preocupación entre comunidades y pueblos indígenas, puesto que podría darse una nueva ronda de centralización de los bosques (y del carbono forestal) y decisiones de arriba hacia abajo respecto al uso de los bosques (Larson 2011) (véase también Mogoi et al. en la versión en inglés de esta colección).

A pesar de los recientes esfuerzos por otorgar derechos nuevos y seguros a las comunidades indígenas y a otras comunidades locales mediante reformas de la tenencia forestal, las regulaciones gubernamentales todavía están fundadas en una tradición de manejo forestal científico y en la cultura burocrática que ha persistido en las agencias forestales del Estado. Como se puede apreciar en los estudios de caso de Asia, América Latina y África presentados a continuación, las regulaciones forestales perpetúan el control del Estado sobre las tierras y los recursos forestales y socavan los beneficios potenciales de la reforma.

\section{Derechos forestales y las regulaciones que los limitan}

Durante los últimos 20 a 30 ańos, las comunidades que viven en los bosques han recibido derechos formales sin precedentes, por lo menos en teoría. En la práctica, sin embargo, estos nuevos derechos han enfrentado grandes obstáculos (Larson et al. 2010; Larson y Dahal en esta colección), lo que sugiere un concepto limitado de lo que constituyen "derechos" en la mayor parte de las agencias forestales estatales. De hecho, muchos de los primeros esquemas de distribución de tierras forestales a los gobiernos locales o a las comunidades, como los de la India y Nepal, tenían como objetivo el otorgamiento tanto de responsabilidades prescritas de manejo y requisitos laborales como de derechos (Saxena 1997; Gilmour 2003). Solo recientemente algunas reformas se han profundizado para reconocer los derechos locales a la gobernanza, aunque probablemente se circunscriban, en su mayoría, a algunos pueblos indígenas y tradicionales de América Latina y Filipinas. 
El caso del Manejo Forestal Conjunto en la India, no analizado en este estudio, brinda un excelente ejemplo de cómo la "cogestión" adolece con frecuencia de serios desequilibrios (véase también Cronkleton en esta colección). Según Sarin (2010), el Manejo Forestal Conjunto no se trata de derechos o la devolución de autoridad, sino más bien de un derecho condicional y la devolución de responsabilidades (véase también Sarin 1993). Los Memorandos de Entendimiento entre el Departamento Forestal y las organizaciones comunitarias fueron diseñados e impuestos por el primero, y aplicados de forma estandarizada en todas las comunidades, incluso en lugares con instituciones consuetudinarias de tenencia y gestión. Como resultado, se socavaron las prácticas indígenas de uso forestal, así como las instituciones de manejo forestal (Nayak y Berkes 2008), y, por lo menos en algunos casos, la diversidad biológica y los medios de vida disminuyeron.

Las políticas forestales de la India han generado conflicto y resistencia (Guha 1989; Jeffrey et al. 2003; Rangarajan 2003; Springate-Baginski et al. 2009). Tal vez el logro más importante de esta lucha, a la luz de la investigación analizada en esta colección, es la aprobación, en el 2006, de la Ley de Tribus Registradas y Demás Habitantes Tradicionales del Bosque (conocida como "Ley de Derechos Forestales"). La ley surgió en respuesta a la constante incapacidad del Gobierno de reconocer los derechos consuetudinarios a la tierra y, en consecuencia, la criminalización de los pueblos forestales (Springate-Baginski et al. 2009). La ley "otorga reconocimiento legal de los derechos a las comunidades tradicionales que habitan en los bosques, corrigiendo en parte la injusticia" causada por las leyes forestales (Perera 2009), beneficiando a los adivasis (el 8\% de la población india, conocida como pueblos originarios).

Sin embargo, la Ley de Derechos Forestales fue promovida por el Ministerio de Asuntos Tribales y no por el Ministerio de Medio Ambiente y Bosques y, tras su aprobación, "nueve diferentes demandas de interés público [...] fueron presentadas por oficiales forestales retirados y conservacionistas que cuestionaban la ley" (Ramdas 2009: 66). Desde entonces, varios informes han destacado tanto la burocratización del proceso y la activa resistencia como el sabotaje a la aplicación de la Ley de Derechos Forestales por el Gobierno de la India (Ramdas 2009; Springate-Baginski et al. 2009; CSD 2010; Kashwan en revisión).

Los esfuerzos por controlar la "forestería comunitaria" y la resistencia a reconocer los derechos locales sobre los bosques no se circunscriben a la India. En algunos casos, obtener un derecho, como el derecho al bosque comunitario, ha sido muy costoso y burocrático. Por ejemplo, el trámite para establecer bosques comunitarios es tan complicado en Camerún, que ninguno se ha establecido sin considerable apoyo externo (Oyono 2002, 2004b). Las concesiones forestales comunitarias en Petén, Guatemala, originalmente incluían una disposición que exigía que cada organización comunitaria contara con el acompañamiento técnico de una $\mathrm{ONG}$, y se invirtieron millones de dólares (Monterroso y Barry 2009). Estos ejemplos, al igual que el Manejo Forestal Conjunto en India, representan casos con un nivel adicional de "regulaciones contractuales" requeridas incluso para obtener el derecho al bosque. 
Después de otorgados, los derechos generalmente están restringidos o limitados por reglamentos, normas o procedimientos que regulan su aplicación. Por ello, en general, las reformas de la tenencia presentan una limitada transferencia de poder y autoridad local sobre la gestión de recursos. Aparentemente, muchos funcionarios del servicio forestal no logran reconocer el hecho de que es más probable que las personas cumplan las normas y observen la conducta de otros, como las normas para el manejo forestal, cuando están "realmente involucradas en las decisiones" referidas a esas normas y cuando los medios de vida están asegurados (Ostrom y Nagendra 2006: 19224). Sin embargo, la tendencia de los funcionarios del servicio forestal a buscar oportunidades para el rentismo y la captación de recursos no es menos importante que la creencia en la capacidad de la comunidad. Más adelante analizamos algunas de las normas y regulaciones utilizadas para restringir las competencias y los recursos otorgados a las comunidades.

\section{Regulaciones que limitan el acceso a la tierra}

A pesar de la reciente tendencia a devolver la propiedad y/o el control de los bosques a las comunidades, el acceso a bosques valiosos puede ser restringido por zonificación, sistemas de clasificación y otras normas de distribución de tierras. Dichas regulaciones pueden considerarse como la primera línea de defensa del Estado o como un "primer corte" (Barry, com. pers.) para asegurar los terrenos forestales valiosos y limitar el área que se devuelve a las comunidades. Dichas regulaciones pueden superponerse a decisiones subsecuentes, lo que limita seriamente los recursos disponibles a las comunidades.

De todas las regiones del mundo, parece ser que en los países asiáticos estudiados es usual que los Gobiernos prioricen la transferencia de "tierras baldías" o áreas degradadas a las comunidades o incluyan requisitos para la reforestación. India es un buen ejemplo de ello (Sarin 1993; Saxena 1997; Sundar 2000; Saigal 2011). Como es el caso en muchos países asiáticos, el manejo forestal en India tiene un legado europeo, en este caso, el dominio colonial británico. India fue uno de los primeros países en crear un servicio forestal profesional: nacionalizó el dominio forestal con la Ley Forestal de 1865. Hasta hoy, la mayor parte de los 77 millones de hectáreas de terrenos forestales es controlada por el Estado. Más de un sexto de la superficie del país (55 millones de hectáreas) se considera tierras baldías. Estas áreas han sido el objetivo de recientes programas de manejo forestal comunitario, como el Manejo Forestal Conjunto y el programa de la Sociedad Cooperativa de Cultivadores de Árboles (TGCS, por sus siglas en inglés). La investigación de nuestro proyecto se dedicó al estudio de este último (Saigal et al. 2009). El programa de la TGCS se creó en respuesta a la creciente preocupación, en la década de los ochenta, por la escasez de leña y forraje, y la creciente degradación de la tierra. Su creador, el Consejo Nacional de Desarrollo de Tierras Baldías, consideraba que el proyecto era una alternativa institucional más efectiva y sostenible para la forestación que el programa forestal social liderado por el Departamento Forestal.

Entre 1991 y 1992, cada una de las tres comunidades estudiadas en Rajastán recibió un contrato de arrendamiento de un área inferior a 40 ha en estas tierras baldías, sin tener en cuenta el tamańo de la población. Estas parcelas tan pequeñas no eran suficientes para 
generar beneficios para los medios de vida de cada uno de los hogares. La mayor parte de las tierras arrendadas eran de calidad pobre y estaban muy degradadas en el momento de la entrega, lo que implicaba esfuerzo, tiempo y dinero para hacerlas productivas nuevamente. En efecto, cerca del 59\% de los hogares encuestados en las tres comunidades consideraba que las TGCS "no eran importantes" para sus medios de vida. En cambio, el Gobierno parecía obtener ganancias del nuevo arreglo de tenencia por lo menos de dos formas. En primer lugar, las TGCS impidieron la ocupación de las áreas arrendadas y, por lo tanto, estas tierras han estado protegidas; en segundo lugar, las TGCS ayudaron a mejorar la condición biofísica de las áreas arrendadas (Saigal et al. 2009). Estos dos logros contribuyen a los objetivos de conservación del Estado. Asimismo, la Agencia Tributaria retiene el derecho de usar la tierra para otros objetivos (Saigal et al. 2009).

De igual modo en Filipinas, otro país conocido por lo "radical” y "progresivo" de su política forestal comunitaria (Pulhin et al. 2007; Utting 2000), las comunidades continúan luchando para obtener el control de áreas forestales productivas. Las primeras iniciativas del Gobierno en el marco del Programa Integrado de Forestería Social arrendaron a las comunidades solo tierras despojadas de árboles y luego extrajeron mano de obra barata de las comunidades para actividades de reforestación y protección (McDermott 2011). Además, el Gobierno, a través del Ministerio de Medio Ambiente y Recursos Naturales, esperaba que estas comunidades detuvieran las ocupaciones de tierras altas, aumentaran la productividad de la agricultura de montaña y controlaran cualquier disconformidad potencial. Al mismo tiempo, el ministerio retiene el poder de otorgar concesiones madereras (ahora llamadas acuerdos de manejo forestal industrial) en áreas de terrenos forestales residuales, siempre y cuando sea rentable y políticamente conveniente hacerlo ( $\mathrm{Li}$ 2002). Aunque la transferencia de la gestión forestal del ministerio a las comunidades locales durante los últimos 25 años ha sido significativa, con cerca de 4,7 millones de hectáreas bajo diferentes instrumentos de tenencia de tierra, las zonas más productivas en general operan a través de acuerdos o concesiones madereras privadas o bajo el Sistema Nacional Integrado de Áreas Protegidas.

Nepal, a pesar de haber sido uno de los países pioneros en materia de forestería comunitaria en Asia, también ha enfrentado desafíos tratando de poner tierras forestales productivas a disponibilidad de los grupos de usuarios de bosques comunitarios (CFUG, por sus siglas en inglés). En la región del Terai, donde se encuentra la mayor parte de los terrenos forestales productivos, el Departamento Forestal retiene el control sobre los bosques de alto valor y solo en contadas ocasiones, después de demandas de las bases, los transfiere a los CFUG (Bhattarai 2006; Ojha et al. 2008). Para el año 2005, solo el 2\% de los bosques del Terai se había transferido a los CFUG, comparado con casi $24 \%$ de los bosques de menor calidad de las tierras altas. El Gobierno sostiene que debe estar a cargo de estas áreas porque los productos de estos bosques deben ser distribuidos en todo el país, incluyendo poblaciones urbanas. Además, la Política Forestal del 2000 estableció un impuesto del $40 \%$ sobre las ganancias generadas por la venta de madera en los CFUG en el Terai e impuso otras restricciones sobre la devolución de los bosques en esta área (Bhattarai 2006). 
En Nepal y en Filipinas, al igual que en la India, los enfoques de manejo forestal del Estado tienen un origen colonial. Las políticas forestales de Nepal se vieron directamente influenciadas por los británicos, cuando sus expertos ayudaron a los gobernantes Rana a crear el Departamento Forestal en 1942 (Paudel et al. 2009). El departamento empezó el proceso de nacionalización de los terrenos forestales y perpetuó la noción colonial de manejo forestal científico en el país. En Filipinas, el manejo forestal fue un legado de dos sistemas, el español y el estadounidense. El Gobierno colonial español estableció la primera oficina forestal en 1863 e introdujo la tradición europea de un manejo forestal centralizada. Por su parte, los colonizadores estadounidenses, que asumieron el poder en 1898, crearon una escuela forestal en 1910 con la ayuda del mismísimo Pinchot. Los conceptos de manejo forestal científico continúan siendo la base del manejo de los recursos forestales en el país.

El uso de regulaciones forestales para restringir el acceso de las comunidades a los terrenos forestales no es solo un fenómeno asiático. En Camerún, por ejemplo, el programa de forestería comunitaria no se aplica a los bosques más productivos (Diaw et al. 2008; Oyono et al. 2009). Un plan de zonificación aprobado en 1993 clasificó los terrenos forestales en bosques permanentes y no permanentes. Los bosques permanentes abarcan parques nacionales, reservas de fauna, reservas para caza, jardines botánicos, jardines zoológicos, bosques de producción (para la extracción maderera), bosques de protección y bosques de investigación, los cuales representan las áreas forestales más ricas, extensas y estratégicas del país. Los bosques no permanentes comprenden bosques menos productivos y tierras agrícolas adyacentes a las comunidades, y es aquí donde, al momento de llevar a cabo la investigación, cerca de 56 comunidades tenían acuerdos de manejo por un período de 25 ańos que les otorgaban acceso, uso y manejo de la tierra con fines de medios de vida (Oyono et al. 2009). Por lo tanto, las comunidades locales han sido legalmente excluidas de los bosques de alto valor, los que son reservados, en su mayor parte, para la explotación comercial y como áreas protegidas. Al igual que en Asia, en Camerún la tendencia del Estado a retener los terrenos forestales valiosos tiene su origen en la tradición colonial (Oyono 2004a).

\section{Conservación y regulaciones de las áreas protegidas}

En ocasiones, los organismos de conservación han apoyado las reformas de la tenencia forestal que favorecen a las comunidades, incluso dentro de áreas protegidas, como en el caso de la creación de las concesiones forestales comunitarias en la Reserva de la Biosfera Maya en Guatemala. Sin embargo, frecuentemente los defensores de la conservación no han logrado comprender lo que podría estar en juego en las limitaciones impuestas a las comunidades a través de las regulaciones que acompañan dichas reformas.

En Brasil, las reservas extractivas (RESEX) se crearon para proteger los derechos de las poblaciones agroextractivas y tradicionales (Pacheco et al. 2008). Pablo Pacheco contribuyó con el estudio de caso de la RESEX en una versión preliminar de este artículo (Puhlin et al. 2010); aquí la resumimos brevemente. Aunque los proyectos de tierras anteriores eran competencia del Instituto Nacional de Colonización y Reforma Agraria, 
la RESEX representó un tipo específico de uso de tierras de conservación según la Ley $\mathrm{n}^{\circ}$ 9985, competencia de la agencia responsable del medio ambiente. En el municipio brasileńo de Porto de Moz en el estado de Pará, las comunidades locales tienen una larga historia de enfrentamientos con empresas madereras y pesqueras. Estas empresas usaban los recursos locales sin que las comunidades recibieran muchos beneficios a cambio (Moreira y Hébette 2003; Salgado y Kaimowitz 2003). Para proteger sus tierras y recursos naturales, las comunidades demandaron la creación de una RESEX. En el 2004, mediante decreto presidencial, se creó la RESEX "Verde para Sempre", que abarca prácticamente 1,3 millones de hectáreas y alberga cerca de 58 comunidades. Si bien la reserva garantizó los derechos de propiedad de los residentes y permitió que las comunidades expulsaran a las empresas madereras de sus tierras, también impuso nuevas restricciones sobre el uso de los bosques a pequeños productores que vivían en la reserva.

Los propietarios que viven dentro de la reserva no reciben plenos derechos de propiedad, pero sí el derecho de usufructo por tiempo indefinido, limitado por una serie de restricciones relativas al uso de tierras. La ley prohíbe el uso de especies en peligro de extinción y la realización de prácticas que erosionen los hábitats de esas especies o que podrían dañar la regeneración natural de los ecosistemas. El aprovechamiento de la madera se permite solo en circunstancias especiales (por ejemplo, cuando complementa otras actividades extractivas). De acuerdo a las regulaciones establecidas en el plan de manejo de la RESEX, la conversión forestal está limitada al 10\% de la superficie total, como también está restringido el desplazamiento de búfalos de agua. Quizá lo más importante es que cualquier actividad que se lleve a cabo en la RESEX debe incluirse en el plan de desarrollo de la reserva, lo cual solo puede suceder después de haberse elaborado y aprobado dicho plan para toda la RESEX, cosa que no ha ocurrido aún.

A pesar de la movilización de las bases para crear la reserva, los objetivos ambientales y de conservación del Gobierno tienden a estar por encima de los intereses de la población local. Las instituciones formales son muy burocráticas e ineficientes en la aplicación sus propias regulaciones. La falta de un plan de manejo impidió que algunas comunidades locales llevaran a cabo operaciones de aprovechamiento, aunque el sistema de reservas extractivas tenía como objetivo proteger los intereses de las comunidades agroextractivas y a las personas cuyos medios de vida tradicionales dependen de la madera y los productos forestales no maderables (PFNM). Las regulaciones que tienen como objetivo la conservación dejan a la población local poca flexibilidad para usar los recursos que les permiten satisfacer sus necesidades materiales, por lo menos de manera legal.

En Guatemala, los conservacionistas lanzaron una iniciativa para expandir las áreas protegidas en el altiplano occidental, una región vital para el equilibrio hidroecológico del país y que tiene importantes bosques remanentes (Elías et al. 2009). La deforestación en esta región ya se encuentra entre las más bajas del país (la tasa de deforestación neta anual es del $0,64 \%$ ) y la mayor parte de los bosques está dentro de tierras comunales o municipales. Aunque las comunidades del altiplano por lo general reciben bien la idea de crear áreas protegidas, no siempre queda claro lo que esto significa en la práctica. De hecho, las restricciones vinculadas a las metas de conservación, como las impuestas a 
la explotación ovina, el uso de leña y el uso del pinabete (Abies guatemalensis Rehder), una especie de pino de altura popular para árboles de Navidad), parecen afectar, en particular, a las familias más pobres, forzándolas a asumir los costos de protección sin ofrecer alternativas o compensación a cambio (Elías 1977). Los proyectos se elaboran con incentivos ecológicos, pero sin considerar la necesidad de garantizar la oferta a largo plazo de leña y madera. La incapacidad de comunicarse y negociar bien con las comunidades respecto a estos temas también ha generado conflicto y, en algunos casos, protestas violentas, como cuando una oficina forestal fue incendiada en la región de Ixil (Larson et al. 2008; véase también Elías en esta colección).

\section{Permisos para el uso comercial de recursos}

Con frecuencia, las agencias forestales del Estado regulan el uso comercial de los recursos forestales de alto valor, como la madera, en nombre del bien público. Aun cuando el Estado transfiere recursos forestales a las comunidades en el marco de los nuevos sistemas de tenencia, las estrictas regulaciones impuestas por el Gobierno siguen restringiendo el flujo de beneficios que las comunidades locales pueden percibir.

El aprovechamiento de madera, en particular, frecuentemente implica un proceso muy complicado y costoso para obtener permisos y licencias. Estos procesos de aprobación contemplan, en ocasiones, los mismos trámites exigidos a las empresas madereras, pero pueden llegar a incluir regulaciones adicionales para las comunidades o ser aplicados de forma que favorezcan a la industria y discriminen a las comunidades (Larson y Ribot 2007). Con frecuencia, estos procesos desafían la capacidad de las comunidades para incluso obtener un permiso. En Camerún, por ejemplo, el trámite para conseguir el plan de manejo exigido para establecer bosques comunitarios puede costar 55000 USD y demorar hasta dos años (Smith 2006). Además, el aprovechamiento debe llevarse a cabo utilizando procedimientos de bajo impacto. En cambio, las concesiones a corto plazo del sector privado conocidas como ventes de coupe, no están tan reglamentadas, pues no es necesaria la elaboración de un plan de manejo ni existen restricciones a los métodos de aprovechamiento (Oyono et al. 2006). Es muy poco lo que se ha hecho para facilitar las oportunidades de mercado para otros actores a fin de que puedan participar en las cadenas de valor de la madera o para agregar valor a los recursos forestales (Larson et al. 2008; Pacheco esta colección).

Por ejemplo, un estudio realizado en Honduras (Navarro et al. 2007) determinó que la obtención de un permiso de aprovechamiento involucraba 20 actores, 53 procesos y 71 pasos diferentes, lo que demoraba, en promedio, entre tres y cuatro meses. Igualmente, en Costa Rica, el proceso de aprobación abarcaba 11 actores, 31 procedimientos y 34 pasos, y podía demorar hasta 18 meses. Un estudio similar en las regiones autónomas de Nicaragua identificó cerca de 30 pasos para extensiones superiores a 500 ha (Navarro et al. 2008). En Cururú, Bolivia, transcurrieron más de dos años desde el inicio del plan de manejo hasta su aprobación final. 
En Nicaragua, los costos del plan general de manejo y del estudio de impacto ambiental para el área de manejo alcanzaron entre 1 y 2 USD por hectárea respectivamente (Argüello 2008). En bosques latifoliados, los planes operativos anuales para las áreas de extracción anual oscilan entre 9 y 12 USD por hectárea. La inversión inicial para estos estudios en Layasiksa, uno de los sitios del proyecto del CIFOR-RRI, superó los 50000 USD, pero, debido a los requisitos impuestos por el Fondo Mundial para la Naturaleza y el Forest Stewardship Council, esto abarcó un área mayor que la de aquellas gestionadas solo para aprovechamiento maderero (Larson et al. 2008). En Filipinas, aunque el plan de trabajo aprobado especifica el volumen previsto de extracción anual, el volumen realmente aprovechado depende de la aprobación del Departamento de Medio Ambiente y Recursos Naturales, que expide los permisos anuales. Sin la autorización, la cooperativa no puede llevar a cabo sus operaciones de aprovechamiento forestal. Sin embargo, dicha aprobación puede fácilmente demorar más de seis meses, en parte debido a que la emite la oficina central del ministerio en Metro Manila, quedándole a la cooperativa solo seis meses para operar. Los costos totales pueden alcanzar hasta 4700 USD. Incluso después de que se ha emitido la autorización y la madera ha sido cortada, las regulaciones para controlar el transporte de la madera aprovechada crean problemas adicionales (Dugan y Pulhin 2006). Las comunidades deben obtener un permiso para trasladar la madera al borde de la carretera y otra para transportar la madera al lugar donde se encuentran los compradores. Dado que el personal del departamento que otorga los permisos se encuentra por lo general a varios kilómetros de distancia, hay más retrasos y costos adicionales de transacción (Pulhin et al. 2008).

Las regulaciones de los bosques comunitarios en Nepal dejan amplio margen para que los forestales del Gobierno interfieran en los derechos de los grupos de usuarios, incluso después de que las comunidades han cumplido con todos los requisitos. El principal documento contractual que regula la práctica del manejo forestal es un plan operativo, preparado y acordado por el funcionario forestal del distrito y el CFUG. Por ello, estos funcionarios usan frecuentemente su influencia administrativa y técnica para incluir disposiciones que van más allá de lo requerido legalmente. Por ejemplo, el plan operativo del CFUG Sundari incluye una cláusula que estipula que cuando se extrae madera del bosque comunitario, el CFUG debe obtener permiso del funcionario forestal del distrito y registrar las cantidades aprovechadas por especie. En un caso, un miembro del CFUG que quería vender en el mercado 300 pies cúbicos de madera excedente tuvo que acudir a la oficina del distrito forestal en más de 12 ocasiones durante un período de cuatro meses antes de obtener la aprobación final (Paudel et al. 2009).

La combinación de complejas burocracias, altos costos iniciales en tiempo y dinero, falta de una institución crediticia y la interferencia de funcionarios forestales representa importantes impedimentos a la inversión comunitaria en planes formales de manejo. En estas condiciones es poco probable que las comunidades lleven a cabo operaciones comunitarias sin un importante apoyo externo u otro tipo de incentivo. 


\section{El futuro de las regulaciones comunitarias}

¿Cuántas regulaciones y de qué tipo se necesitan realmente?, ¿en qué circunstancias y por qué?, y ¿ cuánto es demasiado? Esta sección cuestiona algunas de las justificaciones del actual marco normativo y presenta un modelo simple para conceptualizar el rol del Estado frente al papel de las comunidades en la regulación de los bosques. Por último, aborda el tema de cómo deslindar los problemas fundamentales de los argumentos que probablemente solo representan cortinas de humo generadas por burocracias que se autoperpetúan o funcionarios que desean obtener beneficios económicos.

\section{Problemas de las restricciones actuales al uso forestal comunitario}

Este artículo ha examinado tres tipos de regulaciones que limitan la calidad de los bosques disponibles para las comunidades o restringen la toma de decisiones de estas últimas con respecto al uso y a la venta de recursos. Curiosamente, cada regulación tiene también una dimensión socioespacial y las tres pueden darse (aunque no siempre) en un mismo país: la primera contempla espacios de exclusión comunitaria; la segunda se refiere a espacios donde a una comunidad definida formalmente se le permite usar una cantidad limitada o un recurso específico, y la tercera se refiere a espacios ocupados, manejados e incluso de propiedad comunal, pero que están sujetos a regulación indirecta mediante instrumentos económicos y políticos que aumentan los costos de oportunidad y de transacción para el uso comercial de los recursos. Esto sugiere que las regulaciones de hoy no están totalmente desligadas de las estrategias de territorialización del pasado y que estos diferentes tipos de regulaciones pueden, en ciertos casos, representar diferentes dimensiones socioespaciales de una misma política.

Cada una de las restricciones tiene algún tipo de justificación válida, pero una serie de inquietudes las han puesto en duda. El primer tipo de regulación limita el área disponible para las comunidades en términos de tamaño o calidad de los bosques. La justificación más común es que el Estado es mejor administrador que las comunidades y que los ingresos serán distribuidos más equitativamente. Pero denegarles los bosques a las comunidades es también una tradición colonial perpetuada por las modernas burocracias forestales. Además, generalmente el Estado no ha sido capaz de demostrar que es buen administrador del bosque (Blaikie 1985). Es cierto que otorgar un bosque de alta calidad a una concesión industrial puede generarle más ingresos al Estado que si se la otorga a una comunidad pobre, pero al mismo tiempo, la cuestión aquí es básicamente una de prioridades.

Los otros dos tipos de regulaciones enfatizan la conservación delineando áreas de conservación, imponiendo límites a su uso y exigiendo permisos para actividades con fines comerciales. Estas regulaciones son supuestamente aplicadas para conservar y proteger los ecosistemas y recursos forestales, pero plantean otros problemas que deben ser tomados en cuenta. 
En primer lugar, si bien no hay duda de que se necesitan regulaciones para promover la conservación de los bosques y su uso sostenible, las regulaciones que son complicadas con frecuencia generan y se perpetúan gracias a la corrupción. De hecho, las regulaciones forestales por lo general parecen estar menos relacionadas con la conservación de los bosques y más con el establecimiento y la perpetuación de procesos burocráticos para obtener permisos forestales. En Filipinas, cada paso abre una oportunidad para sacarle dinero a las comunidades (Dugan y Pulhin 2006), un problema ampliamente reconocido también en Nepal (Paudel et al. 2006). En una revisión sistemática de literatura sobre recursos naturales y corrupción, Kolstad y Soreide (2009: 214) concluyen que la corrupción, en la forma de rentismo y clientelismo, "es la principal razón por la que a los países ricos en recursos les va tan mal en el ámbito económico".

En segundo lugar, algunas regulaciones, especialmente aquellas que restringen el uso de los recursos, pueden causar serias dificultades, ya sean innecesarias o sin compensación. Las restricciones a la explotación ovina en el altiplano guatemalteco han afectado más a las mujeres, los miembros más pobres de la sociedad rural (Elías et al. 2009). Los límites al acceso a los recursos, en particular en los primeros ańos de los bosques comunitarios en Nepal, afectaron seriamente a aquellos que más dependían del bosque (Malla 2000; Adhikari et al. 2004; Colfer et al. 2008). De la misma manera, en los primeros años de la forestería comunitaria en Filipinas, el confinamiento del acceso y uso de los recursos comunitarios principalmente a áreas cultivadas perpetuó la distribución, casi centenaria, de beneficios derivados de los recursos forestales a favor de unos cuantos operadores de licencias (Puhlin et al. 2007).

En tercer lugar, muchas restricciones y otras regulaciones son tan poco razonables que simplemente no se pueden aplicar. Onibon et al. (1999) las llamaron "dualismos estériles", definidos como "la coexistencia de una ley estatal inaplicable y prácticas locales no autorizadas" (Benjamin 2008: 2256). Por ejemplo, la incapacidad del Gobierno de avanzar en el plan de desarrollo de la RESEX dio como resultado la suspensión formal de numerosas actividades de medios de vida, pero, en la práctica, las personas siguen llevándolas a cabo para sobrevivir. Asimismo, en ocasiones es tan difícil cumplir las regulaciones de aprovechamiento maderero legal, que las personas se ven obligadas a participar en el mercado informal. Gregerson y Contreras (2010: 3) argumentan que "las regulaciones forestales más exigentes se encuentran, por lo general, en los países con la menor capacidad de aplicarlas" (Cashore y McDermott 2004).

En cuarto lugar, algunas regulaciones tienen consecuencias económicas serias e innecesarias, lo que aumenta la inseguridad para invertir en recursos forestales y comercializarlos. Esto es particularmente cierto en los cambios de políticas como los realizados en Filipinas y Nicaragua, que generaron grandes pérdidas para las operaciones pequeńas con márgenes de ganancia bajos. En Filipinas, el aprovechamiento comercial de madera bajo el programa de manejo forestal comunitario se suspendió en tres ocasiones, dejando a los inversionistas con grandes deudas y obligaciones incumplidas en el mercado (Pulhin et al. 2008). La cooperativa ubicada en el Valle de Compostela en Mindanao perdió cerca de 53400 USD a causa de una sola suspensión en el 2003 (Pulhin y Dressler 2009). 
Del mismo modo, el Gobierno nicaragüense anunció una emergencia forestal y una moratoria que prohibía el aprovechamiento en el 2006, lo que generó pérdidas superiores a 28000 USD a la organización forestal comunitaria más prominente del país (Larson y Mendoza-Lewis 2009).

En quinto lugar, las regulaciones formales pueden tener, en realidad, un efecto contrario sobre la conservación forestal si socavan las estructuras consuetudinarias de gobernanza forestal y las regulaciones de manejo, en aquellos casos donde existan. La imposición de sistemas formales sobre sistemas consuetudinarios ha dado como resultado lo que se ha denominado forum shopping (solución de conveniencia) (Brenda-Beckmann 1981) o la elección deliberada de qué conjunto de regulaciones aplicar; la pérdida de autoridad, de forma tal que ni la autoridad consuetudinaria ni la estatal puedan administrar los recursos de manera eficaz (Nemarundwe 2004); y dinámicas de acceso abierto (Fitzpatrick 2006). La desaparición de las prácticas consuetudinarias efectivas podría también generar pérdidas imprevisibles, por ejemplo las restricciones al pastoreo en Nepal están debilitando una importante cultura tradicional de tierras altas que incluye un conocimiento etnobotánico local inigualable (Banjade y Paudel 2008).

\section{Punto de partida: la comunidad}

Entonces, ¿cuál es la solución? ¿Cómo podemos diseñar regulaciones para las comunidades forestales de forma tal que se las aplique en el lugar y el momento que más se las necesita y que solo complementen la regulación local cuando esta no sea necesaria? En lugar de que el punto de partida sea la perspectiva de la reglamentación estatal, proponemos abordar el problema desde las comunidades. ¿Cuáles son las necesidades y prácticas locales y qué potencial tienen para practicar un manejo forestal sostenible desde las bases? Básicamente, si un mayor control y apropiación local están tras el principio de un mejor manejo sostenible — en tanto contar con mayor seguridad a largo plazo promueve un interés duradero por mantener los recursos-, entonces, ¿hasta qué punto están el exceso de regulaciones y la retención de derechos de manejo interfiriendo con el potencial de las reformas de la tenencia?

Fitzpatrick (2005) argumenta que el diseño de las reformas de tenencia debería basarse en una evaluación de las causas de la inseguridad de los derechos de tenencia que afectan a las comunidades. Según Fitzpatrick, cuanto más externas sean las causas de la inseguridad, menos debería interferir el Estado en asuntos internos; más bien, debería orientar sus actividades hacia la defensa del perímetro del área consuetudinaria de la comunidad. Y a la inversa, cuanto más interna es la causa de la inseguridad, mayor debería ser el rol del Estado en su misión de mediar las decisiones relativas al acceso. Podemos esbozar un argumento similar en relación con las reformas de la tenencia y las causas de la deforestación. Si la deforestación es el resultado de influencias externas, tanto más deberían las reformas tratar de fortalecer los derechos de exclusión de la comunidad y la elaboración de regulaciones internas, y, al mismo tiempo, proporcionar foros apropiados para negociar con usuarios pobres y externos (Mwangi y Dohrn 2008); por otro lado, si 
la deforestación responde a influencias internas, el papel del Estado debería ser mayor. Esto constituye la primera variable clave.

La condición actual de los bosques debería guiar las decisiones referentes al grado en que se debe priorizar la recuperación, o si es suficiente mantener las condiciones actuales del bosque (o manejarlo para ciertos productos). Se debería reforzar los incentivos internos que promueven el mantenimiento del bosque, como la contribución a los medios de vida o los valores culturales, y controlar las presiones externas. Estos incentivos externos constituyen otra variable clave Cuadro 1. El tipo de conceptualización presentada en el cuadro sugiere una manera de aplicar propuestas como "normas mínimas" u opciones de "reglas básicas" más amplias, en lugar de mecanismos y normas de manejo sumamente burocráticas.

Cuadro 1. Grado y tipo del papel regulador del Estado basados en causas de deforestación y "dependencia de los bosques"

\begin{tabular}{|c|c|c|c|}
\hline & & \multicolumn{2}{|c|}{ Causas de la deforestación/degradación } \\
\hline & & Externas (o ninguna) & Internas \\
\hline \multirow{2}{*}{$\begin{array}{l}\text { Contribución } \\
\text { de los bosques } \\
\text { (en pie) a } \\
\text { los medios } \\
\text { de vida o la } \\
\text { reproducción } \\
\text { cultural }\end{array}$} & Fuerte & $\begin{array}{l}\text { No hay intervención del Estado } \\
\text { en la comunidad: el Estado } \\
\text { protege el perímetro de la } \\
\text { comunidad }\end{array}$ & $\begin{array}{l}\text { Rol moderado del Estado: el } \\
\text { Estado facilita la aplicación } \\
\text { de normas }\end{array}$ \\
\hline & Débil & $\begin{array}{l}\text { Rol moderado del Estado: el } \\
\text { Estado protege el perímetro } \\
\text { de la comunidad y facilita la } \\
\text { organización y los incentivos } \\
\text { para mejorar la contribución a } \\
\text { los medios de vida si así lo desea } \\
\text { la comunidad }\end{array}$ & $\begin{array}{l}\text { Rol activo del Estado: mayor } \\
\text { regulación estatal del uso de los } \\
\text { bosques (pero las comunidades } \\
\text { todavía tienen todo el derecho a } \\
\text { participar en las decisiones) }\end{array}$ \\
\hline
\end{tabular}

Fuente: Inspirado en Fitzpatrick (2005)

El cuadro es, por supuesto, una simplificación de la realidad y amerita algunas puntualizaciones importantes. En primer lugar, se parte del supuesto de que los derechos de tenencia han sido otorgados o reconocidos y que abordan los problemas subyacentes de la inseguridad. En segundo lugar, el cuadro solo se refiere a las causas inmediatas de la deforestación. Las políticas del Estado podrían ser una importante causa subyacente de la degradación si promueven varias políticas contradictorias o políticas específicas que fomentan la tala de bosques. Estas políticas también deberían abordarse. En tercer lugar, la degradación que resulta de factores externos podría ser la causante de la degradación interna (Ribot, com. pers.), ya que la población local puede sobreexplotar sus propios recursos, en lugar de que terceros se los "roben". Por ello, debería abordarse la degradación externa primero y, en vista de esto, es posible que ya no se necesite el apoyo del Estado en la aplicación de la reglamentación interna. 


\section{El desafío político}

Los modelos conceptuales pueden ser útiles, pero aún enfrentan el desafío de que las agencias forestales con frecuencia no confían en la capacidad (o las metas) de las comunidades, y tienen una gran cantidad de intereses menos nobles que la protección de los bosques. Nuevamente, el argumento aquí no es que se les debería otorgar plenos derechos sobre los bosques a las comunidades o que ellas son mejores administradoras del bosque que el Estado, sino, más bien, cómo ampliar el ámbito del debate a fin de poder darles una oportunidad. En este sentido, deberíamos tener en cuenta tres consideraciones que nos dan pautas de cómo seguir adelante: en primer lugar, las regulaciones y los derechos son dos temas totalmente diferentes. Aunque en algunos casos los derechos quizá deban ser ganados y condicionales (por ejemplo, algunas de las comunidades que recibieron concesiones en Petén no tenían derechos previos o históricos sobre esas tierras), es posible que las comunidades hayan ganado esos derechos sobre los bosques, independientemente del uso que decidan darles. Es decir, si tienen o no derechos es un tema político que se determina a través de actividades de apoyo, debate público, y leyes y tribunales nacionales e internacionales; luego, los derechos otorgados deberían ser claros, seguros y defendidos por el Estado. Con respecto al uso forestal, no hay razón para que las comunidades estén sujetas a normas más restrictivas que las aplicadas al propio Estado o a la empresa privada.

En segundo lugar, la investigación realizada por Paudel et al. (en esta colección) destaca la importancia de las organizaciones forestales de base de segundo nivel. Organizaciones eficaces, como la Federación de Usuarios de Bosques Comunitarios (FECOFUN) de Nepal y la Asociación de Comunidades Forestales de Petén (ACOFOP) de Guatemala, promueven el intercambio de conocimiento y el desarrollo de capacidades. Ellas pueden superar los obstáculos de comunicación entre los forestales y las comunidades, presionar al Estado en relación a los intereses comunitarios y organizar protestas en contra de leyes y regulaciones poco razonables. También pueden mejorar la gobernanza y el manejo forestal entre las comunidades miembros. Estas organizaciones pueden trabajar con aliados de ONG y donantes para apoyar el debate público, la investigación y el intercambio de información sobre estos temas, incluyendo la denuncia de actos de corrupción o prácticas desleales.

Tercero, los forestales del Estado con visión de futuro son aliados importantes. Los funcionarios de agencias forestales han sido vitales en la obtención de apoyo para la forestería comunitaria en Nepal y México (Bray et al. 2006), y para las concesiones comunitarias en Petén, Guatemala. De la misma manera, en Filipinas, el intento del secretario del Departamento de Medio Ambiente y Recursos Naturales de cancelar todos los acuerdos de manejo forestal comunitario a nivel nacional en el 2005 fracasó gracias al apoyo de algunos forestales del ministerio que defendían los intereses de las comunidades. Las soluciones a largo plazo en este respecto deberán incluir la perspectiva comunitaria en el currículo forestal de las universidades nacionales. 


\section{Conclusiones}

En ocasiones se justifica que el Estado tenga un papel preponderante, incluso a través de restricciones y regulaciones, pero las reformas no deberían ser un instrumento a través del cual obtenga control sobre las comunidades (los ministerios con frecuencia todavía tienden a culpar a las poblaciones locales por la degradación, en vez de considerarlas como aliados). Particularmente preocupantes son las responsabilidades que restringen los medios de vida de manera significativa, en especial aquellos de los miembros más pobres de la sociedad; la incapacidad de abordar o incluso reconocer prácticas ya existentes sobre el terreno o los costos que las comunidades deben asumir por adoptar nuevas prácticas; la corrupción; y la regulación que no se puede aplicar.

Las cuestiones relativas a los derechos y normas de tenencia cobran una renovada importancia ante las estrategias de REDD+. Es posible que REDD+ exija una tenencia clara, así como regulaciones estrictas, para que se cumplan las reducciones de emisiones de carbono. Pero la experiencia con las regulaciones que suelen acompañar las reformas de la tenencia sugiere que es posible que los derechos comunitarios no se respeten y que las normas se impongan, una vez más, "desde arriba", a menos que se exija la aplicación de salvaguardias claras con sistemas de monitoreo independiente (Larson 2011).

El objetivo de las reformas de la tenencia debería ser el de reforzar o modificar la estructura de incentivos a favor del uso y la conservación de los bosques y los recursos forestales. El aparato regulatorio del Estado debería ofrecer incentivos y aumentar la capacidad del manejo forestal a nivel local, basándose en los posibles conocimientos, energía y estructuras organizativas endógenas que en la actualidad vienen siendo ignoradas o marginadas, una oportunidad que aún no ha sido aprovechada y necesita ser armonizada con los sistemas formales de manejo.

\section{Agradecimientos}

Los autores desean agradecer en forma especial a Pablo Pacheco, Tim Synnott y Chip Fay por sus comentarios sobre una versión previa de este artículo, así como a los editores de Conservation and Society y tres revisores anónimos. 


\section{Referencias}

Adhikari, B., S.D. Falco y J.C. Lovett. 2004. Household characteristics and forest dependency: Evidence from common property forest management in Nepal. Ecological Economics 48: 245-257.

Angelsen, A. 2009. La implementación de REDD+: Estrategia nacional y opciones de política. Bogor, Indonesia: Centro para la Investigación Forestal Internacional (CIFOR).

Argüello, A. 2008. Cadena de valor de la madera de la cooperativa Kiwatigni en Layasiksa-RAAN. Informe inédito. Managua: Centro para la Investigación Forestal Internacional (CIFOR) y Masangni.

Banjade, M.R. y N.S. Paudel. 2008. Suspa Community Forest Users Group, Dokakha. Informe desde el sitio de trabajo. Katmandú: Centro para la Investigación Forestal Internacional (CIFOR) y ForestAction.

Benda-Beckmann, K. von. 1981. Forum shopping and shopping forums. Journal of Legal Pluralism 19: 117-159.

Benjamin, C. 2008. Legal pluralism and decentralization: Natural resource management in Mali. World Development 36(11): 2255-2276.

Berglund, N. 2010. View and news from Norway. 14 de octubre. www.newsinenglish. no/2010/10/14/jens-gives-up-on-global-climate-deal. [Consultado el 1 de noviembre del 2010].

Bhattarai, B. 2006. Widening the gap between terai and hill farmers in Nepal: The implications of the New Forest Policy 2000. En: Hanging in the balance: Equity in community-based natural resource management in Asia (eds. Mahanty, S., J. Fox, M. Nurse, P. Stephen y L. McLees). Bangkok: Centro para las Personas y los Bosques; Honolulú, Estados Unidos: East-West Center.

Blaikie, P. 1985. The political economy of soil erosion in developing countries. Londres: Longman.

Bray, D.B., C. Antinori y J.M. Torres-Rojo. 2006. The Mexican model of community forest management: The role of agrarian policy, forest policy and entrepreneurial organization. Forest Policy and Economics 8: 470-484.

Cashore, B. y C. McDermott. 2004. Global environmental forest policies: Canada as a constant case comparison of select forest practice regulations. Victoria, Canadá: International Forest Resources.

Colfer, C.J.P., G.R. Dahal y D. Capistrano (eds.). 2008. Lessons from forest decentralisation in Asia Pacific: Money, justice and quest for good governance. Londres: Earthscan.

Council for Social Development (CSD). 2010. Summary report on implementation of the Forest Rights Act. Nueva Delhi. http://www.forestrightsact.com/component/ $\mathrm{k} 2 /$ item/15. [Consultado el 14 de abril del 2011].

Dahal, G.R., A.M. Larson y P. Pacheco. 2010. Outcomes of reform for livelihoods, forest condition and equity. En: Forests for people: Community rights and forest tenure 
reform (eds. Larson, A.M., D.Barry, G.R. Dahal y C.J.P. Colfer). Pp. 183-209. Londres: Earthscan.

Dana, S.T. y S.K. Fairfax. 1980. Forest and range policy: Its development in the United States. Nueva York: McGraw-Hill.

Diaw, M.C., R. Prabhu y T. Aseh (eds.). 2008. In search for common ground: Adaptive collaborative management of forest in Cameroon. Bogor, Indonesia: Centro para la Investigación Forestal Internacional (CIFOR).

Dixon, J.A. y P.B. Sherman. 1991. Economics of protected areas: A new look at costs and benefits. Londres: Earthscan.

Dugan, P. y J. Pulhin. 2006. Forest harvesting in community-based forest management (CBFM) in the Philippines: Simple tools versus complex procedures. En: A cut for the poor. Proceedings of international conference on managing forests for poverty reduction: Capturing opportunities in forest harvesting and wood processing for the benefit of the poor (eds. Oberndorf, R., P. Durst, S. Mahanty, K. Burslem y R. Suzuki). Ho Chi Minh, Vietnam. FAO RAP Publication 2007/09 y RECOFTC Report No. 19. Bangkok: Organización de las Naciones Unidas para la Alimentación y la Agricultura (FAO) y Centro para las Personas y los Bosques. Del 3 al 6 de octubre del 2006.

Eckersley, R. 1992. Environmentalism and political theory: Toward an ecocentric approach. Londres: University College London Press.

Elías, S., A.M. Larson, y J. Mendoza. 2009. Tenencia de la tierra, bosques y medios de vida en el Altiplano Occidental de Guatemala. Guatemala: Centro para la Investigación Forestal Internacional (CIFOR) y Facultad de Agronomía, Universidad de San Carlos.

Elías, S. 1997. Autogestión comunitaria de recursos naturales: Estudio de caso en Totonicapán. Guatemala: Facultad Latinoamericana de Ciencias Sociales (FLACSO).

Elliott, C. 1996. Paradigms of forest conservation. Unasylva 47(187). http://www.fao. org/docrep/w2149e/w2149e00.htm. [Consultado el 18 de abril del 2011].

Fay, C. y G. Michon. 2003. The contribution of plantation and agroforestry to rural livelihoods: Redressing forestry hegemony-where a forestry regulatory framework is best replaced by an agrarian one. Trabajo presentado en la International conference on rural livelihoods, forests and biodiversity. Bonn, Alemania. Del 19 al 23 de mayo del 2003.

Fernow, B. 1911. The history of forestry. $3^{\text {rd }}$ edition. Toronto, Canadá: University of Toronto Press.

Fitzpatrick, D. 2005. 'Best practice' options for the legal recognition of customary tenure. Development and Change 36(3): 449-475.

Fitzpatrick, D. 2006. Evolution and chaos in property rights systems: The Third World tragedy of contested access. Yale Law Journal 115: 996-1048.

Gilmour, D. 2003. Retrospective and prospective view of community forestry in Nepal. Journal of Forest and Livelihoods 2(2): 5-7. 
Gregerson, H. y A. Contreras. 2010. Rethinking forest regulations: From simple rules to systems to promote best practices and compliance. Washington D.C.: Iniciativa para los Derechos y Recursos (RRI).

Guha, R. 1989. The unquiet woods: Ecological change and peasant resistance in the Himalaya. Oxford, Reino Unido: Oxford University Press.

Harrison, R.P. 1992. Forests: The shadow of civilization. Chicago, Estados Unidos: University of Chicago Press.

Jeffrey, R., N. Sundar, A. Mishra, N. Peter y P. Tharakan. 2003. A move from minor to major: Competing discourses of non-timber forest products in India. En: Nature in the global South: Environmental projects in South and Southeast Asia (eds. Greenough, P. y A.L. Tsing). Durham, Estados Unidos: Duke University Press.

Kashwan, P. (en revisión). Beyond localization: Nature conservation, forest bureaucracies, and policies for restitution of rights.

Kolstad, I. y T. Soreide. 2009. Corruption in natural resource management: Implications for policy makers. Resources Policy 34(4): 214-226.

Larson, A.M. 2011. Forest tenure reform in the age of climate change: Lessons for REDD+. Global Environmental Change 21: 540-549. doi:10.1016/j. gloenvcha.2010.11.008.

Larson, A.M. y J.C. Ribot. 2007. The poverty of forestry policy: Double standards on an uneven playing field. Sustainability Science 2(2): 189-204.

Larson, A.M. y J. Mendoza-Lewis. 2009. Desafíos en la tenencia comunitaria de bosques en la RAAN de Nicaragua. Managua: Centro para la Investigación Forestal Internacional (CIFOR), Universidad de las Regiones Autónomas de la Costa Caribe Nicaragüense (URACCAN) e Iniciativa para los Derechos y Recursos (RRI).

Larson, A.M., D. Barry y G.R. Dahal. 2010. New rights for forest based communities? Understanding processes of forest tenure reform. International Forestry Review 12(1): 78-96.

Larson, A.M., P. Cronkleton, D. Barry y P. Pacheco. 2008. Tenure rights and beyond: Community access to forest resources in Latin America. Occasional Paper No. 50. Bogor, Indonesia: Centro para la Investigación Forestal Internacional (CIFOR).

Li, T.M. 2002. Engaging simplifications: Community-based resource management, market processes and state agendas in upland Southeast Asia. World Development 30(2): 265-283.

Malla, Y. 2000. Impact of community forestry policy on rural livelihoods and food security in Nepal. Unasylva 51(3).

Mantel, K. 1964. History of the international science of forestry with special consideration of Central Europe: Literature, training, and research from the earliest beginnings to the nineteenth century. En: International review of forestry research. Volumen 1 (eds. Romberger, J.A. and P. Mikola). Pp. 1-37. Nueva York: Academic Press.

McDermott, M.H. 2001. Invoking community: Indigenous people and ancestral domain in Palawan, the Philippines. En: Communities and the environment: Ethnicity, gender 
and the state in community-based conservation (eds. Agrawal, A. y C. Gibson). New Brunswick, Estados Unidos: Rutgers University Press.

Monterroso, I. y D. Barry. 2009. Sistema de concesiones forestales comunitarias: Reflexiones sobre la reforma forestal y el futuro del modelo. Guatemala: Centro para la Investigación Forestal Internacional (CIFOR) y Facultad Latinoamericana de Ciencias Sociales (FLACSO).

Moreira, E. y H. Hébette. 2003. Estudo socio-econômico com vista a criação da Resex Verde para Sempre. Belém, Brasil: Universidade Federal do Pará.

Mwangi, E. y S. Dohrn. 2008. Securing access to dryland resources for multiple users in Africa: A review of recent research. Land Use Policy 25: 240-248.

Navarro, G., F. Del Gatto, O. Faurby y A. Arguello. 2007. Verificación de la legalidad en el sector forestal Nicaragüense. Trabajo presentado en el VI Congreso forestal Centroamericano: Competitividad, sostenibilidad forestal en Centroamérica. San Salvador. Del 29 al 31 de agosto del 2007.

Navarro, G., M. Sánchez, A.M. Larson, G. Bermúdez y E. Méndez. 2008. Simplificación de trámites en el sistema de verificación de la legalidad del sector forestal en Nicaragua. Informe de consultoría inédito. Informe 2: Diagnóstico de los permisos forestales de aprovechamiento. Managua: Instituto Nacional Forestal, Deutsche Gesellschaft für Technische Zusammenarbeit y Centro Agronómico Tropical de Investigación y Enseñanza (CATIE).

Nayak, P.K. y F. Berkes. 2008. Politics of co-optation: Community forest management versus joint forest management in Orissa, India. Environmental Management 41: 707-718.

Nemarundwe, N. 2004. Social charters and organization for access to woodlands: Institutional implications for developing responsibilities for resource management to the local level in Chivi District, Zimbabwe. Society and Natural Resources 17: 279-291.

Ojha, H.R., N.P. Timsina, R. Chhetri y K. Paudel. 2008. Communities, forests and governance: Policy and institutional innovations from Nepal. Nueva Delhi: Adroit Publishers.

Onibon, A., B. Dabiré y L. Ferroukhi. 1999. Local practice and decentralization and devolution of natural resources management in West Africa. Unasylva 50: 23-27.

Ostrom, E. y H. Nagendra. 2006. Insights on linking forests, trees, and people from the air, on the ground, and in the laboratory. Proceedings of the National Academy of Sciences 103(51): 19224-19231.

Oyono, P.R. 2002. Forest management, systemic crisis and policy change: socioorganizational roots of ecological uncertainties in the Cameroon's decentralization model. Trabajo presentado en el World Resources Institute workshop on decentralization and the environment. Bellagio, Italia. Del 18 al 22 de febrero del 2002.

Oyono, P.R. 2004a. One step forward, two steps back? Paradoxes of natural resources management decentralisation in Cameroon. Journal of Modern African Studies 42(1): 91-111. 
Oyono, P.R. 2004b. Institutional deficit, representation, and decentralized forest management in Cameroon. Working Paper No. 15. Washington D.C.: Instituto de Recursos Mundiales (WRI).

Oyono, P.R., J.C. Ribot y A.M. Larson. 2006. Green and black gold in rural Cameroon: Natural resources for local justice, governance and sustainability. Working Paper No. 22. Washington D.C.: Instituto de Recursos Mundiales (WRI).

Oyono, P.R., S.S. Kombo y M.B. Biyong. 2009. Les nouvelles niches de droits forestiers communautaires au Cameroun: Effets cumulatifs sur les moyens de subsistance et les formes locales de vulnérabilité. Yaundé: Centro para la Investigación Forestal Internacional (CIFOR).

Pacheco, P., W. Nunes, C. Rocha, I. Vieira, J. Herrera, K. Alves, T. Feitosa, et al. 2008. Acesso à terra e meios de vida: Examinando suas interaçóes em três locais no Estado do Pará. Santa Cruz, Bolivia: Centro para la Investigación Forestal Internacional (CIFOR), Laboratório Agroecológico da Transamazonica y Assessoria Comunitária e Ambiental.

Paudel, D., S.J. Keeling y D.R. Khanal. 2006. Forest products verification in Nepal and the work of the Commission to Investigate the Abuse of Authority. VERIFOR Case Study 10. http://www.verifor.org. [Consultado el 18 de abril del 2011].

Paudel, N.S., M. Banjade y G.R. Dahal. 2009. Improving equity and livelihoods in community forestry, Country Report Nepal. Katmandú: ForestAction y Centro para la Investigación Forestal Internacional (CIFOR).

Peluso, N.L. 1992. Rich forests, poor people: Resource control and resistance in Java. Berkeley, Estados Unidos: University of California Press.

Perera, J. 2009. Scheduled Tribes and Other Traditional Forest Dwellers (Recognition of Forest Rights) Act 2006: A charter of forest dweller's rights? En: Land and cultural survival: The communal land rights of indigenous peoples in Asia (ed. Perera, J.). Mandaluyong City, Filipinas: Banco Asiático de Desarrollo (BAsD).

Pulhin, J.M., A.M. Larson y P. Pacheco. 2010. Regulations as barriers to community benefits in tenure reform. En: Forests for people: Community rights and forest tenure reform (eds. Larson, A.M., D. Barry, G.R. Dahal y C.J.P. Colfer). Pp. 139-159. Londres: Earthscan.

Pulhin, J.M. y W.H. Dressler. 2009. People, power and timber: The politics of community-based forest management. Journal of Environmental Management 91(1): 206-214. doi:10.1016/j.jenvman.2009.08.007.

Pulhin, J.M., J.T. Dizon, R.V.O. Cruz, D.T. Gevana y G.R. Dahal. 2008. Tenure reform on Philippine forest lands; Assessment of socio-economic and environmental impacts. Los Baños, Filipinas: College of Forestry and Natural Resources, University of Philippines.

Pulhin, J.M., M. Inoue y T. Enters. 2007. Three decades of community-based forest management in the Philippines: Emerging lessons for sustainable and equitable forest management. International Forestry Review 19(4): 865-883. 
Ramdas, S.R. 2009. Women, forestspaces and thelaw: Transgressing the boundaries. Review of Women's Studies, Economic and Political Weekly. 44: 65-73.

Rangarajan, M. 2003. The politics of ecology: The debate on wildlife and people in India, 1970-95. En: Battles over nature: Science and the politics of conservation (eds. Saberwal, V. y M. Rangarajan). Delhi, India: Permanent Black.

Saigal, S. 2011. Greening the 'wastelands': Evolving discourse on wastelands and its impact on community rights in India. Trabajo presentado en la Conference of the International Association for the Study of the Commons. Hyderabad, India. Del $11 \mathrm{al}$ 14 de enero del 2011.

Saigal, S., G.R. Dahal y B. Vira. 2009. Cooperation in forestry: Analysis of forestry cooperatives in Rajasthan, India. Cambridge, Reino Unido: Iniciativa para los Derechos y Recursos (RRI), Centro para la Investigación Forestal Internacional (CIFOR) y Cambridge University.

Salgado, I. y D. Kaimowitz. 2003. Porto de Moz: O prefeito 'dono do municipio'. En: Municípios e gestão florestal na Amazônia (ed. Toni, F.). Brasilia: A.S. Editores.

Sarin, M. 1993. From conflict to collaboration: Local institutions in joint forest management. Joint Forest Management Working Paper No. 14. Nueva Delhi: Fundación Ford y Society for the Promotion of Wastelands Development.

Sarin, M. 2010. From superficial tinkering to unpacking state forests in India. Trabajo presentado en la conferencia Taking stock of smallholder and community forestry: Where do we go from here? Organizada por el Centro para la Investigación Forestal Internacional (CIFOR), el Centre de Coopération Internationale en Recherche Agronomique pour le Développement y el Institut de Recherche pour le Développement. Montpellier, Francia. Del 24 al 26 de marzo del 2010.

Saxena, N.C. 1997. The saga of participatory forestmanagement in India. Special Publication. Bogor, Indonesia: Centro para la Investigación Forestal Internacional (CIFOR).

Scott, J.C. 1995. State simplifications: nature, space and people. Journal of Political Philosophy 3(3): 191-233.

Silva, E., D. Kaimowitz, A. Bojanic, F. Ekoko, T. Manurung e I. Pavez. 2002. Making the law of the jungle: The reform of forest legislation in Bolivia, Cameroon, Costa Rica, and Indonesia. Global Environmental Politics 2: 63-97.

Smith, W. 2006. Regulating timber commodity chains: Timber commodity chains linking Cameroon and Europe. Trabajo presentado en la Conference of the International Association for the Study of Common Property (IASCP). Bali, Indonesia. Del 19 al 23 de junio del 2006.

Springate-Baginski, O., M. Sarin, S. Ghosh, P. Dasgupta, I. Bose, A. Banerjee, K. Sarap, et al. 2009. Redressing 'historical injustice' through the Indian Forest Rights Act 2006: A historical institutional analysis of contemporary forest rights reform. Improving Institutions for Pro-Poor Growth (IPPG) Discussion Paper Series No. 29. Manchester, Reino Unido: University of Manchester. www.ippg.org.uk. 
Sundar, N. 2000. Unpacking the 'joint' in joint forest management. Development and Change 31: 255-279.

Utting, P. 2000. An overview of the potential and pitfalls of participatory conservation. En: Forest policy and politics in the Philippines: The dynamics of participatory conservation (ed. Utting, P.). Ciudad Quezón y Manila, Filipinas: Ateneo de Manila University Press e Instituto de Investigaciones de las Naciones Unidas para el Desarrollo Social (UNRISD).

Vandergeest, P. y N. Peluso. 1995. Territorialization and state power in Thailand. Theory and Society 24: 385-426. 


\title{
Condiciones que determinan la participación de los pequeños productores y las comunidades en los mercados de la madera en la América Latina tropicali
}

\author{
Pablo Pachecoii
}

\section{Resumen}

Las reformas de la tenencia forestal han otorgado derechos formales sobre tierras y recursos forestales a los pequeños productores y las comunidades. En este artículo se exponen las diversas formas en las que estos actores locales se relacionan con los mercados de la madera en el contexto de dichas reformas. Asimismo se sostiene que los beneficios económicos que las comunidades pueden obtener del uso de los recursos forestales, principalmente la madera, están influenciados por dos conjuntos de factores que no están directamente asociados con el proceso de reforma de la tenencia. El primer conjunto de factores se refiere a la capacidad de las comunidades para interactuar con otros actores —intermediarios y empresas - en los mercados de la madera y el segundo, a las condiciones específicas de evolución de dichos mercados. Las interacciones entre capacidad comunitaria y condiciones del mercado determinan las formas en las que los pequeños productores y las comunidades participan en los mercados de la madera, lo que influye en los beneficios que pueden obtener del uso comercial de sus bosques para madera. Este artículo se centra en las comunidades forestales que han obtenido derechos de tenencia legales en América Latina; específicamente cuatro comunidades situadas en áreas tropicales de Bolivia, Brasil y Nicaragua. Los tipos de participación analizados deberían ser tomados en cuenta por los decisores de políticas públicas para mejorar los resultados de las reformas de la tenencia forestal en los medios de vida de las poblaciones y en el manejo de los bosques.

\section{Introducción}

El manejo comunitario de los recursos forestales está considerado generalmente como un medio que permite reducir la pobreza y conservar los recursos forestales (Adán et al. 2004; Bray et al. 2005). Algunos autores sostienen que otorgar a los pequeńos productores y las comunidades derechos seguros sobre las tierras forestales conduciría a mejores resultados (Larson et al. 2010).

i Este artículo es una traducción del original, que apareció en inglés en la revista Conservation and Society, en la edición especial sobre Reformas de tenencia forestal (eds. Anne M. Larson y Ganga Ram Dahal). La cita original completa es: Pacheco, P. 2012 Smallholders and Communities in Timber Markets: Conditions Shaping Diverse Forms of Engagement in Tropical Latin America. Conservation and Society 10(2): 114-123. El artículo cuenta con una licencia de Creative Commons de Atribución 3.

ii Centro para la Investigación Forestal Internacional (CIFOR), Bogor, Indonesia - p.pacheco@cgiar.org. 
En teoría, estas reformas permitirían a los usuarios locales de los bosques aumentar los beneficios que obtienen del uso de los recursos forestales. No obstante, la situación no es tan sencilla, y otros autores han expresado reservas sobre si tales reformas pueden ser implementadas (Blaikie 2006; Pacheco 2007). En este artículo se analizan las diversas maneras en las que los pequeños productores y las comunidades interactúan con los mercados de la madera en el contexto de las reformas de la tenencia forestal. Estas interacciones explican principalmente el tipo de beneficios que los usuarios de los bosques obtienen de estos. Aunque los bosques proporcionan muchos usos de subsistencia para las comunidades, este artículo se centra en la madera porque constituye la principal fuente de ingresos monetarios que las comunidades obtienen de los bosques.

En este artículo se sostiene que los beneficios que los pequeños productores y las comunidades obtienen de la madera de sus bosques, en el contexto de las reformas de la tenencia forestal, dependen de su capacidad de relacionarse con los mercados de la madera y de las condiciones del mercado en las que se llevan a cabo sus transacciones. Es preciso examinar estos dos factores para comprender por qué el manejo forestal comunitario fracasa o triunfa a la hora de proporcionar medios de vida seguros a los usuarios locales al mismo tiempo que fomenta la conservación de los bosques. En la práctica, es probable que surja una de las dos situaciones siguientes. Por un lado, el acceso a los mercados de la madera puede ofrecer oportunidades a los pequeños productores y las comunidades para incrementar sus ganancias y, por otro, los mercados pueden transferir ingresos económicos provenientes del uso de recursos forestales a otros actores mejor posicionados en la cadena de valor (por ejemplo: comerciantes, intermediarios y procesadores de madera). Determinar las condiciones en las que se pueden producir estas dos situaciones tiene importantes implicaciones para las políticas.

El análisis de la participación de los pequeños productores y comunidades en los mercados de la madera se basa en cuatro casos de comunidades forestales en tres países en América Latina: el territorio indígena de la Región Autónoma del Atlántico del Norte (RAAN) en Nicaragua; las tierras comunitarias de la provincia de Guarayos en Santa Cruz (Bolivia); la zona de colonización de la Amazonia boliviana; y la reserva extractiva (RESEX) de la municipalidad de Porto de Moz en el estado de Pará (Brasil). Estos diferentes lugares han sido seleccionados como estudios de casos para asegurar una muestra variada de situaciones en América Latina con respecto a los procesos más significativos de reforma de la tenencia, como el reconocimiento de los derechos colectivos de tenencia de pueblos indígenas, la asignación de terrenos forestales a pequeños colonos mediante derechos de tenencia individuales y colectivos, y el reconocimiento de los derechos de los colonos tradicionales en reservas extractivas. Estos modelos de tenencia han sido documentados en otros estudios (Larson et al. 2008; Pacheco et al. 2008). Los cuatro estudios de casos son representativos de un mayor número de situaciones que se presentan en la América Latina tropical.

El objetivo de estos cuatro estudios es analizar situaciones diversas y contrastantes en términos de capacidad comunitaria y condiciones del mercado, con el fin de identificar situaciones representativas para proporcionar insumos a los debates de políticas sobre 
opciones para aumentar los beneficios de las comunidades y simultáneamente favorecer la conservación de los bosques. El análisis comparativo realizado aquí se basa en la revisión de literatura y en el trabajo de campo efectuado durante 2007 y 2008 . Las técnicas usadas para la toma de datos consistieron en grupos focales, entrevistas semiestructuradas con informantes clave y entrevistas en profundidad con operadores forestales.

Este artículo está organizado en cinco secciones, incluida esta introducción. La segunda sección hace un repaso de los análisis existentes sobre la forestería comunitaria y los mercados de la madera, y ofrece un marco analítico para comprender las interacciones de los pequeños productores y las comunidades con los mercados de la madera. A continuación, se presentan los cuatro estudios de casos y se describen los diferentes tipos de relaciones establecidas por los pequeños productores y las comunidades en los mercados de la madera, ya sean estables o esporádicas. En la cuarta sección se analizan los cuatro casos basándose en el marco analítico inicial y en una evaluación de las principales implicaciones. En la última sección se presentan las conclusiones principales del artículo.

\section{Marco analítico: Comunidades y mercados de la madera}

En líneas generales, algunos analistas perciben la relación con el mercado como una forma para resolver el estado de privaciones que a menudo padecen las comunidades forestales. No obstante, para lograr este propósito, éstas comunidades deben mejorar su capacidad de interacción con dichos mercados para poder competir eficazmente con otros actores e incrementar los beneficios de las transacciones comerciales. Esta perspectiva predomina en el debate actual sobre las interacciones entre comunidades y mercados forestales (Donovan et al. 2008a, b). Otros autores sugieren que la integración en el mercado no es la panacea para mejorar los medios de vida de los usuarios de los bosques, porque muchas comunidades no pueden acceder a las rentas económicas de sus bosques; en cambio, actores mejor posicionados en la cadena de valor, capturan la mayoría de los beneficios (Pokorny y Johnson 2008).

Es preciso considerar dos conjuntos de factores al evaluar cómo los pequeños productores y las comunidades interactúan con otros actores en los mercados de la madera. El primero está vinculado a la capacidad de los pequeños productores y las comunidades para competir en estos mercados y obtener beneficios de los mismos y el segundo, a las condiciones específicas de desarrollo del mercado de la madera.

En lo que respecta al primer grupo de factores, sobre la capacidad de pequeños productores y comunidades, usualmente se sugiere que que las comunidades pueden beneficiarse de los mercados solo si mejoran su posición competitiva frente a otros actores involucrados en la cadena de valor de la madera. Esto está vinculado a su capacidad para crear y gestionar empresas forestales, establecer relaciones de confianza duraderas con los compradores, procesar productos para suministrar al mercado y así acceder al capital financiero (Donovan et al. 2008b). Otros factores importantes están relacionados con el acceso a mercados e información sobre sus condiciones, su capacidad y experiencia para negociar en dichos mercados (Macqueen 2008). 
La capacidad de comercialización depende del nivel de organización y la capacidad de gestión de los pequeños productores y las comunidades. Un supuesto frecuente es que estos actores locales pueden aumentar sus beneficios únicamente a través de la agregación de valor, lo que implica avanzar en la integración vertical de las actividades de producción y procesamiento (Donovan et al. 2006). No obstante, no siempre la integración vertical proporciona una mayor competitividad en el mercado, en el sentido de que las empresas más integradas son más competitivas y por lo tanto obtienen mayores beneficios. Antinori y Bray (2005), al evaluar la forestería comunitaria en Oaxaca (México), encontraron márgenes de beneficio bruto relativamente altos en cuatro grupos diferenciados por nivel de integración (madera en pie, madera en rollo, madera aserrada y productos terminados). Curiosamente, las empresas comunitarias dedicadas al procesamiento de madera en rollo obtuvieron más beneficios que las que trabajaban con productos terminados, aunque los autores sugieren que, a la larga, el segundo grupo tenderá a obtener mayores ingresos.

El segundo grupo de factores está relacionado con las estructuras de mercado y los factores que las determinan, por lo que el debate se centra en comprender cuáles serían las condiciones del mercado que podrían favorecer mejor a las comunidades. Molnar et al. (2007) señalan que el comercio forestal mundial está dominado por grandes empresas multinacionales, y que los productores locales de madera, en el nivel global, están cada vez más forzados a competir con productores de grandes volúmenes a bajo costo. No obstante, la creciente importancia de los mercados nacionales tiende a favorecer a los pequeńos productores y las comunidades que llevan a cabo operaciones forestales de pequeña escala y, a menudo, baja intensidad. Estos autores sugieren que la mencionada tendencia puede continuar a futuro, ya que los productores nacionales cuentan con la ventaja competitiva de menores costos de transporte y suficiente flexibilidad de suministro para satisfacer la demanda de los mercados domésticos de la madera.

Adicionalmente, las regulaciones forestales también influyen sobre las condiciones del mercado. Esto se debe a que ellas afectan las relaciones entre las comunidades y los mercados incidiendo en los costos de transacción para que los pequeños productores y las comunidades lleguen al mercado —a menudo incrementándolos — o a que dichas regulaciones imponen obstáculos directos a la participación en el mercado (Kaimowitz 2003). Esto ha conducido a argumentos que sostienen la importancia de equilibrar las relaciones entre actores de modo que los pequeños productores y las comunidades puedan competir en mejores condiciones en los mercados de la madera, así como a suprimir los obstáculos institucionales a los que se enfrentan. Las condiciones que favorecerían a los pequeńos productores y las comunidades son normas con costos bajos para su implementación tanto en la extracción, transporte y comercialización (Scherr et al. 2004). Debido a los altos costos de transacción de las normativas forestales, los pequeños productores y las comunidades que no pueden cubrir los costos para implementar las normas, están forzados a vincularse de forma informal con los mercados, muchas veces quebrando la normativa forestal vigente.

Por lo tanto, una perspectiva adicional tiene que ver con las relaciones entre los pequeńos productores y las comunidades y los mercados que operan al margen de 
las regulaciones forestales, relaciones denominadas informales o ilegales, refiriéndose las primeras a prácticas dentro del ámbito de la ley pero no reguladas y las segundas a prácticas que contravienen normas forestales específicas (Pacheco et al. 2008). Las causas del aprovechamiento ilegal de la madera han sido analizadas en otros trabajos (Contreras 2005). El aprovechamiento ilegal de madera tiene importantes consecuencias en el funcionamiento del mercado. Aunque el aprovechamiento ilegal contribuye a distorsionar los mercados de la madera ya que usualmente tiende a reducir el precio de la madera, muchas personas, incluyendo individuos con pocos recursos obtienen ingresos del aprovechamiento y los consumidores también pueden beneficiarse de precios más bajos (Taconni 2007). No obstante, en los mercados informales las relaciones suelen ser más asimétricas, por lo que a menudo los pequeños productores y las comunidades que venden su madera en estos mercados suelen obtener precios comparativamente menores (Pacheco et al. 2008). Las implicaciones ambientales del aprovechamiento ilegal son ambiguas, aunque es probable que las personas con acceso más reducido a los mercados y con menos capital destruyan mucho menos bosque que los grupos con más recursos, simplemente porque tienen menos oportunidades y capital para hacerlo (Taconni 2007).

En resumen, para evaluar las interacciones de los pequeños productores y las comunidades con los mercados se requiere examinar dos grupos de factores: la capacidad de los pequeños productores y comunidades y las condiciones del mercado, las que a su vez están determinados por varios otros factores. Los principales factores que determinan la capacidad de la comunidad para relacionarse con los mercados son: el acceso al mercado, el poder de negociación, el conocimiento de las dinámicas del mercado y la capacidad organizativa; algunos de estos factores pueden fortalecerse mediante la asistencia de organizaciones externas. Los factores que inciden en el desarrollo de las condiciones del mercado comprenden la distorsión de precios, la información incompleta debido a relaciones asimétricas y las regulaciones estatales de los mercados. Las interacciones entre estos dos grupos de factores determinan hasta cierto punto lo que denomino "formas de participación en el mercado" y si las relaciones de los usuarios locales del bosque con el mercado son estables o esporádicas.

Las condiciones que definen la capacidad de la comunidad para interactuar con los mercados son bastante diversas. En particular, la localización tiene gran influencia en las interacciones de la comunidad con los mercados, no solo en términos de distancia geográfica, sino también respecto a las redes del mercado. El hecho bastante obvio de que las comunidades más próximas a las ciudades tienden a depender más de ingresos en efectivo y, por consiguiente, están más fuertemente articuladas con los mercados, tiene importantes implicaciones para los bosques ya que aumenta la presión de los compradores, lo que provoca, a su vez, mayor demanda local y mercados más transparentes. La ubicación también puede generar presiones adicionales sobre los bosques y, como resultado, tiende a ocasionar una mayor degradación forestal.

La fortaleza de la organización de las comunidades, influenciada hasta cierto punto por el apoyo externo para desarrollar sus capacidades, incide en el poder de negociación que tienen respecto a otros actores que intervienen en la cadena de la madera. Algunas 
comunidades, sobre todo las de pueblos indígenas, probablemente como resultado de la influencia externa de donantes, han sido capaces de crear empresas forestales comunitarias para realizar operaciones de explotación comercial, aunque con diversos grados de éxito. No obstante, en la mayoría de los casos las comunidades no han logrado avanzar en la cadena de valor y por eso usualmente se mantienen como proveedores de madera en rollo. Los pequeños productores o usuarios del bosque que no pertenecen a una organización comercial generalmente mantienen relaciones precarias con los mercados madereros.

Las condiciones que definen el desarrollo del mercado están estrechamente vinculadas a problemas estructurales que afectan a los mercados de la madera. Por ejemplo, el sector industrial maderero, que mantiene sólidos vínculos con algunos propietarios e intermediarios de aserraderos locales, tiende a influir a menudo en los precios finales pagados por la madera a los pequeños productores y las comunidades. En muchos casos, los mercados madereros están dominados por unos pocos compradores, que influyen en el precio final. En otros casos, la presencia de gran cantidad de compradores mejora la competencia por la madera. Con frecuencia el acceso a información es sumamente asimétrico, ya que los intermediarios y procesadores disponen de más información que los pequeños productores y las comunidades. Las regulaciones también influyen sobre las condiciones del mercado. Son frecuentes las normas que restringen el manejo de los recursos forestales por parte de pequeńos productores y comunidades y afectan indirectamente su participación al imponer costos de transacción relativamente altos. No obstante, las normas que inciden de forma directa en los mercados forestales, ya sea mediante cuotas o precios de la madera, no son frecuentes ya que la mayoría de los mercados suelen estar poco regulados o desregulados.

\section{Cuatro estudios de casos en la América Latina tropical}

Cuatro estudios de casos han sido seleccionados para evaluar las capacidades de las comunidades, el desarrollo del mercado y las formas de participación en el mercado. En dos de los casos, las comunidades indígenas manejan sus bosques con fines comerciales: Layasiksa en la RAAN de Nicaragua, donde las comunidades indígenas cuentan con derechos de tenencia consolidados sobre los recursos forestales, y Cururú en Guarayos, en el departamento de Santa Cruz (Bolivia), donde la comunidad ha consolidado sus derechos sobre los recursos forestales en un contexto más amplio de intereses en conflicto no resueltos. En ambos casos, las relaciones con el mercado están mediadas por una empresa forestal comunitaria que gestiona las actividades a lo largo de la cadena de valor, desde la tala hasta el procesamiento y la comercialización de la madera. Los otros dos casos son representativos de situaciones en las que los pequeños productores toman decisiones individuales con respecto a sus bosques: Iturralde, en el departamento de La Paz (Bolivia), donde predomina el acceso individual a las zonas boscosas; y la RESEX de Porto de Moz, en el estado de Pará (Brasil). Las principales características de los cuatro casos se resumen en el Cuadro 1. 


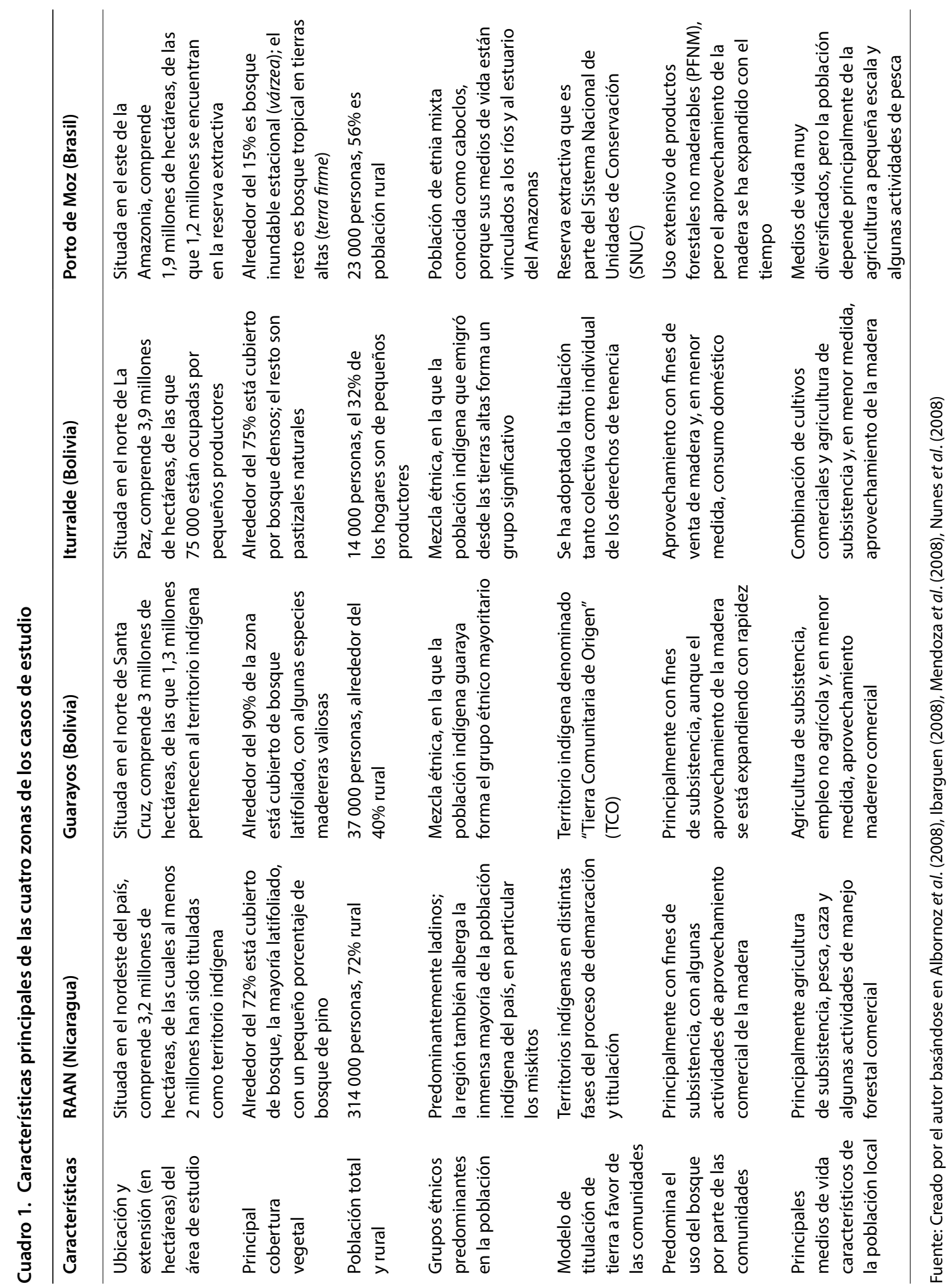




\section{La comunidad de Layasiksa de la Región Autónoma del Atlántico Norte, Nicaragua}

Las comunidades indígenas y étnicas de las regiones autónomas de la costa caribeña de Nicaragua están obteniendo gradualmente títulos formales de sus bosques y otras tierras tradicionales. Una ley del 2002 garantizó el reconocimiento formal de los derechos de las comunidades indígenas, pero el interés real de titular los territorios indígenas solo surgió cinco años más tarde, con la vuelta al poder del partido Sandinista. No obstante, la titulación ha sido lenta. Layasiksa es una de las comunidades que solicitó y logró en 1996 el reconocimiento formal de parte del territorio reclamado (35 $000 \mathrm{ha}$ ), pero pasaron varios ańos antes de que la comunidad consiguiera hacer valer sus derechos de exclusividad sobre esa zona (Larson 2008). Layasiksa ha creado su propia empresa comunitaria, Kiwatingni, para llevar a cabo sus operaciones de manejo forestal.

La comunidad elaboró dos planes de manejo forestal para bosques caducifolios y certificó sus operaciones forestales con la ayuda de donantes. Algunos técnicos del Fondo Mundial para la Naturaleza (WWF, por sus siglas en inglés), que ayudó a Kiwatingni, ha fundado su propia empresa, Masangni, que juega un importante papel en la contratación, la supervisión y la capacitación de la comunidad. Kiwatingni contrata, por medio de Masangni, los servicios de un técnico forestal para elaborar y supervisar el plan operativo anual. Kiwatingni ha diversificado relativamente las operaciones forestales, que van desde la extracción hasta la producción de madera aserrada. Un plan de manejo (que abarca 4950 ha) corresponde a una concesión de 10 años a la empresa Prada S.A., que posee un aserradero en la municipalidad vecina, y el otro (que abarca 4664 ha) es gestionado por Kiwatingni (Argüello 2008).

La concesión a Prada S.A. comprende la venta de madera en pie, que se vende a 6 USD/ $\mathrm{m}^{3}$. Dado que la comunidad firmó el contrato en el 2002 sin ninguna disposición para renegociar el precio durante el plazo de 10 ańos, se vio obligada a vender a este precio a pesar del aumento del precio de la madera, hasta que Prada S.A. aceptó pagar 7 USD/ $\mathrm{m}^{3}$ por la madera extraída en el 2008 (Larson et al. 2008). La comunidad no participa en ninguna de las decisiones sobre el aprovechamiento, que han sido cedidas por completo a la empresa. Por lo tanto, las actividades de la comunidad se concentran en la segunda zona, donde Kiwatingni toma todas las decisiones con respecto a la elección de las especies, las técnicas de cosecha, los porcentajes que se venden como troncos o como madera aserrada, etcétera. Kiwatingni no posee maquinaria pesada ni aserraderos, sino que los alquila y supervisa minuciosamente a los proveedores de servicios de saca, transporte y aserrado de la madera (Larson y Mendoza 2008).

Toda la madera en rollo es vendida a Prada S.A, pese a que esta empresa paga un precio ligeramente menor por tronco que otros compradores. No obstante, ella paga en efectivo al tiempo de la entrega de la madera, es menos estricta sobre la calidad y compra también otras especies menos valiosas, ya que su principal producto es la madera contrachapada. Asimismo, suministra todo el combustible requerido para las operaciones de Kiwatingni (Argüello 2008). De este modo, las operaciones de la comunidad dependen mucho de Prada S.A. Layasiksa también contrata servicios para producir su madera aserrada 
y siempre ha trabajado con el mismo aserradero a pesar de la presencia de varios aserraderos portátiles en la localidad. La mayoría de los compradores se encuentran en Managua, la capital de Nicaragua. La comunidad contrata a camioneros locales para transportar madera a Managua según su necesidad (Argüello 2008) y trata directamente con los clientes, en lugar de con los comerciantes. Masangni juega un papel central en la comercialización ayudando a negociar precios, promoviendo el uso de especies menos conocidas y ejerciendo presiones políticas a favor del uso de madera certificada.

En el 2007, Kiwatingni obtuvo beneficios de unos 17500 USD, o el 9\%, una cifra baja comparada con empresas similares. Este importe incluye los costos de capacitación y asistencia técnica entendidos como costos de producción, que Masangni realmente cubrió. Según la contabilidad de la comunidad, que excluye estos costos, las ganancias fueron de unos 30000 USD (Larson y Mendoza 2008). Al mismo tiempo, la comunidad ingresó casi 22000 USD en concepto de salarios, lo que en general significa que alrededor de 0,43 USD de cada dólar generado en la cadena, de la planificación a la venta, retornó a la comunidad (Argüello 2008).

\section{Empresas forestales comunitarias en Guarayos, Bolivia}

La provincia boliviana de Guarayos, en el departamento de Santa Cruz, alberga a la población indígena guaraya y constituye una frontera forestal que cambia rápidamente. En 1996, este grupo indígena presentó una reivindicación territorial al Gobierno sobre 2,2 millones de hectáreas; ya se ha titulado una superficie total de un millón de hectáreas (Albornoz et al. 2008). La superficie restante está experimentando una intensa presión por parte de propietarios grandes y medianos, quienes también demandan derechos de tenencia claros para sus operaciones agrícolas y ganaderas. En 1996, una ley inició un proceso de regularización de la tierra para aclarar los derechos de tenencia de las reclamaciones de tierras indígenas, así como las de productores individuales situados dentro de las tierras reivindicadas. Además, alrededor de 562000 ha de bosques productivos fueron otorgadas en concesiones a 11 empresas madereras tras la aprobación de la Ley Forestal en 1996 (Vallejos 1998). La proximidad de Guarayos a una carretera pavimentada que conecta las ciudades de Santa Cruz y Trinidad — centros urbanos de las tierras bajas bolivianas — ha incrementado el interés en los recursos forestales de la zona.

Las comunidades indígenas procuraron elaborar planes de manejo forestal como una estrategia para consolidar la ocupación de áreas forestales que no estaban ocupadas y que terceras personas podían considerar como disponibles. Del 2000 al 2004, seis grupos indígenas obtuvieron la aprobación de planes de manejo de bosques situados alrededor de sus comunidades y crearon empresas forestales comunitarias, a menudo con la ayuda de proyectos forestales y organizaciones no gubernamentales (ONG). Un total de 211178 ha de bosque fueron asignadas a planes de manejo, con planes individuales que iban desde 2433 ha a 60000 ha (Albornoz et al. 2008). Aunque la mayoría de estas comunidades ha tenido dificultades para ejecutar sus planes de manejo forestal, la comunidad de Cururú es una de las pocas que ha sido capaz de llevar a cabo sus operaciones forestales, y la mayor parte de las otras comunidades ha operado informalmente en los mercados de la madera. 
En el 2001 la comunidad de Cururú formó la Asociación Indígena Maderera Cururú, como parte de una estrategia de apoyo comunitario desarrollada por un proyecto forestal financiado por la Agencia de los Estados Unidos para el Desarrollo Internacional y llamado Proyecto de Manejo Forestal Sostenible Bolivia (más conocido como BOLFOR), y otras ONG. La comunidad consta de unas 40 familias, que reservaron una extensión de 26420 ha para el manejo forestal (Albornoz et al. 2008). El plan de manejo forestal fue aprobado en el 2002, con un ciclo de corta de 30 años. Desde entonces, la asociación maderera ha realizado operaciones forestales anualmente; para el año 2009, estas constituían la actividad económica más importante de la comunidad. Adicionalmente, en el 2007, Cururú logró certificar sus operaciones forestales con el Consejo de Manejo Forestal (FSC), aunque esto solo fue posible gracias al apoyo financiero de donantes externos y de las empresas madereras que compran madera en rollo a la comunidad y que ya han certificado sus propias cadenas de custodia (Rozo y Moreno 2007).

En el 2002, la asociación comercializó seis especies y vendió un total de $1030 \mathrm{~m}^{3}$. En el 2003, vendió madera en rollo a las empresas SOBOLMA y Monteverde. Desde el 2006, ha aumentado su cartera de compradores al incluir las principales empresas de la zona: INKA Parket, La Chonta y CIMAL (Albornoz et al. 2008). CIMAL suscribió un contrato de cinco años con la asociación maderera, con negociación anual de precios y volúmenes. Esta expansión ha conducido a un significativo incremento de las ganancias procedentes del aprovechamiento de la madera. En el 2002 la comunidad obtuvo un beneficio de 14900 USD; que se convirtieron en más del doble en el 2007, llegando a alrededor de 34500 USD y generando un considerable flujo de ingresos para las familias involucradas de unos 1014 USD por familia (BOLFOR II 2007).

El flujo de ingresos de la madera ha tenido importantes repercusiones en la economía de la comunidad. Los medios de vida de la población han pasado a depender de la agricultura de subsistencia y el trabajado asalariado no agrícola a las actividades económicas forestales, lo que permite a los jóvenes permanecer en la zona en lugar de migrar estacionalmente para trabajar fuera de la comunidad. No obstante, han surgido tensiones entre los miembros de la comunidad con respecto a la distribución de los beneficios del plan de manejo. Los ingresos son esporádicos, con frecuencia los pagos de efectivo solo se hacen en los meses siguientes a la cosecha anual, a veces con cierta demora. Además, se han producido tensiones entre familias de líderes (quienes invirtieron más y, por lo tanto, ganan más con el proyecto) y sus vecinos (Albornoz et al. 2008).

\section{Colonos de Iturralde, en el norte de La Paz, Bolivia}

Iturralde, una provincia al norte de La Paz, en Bolivia, cuenta con una importante cobertura forestal. Está relativamente distante del principal centro de consumo en la ciudad de La Paz, aunque recientes mejoras de la infraestructura viaria han mejorado los flujos comerciales de la región. En esta provincia el aprovechamiento forestal es intenso, y mucha madera se extrae de modo informal. La extracción de madera se lleva a cabo en pequeñas parcelas de colonos que empezaron a migrar a la zona pocos años atrás. Desde mediados de la década del 2000, la agencia estatal de tierras, el Instituto Nacional de 
Reforma Agraria (INRA), ha ido ejecutando un proceso de regularización de tierras de parcelas individuales, aunque hasta la fecha ha privilegiado la titulación colectiva, ya que el proceso es menos costoso y requiere menos tiempo.

En la provincia de Iturralde, unas 900 familias de colonos (alrededor de 4500 personas) ocupan una extensión total de 75000 ha en régimen de propiedad individual y colectiva. La expansión de los asentamientos de pequeños colonos en la región ha llevado inevitablemente al aumento de las actividades madereras, a pesar de que la mayoría recibió o se asentó informalmente, parcelas de 50 ha destinadas a actividades agrícolas. Los pequeños colonos rara vez obtienen los planes de manejo forestal requeridos que, en teoría, les otorgarían el derecho legal a usar la madera de sus bosques. No obstante, incluso si estuvieran dispuestos a pagar para elaborar dichos planes, la mayor parte de ellos no podría hacerlo porque no poseen derechos formales de propiedad sobre la tierra que ocupan (Pacheco et al. 2008). Algunos pequeños productores extraen los árboles de sus parcelas individuales; a menudo, los que han agotado la madera valiosa localizada en sus propias parcelas tienden a extraer madera de tierras públicas, incluyendo áreas protegidas como el vecino Parque Nacional Madidi (creado a mediados de la década de los noventa).

Las empresas madereras y las asociaciones de pequeños usuarios de los bosques, ambas con acceso a concesiones forestales en la zona, también suministran madera. Está creciendo la cantidad de aserraderos en la region, algunos de los cuales son operados por grandes empresas madereras. Aproximadamente una quinta parte de los permisos de aprovechamiento forestal de la zona han sido otorgados en asentamientos de colonización, mientras que el resto se han otorgado en bosques en concesión y en propiedades de gran tamaño (Ibarguen 2008). La madera se suministra a varios cientos de pequeños aserraderos y carpinterías, así como a unas cuantas plantas procesadoras de madera ubicadas en su mayoría en la ciudad más importante, La Paz (Solares 2008). Ibarguen (2008) sugiere que las actividades de aprovechamiento de la madera, tanto las ganancias de la venta de árboles como el trabajo asalariado, constituyen una importante fuente de ingresos para los pequeños productores, que complementan los obtenidos en la agricultura. No obstante, los ingresos provenientes de la extracción maderera varían mucho de unos colonos a otros.

La mayoría de la madera extraída procede de áreas sin permisos legales y es vendida a comerciantes locales, quienes la envían a la ciudad de La Paz. El comercio de madera ilegal tiene lugar a lo largo de toda la cadena de valor, desde la extracción hasta el transporte y el procesamiento final. Muchas empresas madereras que operan legalmente en concesiones forestales compran madera ilegal, al igual que lo hacen comerciantes locales que pueden ser financiados por compañías procesadoras de escala mediana o agencias de exportación de madera radicadas en la capital. Los pequeños productores constituyen solo una pequeña parte de esta intrincada red. En algunos casos, los madereros locales financian la formulación de planes de manejo forestal en tierras comunitarias, pero solo los utilizan para obtener permisos de aprovechamiento forestal que luego venden, una actividad más productiva que las propias actividades forestales en sí. Según Ibarguen (2008), siete 
comerciantes de la provincia de Iturralde tienen capacidad para adelantar dinero que financie las operaciones forestales, la maquinaria para la extracción y el transporte, y la información necesaria sobre los compradores, así como las mejores formas de evitar los puntos de control de la agencia forestal. Con frecuencia estos comerciantes movilizan recursos que promueven la tala ilegal dentro del Parque Nacional Madidi y otros bosques públicos.

Las cifras disponibles sugieren que la extracción ilegal de madera en terrenos públicos es más rentable que el aprovechamiento forestal legal en las parcelas de pequeńos productores. Las ganancias de los pequeños productores dependen de las especies y del volumen, así como de la capacidad de negociar. Según Ibarguen (2008), la ganancia media del manejo forestal en una parcela de 35 ha es de unos $8 \mathrm{USD} / \mathrm{m}^{3}$, lo que hace un total de $2800 \mathrm{USD}$ en una cosecha de $350 \mathrm{~m}^{3}$. Sin embargo, los beneficios del aprovechamiento ilegal de la caoba llegan a $165 \mathrm{USD} / \mathrm{m}^{3}$. Debido a la mayor disponibilidad de caoba —agotada en los demás lugares - los pequeños productores pueden obtener más dinero a través de su extracción de las áreas protegidas nacionales.

\section{Comunidades tradicionales en Porto de Moz, Brasil}

La municipalidad de Porto de Moz, en el curso inferior del río Xingu, al norte del estado de Pará (Brasil), ha sido ocupada por pequeños productores tradicionales que se asentaron en la zona a lo largo de varios procesos migratorios vinculados a la expansión de las actividades extractivas en la Amazonia, principalmente caucho (Nunes et al. 2008). Las operaciones madereras que empezaron en los años setenta se intensificaron en las décadas de los ochenta y noventa, cuando Porto de Moz fue ocupado por grandes empresas madereras interesadas en extraer especies de alto valor comercial; esto provocó varios conflictos de tierras con las comunidades (Moreira y Hébette 2003). Un movimiento de amplia base que reunía a comunidades residentes y ONG ambientales consiguió atraer la atención a la zona y, en el 2004, el Gobierno federal creó la reserva extractiva (RESEX) Verde para Sempre (Nunes et al. 2008).

La RESEX obligó a salir a las empresas madereras que trabajaban en la reserva y otorgó derechos colectivos de tenencia de tierra, con algunas restricciones, a los pequeños productores que residían en ella. Los pequeños productores pudieron mantener sus derechos familiares de hecho. La creación de la RESEX tuvo como consecuencia la reestructuración de los mercados de madera locales, ya que los madereros de la localidad asumieron el rol de promoción del aprovechamiento forestal que anteriormente tenían las empresas madereras. Como los madereros lograron más poder político, crecieron los mercados informales de madera, suministrando madera a los aserraderos de la zona y a Belém, la capital del estado de Pará (Nunes et al. 2008). De esta manera, las redes informales existentes siguieron operando pero con distintas fuentes de capital financiero. Las empresas madereras desplazaron la presión del aprovechamiento a la parte este de la reserva, tanto a tierras comunitarias como a bosques públicos, particularmente hacia el Bosque Nacional de Caxiuanã (Nunes et al. 2008). 
Para realizar operaciones forestales en la RESEX, se exigió a las comunidades que formularan un plan para el desarrollo sostenible de toda la reserva, pero dichos planes tardaban varios años en ser aprobados, y las comunidades no pudieron elaborar planes para el manejo de la madera. No obstante, esta incapacidad no evitó el aprovechamiento informal de madera; por el contrario, la extracción en tierras comunitarias al este de la RESEX se intensificó debido a las crecientes presiones de madereros e intermediarios. Los pequeños productores son abordados por aserradores locales interesados en unos pocos árboles valiosos; los aserradores son financiados por comerciantes, quienes también pagan a los productores de camiones forestales (bufeteiros). Porto de Moz tiene tres comerciantes locales de madera en rollo y otros tres interesados en madera aserrada. También es posible encontrar compradores en municipalidades vecinas. Los tres grandes aserraderos que trabajan en la zona suelen comerciar con compradores locales, pero también utilizan sus propias redes para asegurarse el suministro de madera.

No se dispone de información sobre la cantidad de madera vendida en Porto de Moz, pero Nunes et al. (2008) aportan cifras de los costos y beneficios de las operaciones informales de aprovechamiento de madera. Con frecuencia los pequeños productores venden solo árboles en pie, a 13 USD cada uno, porque no pueden hacer frente a los costos de extracción de la madera como combustible, mano de obra y maquinaria. Un operador de motosierra gana unos 70 USD por cortar y vender un árbol al intermediario de la zona. El precio de venta aumenta a más de 200 USD por árbol cuando se transforma y se vende como tablones. Los pequeños productores tienen poco margen de negociación de precios. Los aserradores pueden negociar precios con los comerciantes, pero dependen de anticipos de efectivo de esos mismos comerciantes para sus propias actividades forestales, un factor que limita su poder de negociación.

\section{Análisis: Condiciones que determinan las formas de participación en el mercado}

No hay una respuesta sencilla en relación a cuáles son los factores que influyen en los beneficios que los usuarios locales obtienen provenientes de la madera de sus bosques. En el Cuadro 2 se presentan los factores que definen la participación de la comunidad en los mercados en los cuatro estudios de caso. El primer conjunto de factores define la capacidad de una comunidad para participar en los mercados de la madera, el segundo conjunto de factores define las condiciones de desarrollo del mercado, y las interacciones entre los dos determinan las formas de participación en el mercado. Este análisis muestra que existe una diversidad significativa en las diversas formas a través de las cuales los pequeños productores y las comunidades interactúan con los mercados.

Los beneficios — medidos en ingresos monetarios - que los pequeños productores y las comunidades obtienen del aprovechamiento de la madera varían considerablemente de una zona a otra. El beneficio neto estimado es de unos 30000 USD en Layasiksa y 34500 USD en Cururú; los ingresos por familia ascienden a 177 y 1014 USD, 


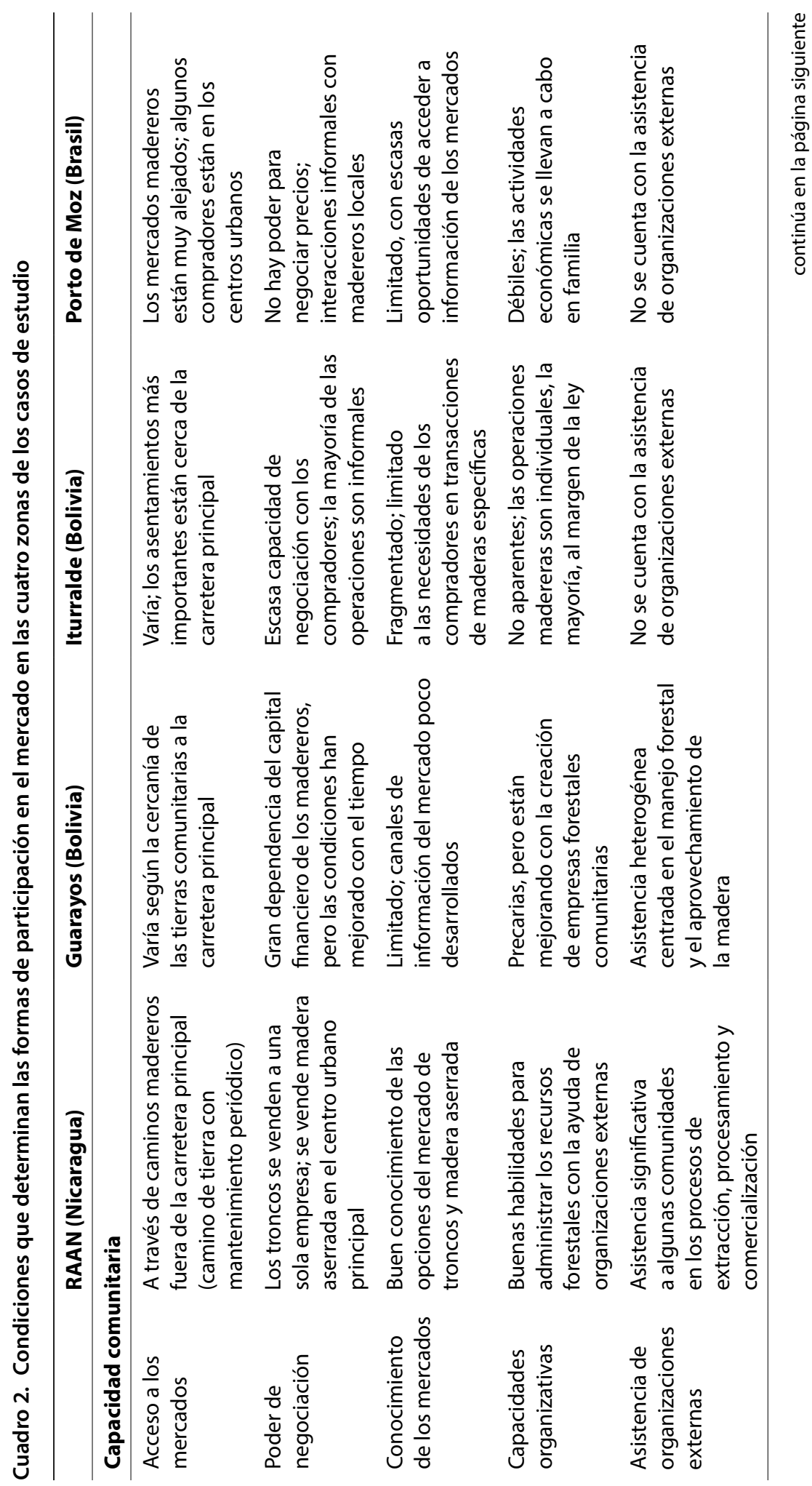




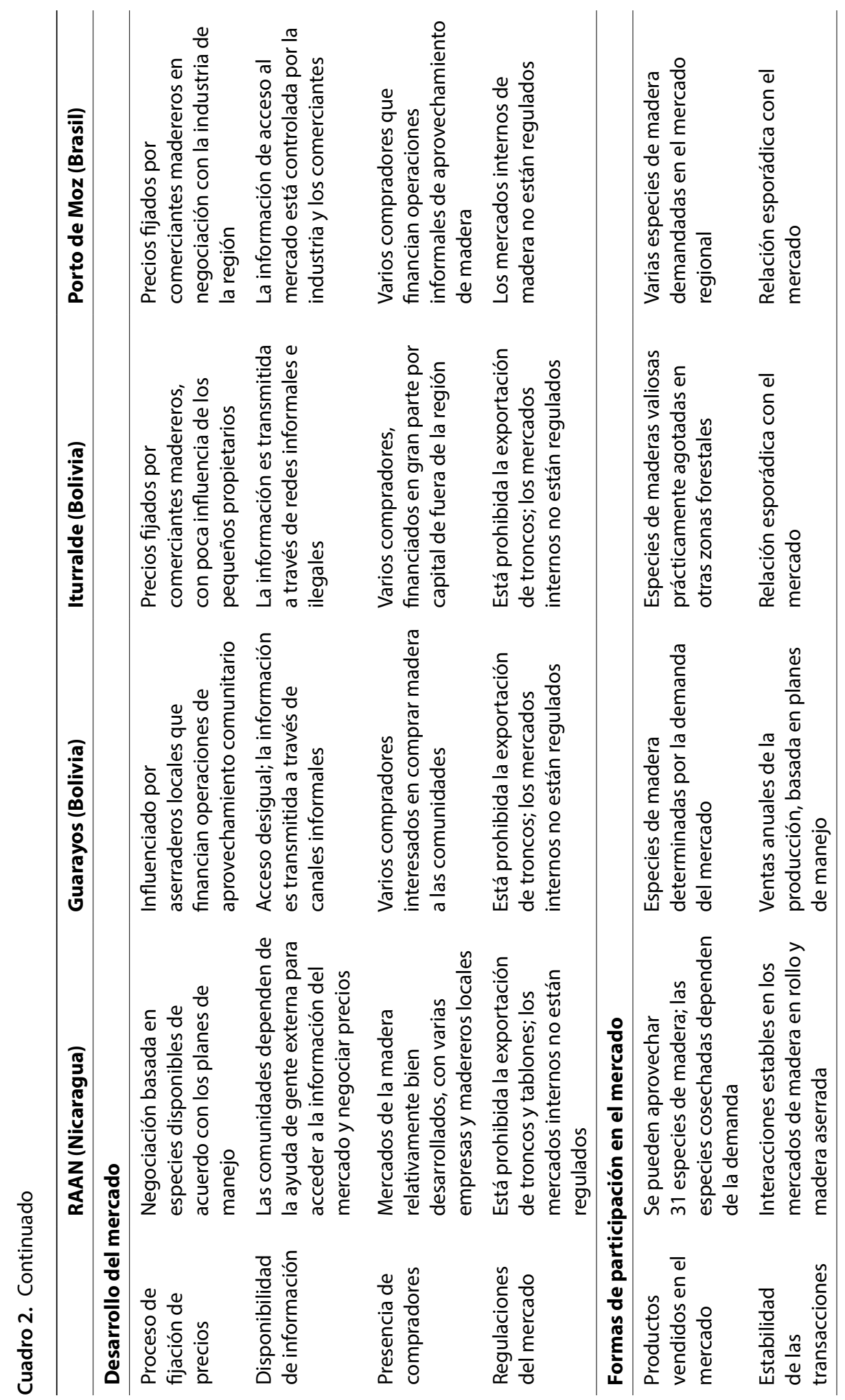


respectivamente (Albornoz et al. 2008; Argüello 2008). Por su parte, un pequeño productor del norte paceño puede obtener alrededor de 2800 USD netos por extraer árboles valiosos de un lote de 35 ha (Ibarguen 2008) y, en Porto de Moz, los aserradores pueden tener unos ingresos mensuales de 1000 USD por convertir cinco árboles en tablones (Nunes et al. 2008). Aunque los miembros de las empresas comunitarias obtienen menos ingresos anuales de la extracción legal de madera comercial en comparación con lo que podrían obtener mediante operaciones madereras ilegales, pueden contar con un ingreso regular durante muchos ańos. Por el contrario, los pequeños productores que trabajan individualmente a menudo reciben grandes sumas por los árboles valiosos extraídos de sus parcelas, pero a través de un pago único, y los árboles más valiosos tienden a ser agotados.

Los estudios de casos indican que solo las comunidades de territorios indígenas, de la RAAN y Guarayos, que han recibido asistencia externa para ejecutar sus planes de manejo forestal y para procesar y comercializar su madera, han sido capaces de obtener flujos monetarios significativos durante un período largo de tiempo. Esto contrasta con los pequeños productores y aserradores, cuyos ingresos por la madera están más concentrados en períodos más breves. Muchas otras comunidades de los mismos territorios se enfrentan a varias restricciones para ejecutar sus operaciones forestales. En todos los casos analizados aquí, los usuarios locales de los bosques tienen un poder de negociación limitado; este es incluso menor en los mercados informales, en los que la desventaja se agrava por el escaso conocimiento del funcionamiento de los mercados de la madera, limitando así las opciones que los pequeńos productores y comunidades tienen al negociar con madereros y comerciantes.

Con frecuencia, el acceso a los mercados está muy relacionado con el poder de negociación. Los pequeños productores y las comunidades de lugares remotos, como el norte de La Paz y Porto de Moz, tienen escaso poder de negociación en los mercados y pocas oportunidades de adquirir información o participar periódicamente en los mercados madereros; esto los hace mucho más dependientes de los comerciantes que operan de manera informal. Otro factor significativo que determina las interacciones con el mercado es la capacidad organizativa de los usuarios de bosques. Por ejemplo, las comunidades indígenas de la RAAN y Guarayos, que llevan a cabo sus operaciones de aprovechamiento y comercialización de madera de forma colectiva, con frecuencia a través de empresas forestales comunitarias, tienen más probabilidades de hacer negocios más ventajosos que los pequeńos productores del norte de La Paz y Porto de Moz, cuya falta de acceso colectivo a los bosques incrementa su propensión a agotar la madera valiosa de sus parcelas individuales.

Es evidente que las empresas forestales comunitarias orientadas a la extracción comercial de madera han ayudado a algunas comunidades a establecer relaciones más formales y duraderas con los mercados de la madera, proporcionando con ello una fuente regular de ingresos provenientes del aprovechamiento. En los casos analizados en este estudio, los pequeńos productores y las comunidades no han podido avanzar en la cadena de valor; suelen permanecer como proveedores de madera en rollo, lo que merma su capacidad para negociar con los comerciantes y los propietarios de aserraderos. No obstante, al participar 
en el mercado, las empresas comunitarias mejoran gradualmente sus habilidades de negociación para cerrar tratos con compradores, contratar proveedores de servicios y negociar con funcionarios del Gobierno. En muchos casos, con la aprobación de un plan de manejo forestal, que es el primer paso del manejo forestal formal, la empresa comunitaria puede establecer relaciones permanentes con el mercado. Sin embargo, para beneficiarse de los mercados, las comunidades primero deben superar exigencias legales, obtener recursos financieros y mejorar su contabilidad y sus habilidades de comercialización. Para hacerlo, a menudo necesitan la ayuda de actores externos, como las ONG. La mayoría de los pequeńos productores no han sido capaces de crear organizaciones comerciales, y sus vínculos con los mercados siguen siendo precarios.

En cuanto a los factores que definen el desarrollo del mercado, los pequeños productores y las comunidades obtendrían mayores beneficios si pudieran vender sus productos en mercados más competitivos y con condiciones más transparentes que las actuales. En la mayor parte de los estudios de casos evaluados, los mercados de la madera se caracterizan por una relativa presencia de compradores; no obstante, a excepción de la RAAN, el establecimiento de precios no es transparente porque los pequeños productores y las comunidades suelen depender de unos pocos compradores, quienes con frecuencia adelantan capital a los usuarios de los bosques para financiar sus operaciones forestales. Por ello, la mayoría de las comunidades indígenas, como en el caso de la RAAN y Guarayos, están obligadas a aceptar los precios y a menudo dependen de los comerciantes y las empresas madereras, que tienen mejores vínculos con los mercados que se encuentran más adelante en la cadena. La venta de madera aserrada reduciría los costos de transporte y simplificaría el acceso a mercados más remotos en los que los vendedores podrían llegar a acuerdos más atractivos, pero no todas las empresas comunitarias pueden gestionar sus propios aserraderos. Como solución tecnológica alternativa, algunos pequeños productores operan en mercados informales usando motosierras para producir tablones, por los que con frecuencia reciben precios más altos en el mercado. No hay suficiente evidencia empírica sobre la repercusión de la extracción y el aserrado de madera a pequeña escala en la condición del bosque, pero puede ser muy variable. La evaluación de estos impactos, influenciados por las interacciones con el mercado, queda fuera del ámbito de este artículo.

En síntesis, la capacidad comunitaria y las condiciones del mercado definen las formas de relación con el mercado. De las cuatro zonas, las dos con comunidades indígenas han sido capaces de mantener interacciones estables en los mercados de madera en rollo y madera aserrada. No obstante, esto solo se aplica a las comunidades que obtuvieron asistencia externa para aplicar los planes de manejo forestal, crear empresas forestales comunitarias y participar en los mercados. Por el contrario, la mayoría de las comunidades no han podido superar los obstáculos legales y económicos para el manejo forestal comercial. Los pequeños productores de Iturralde y Porto de Moz solo tienen una relación esporádica con los mercados a través de la madera que extraen dentro o fuera de sus parcelas individuales o familiares. Con frecuencia, estas operaciones forestales son informales y, en muchos casos, ilegales, ya que estos pequeños productores no pueden superar las restricciones legales. 


\section{Conclusiones}

Aunque las reformas de la tenencia han generado algunas ventajas para los pequeños productores y las comunidades, ni siquiera la tenencia segura garantiza que la población local se beneficie del uso comercial de sus recursos forestales, principalmente la madera, porque tales ventajas dependen de la capacidad comunitaria y de las condiciones específicas del desarrollo del mercado. Las reformas de la tenencia no afectan a las condiciones estructurales en las que operan los mercados forestales ni a las interacciones entre los pequeños productores y las comunidades con comerciantes, intermediarios, propietarios de aserraderos y la industria. Las condiciones específicas de los mercados y las formas en que los pequeńos productores y las comunidades participan en ellos contribuyen considerablemente a explicar el alcance de los beneficios que estos actores locales obtienen del uso comercial de los bosques madereros.

Los cuatro casos presentados sugieren que la capacidad de los pequeños productores y las comunidades es un determinante crucial respecto de si las interacciones de estos actores locales con los mercados son estables o esporádicas. Además, existen varias distorsiones que afectan a los mercados de la madera y, con frecuencia, obran contra los pequeños productores y las comunidades, en favor de actores más poderosos. Los mercados de la madera suelen estar dominados por grupos reducidos de empresas y compradores que ejercen considerable influencia sobre los precios finales. En muchos casos, las limitaciones normativas crean obstáculos adicionales para los pequeños productores y las comunidades, empujándolos al aprovechamiento forestal informal. Como resultado de estos factores, la participación de los pequeños productores y comunidades en los mercados foretales, desafortunadamente para los primeros, está dominada por una relación de clientelismo y por información asimétrica. A menudo, las distorsiones del mercado inhiben la capacidad de estos actores locales así como el mayor desarrollo del mercado, y tienden a mantenerse en el tiempo.

Las políticas para mejorar los beneficios que los pequeños productores y las comunidades obtienen del uso comercial de la madera deben estar enfocadas a aumentar la capacidad comunitaria respecto a los mercados y modificar las condiciones en las que operan dichos mercados. Para lograr estos objetivos es necesario examinar todo el conjunto de factores que explica las condiciones actuales, yendo más allá de una perspectiva que solo enfatiza la creación de capacidad para el manejo forestal y la comercialización. En cambio, es preciso centrarse en remediar los fallos estructurales de los mercados de la madera. Obviamente, esto constituye un objetivo más exigente. Para ser eficaces, estas acciones de políticas deben abordar estas dos cuestiones — la capacidad comunitaria y las condiciones del mercado- al mismo tiempo, dado que se las dos se complementan estrechamente.

La creación de capacidad comunitaria requiere la promoción de condiciones que permitan que las comunidades desarrollen iniciativas emprendedoras que aumenten sus conocimientos y capacidades actuales, en lugar de realizar intervenciones basadas en modelos homogéneos de aprovechamiento. Tanto los enfoques basados en las demandas específicas de los pequeños productores y las comunidades en relación con la provisión de servicios técnicos, como el fortalecimiento de redes que promuevan el aprendizaje y la transmisión horizontal de conocimientos y experiencias, son ejemplos de iniciativas 
que pueden contribuir a mejorar las capacidades locales para el manejo de los recursos forestales. Además, las comunidades necesitan herramientas y plataformas de servicios que les permitan mejorar su comprensión del funcionamiento de los mercados y las tendencias futuras y hacer estimaciones más precisas sobre el valor actual y futuro de sus bosques, de manera que puedan tomar decisiones con un mayor conocimiento de causa.

Por último, es necesaria la intervención de políticas públicas para superar las principales distorsiones estructurales del mercado expuestas en este artículo, particularmente las relacionadas con la fijación de precios, las relaciones de clientelismo y la información asimétrica. Además, las reglamentaciones que limitan a las comunidades en el uso de los recursos deben adecuarse a las necesidades de los usuarios del bosque. Las agencias forestales estatales deben establecer alianzas más sólidas con las comunidades, que les permitan a estas competir en los mercados de la madera en mejores condiciones. Poner a disposición de las comunidades servicios financieros y otros servicios técnicos contribuiría a abordar las asimetrías del mercado.

\section{Agradecimientos}

Agradezco el valioso apoyo de Marco A. Albornoz, Roberto Ibarguen, Marco Toro y Westphalen Nunes en el trabajo de campo en Bolivia y Brasil. También agradezco los aportes de Anne Larson, que ha contribuido con información para el caso de Nicaragua. También deseo dar las gracias a Augusta Molnar, David Kaimowitz y dos revisores anónimos por sus valiosos comentarios, que ayudaron a mejorar una versión anterior de este artículo. Cualquier error es mi exclusiva responsabilidad.

\section{Referencias}

Adams, W.M., R. Aveling, D. Brockington, B. Dickson, J. Elliott, J. Hutton, D. Roe, et al. 2004. Biodiversity conservation and the eradication of poverty. Science 306(5699): 1146-1149.

Albornoz, M., P. Cronkleton y M. Toro. 2008. Estudio Regional Guarayos: Historia de la configuración de un territorio en conflicto. Santa Cruz, Bolivia: Centro de Estudios para el Desarrollo Laboral y Agrario (CEDLA) y Centro para la Investigación Forestal Internacional (CIFOR).

Antinori, C. y D. Bray. 2005. Community forest enterprises as entrepreneurial firms: Economic and institutional perspectives from Mexico. World Development 33(9): 1529-1543.

Argüello, A. 2008. Cadena de valor de la madera de la cooperativa Kiwatingni en Layasiksa-RAAN. Managua: Centro para la Investigación Forestal Internacional (CIFOR) y Masangni.

Blaikie, P. 2006. Is small really beautiful? Community-based natural resource management in Malawi and Botswana. World Development 34: 1942-1957.

Proyecto de Manejo Forestal Sostenible en Bolivia (BOLFOR) II. 2007. Beneficios del Plan de Manejo Forestal de la comunidad Cururú, Gestión 2006. Santa Cruz, Bolivia: Proyecto BOLFOR II. 
Bray, D.B., L. Merino-Pérez y D. Barry. 2005. The community forests of Mexico: Managing for sustainable landscapes. Austin, Estados Unidos: University of Texas Press.

Contreras, A. 2005. Best practices for improving law compliance in the forest sector. Roma: Organización de las Naciones Unidas para la Alimentación y la Agricultura (FAO).

Donovan, J., D. Stoian, S. Grouwles, D. Macqueen, A. van Leeuwen, G. Boetekees y K. Nicholson. 2008a. Towards an enabling environment for small and medium forest enterprise development. San José: Centro Agronómico Tropical de Investigación y Enseńanza (CATIE), Organización de las Naciones Unidas para la Alimentación y la Agricultura (FAO), Instituto Internacional de Medio Ambiente y Desarrollo (IIMAD), Servicio Holandés de Cooperación al Desarrollo (SNV) y Organización Intereclesiástica para la Cooperación al Desarrollo (ICCO).

Donovan, J., D. Stoian, D. Macqueen y S. Grouwels. 2006. The business side of sustainable forest management: Development of small and medium forest enterprises for poverty reduction. En: Natural Resource Perspectives 104. Londres: Instituto de Desarrollo de Ultramar (ODI).

Donovan, J., D. Stoian y N. Poole. 2008b. Global review of rural community enterprises: The long and winding road for creating viable businesses and potential shortcuts. San José: Centro Agronómico Tropical de Investigación y Enseñanza (CATIE), School of Oriental and African Studies.

Ibarguen, R. 2008. La última frontera y las comunidades de pequeños parcelarios en el norte paceño. La Paz: Centro de Estudios para el Desarrollo Laboral y Agrario (CEDLA) y Centro para la Investigación Forestal Internacional (CIFOR).

Kaimowitz, D. 2003. Forest law enforcement and rural livelihoods. International Forestry Review 5(3): 199-210.

Larson, A. 2008. Land tenure rights and limits to forest management in Nicaragua's North Atlantic Autonomous Region. Trabajo presentado en The $12^{\text {th }}$ Biennial Conference of the International Association for the Study of Commons. Cheltenham, Reino Unido: Asociación Internacional para el Estudio de los Recursos Comunes (IASC). Del 14 al 18 de julio del 2008.

Larson, A., D. Barry y G. Dahal. 2010. Forests for people: Community rights and forest tenure reform. Londres: Earthscan.

Larson, A. y J. Mendoza. 2008. Desafíos en la tenencia comunitaria de bosques en la RAAN de Nicaragua. Managua: Centro para la Investigación Forestal Internacional (CIFOR), Iniciativa para los Derechos y Recursos (RRI) e Instituto de Recursos Naturales, Medio Ambiente y Desarrollo Sostenible (IREMADES) de la Universidad de las Regiones Autónomas de la Costa Caribe Nicaragüense (URACCAN).

Larson, A.M., P. Cronkleton, D. Barry y P. Pacheco. 2008. Tenure rights and beyond: Community access to forest resources in Latin America. Bogor, Indonesia: Centro para la Investigación Forestal Internacional (CIFOR).

Macqueen, D. 2008. Small and medium forestry enterprise: Supporting small forest enterprises. Londres: Instituto Internacional de Medio Ambiente y Desarrollo (IIMAD). 
Mendoza, J., O.C. Hendy y T.R. Lino. 2008. Estudio de caso: Acceso, medios de vida y gobierno comunitario en las reformas de tenencia forestal Comunidad de Layasiksa, Region Autónoma del Atlántico Norte (RAAN), Nicaragua. Managua: Instituto de Recursos Naturales, Medio Ambiente y Desarrollo Sostenible (IREMADES) de la Universidad de las Regiones Autónomas de la Costa Caribe Nicaragüense (URACCAN).

Molnar, A., M. Liddle, C. Bracer, A. Khare, A. White y J. Bull. 2007. Community-based forest enterprises in tropical forest countries: Status and potential. Washington D.C.: Organización Internacional de las Maderas Tropicales (OIMT), Iniciativa para los Derechos y Recursos (RRI) y Forest Trends.

Moreira, E. y H. Hébette. 2003. Estudo socio-econômico com vista à criação da Resex Verde para Sempre. Belém, Brasil: Universidade Federal do Pará.

Nunes, W., P. Mourão, R. Lobo y G. Cayres. 2008. Entre sonhos e pesadelos: acesso à terra e manejo florestal nas comunidades rurais em Porto de Moz. Belém, Brasil: Centro para la Investigación Forestal Internacional (CIFOR).

Pacheco, D. 2007. An institutional analysis of decentralization and indigenous timber management in common-property areas of Bolivia's lowlands. Tesis doctoral. Indiana University, Bloomington, Estados Unidos.

Pacheco, P., D. Barry, P. Cronkleton y A. Larson. 2008. The role of informal institutions in the use of forest resources in Latin America. Bogor, Indonesia: Centro para la Investigación Forestal Internacional (CIFOR).

Pokorny, B. y J. Johnson. 2008. Community forestry in the Amazon: The unsolved challenge of forests and the poor. En: Natural Resources Perspective No. 112. Londres: Instituto de Desarrollo de Ultramar (ODI).

Rozo, B. y M. Moreno. 2007. Informe de evaluación para la certificación del manejo forestal de Asociación Indigena Maderera Cururú (AIMCU) e INPA Parket Ltda. en Guarayos, Santa Cruz - Bolivia. Santa Cruz, Bolivia: SmartWood.

Scherr, S.J., A. White y D. Kaimowitz. 2004. A new agenda for forest conservation and poverty reduction: Making markets work for low-income producers. Washington D.C.: Forest Trends, Centro para la Investigación Forestal Internacional (CIFOR) y Unión Internacional para la Conservación de la Naturaleza (UICN).

Solares, A.M. 2008. Las MIPYMES en las exportaciones bolivianas. La Paz: Agencia de los Estados Unidos para el Desarrollo Internacional (USAID) e Instituto Boliviano de Comercio Exterior.

Taconni, L. 2007. Illegal logging: Law enforcement, livelihoods and the timber trade. Londres: Earthscan.

Vallejos, C. 1998. Ascensión de Guarayos: indígenas y madereros. En: Municipios y Gestión Forestal en el Tropico Boliviano (eds. Pacheco, P. and D. Kaimowitz). Pp. 51-82. La Paz: Centro para la Investigación Forestal Internacional (CIFOR), Centro de Estudios para el Desarrollo Laboral y Agrario, (CEDLA), Taller de Iniciativas y Estudios Rurales y de Reforma Agraria, y Proyecto de Manejo Forestal Sostenible en Bolivia (BOLFOR). 



\title{
Organizaciones de segundo nivel y la democratización de la gobernanza forestal
}

\author{
Estudios de caso de Nepal y Guatemalai
}

Naya Sharma Paudeli, Iliana Monterroso ${ }^{\text {iii }}$ y Peter Cronkleton ${ }^{\text {iv }}$

\section{Resumen}

Este documento examina el papel emergente de las organizaciones de segundo nivel en la democratización de la gobernanza forestal, analizando dos casos de acción colectiva basada en el manejo forestal en Nepal y Guatemala. Estudia las condiciones que rodean la aparición y el crecimiento de estas organizaciones de segundo nivel y examina la naturaleza de sus enfoques organizativos, acciones estratégicas, y los resultados obtenidos en términos de democratizar la gobernanza forestal. Las organizaciones estudiadas en este documento son producto de procesos de descentralización más amplios y representan poblaciones forestales organizadas y empoderadas. Estas organizaciones pueden inclinar el equilibrio de fuerzas a favor de instituciones comunitarias, y obligar a los organismos estatales a asumir mayor responsabilidad respecto a las necesidades de los ciudadanos que dependen del bosque. Como resultado, al llevar la acción colectiva más allá de la comunidad, hasta un segundo nivel, estas organizaciones han influido en la gobernanza forestal haciéndola más democrática, equitativa y productiva.

\section{Introducción}

La amplia diversidad de acuerdos institucionales que ha proliferado en muchos países en desarrollo para administrar las tierras comunales, en particular bosques, pastos y sistemas de irrigación, han atraído el interés de académicos y estudiosos de políticas (Ostrom 1990). Algunas veces, organizaciones comunitarias locales se han unido con otras similares para formar lo que llamamos organizaciones de segundo nivel, que incluyen federaciones,

i Este artículo es una traducción del original, que apareció en inglés en la revista Conservation and Society, en la edición especial sobre Reformas de tenencia forestal (eds. Anne M. Larson y Ganga Ram Dahal). La cita original completa es: Paudel, N.S., Monterroso I. and Cronkleton, P. 2012 Secondary Level Organisations and the Democratisation of Forest Governance: Case Studies from Nepal and Guatemala. Conservation and Society 10(2): 124-135. El artículo cuenta con una licencia de Creative Commons de Atribución 3.

ii ForestAction, Katmandú, Nepal - naya@forestaction.org.

iii Iniciativa para los Derechos y Recursos (RRI), Washington D.C., Estados Unidos imonterroso@flacso.edu.gt.

iv Centro para la Investigación Forestal Internacional (CIFOR), Lima, Perú - pcronkleton@cgiar.org. 
cooperativas, redes, asociaciones y alianzas. De hecho, los expertos han utilizado distintos términos para estas organizaciones de nivel superior: organizaciones de base de segundo nivel (Taylor 2010), organizaciones de segundo grado, segundo orden, supracomunales o de mesonivel (Carroll y Bebbington 2000). En algunos casos, estas organizaciones de segundo nivel han pasado por un proceso de formalización y ahora desempeñan una función cada vez más importante en la gobernanza forestal (Timsina 2003; Cronkleton et al. 2008; Paudel et al. 2008). Este documento estudia el surgimiento de organizaciones de segundo nivel, sus estrategias de resistencia y participación en el gobierno, y los resultados en cuanto a la mejora de los medios de vida, principalmente mediante la "democratización" ${ }^{1 "}$ de la gobernanza forestal.

Aunque las teorías de acción colectiva a menudo se centran en esfuerzos de la base a nivel de la comunidad (Baland y Platteau 1996; Ostrom 1999), la función desempeñada por organizaciones de segundo nivel en la gobernanza forestal ha recibido menos atención (Colchester et al. 2003; Paudel et al. 2008; Taylor 2010). Con la aparición y expansión de organizaciones de segundo nivel vinculadas a la gobernanza forestal, han surgido varias cuestiones teóricas y prácticas: ¿En qué se diferencian las organizaciones de segundo nivel de las instituciones comunitarias?, ¿Cómo han contribuido las organizaciones de segundo nivel a la democratización de la gobernanza forestal?, ¿Cómo ha influido este proceso en la tenencia forestal y la distribución de beneficios? La primera cuestión es relativamente directa. Por lo general, las instituciones comunitarias están directamente involucradas en la gestión de los recursos naturales, mientras que la formulación de las normas y políticas que rigen el uso y manejo de los recursos forestales están más allá del nivel comunitario, y normalmente a cargo de actores con más poder económico y político. Como resultado, comunidades, agricultores, habitantes de los bosques y pequeños productores con frecuencia quedan al margen de los procesos clave de toma de decisiones. Como se describirá a continuación, se produce una excepción cuando las partes interesadas locales ponen en común los intereses de muchas comunidades o paisajes más extensos, lo que les permite tener mayor influencia en la formulación de políticas públicas y en las instituciones. Cuando agentes poderosos del Estado y el mercado influyen en las políticas y prácticas forestales, la población local puede adoptar estrategias que les proporcionen reconocimiento y voz en los procesos de decisión, y economías de escala en el comercio y desarrollo empresarial, que compensen su relativa debilidad como individuos. En los casos estudiados aquí, las organizaciones de segundo nivel fueron subproductos de la descentralización forestal, con frecuencia fortaleciendo y profundizando estos procesos mediante negociación permanente con organismos estatales y del mercado.

$\mathrm{Al}$ recurrir a casos específicos, es posible ilustrar cómo algunas organizaciones de segundo nivel democratizaron la gobernanza forestal y aumentaron los beneficios para las comunidades que las forman. Comprender cómo los pueblos que habitan en los bosques desarrollaron este nivel de acción colectiva para posibilitar su éxito permitiría un mejor entendimiento no solo de cómo funcionan estos mecanismos organizativos, sino también de qué factores promueven y limitan los resultados que producen para sus miembros. Al centrarnos en dos exitosas organizaciones de segundo nivel que surgieron en contextos muy distintos, analizamos cómo las instituciones comunitarias y los grupos 
de ciudadados interesados participan realmente en dichas organizaciones e influyen en la política forestal y en las prácticas de manejo en diferentes niveles de gobernanza. Los dos casos examinados son la Federación de Usuarios de Bosques Comunitarios de Nepal (FECOFUN) y la Asociación de Comunidades Forestales de Petén, Guatemala (ACOFOP). Estas dos organizaciones de segundo nivel son asociaciones de organizaciones comunitarias involucradas en el manejo forestal y las respectivas actividades sociales y económicas. Estas organizaciones realizaron acciones de incidencia política para defender los intereses de los miembros y asegurar que fueran tomados en cuenta por los responsables del diseño de políticas. Los casos resaltan cómo estas organizaciones participaron en la promoción de políticas para garantizar los derechos de las comunidades a ser titulares de propiedades forestales o a obtener concesiones forestales, a gestionar estos recursos forestales de manera proactiva y a beneficiarse de ellos.

Este estudio se basa en un proyecto de investigación, exhaustivo y plurianual, que analizó las reformas de tenencia forestal en 10 países diferentes (para más detalles, véase Larson y Dahal, en esta colección) $)^{2}$. Entre los sitios analizados, destacaron los casos de Nepal y norte de Guatemala porque las organizaciones de segundo nivel desempeñaron un papel importante en la definición de la gobernanza de los recursos forestales. Aunque existen diferencias socioeconómicas, culturales y geográficas entre estos dos países, ambos han experimentado significativas reformas recientemente que han transferido derechos de tenencia forestal a la población local.

En este artículo se usan datos primarios recopilados durante entrevistas con informantes clave involucrados en los procesos de reforma de tenencia de cada país, incluyendo representantes de la comunidad, el gobierno y organizaciones de desarrollo. Además, se analizó la literatura sobre reforma de la tenencia para ver las funciones desarrolladas por las organizaciones de segundo nivel en el ámbito local, nacional y regional. Se analiza, por ejemplo, de qué manera las redes, los movimientos sociales y otras formas de organización comunitaria participan en la profundización e institucionalización de los procesos de reforma de la tenencia.

El estudio está organizado en cuatro partes. La segunda sección muestra un análisis del debate actual sobre la acción colectiva desplegada por organizaciones de segundo nivel. La tercera presenta dos estudios de caso de Nepal y Guatemala. La cuarta sección se basa en los casos para identificar algunos patrones comunes y muestra cómo la acción colectiva de las organizaciones de segundo nivel puede contribuir a democratizar el sector forestal. La última sección extrae algunos aprendizajes de la dinámica de las organizaciones de segundo nivel.

\section{Organizaciones de segundo nivel de las comunidades dependientes de los bosques: debates emergentes}

La dinámica de las instituciones locales de manejo de los recursos naturales ha sido el centro de la teoría de la propiedad de los comunes durante décadas (Ostrom 1990; 
Baland y Platteau 1996; Agrawal 2001; Agrawal y Ostrom 2001; Bromley 2004). Estas teorías analizan la función de las instituciones locales que gobiernan los bienes comunes. Muchos de estos estudios surgieron para rebatir la inevitabilidad de la 'tragedia de los comunes' (Hardin 1968), una teoría que sostiene que los sistemas de manejo comunitario producen ciclos descendentes de degradación de los recursos. En su artículo, Hardin analiza los bienes comunes y los de acceso abierto, sin distinguir entre ellos en el desarrollo de sus conclusiones. Muchos estudios posteriores sobre los bienes comunes revelaron que la mayoría de esos recursos no eran de acceso abierto, sino que más bien eran gestionados comunitariamente a través de instituciones locales bien desarrolladas y con arraigo cultural. En la actualidad, el enfoque ha pasado a analizar cómo funcionan los sistemas de manejo colectivo a un nivel superior cuando se otorga a las instituciones comunitarias un papel para manejar bosques locales, pastos y sistemas de irrigación.

Aunque la dinámica de las instituciones comunitarias ha sido bien documentada, la acción colectiva a un segundo nivel, más allá de las instituciones comunitarias, ha recibido menos atención. Algunos estudios han mostrado que las redes comunitarias forestales a nivel nacional, regional e internacional han popularizado los discursos de forestería comunitaria y atraído el interés de muchos organismos de desarrollo nacionales e internacionales (Colchester et al. 2003; Wollenberg et al. 2005; Cronkleton et al. 2008; Taylor 2010). Estos estudios han descubierto que las redes contribuyeron a la forestería comunitaria al fomentar el intercambio de información y la sensibilización, apoyar a los grupos nacionales y proporcionarles espacios para que afirmen sus derechos. Ellos ilustran cómo estas organizaciones de segundo nivel cambian constantemente, siendo necesario encontrar un equilibrio en su capacidad de promoción para perseguir múltiples objetivos. No obstante, la dependencia del apoyo de donantes, las crisis internas de gobernanza y los enfoques de arriba abajo de las instituciones de base, fueron identificados como los mayores retos de estas redes. Wollenberg et al. (2005: 11) también observaron que las redes proporcionan una amplia gama de recursos, intercambios, capacidades, estrategias y contactos a los agentes locales que apoyan los movimientos de base en defensa de los derechos. Sin embargo, estos estudios tienden a centrarse en redes y alianzas internacionales que trabajan en la forestería comunitaria, y no en los representantes directos de instituciones comunitarias. Trabajos más recientes, como el de Taylor (2010), indican la necesidad de estudiar las relaciones entre las acciones a nivel comunitario y su respuesta a las presiones externas, al mismo tiempo que abordan los continuos problemas de representación, equidad y legitimidad.

En respuesta al creciente interés en las organizaciones de segundo nivel, los estudiosos se han centrado en la emergencia y las dinámicas de tales organizaciones (Ojha et al. 2007; Cronkleton et al. 2008; Taylor 2010) y sus resultados generales (Komarudin et al. 2008). En este estudio, nuestro enfoque de las organizaciones de segundo nivel es principalmente desde la perspectiva de los movimientos sociales. Aunque otros fundamentos teóricos empleados en el análisis de las organizaciones de segundo nivel proceden del estudio de federaciones agrarias (Bebbington 1996, 1997; Taylor 2010), la teoría de los movimientos sociales considera la acción colectiva como el eje del cambio social. Frecuentemente, 
los movimientos sociales surgen de la resistencia, reflejando reclamos sobre injusticias percibidas, pero también responden a otros postulados, como mejorar los medios de vida locales.

Las organizaciones de segundo nivel conformadas por redes comunitarias surgieron de la acción colectiva a nivel local. La expansión de la escala y el alcance de una acción colectiva a un foro relativamente mayor es lo que se denomina un movimiento social. La idea de acción colectiva consciente dirigida al cambio social también puede ser considerada un movimiento social (Touraine 1985; Neidhardt y Rucht 1991). Mediante la acción colectiva, los movimientos sociales pueden producir y reproducir nuevas narrativas en contextos en los que los propios movimientos están en evolución constante para responder a las condiciones cambiantes.

Los casos de acción colectiva desarrollados por las poblaciones que viven en el bosque que se estudian aquí comparten varias características. En primer lugar, estos movimientos sociales forestales se apartaron de instituciones estatales y partidos políticos, y ahora operan como organizaciones civiles creando "nuevos espacios y nuevas solidaridades" (Cohen 1983: 106). A diferencia de los movimientos políticos convencionales, estos movimientos no están guiados por elevadas posiciones ideológicas ni tienen ninguna intención de dirigir la nación, aunque buscan más autonomía a nivel subnacional o local. En cambio, aceptan en gran medida la legitimidad del régimen político y tratan de ejercer su influencia en materias específicas de las políticas nacionales. En segundo lugar, estos movimientos no constituyen clases (económicas) fundamentales (Offre 1985: 831); por el contrario, son agregados de varios grupos sociales de todo nivel económico, casta, etnia, género, etc. Las personas de diferentes grupos sociales pueden compartir inquietudes comunes y formar alianzas para promover sus intereses colectivos, como derechos de tenencia más sólidos o precios más justos en el mercado. En tercer lugar, estos movimientos no están dirigidos por sindicatos ni otras organizaciones políticas, sino que son expresiones consolidadas de las voces colectivas de moradores de los bosques, pequeños agricultores y minorías étnicas, y se dirigen contra la "acumulación por desposesión” (Harvey 2003). A este nivel, con frecuencia la acción colectiva tiene como objetivo oponerse al control del Estado o a la privatización de los bosques u otros recursos naturales.

El camino hacia la democratización de la gobernanza forestal a través de procesos de reforma de la tenencia está cargado de un alto nivel de incertidumbre (Ribot et al. 2006). Al estudiar casos de seis países en desarrollo, Ribot et al. (2006) expusieron que los gobiernos centrales usan diversas estrategias para conservar el control centralizado al dificultar la descentralización democrática de la gobernanza de los recursos. Una estrategia posible para ayudar a contrarrestar esta tendencia centralizadora y que sirve como un poderoso agente de descentralización democrática es formar coaliciones amplias de diversos actores, incluyendo grupos de intereses cívicos. En este documento se estudia el papel potencial de las organizaciones de segundo nivel de comunidades forestales para promover la descentralización democrática de la gobernanza forestal. 


\section{Casos de estudio de organizaciones de segundo nivel y la lucha por configurar la gobernanza forestal}

\section{Caso 1: Federación de Usuarios de Bosques Comunitarios de Nepal}

Nepal se ha convertido en un ejemplo interesante de gobernanza forestal descentralizada debido a su renombrado programa forestal comunitario. No obstante, las políticas forestales siempre han oscilado entre el manejo burocrático y gubernamental de arriba abajo y el manejo comunitario autónomo a cargo de la población local (Bhattarai et al. 2002). De hecho, los derechos que sustentan el dinámico sector forestal de Nepal habrían sido socavados si no hubiese aparecido una influyente federación de usuarios de bosques comunitarios que contrarrestó la fuerza centralizadora del Estado.

Nepal inició sus actividades de forestería comunitaria a finales de la década de los setenta en respuesta a las altas tasas de deforestación y degradación, en particular en las colinas centrales. El programa cobró impulso después de los cambios políticos que condujeron al establecimiento de un modelo parlamentario multipartidista en los años noventa. En consecuencia, el nuevo parlamento ratificó la Ley Forestal de 1993, que permite a los funcionarios forestales de los distritos (DFO, por sus siglas en inglés) ceder partes de los bosques nacionales a organizaciones locales registradas llamadas grupos de usuarios de bosques comunitarios (CFUG, por sus siglas en inglés) (HMG/MoLJ 1993). Un CFUG es una entidad colectiva que representa a los hogares que viven cerca de un fragmento de bosque determinado ${ }^{3}$, el bosque comunitario, y en la que los miembros son representantes de los hogares de la localidad. La Ley Forestal de 1993 reconoció a los CFUG como instituciones autónomas e independientes para gestionar recursos forestales y los fondos correspondientes (HMG/MoLJ 1993: Artículo 43).

Inicialmente, los grupos de usuarios de los bosques comunitarios procuraron aprender y beneficiarse del intercambio mutuo y compartir con otros CFUG que se enfrentaban a retos similares. La red surgida prestó apoyo técnico fundamental a sus CFUG miembros para redactar planes operativos, llevar los registros adecuados, introducir mejores prácticas de manejo forestal y mantener los estándares generales de manejo forestal sostenible según las normas locales y mundiales (como las del Forest Stewardship Council).

La respuesta de las comunidades a los distintos retos y oportunidades durante la primera fase del programa de forestería comunitaria condujo gradualmente al surgimiento y desarrollo de la Federación de Usuarios de Bosques Comunitarios de Nepal (FECOFUN). Cuando el programa de forestería comunitaria empezó a tomar fuerza a finales de los años noventa, los bosques se regeneraron progresivamente y aumentó el potencial de comercialización de varios productos forestales. Junto con esta posibilidad creciente de venta de productos forestales, la forestería comunitaria comenzó a atraer el interés de empresarios, líderes locales influyentes y funcionarios forestales. En consecuencia, se informó sobre algunos casos de sobreexplotación y malversación de fondos (ForestAction y SEACOW 2002). En respuesta a esta situación, las autoridades forestales reaccionaron de manera exagerada y tomaron una serie de decisiones políticas que socavaron la autonomía de los CFUG. Según comenta Shrestha (2001), durante ese período hubo una reacción 
contra la forestería comunitaria tal como ilustran importantes decisiones de políticas que incluyeron un retroceso de los derechos comunitarios: a la Timber Corporation of Nepal (TCN), una empresa paraestatal, se le otorgó el monopolio del comercio de madera; los funcionarios de distrito recibieron poderes para tomar decisiones relativas a los CFUG; se detuvo la transferencia de más bosques comunitarios en la región de Terai y se eliminó la prioridad especial de manejo comunitario sobre otros regímenes de manejo forestal establecidos en el Reglamento Forestal de 1995.

FECOFUN surgió a partir de los CFUG (Grupos de Usuarios de Bosques Comunitarios) a principios de los años noventa ${ }^{4}$. Hoy en día se ha convertido en la mayor organización civil del país, representando a más de 15000 CFUG que suponen más de diez millones de personas, La organización de FECOFUN está estructurada en cuatro niveles diferentes: aldea, subdistrito, distrito y nacional. Los grupos de usuarios de bosques comunitarios son la base de FECOFUN, y todos los niveles de sus organizaciones subsidiarias parten de ahí. Los líderes de cada nivel son elegidos democráticamente por miembros del nivel inmediatamente inferior. Aunque FECOFUN desarrolla su política general y su programa anual a nivel nacional durante la asamblea general y otros encuentros regulares, y los aplica a través de sus redes, los niveles inferiores son libres de crear y aplicar sus propios programas basados en las prioridades locales.

Dos factores importantes impulsaron a los CFUG a empezar a colaborar, un proceso que condujo a la creación de FECOFUN. En primer lugar, aunque el gobierno transfirió un conjunto de derechos a las comunidades, era difícil cumplir los términos y condiciones, por lo que los CFUG se enfrentaron con dificultades para afianzar esos derechos. En los primeros ańos de la forestería comunitaria, los CFUG disponían de poca capacidad para abordar muchos de los desafíos institucionales y técnicos, como crear comités ejecutivos funcionales, redactar estatutos para los grupos y planes operativos forestales, y llevar a cabo las actividades de manejo forestal recomendadas. Igualmente, a pesar de las estrictas disposiciones legales, la burocracia forestal intentó minar el espíritu de la Ley Forestal de 1993 emitiendo directrices restrictivas y circulares operativas, o haciendo uso de su poder discrecional para frustrar la plena implementación.

En segundo lugar, el recién establecido sistema parlamentario y el acceso a la ayuda solidaria de organismos nacionales e internacionales proporcionó un entorno posibilitador para el crecimiento de FECOFUN. El nuevo régimen político multipartidista promovió el discurso, las normas y los principios democráticos, y espacios abiertos para que florecieran diversas formas de grupos ciudadanos. Más aún, la ayuda internacional al desarrollo de la forestería comunitaria, que había estado centrada en los CFUG y la capacidad del gobierno para apoyarlos, pasó a colaborar con los CFUG. Una vez fundada y reforzada, la red resultante se convirtió en FECOFUN. Sólo la Fundación Ford y proyectos forestales bilaterales de los gobiernos suizo, británico y danés se hicieron cargo de más del 95 por ciento de los costos de FECOFUN durante su primera etapa (FECOFUN 1999). Otros socios del desarrollo, como el Centro Internacional para el Desarrollo Integrado de las Zonas Montañosas (ICIMOD), Ayuda en Acción y la Cooperativa para Asistencia y Alivio en Cualquier Parte (CARE)-Nepal entre otros, han prestado una ayuda crucial para actividades de capacitación, el desarrollo institucional y la creación de redes. Además, 
algunos profesionales con sólida fe en la gestión comunitaria hicieron, por un lado, un importante aporte intelectual y de asesoría y, por otro, ayudaron a la expansión nacional e internacional de la red. Los que los apoyaron, además de ayudar a la red, también inculcaron la idea de que trabajar en red era algo esencialmente bueno. No obstante, sobre todo, los líderes de FECOFUN demostraron tener buena visión de futuro y alto nivel de compromiso político, uno de los factores clave de su éxito.

Las decisiones gubernamentales en materia de políticas alarmaron a FECOFUN, que las consideró una amenaza a los derechos comunitarios. En respuesta, FECOFUN consolidó gradualmente su movimiento de resistencia contra las decisiones del Gobierno. La organización tomó las calles en protesta contra esas decisiones, organizó a sus miembros constituyentes y lideró la campaña política para defender los derechos comunitarios. Durante este proceso, también creó alianzas con activistas civiles y políticos que simpatizaban con el programa de derechos comunitarios. El Plan Maestro del Sector Forestal de 1989 y la Ley Forestal de 1993, que formalizan explícitamente los derechos comunitarios, sirvieron de base principal en la lucha de FECOFUN para lograr este fin. Además del movimiento de resistencia, FECOFUN participó de manera creciente y constructiva en foros de políticas, y presionó por procesos de políticas más inclusivos. De hecho, la intervención de FECOFUN ha sido una contribución importante para institucionalizar procesos que involucren múltiples actores en la redacción de políticas del sector forestal. Por ejemplo, FECOFUN está representado en el Comité de Coordinación del Sector Forestal (CCSF), el Comité de Coordinación Forestal del Distrito (CCFD), y algunos grupos de trabajo y equipos de trabajo ocasionales que se establecen para revisar políticas específicas. En consecuencia, la tradicional relación de desigualdad entre autoridades forestales y FECOFUN está cambiando gradualmente. Durante este período, los procesos de políticas forestales se han hecho progresivamente más participativos e inclusivos en varios aspectos, como procesos con múltiples actores, la ampliación de consultas en temas de políticas clave y estudios de diagnóstico para revisar el impacto de las políticas.

La activa participación de FECOFUN en el movimiento democrático que derribó con éxito la monarquía centenaria y estableció una nueva república en Nepal, realzó el perfil político de la organización. Por consiguiente, los líderes de FECOFUN han establecido estrechas relaciones con dirigentes políticos, han movilizado a partidos políticos para causas comunitarias, han accedido a información crucial sobre decisiones de política forestal y han movilizado a los medios de comunicación. Como resultado, ellos han cambiado las relaciones de poder entre el Estado y la comunidad -históricamente desiguales - a favor de las comunidades forestales y sus redes. El gobierno ya no puede ignorar las opiniones de las partes interesadas del sector forestal comunitario, y reconoce que desempeñan funciones significativas en el manejo forestal, un resultado poco probable si los CFUG hubiesen intentado ejercer tal influencia por su cuenta.

Como muestra el Cuadro 1, el movimiento encabezado por FECOFUN ha logrado revertir algunas de las decisiones regresivas, aunque no ha conseguido influir sobre otras. Por ejemplo, se revocaron la decisión de conceder a TCN el monopolio sobre productos forestales de la comunidad y el embargo bancario de los CFUG, ya que hubo un fuerte 
Cuadro 1. Principales amenazas de políticas y respuestas de FECOFUN

\begin{tabular}{|c|c|c|c|}
\hline Fecha & $\begin{array}{l}\text { Principales problemas de } \\
\text { políticas }\end{array}$ & Actividades de FECOFUN & Logros \\
\hline $\begin{array}{l}\text { Febrero } \\
\text { de } 1998\end{array}$ & $\begin{array}{l}\text { Se otorga a la Timber } \\
\text { Corporation of Nepal } \\
\text { (TNC), una empresa } \\
\text { paraestatal, el monopolio } \\
\text { del comercio de madera. }\end{array}$ & $\begin{array}{l}\text { Protestas callejeras } \\
\text { organizadas, conferencia } \\
\text { de prensa, grupos } \\
\text { informales de presión con } \\
\text { otras partes interesadas. }\end{array}$ & $\begin{array}{l}\text { El Gobierno cambió su } \\
\text { decisión, lo que supuso } \\
\text { que el monopolio del TCN } \\
\text { no pudo ser sujeto para } \\
\text { manejar a bosques en } \\
\text { manos de comunidades y } \\
\text { gobiernos locales. }\end{array}$ \\
\hline $\begin{array}{l}\text { Febrero } \\
\text { de } 1999\end{array}$ & $\begin{array}{l}\text { La primera enmienda a } \\
\text { la Ley Forestal de } 1993, \\
\text { destinada a otorgar más } \\
\text { poder a los DFO para } \\
\text { que emprendan acciones } \\
\text { contra los miembros de } \\
\text { los CFUG, exigía invertir el } \\
50 \% \text { de los fondos de los } \\
\text { CFUG en manejo forestal. }\end{array}$ & $\begin{array}{l}\text { Animó a los CFUG } \\
\text { a desobedecer las } \\
\text { disposiciones, sensibilizó } \\
\text { a los CFUG sobre las } \\
\text { repercusiones de la } \\
\text { enmienda. }\end{array}$ & $\begin{array}{l}\text { Éxito parcial; tanto los } \\
\text { miembros de los DFO } \\
\text { como los de los CFUG } \\
\text { pueden emprender } \\
\text { acciones contra el comité } \\
\text { del CFUG por mala } \\
\text { administración; el } 25 \% \text { de } \\
\text { los fondos se invertirán en } \\
\text { manejo forestal. }\end{array}$ \\
\hline $\begin{array}{l}\text { Abril de } \\
2000\end{array}$ & $\begin{array}{l}\text { Circular del gobierno para } \\
\text { restringir la forestería } \\
\text { comunitaria en la región } \\
\text { del Terai. }\end{array}$ & $\begin{array}{l}\text { Asamblea, conferencia } \\
\text { de prensa, envío de } \\
\text { memorando, grupos de } \\
\text { presión con responsables } \\
\text { políticos. }\end{array}$ & $\begin{array}{l}\text { El Gobierno ha levantado } \\
\text { recientemente la } \\
\text { prohibición de manejo } \\
\text { forestal comunitario en la } \\
\text { región de Terai. }\end{array}$ \\
\hline $\begin{array}{l}\text { Agosto } \\
\text { de } 2002\end{array}$ & $\begin{array}{l}\text { Enmienda presentada para } \\
\text { derogar la provisión de } \\
\text { "prioridad especial" de la } \\
\text { forestería comunitaria. }\end{array}$ & $\begin{array}{l}\text { Rechazo de la decisión, } \\
\text { arguyendo que abre } \\
\text { los bosques a la } \\
\text { apropiación por parte de } \\
\text { empresas privadas. }\end{array}$ & $\begin{array}{l}\text { Sin éxito; la enmienda } \\
\text { permite al Gobierno } \\
\text { entregar parte de los } \\
\text { bosques nacionales a } \\
\text { empresas privadas sin dar } \\
\text { prioridad a la comunidad } \\
\text { que vive del bosque. }\end{array}$ \\
\hline $\begin{array}{l}\text { Julio de } \\
2003\end{array}$ & $\begin{array}{l}\text { Decreto ley financiero para } \\
\text { recaudar un impuesto } \\
\text { del } 40 \% \text { en las ventas de } \\
\text { productos forestales de } \\
\text { los CFUG. }\end{array}$ & $\begin{array}{l}\text { Campañas en toda } \\
\text { la nación contra la } \\
\text { disposición, protestas } \\
\text { callejeras, asambleas, } \\
\text { grupos de presión con } \\
\text { responsables políticos, } \\
\text { proceso judicial. }\end{array}$ & $\begin{array}{l}\text { El impuesto es reducido al } \\
15 \% \text { y limitado a la venta } \\
\text { de sólo dos especies de } \\
\text { madera (Shorea robusta y } \\
\text { Dalbergia sissoo). }\end{array}$ \\
\hline $\begin{array}{l}2005- \\
2006\end{array}$ & $\begin{array}{l}\text { El Gobierno embarga } \\
\text { cuentas bancarias de } \\
\text { los CFUG. }\end{array}$ & $\begin{array}{l}\text { Se organizaron } \\
\text { concentraciones en } \\
\text { distintos distritos. }\end{array}$ & $\begin{array}{l}\text { El Gobierno revocó los } \\
\text { embargos de cuentas } \\
\text { bancarias. }\end{array}$ \\
\hline $\begin{array}{l}2006- \\
2007\end{array}$ & $\begin{array}{l}\text { Alrededor de una docena } \\
\text { de bosques comunitarios } \\
\text { fueron utilizados } \\
\text { por el Gobierno para } \\
\text { barracones militares y } \\
\text { acantonamientos de } \\
\text { maoístas rebeldes. }\end{array}$ & $\begin{array}{l}\text { Envío de un memorando } \\
\text { al Gobierno con opciones } \\
\text { alternativas. }\end{array}$ & $\begin{array}{l}\text { La mayoría de los bosques } \\
\text { comunitarios han sido } \\
\text { devueltos. }\end{array}$ \\
\hline
\end{tabular}


rechazo público a esas decisiones. No obstante, el movimiento no pudo influir en la decisión relativa al problema de la autoridad de los DFO sobre los grupos de usuarios de bosques comunitarios, ni en materia de impuestos, ya que el Estado adoptó una postura muy firme en estos asuntos y FECOFUN no logró el respaldo público total. Sin embargo, aparte del éxito parcial al influir en algunas decisiones, el movimiento también fortaleció la acción colectiva de los CFUG para lograr metas en el manejo forestal. Por ejemplo, FECOFUN ha fomentado un objetivo de equidad consistente en alcanzar una representación del 50 por ciento de mujeres en puestos de liderazgo, y mayor asignación de fondos de CFUG para actividades que fortalezcan medios de vida a favor de los pobres dentro de la forestería comunitaria. Además de las demandas internas, el discurso de democracia inclusiva de FECOFUN, que surgió en paralelo a un movimiento maoísta y a la influencia de donantes del sector forestal, promovió la equidad. Como resultado, las Directrices de Forestería Comunitaria 2009 que el Gobierno publicó recientemente institucionalizaron la disposición de una representación femenina del 50 por ciento. Igualmente, el gran número de personas en su red nacional y su fuerte presencia en foros nacionales e internacionales han ayudado a FECOFUN a desafiar los desequilibrios de poder existentes entre la burocracia forestal y las comunidades locales.

A pesar de sus éxitos, FECOFUN se ha enfrentado a muchos desafíos institucionales y programáticos. Contrario a los valores y objetivos expresados por la organización, la preparación de un nuevo liderazgo, especialmente mediante la participación de mujeres y grupos marginados, parece inadecuada (Nightingale 2003; Pokhrel et al. 2007). Además, con frecuencia la organización adopta una postura defensiva en muchos temas de política forestal y apoya o rechaza el programa o la propuesta basándose en su posición visceral de que las comunidades siempre tienen razón (Ojha et al. 2008). Una de las mayores amenazas es que, como muchos dirigentes de FECOFUN están afiliados a un partido político u otro, a menudo FECOFUN es acusado de que, en ciertos momentos, podría ser utilizado por la agenda de un partido. Del mismo modo, FECOFUN suele estar bajo presión para cumplir las crecientes exigencias de servicios por parte de los CFUG, como capacitación, diseño de planes operativos o vinculación a los mercados. La sostenibilidad financiera se ha convertido en otro importante reto, especialmente en el contexto de la financiación institucional —flexible y menguante — recibida de organismos internacionales de ayuda. Esto puede limitar en última instancia la capacidad de FECOFUN para hacer frente a la enorme demanda de los CFUG que lo constituyen y responder a cualquier proceso de política forestal nacional en curso (Timsina 2003; Ojha et al. 2007). Mientras tanto, lograr un equilibrio entre responder a las demandas de apoyo técnico de los CFUG y abordar muchos problemas de política forestal nacional representa un desafío cada vez más serio. Además, FECOFUN, como influyente red nacional, ha convertido a los CFUG en poderosas organizaciones locales, creando así una pluralidad institucional a nivel local que tiende a socavar los gobiernos locales.

\section{Caso 2: Asociación de Comunidades Forestales de Petén, Guatemala}

La Región de Petén en Guatemala se ha convertido en un ilustrativo ejemplo de cómo los esfuerzos gubernamentales para implementar políticas de conservación pueden provocar resistencia en los pueblos que dependen del bosque, llevándolos a la creación de una 
influyente organización de segundo nivel. Una prominente decisión política que formó parte de este proceso fue la creación de la Reserva de la Biosfera Maya (RBM) en 1990. La RBM cubre aproximadamente dos millones de hectáreas de bosque tropical latifoliado de tierras bajas, e introdujo políticas específicas de uso de la tierra para conservar la rica diversidad biológica de la región. No obstante, una vez creada, el Gobierno se enfrentó a grandes desafíos para administrar la reserva y reconciliar sus objetivos de conservación con los sistemas de medios de vida de las comunidades residentes dentro de la reserva y sus alrededores. Los planes iniciales intentaron establecer un régimen de protección estricta que no contemplaba la presencia a largo plazo de comunidades y familias que viven en los bosques de la zona y dependen de ellos, y exigía su desalojo o duras restricciones en sus actividades de subsistencia. La intensa reacción de las comunidades afectadas amenazó el objetivo de conservación de la biodiversidad que tenía el gobierno para la RBM. En respuesta a la creciente tensión, organizaciones de conservación propusieron la creación de concesiones forestales comunitarias en la zona de amortiguamiento (llamada zona de uso múltiple o ZUM) alrededor de la zona núcleo de la RBM, como una estrategia para proporcionar beneficios económicos a los residentes y asegurar su participación activa en el manejo sostenible de los bosques que rodean la reserva. En 1994, el Gobierno presentó formalmente un sistema de concesiones comunitarias. Este sistema de concesiones reconoció los derechos de asentamiento de las comunidades ya existentes y, al mismo tiempo, propuso potencialmente incentivos para el manejo forestal y los planes de conservación de la biodiversidad. La premisa de esta decisión fue que la concesión de estas áreas de bosque satisfaría los intereses contrapuestos de todas las partes: industria, conservación y comunidades. No obstante, los residentes locales - dispersos y con frecuencia aislados en comunidades rurales - pronto aprendieron que sería necesaria la acción colectiva local para beneficiarse plenamente de las nuevas oportunidades.

Las primeras áreas de concesión ofrecidas a las comunidades en 1994 eran pequeñas, lo que recortaba su viabilidad económica y no satisfacía las demandas históricas de derechos sobre los recursos forestales. Además, el sistema establecido por el Gobierno y organismos de financiación como la Agencia de los Estados Unidos para el Desarrollo Internacional (USAID) ponía considerable autoridad y control en manos de organismos gubernamentales y ONG en lugar de hacerlo directamente en manos de las organizaciones comunitarias participantes. Como la población estaba dispersa en asentamientos por todo el bosque, la comunicación era limitada, y la heterogeneidad de las comunidades les dificultó unirse en torno a intereses comunes. Por ejemplo, mientras algunas comunidades deseaban formalizar sus derechos consuetudinarios a residir en el bosque y aprovechar productos forestales no maderables (PFNM), los que vivían fuera de la ZUM reclamaban recursos forestales dentro de la zona de amortiguamiento. El malestar de la población rural que habitaba dentro y alrededor de la ZUM aumentó cuando se conocieron estas limitaciones. Sin embargo, las comunidades carecían de una voz común para unificar sus demandas de recursos (Sundberg 1998). Finalmente, los líderes comunitarios se movilizaron en un frente unido para reaccionar contra las decisiones centralizadas, proponiendo a cambio un aumento del tamaño de las concesiones, mayores niveles de acceso y que se otorgara más control a las comunidades. Esto preparó los cimientos para la creación de ACOFOP (Asociación de Comunidades Forestales de Petén). ACOFOP es una organización de segundo nivel fundada en 1997 para representar los intereses comunes de comunidades y organizaciones comunitarias que poseen concesiones forestales. 
ACOFOP representa a 23 comunidades y organizaciones comunitarias miembros dentro y alrededor de la RBM. Estas comunidades están agrupadas en 12 organizaciones miembros de ACOFOP con concesiones en la ZUM. ACOFOP se rige por una asamblea general de miembros, una junta directiva integrada por representantes de concesiones y un comité supervisor formado por tres miembros (Taylor 2010). En sus orígenes, ACOFOP fue creada como grupo de presión para lograr más acceso a los recursos y derechos de manejo para las comunidades. Los líderes de ACOFOP continuaron luchando para aumentar el tamaño de las concesiones comunitarias hasta una escala económicamente viable y ayudaron a organizaciones comunitarias a obtener estatus legal. Además, negociaron un cambio en el marco legal para permitir la asignación de derechos de concesión a comunidades ubicadas fuera de la ZUM. Aunque la primera concesión comunitaria que se otorgó era de solo 7000 hectáreas, los contratos de concesión posteriores oscilaban entre 20000 y 93000 hectáreas de bosque. En total, las concesiones comunitarias comprenden unas 375000 hectáreas de bosques de manejo sostenible certificado, y benefician a más de 2000 familias pertenecientes a organizaciones de concesiones comunitarias (Monterroso y Barry 2009). Sobre todo, ACOFOP fue clave para garantizar que los grupos comunitarios participaran activamente en el proceso de decisión para establecer un sistema de concesiones. Más adelante asumió funciones adicionales de coordinación económica, en particular las relacionadas con la producción de madera y, más recientemente, la diversificación, para abarcar la comercialización de PFNM y la prestación de servicios técnicos (Taylor 2010).

ACOFOP ha influido en la democratización de los derechos de tenencia en el Petén guatemalteco por dos vías. En primer lugar, se enfrentó a las decisiones centralizadas que limitaban los derechos de uso y acceso, e impulsó los intereses de los miembros para asegurar el derecho a concesiones a una escala viable desde el punto de vista económico. En fecha más reciente, se ha centrado en labores de promoción política para garantizar que se escuchen las voces locales, se respeten los derechos de las concesiones comunitarias y que agentes externos no invadan sus tierras violando los derechos de exclusión. En segundo lugar, ACOFOP también presta asistencia técnica y acompaña a sus comunidades miembros fortaleciendo sus competencias organizativas, técnicas y productivas. Esta organización de segundo nivel facilita la autogestión comunitaria, favoreciendo la capacidad de las organizaciones miembros para participar en los procesos de decisión (ACOFOP 2005). En la actualidad, la asociación tiene una oficina técnica que implementa proyectos financiados parcialmente por proyectos de donantes. Además, ACOFOP facilita un mejor acceso al mercado, reduce los costos de transacción de las actividades de manejo forestal, y facilita a los miembros el acceso a créditos.

No obstante, la tarea de incidencia política de ACOFOP para proteger los derechos de manejo y de exclusión que tienen los miembros frente a intereses externos es la que requiere más esfuerzo e inversión de recursos económicos. En el Cuadro 2 se muestra la lucha de ACOFOP para asegurar los derechos comunitarios sobre el bosque. Por ejemplo, ACOFOP logró eliminar el requisito de que los planes y las actividades de manejo comunitario sean supervisados y certificados por ONG designadas. 
Cuadro 2. Principales acciones de ACOFOP y sus resultados

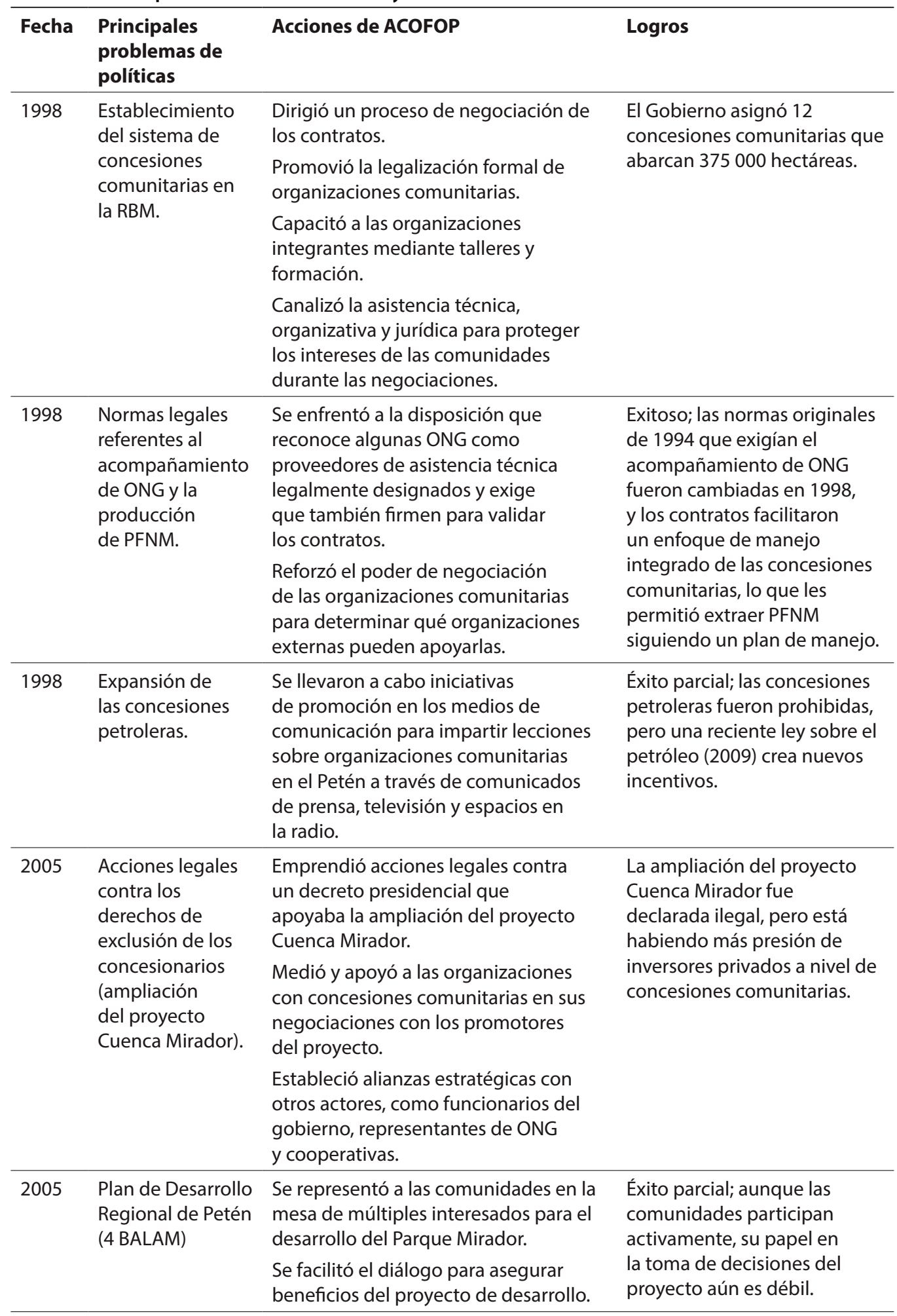


Dos grandes batallas contra inversores privados y entidades estatales ilustran mejor el papel desempeñado por ACOFOP en la protección de los intereses de concesiones comunitarias. En un caso, ACOFOP luchó para derogar una ley de 1998 que permitía la expansión de la prospección y extracción petrolera dentro del área de concesión comunitaria en la ZUM. Esta batalla sólo ha tenido un éxito parcial, porque la Ley del Petróleo de 2009 creó nuevos incentivos y un marco legal para ampliar los contratos petroleros dentro de la RBM. Aunque no ha habido actividades extractivas dentro de la ZUM, los miembros de ACOFOP están preocupados porque aproximadamente el 90 por ciento de la reserva nacional de petróleo se encuentra en el Petén.

El otro ejemplo se refiere a los esfuerzos realizados por inversores privados para promocionar el turismo cultural y arqueológico en la zona norte de la RMB, ampliando el parque nacional existente, de 81 kilómetros cuadrados, a una zona denominada proyecto Cuenca Mirador, que supera los 2000 kilómetros cuadrados. Esta ampliación podría anular seis contratos de concesión, incluidas las concesiones de cinco comunidades. El Proyecto Cuenca Mirador fue aprobado por decreto presidencial en 2002 (129-2002). A ACOFOP le costó tres años revocar la autorización legal para la ampliación del parque nacional (Monterroso 2007; Taylor 2010). No obstante, en 2010 se discutía otra propuesta en el Congreso Nacional para aprobar una ley que renueva el proyecto Cuenca Mirador. Si tiene éxito, restringirá los derechos de concesión existentes para dar paso a una iniciativa dirigida por inversores privados.

La activa participación de ACOFOP con actores externos, estableciendo relaciones directas con donantes y presionando a instituciones gubernamentales nacionales en su función de representante de las concesiones comunitarias, ha contribuido a la aparición de alianzas entre entidades de conservación, concesionarios comunitarios, el sector maderero y el gobierno local (Monterroso y Barry 2009). De hecho, el éxito de la experiencia de las concesiones comunitarias ha sido un ejemplo útil para muchas otras iniciativas comunitarias en Guatemala y otros lugares. Una diversidad de resultados adicionales a los mencionados acá han sido atribuidos a ACOFOP (Barry y Monterroso 2008; Monterroso y Barry 2009). ACOFOP aseguró los derechos de manejo y usufructo de los productos forestales durante al menos 25 años, con la posibilidad de renovación. Mejoró los sistemas de gobernanza local, basados en un conjunto ampliado de derechos de acceso, uso y decisión sobre los recursos naturales. Las organizaciones concesionarias aumentaron significativamente sus ingresos, generando oportunidades de empleo para miembros de las comunidades. ACOFOP presionó para que los bancos locales aceptaran planes anuales de manejo forestal como aval, lo que permite a las concesiones comunitarias solicitar crédito. Además, los miembros de ACOFOP han ejercido más control sobre la tala y la quema ilegal para mantener la cobertura forestal. Por último, al integrar las organizaciones locales dispersas en un solo órgano representativo, se fortalecieron las voces de las comunidades y se aseguraron los derechos exclusivos de estas.

No obstante, aunque ACOFOP ha tenido éxito en muchos aspectos, se enfrenta a cinco grandes desafíos. En primer lugar, está sometida a gran presión por parte de las comunidades integrantes, que solicitan ayuda técnica para cumplir los criterios y las 
normas de los contratos, como normas de certificación, así como ayuda para acceder a mercados adecuados para productos forestales. En segundo lugar, ACOFOP debe ejercer un liderazgo eficaz para mantener los derechos comunitarios frente a reivindicaciones superpuestas, como son los crecientes reclamos de tierra por parte de comunidades campesinas. En tercer lugar, deben responder a la falta de voluntad política del gobierno para apoyar plenamente sus derechos, manteniendo estrecha comunicación con sus organizaciones miembros y estableciendo alianzas. ACOFOP ha tenido que actuar de "órgano de control" para proteger y mejorar los derechos de tenencia de sus organizaciones integrantes. En cuarto lugar, ACOFOP necesita mantener legitimidad y credibilidad entre sus miembros garantizando una representación democrática y mayor rendición de cuentas, lo que supone más desafíos institucionales (Monterroso y Barry 2009). Por último, ACOFOP debe encontrar un equilibrio entre sus funciones política y económica, y estas funciones varían constantemente. ACOFOP también se esfuerza por gestionar problemas de representación, equidad y legitimidad (Taylor 2010).

\section{Las organizaciones de segundo nivel como agentes que surgen en la democratización de la gobernanza forestal}

Los casos anteriores se centran en dos aspectos importantes de las organizaciones de segundo nivel: su surgimiento y crecimiento, y sus acciones estratégicas para democratizar la gobernanza forestal. En esta sección sintetizaremos estas experiencias para extraer aprendizajes y analizar las implicaciones de la contribución de las organizaciones de segundo nivel a la gobernanza forestal.

\section{Surgimiento y crecimiento de las organizaciones de segundo nivel}

Los dos casos expuestos ilustran por lo menos cuatro factores que apoyan el surgimiento y el crecimiento de las organizaciones de segundo nivel. En primer lugar, respondieron al percibir amenazas a las formas de acceso a valiosos recursos, amenazas que actuaron como catalizadores y forzaron a los grupos comunitarios a unirse y crear redes, federaciones y alianzas. Al unirse, mejoraron su acceso a información crucial, ampliaron las voces de los miembros y aumentaron su poder de negociación y su capacidad para exigir responsabilidad a las autoridades. Las comunidades forestales del Petén defendieron sus derechos cuando vieron que sus intereses corrían peligro debido a la creación de la Reserva de la Biosfera Maya. Cuando se encontraron con sus derechos restringidos y vieron que el tamaño de las concesiones no era el adecuado, empezaron a establecer contactos y a organizarse en una asociación de organizaciones comunitarias para defender y ampliar sus derechos de tenencia. Los grupos de comunidades comenzaron estos movimientos cuando se dieron cuenta de que se enfrentaban a una amenaza común a sus intereses colectivos de medios de vida.

FECOFUN fue creado en respuesta a la percepción de que los CFUG estaban siendo tratados simplemente como receptores pasivos, mientras el Gobierno y los donantes extendían la forestería comunitaria por todo el país. Tal como se estaba desarrollando 
el programa, casi no tenían voz. Esta organización de segundo nivel surgió porque la acción colectiva de los grupos comunitarios de base era inadecuada, debido en particular a complejas dinámicas sociopolíticas causadas por conflictos de intereses, negociaciones complicadas, y procesos legislativos alejados de la capacidad de las comunidades locales. Los grupos comunitarios intentaron crear sus redes para relacionarse con agentes poderosos en distantes entidades estatales, mercado u organismos de desarrollo internacional. En particular, los CFUG de Nepal trataron de organizar y consolidar sus voces para influir en las prácticas institucionales del organismo forestal del gobierno.

En segundo lugar, en ambos casos la transición política a una gobernanza más democrática, participativa y responsable creó espacios para el surgimiento de estas organizaciones de segundo nivel. En Guatemala, este período estuvo marcado por el fin de la guerra civil, el retorno de los ciudadanos desplazados y el desarrollo de políticas que permitieron a comunidades de los bosques fundar, consolidar e institucionalizar ACOFOP. Del mismo modo, un sistema político parlamentario y multipartidista en Nepal facilitó una apertura para el resurgimiento de organizaciones de base y acciones cívicas que contribuyeron a la creación de FECOFUN. Previamente, la creación de tales asociaciones comunitarias en Nepal, en particular redes nacionales, hubiera sido casi imposible en el régimen político autocrático que existía antes de 1990. Más aún, las alianzas con otros grupos cívicos y medios de comunicación sólo fueron posibles por la política liberal recientemente establecida en Nepal.

En tercer lugar, la función de los dirigentes de base siguió siendo crucial para el desarrollo de esas organizaciones. Estos dirigentes surgieron de movimientos de base para fortalecer los derechos comunitarios sobre los recursos naturales o de movimientos políticos ciudadanos para obtener más libertad. Por ejemplo, muchos activistas que lucharon para lograr más libertad política en Nepal, posteriormente se unieron a redes de ciudadanos y surtieron de líderes a FECOFUN. Los líderes dedicaron su tiempo, esfuerzo, conocimientos, capital social y conexiones políticas para nutrir, fortalecer y ampliar las organizaciones. Fueron capaces de reunir a diferentes grupos comunitarios bajo una sola sombrilla. Vincularon estratégicamente los movimientos de derechos forestales a movimientos ciudadanos más amplios y se destacaron en los pasillos de poder de los ministerios del gobierno. Los dirigentes obraron como "agentes especializados en la solución de problemas", articulando eficazmente los intereses de las bases con los intereses nacionales. Detectaron y definieron reivindicaciones, desarrollaron una identidad de grupo, idearon estrategias y movilizaron a las masas, a menudo aprovechando oportunidades políticas.

En cuarto lugar, el solidario apoyo financiero y técnico de organismos internacionales de ayuda ha contribuido decisivamente en momentos clave. Dicho apoyo ayudó a las organizaciones comunitarias a aumentar su capacidad, incrementar la interacción entre miembros, coordinar sus acciones y a expandir sus redes a nivel subnacional, nacional e incluso internacional. Por ejemplo, estas organizaciones han establecido colaboraciones funcionales con muchas redes internacionales, como la Asociación Campesina e Indígena de Agroforestería Comunitaria (ACICAFOC) en América Central, la Alianza Global de Forestería Comunitaria (AGFC) y la Iniciativa para los Derechos y Recursos (RRI). 
Los dos casos ilustran que el surgimiento de movimientos sociales depende en gran parte de las oportunidades políticas que pueden facilitar o inhibir la acción colectiva. Como movimientos sociales, estas organizaciones de segundo nivel surgieron de oportunidades políticas que luego fueron ampliadas por los propios movimientos, generando más oportunidades para nuevos movimientos. Estos casos demuestran que las organizaciones de segundo nivel florecen en un régimen político relativamente liberal en el que los derechos básicos de los ciudadanos se respetan y los medios de comunicación trabajan con libertad. Además, estos casos también confirman que, cuanto mayor sea la descentralización espacial y funcional de un sistema político determinado, más efectivos serán los movimientos sociales (Zald y McCarthy 1987). Por ejemplo, FECOFUN no habría existido sin el programa de forestería comunitaria del Gobierno nepalí. El programa de forestería descentralizada abrió más espacios a las iniciativas comunitarias, lo que llevó a la creación de diferentes grupos locales, y más adelante surgieron y prosperaron organizaciones de segundo nivel como redes, cooperativas, y alianzas. Estas organizaciones de segundo nivel aparecieron como movimientos sociales basados en el bosque. Se ha observado que los movimientos sociales basados en el bosque con frecuencia surgen en situaciones de mínima presencia del Estado, cuando en las comunidades locales aparece una conciencia común de amenaza a los intereses de sus medios de vida colectivos (Cronkleton et al. 2008).

\section{Acciones estratégicas para democratizar la gobernanza forestal}

Las organizaciones de segundo nivel adoptan diversas estrategias para desarrollar su agenda de promover derechos comunitarios y democratizar la gobernanza forestal. FECOFUN y ACOFOP movilizaron las redes existentes de sus grupos comunitarios integrantes, su capital social y el apoyo externo para ejercer una gran presión política con el fin de obtener el reconocimiento de los derechos de las comunidades. Hemos identificado cuatro estrategias principales: aumentar la capacidad institucional y técnica de los miembros integrantes; asegurar que los intereses locales influyan en el discurso público sobre manejo de los bosques y del medio ambiente; enfrentarse a las decisiones del Gobierno que no respondan a los intereses locales mediante movilizaciones masivas; y establecer relaciones constructivas con organismos gubernamentales para garantizar que las políticas e instituciones forestales respeten los derechos locales.

Tras ser capacitadas, estas organizaciones de segundo nivel facilitan a sus grupos integrantes instrucción, apoyo institucional, información crucial y vínculos con organismos gubernamentales y con el mercado. FECOFUN y ACOFOP han proporcionado capacitación masiva, intercambio de aprendizaje entre pares y otras herramientas de empoderamiento para aumentar la capacidad de sus organizaciones miembros. Con frecuencia sus estrategias combinan el 'know-how' técnico con el empoderamiento político. Los aspectos técnicos incluyen apoyo en el aprendizaje de prácticas de silvicultura, desarrollo empresarial y gestión de organizaciones. La creación de capacidad política comprende aumentar los conocimientos jurídicos y de políticas, mejorar las capacidades de liderazgo y organizar campañas e iniciativas de creación de redes. Su capacitación también incluye practicar una gobernanza más democrática e inclusiva dentro de las propias organizaciones. 
Las organizaciones de segundo nivel juegan un papel importante al influir en el discurso público introduciendo los puntos de vista y necesidades de sus integrantes en el debate nacional relacionado con la gobernanza de recursos naturales. Las organizaciones de segundo nivel resaltaron historias de éxito de gestión comunitaria, expusieron los puntos débiles de la gestión estatal, movilizaron a los medios de comunicación para difundir sus mensajes y aprovecharon las redes internacionales de sociedad civil y los movimientos de derechos para apoyar su campaña. Aunque estas organizaciones han aparecido al amparo de políticas descentralizadas y participativas, han dirigido la lucha para trasladar los derechos recientemente adquiridos sobre los recursos forestales a la práctica cotidiana. Esto ha sucedido especialmente cuando los organismos estatales han intentado socavar el espíritu de las políticas originales. Las autoridades forestales de Nepal con frecuencia interpretan el programa forestal comunitario desde un punto de vista instrumental y funcionalista, que consiste en asegurar la participación local en la conservación de los bosques. No obstante, FECOFUN ha promovido una interpretación opuesta: que la forestería comunitaria consiste en reconocer los derechos fundamentales de la población a su base de recursos naturales y en promover su autonomía en el manejo de dichos recursos. Del mismo modo, ACOFOP ha argumentado que mejorar los medios de vida locales a través de concesiones comunitarias puede contribuir a un programa de conservación más amplio, dentro y alrededor de la Reserva de la Biosfera Maya. Anteriormente, las organizaciones para la conservación concebían programas de conservación muy restrictivos e intentaban excluir a la población local. Las organizaciones de segundo nivel fueron capaces de establecer y promover nuevos discursos y políticas ambientales que reconocieron gradualmente los derechos comunitarios en el manejo forestal. Incluso las organizaciones para la conservación ahora han afirmado que el manejo con base en la comunidad puede fomentar la biodiversidad (Bray et al. 2008).

Las actividades de resistencia son una de las principales estrategias adoptadas por las organizaciones de segundo nivel cuando sienten que los derechos comunitarios están siendo amenazados o que no se escucha su voz. (Véanse en Cuadro 1 y Cuadro 2 una lista de campañas y acciones políticas llevadas a cabo por FECOFUN y ACOFOP). De hecho, el poder político de estas organizaciones, basado en las masas, con frecuencia ha actuado como un elemento disuasorio frente a decisiones gubernamentales que podrían menoscabar derechos comunitarios. Las organizaciones de segundo nivel proveen el liderazgo para la expresión colectiva de un programa comunitario, generalmente movilizando a sus delegados en extensas regiones con manifestaciones para defender sus intereses.

FECOFUN y ACOFOP también han emprendido estrategias de defensa legal en el caso de que se violen las normas que protegen los derechos comunitarios. Han acudido a los tribunales a defender sus casos, representando los intereses de las comunidades y defendiendo sus derechos al hacer frente a las infracciones de otros agentes, incluido el Estado. FECOFUN, por ejemplo, ha defendido varios casos en los tribunales representando a grupos de usuarios de bosques comunitarios. Igualmente, en Guatemala, ACOFOP se enfrentó a decisiones de políticas que socavaban los intereses de las comunidades y cumplió una función fundamental al canalizar las demandas de los concesionarios comunitarios. Como el caso de estudio expone, ACOFOP logró incrementar el tamaño de las concesiones y ampliar los derechos asignados en los contratos de concesión 
mediante su persistente resistencia y su participación constructiva. Asimismo, ACOFOP ha logrado eliminar la disposición obligatoria de que los planes de manejo y otras actividades sean supervisados y certificados por ONG.

En estos casos, las organizaciones de segundo nivel (en comparación con organizaciones comunitarias locales) pudieron interactuar con representantes del Gobierno y el mercado a niveles más altos. Así crearon nuevos espacios de negociación a nivel intermedio, sirviendo eficazmente de intermediarios. Al ampliar las instancias, las tradicionales relaciones desiguales de poder entre autoridades y comunidades han empezado a desmoronarse y han surgido nuevas configuraciones de poder. Por ejemplo, funcionarios del Gobierno y dirigentes de FECOFUN ahora se sientan juntos frecuentemente en talleres internacionales y aplauden la forestería comunitaria, lo que refleja que su relación ha tomado una forma diferente a pesar del nivel de conflicto en su país. Estos encuentros sirven de canales alternativos de comunicación y resolución de conflictos. De igual manera, la creciente relación de ACOFOP con organismos donantes y alianzas internacionales ha elevado su estatus en el proceso político nacional. Debido a que las organizaciones de segundo nivel son eficaces para movilizar la resistencia popular y pueden usar alianzas más amplias, han aumentado su influencia en la lucha por el poder (Tilly 1978: 78).

Las organizaciones de segundo nivel aportan otro nivel de mediación en el proceso de reforma de la tenencia, promoviendo los puntos de vista e intereses de la comunidad mediante la participación constructiva en la redacción de políticas nacionales. Los procesos de reforma de tenencia tradicionales e impulsados por el Estado se originan a nivel central y son implementados a través de la burocracia estatal, normalmente como un proceso de arriba abajo, en el que las comunidades son tratadas como destinatarios pasivos. En los últimos años, las organizaciones de segundo nivel se han beneficiado de la creciente corriente de procesos de políticas con múltiples interesados. También los organismos gubernamentales y los de ayuda internacional han empezado a invitar a estas organizaciones como participantes permanentes en la formulación de cualquier política, plan o programa importante. En consecuencia, se han convertido en agentes clave en los foros de políticas en materia de gobernanza de bosques y recursos naturales; FECOFUN se ha convertido en un miembro activo de los foros de políticas con múltiples interesados en Nepal, y ACOFOP es miembro del Consejo Nacional de Áreas Protegidas de Guatemala.

El Cuadro 3 muestra un resumen de las diferentes estrategias y sus impactos en la democratización de la gobernanza forestal o el fortalecimiento de los derechos comunitarios.

A pesar de los logros, las organizaciones de segundo nivel han estado enfrentando tres desafíos importantes. En primer lugar, estas redes deben transformarse continuamente para adaptarse al cambiante contexto, con el fin de cumplir adecuadamente las expectativas de sus miembros y partes interesadas. Se enfrentan a demandas de apoyo técnico e institucional para las organizaciones integrantes, necesario para cumplir los cada vez más exigentes criterios y normas. Tanto FECOFUN como ACOFOP se enfrentan 
Cuadro 3. Estrategias e impactos de las organizaciones de segundo nivel

\begin{tabular}{|c|c|c|}
\hline Estrategias principales & Actividades asociadas & Resultados en la gobernanza \\
\hline $\begin{array}{l}\text { Desarrollar la capacidad } \\
\text { técnica e institucional en } \\
\text { los grupos comunitarios } \\
\text { integrantes. }\end{array}$ & $\begin{array}{l}\text { Ayudar a aumentar las } \\
\text { habilidades de manejo forestal } \\
\text { y gestión empresarial de los } \\
\text { grupos, sus conocimientos } \\
\text { legales, la capacidad de } \\
\text { liderazgo, sus redes y la } \\
\text { gobernanza interna del grupo. }\end{array}$ & $\begin{array}{l}\text { Mejoró el funcionamiento } \\
\text { y la eficacia de los grupos } \\
\text { comunitarios, la fortaleza } \\
\text { institucional y los beneficios } \\
\text { de los medios de vida. }\end{array}$ \\
\hline $\begin{array}{l}\text { Influir en los discursos } \\
\text { ambientales que legitiman } \\
\text { y dan voz a los intereses } \\
\text { comunitarios. }\end{array}$ & $\begin{array}{l}\text { Destacar el éxito comunitario } \\
\text { como una poderosa crítica } \\
\text { a la ineptitud del gobierno } \\
\text { en el manejo de los recursos; } \\
\text { generar y comunicar una } \\
\text { contra narrativa a los puntos } \\
\text { de vista dominantes sobre } \\
\text { manejo comunitario y } \\
\text { conservación. }\end{array}$ & $\begin{array}{l}\text { Apoyo público a más } \\
\text { derechos comunitarios y a } \\
\text { un manejo de los bosques } \\
\text { descentralizado y basado en } \\
\text { las comunidades. }\end{array}$ \\
\hline $\begin{array}{l}\text { Desafiar las decisiones } \\
\text { del gobierno. }\end{array}$ & $\begin{array}{l}\text { Protestas callejeras, asambleas, } \\
\text { campañas en medios de } \\
\text { comunicación, presión } \\
\text { con dirigentes políticos y } \\
\text { burocráticos, litigios públicos, } \\
\text { falta de cooperación. }\end{array}$ & $\begin{array}{l}\text { Se combaten las políticas } \\
\text { de arriba abajo que socavan } \\
\text { derechos comunitarios y, } \\
\text { en muchos casos, no son } \\
\text { promulgadas; los organismos } \\
\text { estatales y privados } \\
\text { responden con interés y } \\
\text { responsabilidad. }\end{array}$ \\
\hline $\begin{array}{l}\text { Participación constructiva en } \\
\text { el proceso de formulación } \\
\text { de políticas. }\end{array}$ & $\begin{array}{l}\text { Participar activamente, hacer } \\
\text { aportaciones fundamentales } \\
\text { e influir en organismos donde } \\
\text { participan múltiples actores y } \\
\text { foros de políticas nacionales. }\end{array}$ & $\begin{array}{l}\text { Se formulan e introducen } \\
\text { políticas progresistas } \\
\text { orientadas a la población. }\end{array}$ \\
\hline
\end{tabular}

al importante desafío de aumentar la capacidad de sus organizaciones miembros para satisfacer al mercado y los requisitos del gobierno.

En segundo lugar, estas organizaciones deben encontrar un delicado equilibrio entre los aspectos técnicos de gestión y producción como normas, prácticas de silvicultura, organización empresarial, información del mercado y habilidades de negociación por una parte, y garantizar los derechos y la autonomía de las comunidades por la otra. Existe un conflicto interno en el tema de prioridades dentro de las organizaciones. Si se centran demasiado en aspectos técnicos de la producción se acercarían a ser simplemente ONG normales y, por lo tanto, les resultaría difícil justificar la existencia de la federación. Por el contrario, si se centran estrictamente en la promoción política, pueden ignorar las múltiples necesidades acuciantes de las instituciones en sus operaciones cotidianas.

En tercer lugar, cuando las organizaciones de segundo nivel se involucran en problemas de descentralización más amplios, comercio justo y autonomía de las comunidades a nivel 
regional y mundial, tienden a ignorar muchos problemas domésticos importantes. A veces hay concesiones entre la campaña global y la agenda local. Por ejemplo, cuando los dirigentes de FECOFUN o ACOFOP están involucrados en la negociación de programas regionales o globales concernientes a reformas de la gobernanza y derechos comunitarios, posiblemente no presten suficiente atención a los programas locales de seguridad de la tenencia, medios de vida, equidad y democracia interna. Esto es particularmente cierto en sociedades diferenciadas internamente, en las que estas organizaciones de segundo nivel suelen estar lideradas por grupos sociales más privilegiados. Aunque estas organizaciones han hecho esfuerzos conscientes para abordar muchos de estos problemas de gobernanza interna, aún queda mucha distancia entre la retórica organizativa y la práctica institucional de cada día. Es más, como argumentaron Ribot et al. (2008), la pluralidad institucional creada a nivel local por estas redes influyentes ha tendido a socavar los organismos gubernamentales locales, por lo que, en cierta manera, han debilitado la democracia de las bases.

\section{Lecciones y conclusiones}

El análisis de estas dos organizaciones forestales de segundo nivel sugiere que, en estos procesos, las organizaciones de segundo nivel han desempeñado una función clave al ampliar la acción colectiva, facilitar el flujo e intercambio de información, hacer frente a las desigualdades existentes en las estructuras de poder y obtener fuerza política para defender sus intereses. En consecuencia, estas organizaciones de segundo nivel se han convertido en importantes fuerzas en la mejora de la gobernanza forestal al profundizar, apoyar e institucionalizar el papel de las comunidades locales y dar voz a la población local en la gobernanza forestal.

Las organizaciones de segundo nivel contribuyen al avance de la forestería comunitaria al incrementar la capacidad de las organizaciones comunitarias para influir en los cambios externos. La consolidación como organizaciones de segundo nivel permitió a ambos grupos hacer frente a poderosos intereses externos que intentaban aprovecharse de las reformas de tenencia forestal, así como defender sus derechos de exclusión al crear alianzas políticas. Esta capacidad es esencial, si éstas desean disfrutar de una tenencia segura a largo plazo. Además, estas organizaciones desempeñan una función importante en el proceso de adquirir y mantener la legitimidad de los esfuerzos de reforma de la tenencia (Monterroso y Barry, esta colección). ACOFOP crea nuevas oportunidades de promoción política para las organizaciones de base a nivel regional y nacional.

Las organizaciones de segundo nivel también asumen la función de facilitar, coordinar y promover los intereses de sus organizaciones de primer nivel, mientras que estas están directamente involucradas en el manejo diario de sus recursos. Los casos estudiados ilustran situaciones en las que la población que depende del bosque ha aprendido a colaborar más allá de sus comunidades de origen, y ya no les satisface ser destinatarios pasivos de los programas gubernamentales de desarrollo forestal. Estos actores colectivos han surgido como fuerzas importantes para promover la toma de decisiones participativa e inclusiva y, por lo tanto, democratizar la gobernanza forestal. 
Las organizaciones de segundo nivel también han sido capaces de mantener, profundizar e institucionalizar políticas y prácticas de descentralización al enfrentarse a las estructuras políticas de poder, influir en las políticas estatales y participar activamente en las instituciones del mercado. Todo esto sugiere que las organizaciones de segundo nivel se han convertido en importantes agentes en el proceso de creación de políticas forestales, especialmente mejorando la seguridad de la tenencia y los beneficios de los medios de vida para las comunidades forestales.

Los casos expuestos en este estudio permitieron comprender mejor no solo cómo funcionan estos mecanismos organizativos, sino también qué resultados producen para los miembros. Ilustran que las organizaciones de segundo nivel son capaces de interactuar con representantes del gobierno y el mercado a niveles más altos, donde las organizaciones comunitarias locales tienen escaso acceso.

La población rural que depende de los bosques crea organizaciones de segundo nivel cuando siente que sus derechos comunitarios están siendo amenazados. No obstante, se enfrentan a grandes desafíos. Estas redes deben transformarse continuamente para hacer frente a condiciones cambiantes y así poder cumplir adecuadamente las expectativas de sus integrantes. Otro desafío importante es que estas organizaciones deben encontrar un equilibrio entre las exigencias económicas y de producción de los miembros por una parte, y la promoción y negociación política por la otra para asegurar los derechos y la autonomía de la comunidad. Además, cuando las organizaciones de segundo nivel se involucran en problemas de descentralización más amplios, comercio justo y autonomía de las comunidades a nivel regional y mundial, pueden perder de vista muchos problemas domésticos importantes.

\section{Notas}

1. Estos movimientos han democratizado la gobernanza forestal porque han asegurado que las comunidades locales alrededor de áreas forestales expresen sus intereses, y han influido en procesos que determinan sus derechos de propiedad y control de los recursos forestales.

2. El estudio, realizado por CIFOR, se llevó a cabo durante 2006-2008 en Brasil, Bolivia, Nicaragua, Guatemala, Camerún, Ghana, Burkina Faso, Nepal, Filipinas e India.

3. El tamaño medio de los bosques comunitarios en Nepal es de 85 hectáreas.

4. FECOFUN fue inscrita formalmente como organización no gubernamental en septiembre de 1995.

\section{Referencias}

ACOFOP. 2005. Guía básica para los habitantes de las comunidades forestales. Petén, Guatemala. Guatemala.

Agrawal, A. 2001. Common property institutions and sustainable governance of resources. World Development 29(10): 1649-1672. 
Agrawal, A. y E. Ostrom. 2001. Collective action, property rights, and decentralization in resource use in India and Nepal. Politics \& Society 29(4): 485-514.

Baland, J.M. y J.P. Platteau. 1996. Halting degradation of natural resources: Is there a role for rural communities? Oxford: FAO y Claredendron Press.

Barry, D. e I. Monterroso. 2008. Institutional change and community forestry in the Mayan Biosphere Reserve Guatemala. Proceedings of the International Association for the Study of the Commons IASC. Julio de 2008. Cheltenham, Inglaterra.

Bebbington, A. 1996. Organizations and intensifications: Campesino federations, rural livelihoods and agricultural technology in the Andes and Amazonia. Word Development 24(7): 1161-1178.

Bebbington, A. 1997. Social capital and rural intensification: Local organizations and islands of sustainability in the rural Andes. The Geographical Journal 163: 180-197.

Bhattarai, K., D. Conway y N. Shrestha. 2002. The vacillating evolution of forestry policy in Nepal: Historically manipulated, internally mismanaged. International Development Planning Review 24(3): 315-338.

Bray, D.B., E. Duran, V.H. Ramos, J.F. Mas, A. Velazquez, R.B. McNab, D. Barry y J. Radachowsky. 2008. Tropical deforestation, community forests, and protected areas in the Maya Forest. Ecology and Society 13(2): 56. http://www.ecologyandsociety. org/vol13/iss2/art56/.

Bromley, D.W. 2004. Reconsidering environmental policy prescriptive: Consequentialism and volitional pragmatism. Environmental and Resource Economics 128(1): 73-99.

Carroll, T.F., A.J. Bebbington. 2000. Peasant federations and rural development policies in the Andes. Policy Science 33: 433-457.

Cohen, J.L. 1983. Rethinking social movements. Berkeley Journal of Sociology 28: 97-114.

Colchester, M., T. Apte, M. Laforge, A. Mandondo y N. Pathak. 2003. Bridging the gap: Communities, forests and international networks. Informe de síntesis del proyecto 'Learning Lessons from International Community Forestry Networks'. Bogor: CIFOR Occasional Paper No. 41.

Cronkleton P., P.L. Taylor, D. Barry, S. Stone-Jovicich y M. Schmink. 2008. Environmental governance and the emergence of forest based social movements. Bogor: Centro para la Investigación Forestal Internacional.

Federación de Usuarios de Bosques Comunitarios de Nepal (FECOFUN). 1999. Samayik Prakashan. Volumen 3. Katmandú: FECOFUN.

Federación de Usuarios de Bosques Comunitarios de Nepal (FECOFUN). 2002. Report of Third National Council Meeting. Katmandú: FECOFUN.

Forest Action y SEACOW. 2002. Community forestry in Nepal: Other side of the coin. Video documental. Katmandú: ForestAction.

Hardin, G. 1968. The tragedy of the commons. Science 162: 1243-1248.

Harvey, D. 2003. The new imperialism. Oxford, Oxford University Press.

His Majesty's Government of Nepal/Ministry of Law and Justice (HMG/MoLJ). 1993. Forest Act (2049). Katmandú: HMG/MoLJ. 
Komarudin, H., Y. Siagian y C. Colfer. 2008. Collective action to secure property rights for the poor. CAPRi Working Paper No 90.

Monterroso, I. y D. Barry. 2009. Sistema de concesiones forestales comunitaria: Tenencia de la tierra, bosques y medios de vida en la Reserva de la Biósfera Maya en Guatemala. Centro para la Investigación Forestal Internacional; Facultad Latinoamericana de Ciencias Sociales. Editorial de Ciencias Sociales, Guatemala.

Monterroso, I. 2007. Nuevas tendencias y procesos que influyen en el manejo comunitario forestal en la Zona de Usos Múltiples Reserva de Biósfera Maya en Petén, Guatemala. Informe para el proyecto CIFOR-ACOFOP. Manuscrito inédito.

Neirdhardt, F. y D. Rutcht. 1991. The analysis of social movements: The state of the art and some perspectives for further research. Westview Press. $464 \mathrm{pp}$.

Nightingale A.J. 2003. Nature, society and development: Cultural, social and ecological change in Nepal. Geoforum 34: 525-540.

Offe, C. 1985. New social movements: Challenging the boundaries of institutional politics. Social Research 52(4): 817-868.

Ojha, H., D.R. Khanal, N.S. Paudel, H. Sharma y B. Pathak. 2007. Federation of community forest user groups in Nepal: An innovation in democratic forest governance. Actas de la Conferencia Internacional sobre Reducción de la Pobreza y los Bosques, Bangkok, Tailandia. Septiembre de 2007. Bangkok: RECOFTC-RRI.

Ojha, H., N. Timsina, R. Chhetri y K. Paudel. 2008. Communities, forests and governance: Policy and institutional innovations from Nepal. Nueva Delhi: Adroit Publishers.

Ostrom, E. 1990. Governing the commons: The evolution of institutions for collective action. Nueva York, NY: Cambridge University Press.

Ostrom, E. 1999. Self-governance and forest resources. Bogor: CIFOR Occasional Paper Series 20.

Paudel, N.S., I. Monterroso y P. Cronkleton. 2008. Community networks, collective action and forest management benefits. En: Community rights and forest tenure reform (eds. Larson, A.M., D. Barry, G.R. Dahal y C.J.P. Colfer). Pp: 116-138. Londres: EarthScan.

Pokhrel, B. K, P. Branney, M. Nurse y Y.B. Malla 2007. Community forestry: Conserving forests, sustaining livelihoods and strengthening democracy. Journal of Forest and Livelihood 6(2): 8-19.

Ribot, J., A. Chhatre y T. Lankina. 2008. Introduction: Institutional choice and recognition in the formation and consolidation of local democracy. Conservation and Society 6(1): 1-11.

Ribot, J.C., A. Agrawal y A. Larson. 2006. Recentralizing while decentralizing: How national governments reappropriate forest resources. World Development 34(11): 1864-1886.

Shrestha, N.K. 2001. The backlash: Recent policy changes undermine user control of community forests in Nepal. Forest, Trees and People Newsletter (44): 62-65. 
Sundberg, J. 1998. NGO landscapes in the Maya Biosphere Reserve, Guatemala. Geographical Review 88(3): 388-412.

Taylor, P. 2010. Conservation, community, and culture? New organizational challenges of community forest concessions in the Maya Biosphere Reserve of Guatemala. Journal of Rural Studies 26(2): 173-184.

Tilly, C. 1978. From mobilization to revolution. Reading, MA: Addison-Wesley.

Timsina, N. 2003. Viewing FECOFUN from the perspective of popular participation and representation. Journal of Forest and Livelihood 2(2): 67-71.

Touraine, A. 1985. An introduction to the study of social movements. Social Research 52(4): 749.

Wollenberg, E., M. Colchester, G. Mbugua y T. Griffiths. 2005. Linking social movements: How international networks can better support community action about forests. CIFOR Working Paper Series No. 31. Bogor: Centro para la Investigación Forestal Internacional.

Zald, M. y J.D. McCarthy (eds.). 1987. Social movements in an organizational society. New Brunswick, NJ: Transaction Books. 



\section{Estudios de caso latinoamericanos}

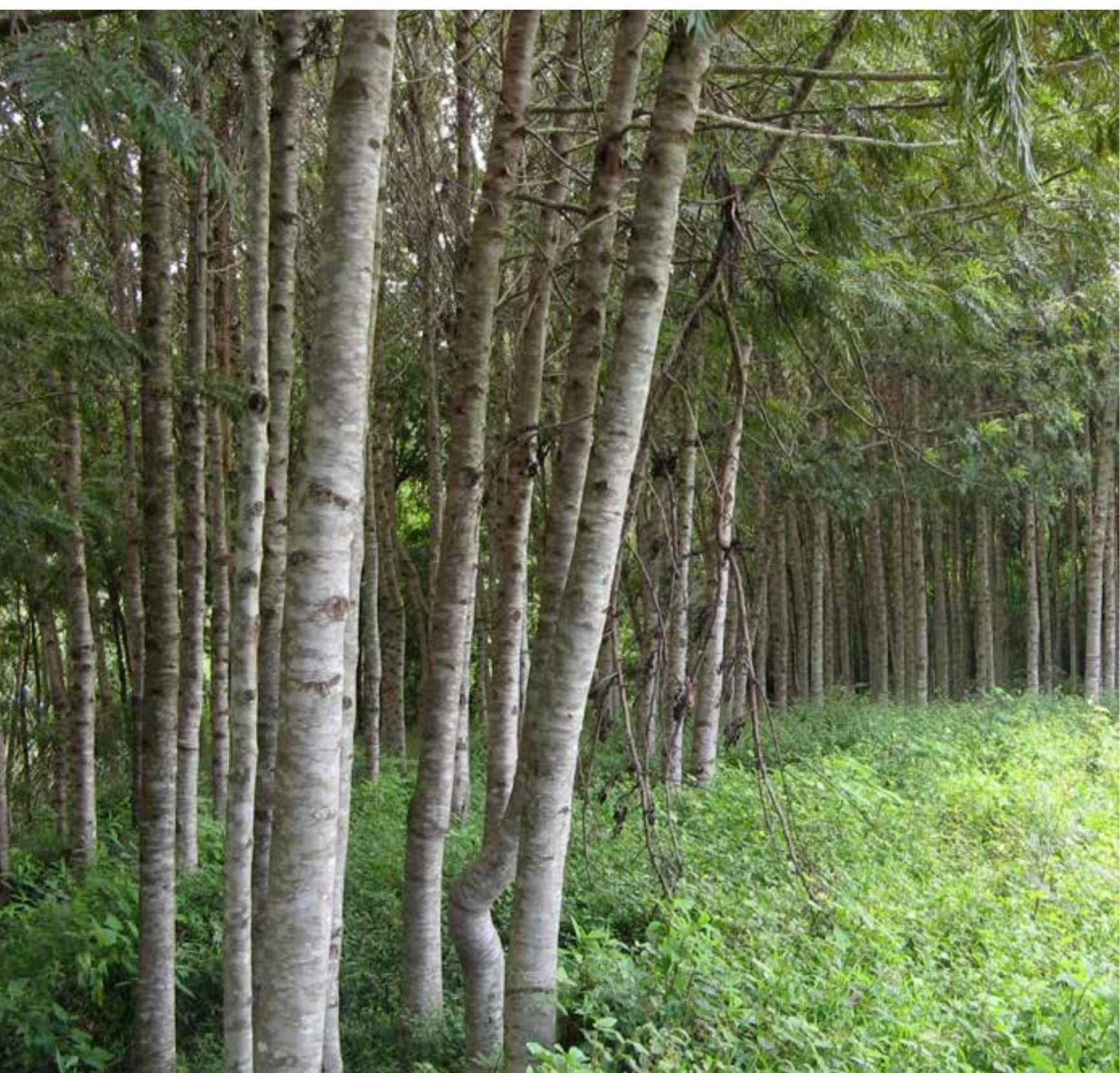





\title{
La legitimidad de los derechos forestales
}

\author{
Los fundamentos de la reforma de tenencia forestal en las áreas protegidas \\ de Petén, Guatemalai
}

Iliana Monterroso oi,iii y Deborah Barryii

\section{Resumen}

En las últimas décadas, los bosques en el mundo han experimentado un proceso importante de reconocimiento y transferencia de derechos a comunidades o individuos, referido aquí como "reformas de tenencia forestal". Entre las regiones en desarrollo, América Latina ha sido testigo del reconocimiento y de la transferencia más importante de estos derechos de tenencia a comunidades que habitan en los bosques y que dependen de ellos. Este artículo examina el proceso de reforma en Guatemala, donde el Estado ha reconocido y transferido derechos a grupos locales organizados que han establecido un sistema de concesiones comunitarias en la zona de uso múltiple en la Reserva de la Biosfera Maya. Analizamos la evolución de reclamos sobre los usos de los bosques y nos centramos en los elementos de legitimidad que sustentan el proceso a través del cual una demanda se convierte en derecho. Los resultados muestran que para sostener el proceso de reforma de tenencia forestal en el tiempo, es importante entender cómo se transfieren y distribuyen los arreglos de tenencia entre los que reciben los derechos y cómo este proceso es influenciado por los elementos que sustentan la legitimidad, así como los elementos que definen la autoridad. Entender los fundamentos de la legitimidad que sustentan las reformas de tenencia forestal es clave para identificar las formas en que estos procesos pueden funcionar y también es importante para desarrollar marcos de política más sólidos que llenen los vacíos y resuelvan las incongruencias de los sistemas gubernamentales de manejo forestal.

i Este artículo es una traducción del original, que apareció en inglés en la revista Conservation and Society, en la edición especial sobre Reformas de tenencia forestal (eds. Anne M. Larson y Ganga Ram Dahal). La cita original completa es: Monterroso, I. and Barry, D. 2012 Legitimacy of Forest Rights: The Underpinnings of the Forest Tenure Reform in the Protected Areas of Petén, Guatemala. Conservation and Society 10(2): 136-150. El artículo cuenta con una licencia de Creative Commons de Atribución 3.

ii Iniciativa para los Derechos y Recursos (RRI), Washington D.C., Estados Unidos imonterroso@flacso.edu.gt.

iii Facultad Latinoamericana de Ciencia Sociales (FLACSO) Guatemala, Ciudad de Guatemala, Guatemala. 


\section{Introducción}

Durante los últimos 20 años, América Latina ha sido testigo de importantes procesos de reconocimiento de derechos de tenencia sobre tierras forestales que anteriormente eran de propiedad estatal, y de la transferencia de estos derechos a comunidades que habitan en los bosques o que dependen de ellos, incluyendo grupos indígenas y campesinos (Larson et al. 2010a; RRI y OIMT 2009; Sunderlin et al. 2008). En total, al año 2008, prácticamente el $25 \%$ de los bosques de la región son propiedad de comunidades y pueblos indígenas, y otro 7\% se ha designado para su uso (White y Martin 2002; RRI y OIMT 2009). En América Latina esto asciende a un total de 216 millones de hectáreas de bosques en manos de estos grupos (67 millones de hectáreas desde el 2002), lo que representa un cambio importante en los activos de la población rural pobre. Esta es una tendencia importante ya que los resultados positivos - la conversión de recursos forestales en activos o medios de vida comunitarios e ingresos al tiempo que se conservan las reservas de bosques — están asociados al fortalecimiento de los acuerdos institucionales para la toma de decisiones a nivel local y a una mejora general en la gobernanza forestal y ambiental (Larson 2010; Lemos y Agrawal 2006).

Este artículo se basa en una investigación llevada a cabo en Guatemala como parte de un estudio global comparativo que analizó 30 casos en 10 países donde las comunidades habían ganado derechos estatutarios sobre tierras forestales y recursos naturales durante los últimos 20 años $^{1}$ (véase Larson en esta colección). El proceso de reconocimiento de derechos ha sido definido como una reforma de la tenencia forestal (véase Larson et al. $2010 \mathrm{a}, \mathrm{b})$. Aunque Guatemala es un país pequeño con extensiones relativamente limitadas de bosques templados y tropicales, durante la última década se han estado llevando a cabo innovadores cambios en el régimen de tenencia forestal que han conducido a los resultados positivos mencionados anteriormente. En este caso, analizamos el proceso de reconocimiento y ampliación de los derechos comunitarios en Petén, donde se han otorgado contratos de concesiones forestales — por un período de 25 años, entre el Estado y comunidades organizadas - en más de 400000 ha dentro del área protegida más grande de Mesoamérica: la Reserva de la Biosfera Maya. El sistema de concesiones comunitarias en la zona de uso múltiple representa cerca del 15\% de la cobertura total de bosque del país, incluyendo los parques nacionales (IARNA et al. 2006). Junto con estos, las concesiones constituyen el área de conservación más grande dentro de la selva maya (una superficie de $155020 \mathrm{~km}^{2}$, incluyendo México, Petén y Belice).

Existen dos características particularmente interesantes de la reforma forestal guatemalteca. En primer lugar, la titulación de tierras, el otorgamiento de plenos derechos de propiedad, no fue el mecanismo empleado por el Estado para asegurar los derechos. Más bien, los derechos se derivaron del establecimiento de un área protegida. Esto nos da un ejemplo único y útil que apoya el trabajo de varios autores (Cousins et al. 2005; Broegaard 2005; Benda-Beckman y Von Benda-Beckman 1999) que han analizado los mecanismos que garantizan la seguridad de la tenencia, más allá de la propiedad privada. En segundo lugar, la reforma de tenencia en Guatemala no otorgó derechos de enajenación (derechos para vender o arrendar la tierra), pero sí reconoció importantes derechos de uso, acceso, 
manejo y exclusión sobre los bosques. Esto crea una oportunidad única para observar los cambios en los reclamos sobre estos recursos forestales.

Para poder entender los orígenes, la naturaleza y los resultados iniciales de la reforma de tenencia en Guatemala, analizamos el surgimiento de las concesiones comunitarias como modelo para la conservación de los bosques en Petén, el rol de los grupos de usuarios forestales con reivindicaciones de acceso al área, el complejo conjunto de derechos reconocidos, las entidades del Estado (que otorgan derechos) involucradas en el proceso de reconocimiento y los grupos sociales (que reciben los derechos/los titulares de los derechos) que se benefician de esta reforma. Argumentamos que, al estudiar las reformas de la tenencia forestal, es muy importante entender la lógica o la justificación para el reconocimiento del derecho y la entidad que autoriza el derecho. Igualmente importantes son las fuentes de legitimidad de las estructuras locales y gubernamentales involucradas en el proceso, y la capacidad de los grupos locales para crear instituciones que puedan defender estos derechos frente a las agencias gubernamentales. En el caso de Guatemala, las nuevas normas que regulan las concesiones comunitarias generaron la demanda para la producción de nuevas instituciones. Diferentes formas de acción colectiva surgen para poder ejercer los nuevos derechos, obtener beneficios directos de las actividades de manejo y garantizar la capacidad de excluir a terceros.

Las siguientes secciones presentan los resultados de la investigación, que muestran importantes cambios derivados del reconocimiento de los derechos forestales comunitarios en la zona de uso múltiple de la Reserva de la Biosfera Maya. Exploramos los fundamentos de la legitimidad de los que reciben los derechos y de los que otorgan los derechos, y demostramos de qué forma se establece la legitimidad como un proceso de reconocimiento mutuo de la autoridad sobre este derecho. Por un lado, analizamos el proceso de cómo las instituciones estatales en Guatemala legitiman su autoridad en Petén, mientras que, por el otro, examinamos cómo las concesiones locales se convirtieron en formas legítimas de acceso y manejo de los recursos forestales. Argumentamos que entender los elementos que mantienen la legitimidad de los derechos de tenencia forestal es vital para identificar las formas en que estos procesos pueden funcionar mejor para obtener resultados para los bosques y los medios de vida. La siguiente sección revisa brevemente importantes aspectos teóricos y metodológicos de este estudio. La sección 3 presenta y analiza los principales resultados, mientras que la sección 4 resalta las recomendaciones para los interesados. Finalmente, la última sección revisa las principales conclusiones de este trabajo.

\section{Aspectos teóricos y metodológicos}

En trabajos anteriores, varios autores (Clark 2000; Cousins 2007; Sikor y Lund 2009) argumentan que, dentro del proceso de otorgamiento de derechos de tenencia, la autorización de derechos está íntimamente relacionada con la legitimidad del que los otorga y del que los recibe. Estos dos grupos de actores juegan roles vitales en el mantenimiento de la seguridad de esos derechos y del modelo de tenencia más amplio que 
sustentan. Esta sección presenta el marco teórico utilizado para analizar los resultados del trabajo de campo. En primer lugar, analizamos los temas relacionados con el concepto de legitimidad y el proceso de ejercer autoridad y legitimar las reivindicaciones sobre los bosques. El resultado de este proceso de legitimación es el reconocimiento de derechos, la base de las reformas de la tenencia forestal. En segundo lugar, analizamos los instrumentos analíticos usados para entender los cambios en la asignación de derechos derivados del proceso de reforma de la tenencia.

\section{El concepto de legitimidad: el ejercicio de la autoridad y la legitimación de las reivindicaciones de acceso y los reclamantes}

Aunque el concepto de legitimidad ha sido analizado ampliamente en las ciencias sociales y políticas (Arneson 2003; Habermas 2004; Weber 1921), hemos adoptado la definición de trabajo de Suchman (1995) para el análisis de los procesos de reforma de la tenencia forestal en Petén. En su análisis, Suchman (1995: 574) define la legitimidad como una "percepción o suposición generalizada de que las acciones de una entidad son deseables, correctas o apropiadas dentro de algún sistema socialmente construido de normas, valores, creencias y definiciones". Si bien este autor basa su conceptualización de legitimidad en un punto de vista social y conductual, también nos da elementos para explorar las dimensiones normativas y evaluativas del concepto. De particular importancia para esta investigación resulta su visión de legitimidad orientada a los resultados. Esto coincide con los autores (Arneson 2003; Bohman 1996) que argumentan que para poder explicar cómo las políticas, acciones y decisiones se legitiman, es importante entender las normas, los valores, los acuerdos institucionales y las creencias. Estos elementos nos dan una idea de la motivación a nivel colectivo que sustentan las acciones.

En nuestro análisis del proceso de reforma de la tenencia forestal hemos observado que pueden existir múltiples acciones legítimas y grupos sociales. En este estudio diferenciamos a los reclamantes forestales en Petén entre los que reciben los derechos (por ejemplo, los grupos organizados, las organizaciones no gubernamentales) y los que otorgan los derechos (por ejemplo, el Estado). La definición de reivindicaciones y reclamantes depende del contexto y del tiempo. Pueden surgir nuevos actores y el rol de los actores cambia en función del contexto histórico. La existencia de diferentes estrategias y grupos de legitimación es producto de una construcción colectiva, lo que demuestra que, como construcción social, la legitimidad está con frecuencia en disputa. Por ello es importante entender cómo la existencia de múltiples acciones legítimas puede facilitar la resolución de conflictos relacionados con un tema particular.

En el análisis de la reforma de la tenencia forestal en Petén (1985-2007), los cambios en el contexto económico y político (antes y después de dicha reforma) influyeron en el surgimiento de nuevos actores sociales y estatales quienes, a su vez, tienen diferentes reivindicaciones sobre los bosques. En esta investigación, el análisis histórico fue vital para delinear el proceso y demostrar los roles cambiantes de las entidades estatales (y de los grupos sociales vinculados a estos procesos) en el tiempo. Cuando analizamos el papel cambiante del Estado, prestamos especial atención a los mecanismos que ordenan el 
espacio, es decir, las estrategias de territorialización ${ }^{2}$ (Sikor y Lund 2009), como un tipo de legitimación usada por el Estado en Guatemala para establecer su autoridad en Petén. El Estado refuerza un grupo de normas para establecer su autoridad y con ello genera la demanda de la creación de un nuevo conjunto de organizaciones.

En el análisis de las dinámicas de legitimación, los reclamantes del modelo de tenencia incluyen a aquellos individuos que se hicieron miembros de las organizaciones concesionarias, así como otros usuarios forestales con reivindicaciones de acceso a los recursos dentro de la Reserva de la Biosfera Maya. Esto significa que en el proceso de garantizar derechos de acceso a los miembros de una concesión, el Estado guatemalteco deniega la misma garantía a otros reclamantes. Esta exclusión puede generar conflicto, como cuando las reglamentaciones formales reconocen los derechos de extracción a grupos diferentes dentro del mismo territorio. Esta es una señal clara de que la legitimidad, como construcción social, es cuestionada frecuentemente.

Además, los conceptos de legitimidad, autoridad y poder están íntimamente relacionados. Weber (1921) definió el proceso de crear autoridad como uno vinculado a la capacidad de ejercer poder en una forma que sea "legítima". En esta definición la autoridad se refiere a la capacidad de influir en otros actores sociales. Por ello, cuando se analiza la legitimidad, es importante examinar los procesos mediante los cuales se establece, fortalece y cuestiona la autoridad (Sikor y Lund 2009). Por último, es importante señalar que existen diferentes instituciones políticas y legales que legitiman la autoridad. Cuando las reivindicaciones de acceso se disputan arduamente y las relaciones de poder se tornan difusas, como en el caso de Petén, Sikor y Lund (2009: 12) sugieren centrarse en "cómo se crean, consolidan y expanden las instituciones del Estado y su autoridad"; Sikor y Lund (2009:12) sugieren no considerar al Estado como un "conjunto de instituciones congruentes".

En otras palabras, puede haber autoridades del Estado que compiten unas con otras, así como competencia entre el Estado y otros actores. La legalidad de las reglamentaciones y procedimientos formales como fuentes globales de autoridad legítima no es suficiente (Habermas 2004); si bien el rol del Estado es importante, la autoridad política no es exclusiva de los actores estatales. Durante los últimos años se ha producido un alejamiento claro de las entidades del Estado y una participación creciente de actores no gubernamentales en la esfera de la gobernanza. Por ello, surgen preguntas relativas a la legitimidad de las instituciones sociales — particularmente con respecto a la representación y la rendición de cuentas (Lemos y Agrawal 2006)_-, que requieren un examen de otras esferas donde se ejercen el poder y la autoridad. Por ejemplo, la certificación por terceros de la producción sostenible de productos forestales también ha sido analizada como un instrumento de legitimación, fortaleciendo las normas para garantizar la aplicación de normas en las actividades de manejo forestal (Cashore 2002; Eden 2009). Otros estudios han investigado las condiciones que explican la participación en los sistemas de comanejo en las áreas protegidas y han determinado que la legitimidad es un factor clave que favorece la participación de las mujeres (Nuggehalli y Stalker 2009). Además, al abordar el tema de las asociaciones de segundo nivel en las concesiones de Petén, Taylor (2009) 
argumenta que es importante contar con una organización efectiva para mantener la representación, la igualdad y la legitimidad (véase también Paudel et al. en esta colección).

Por último, si bien la legitimidad de los resultados y los actores son elementos importantes, en este artículo argumentamos que no son suficientes para entender cómo las reivindicaciones sobre los bosques se convierten en derechos. Por esa razón, también nos concentramos en el proceso y las estrategias que determinan la legitimidad del proceso de reforma de la tenencia. La falta de legitimidad de las antiguas instituciones responsables de la tenencia de tierras en Petén fue estudiada por Clark (2000) con el objetivo de demostrar cómo la inseguridad de la tenencia fomenta la colonización, deforestación y la conversión de los bosques. Este investigador basó sus resultados en tres estudios de casos, uno de ellos referido a la Reserva de la Biosfera Maya. Otro trabajo vinculado a este tema es el de Larson (2010), quien resalta la importancia de la configuración de autoridad. En su estudio de los territorios indígenas de Nicaragua, Larson (2010) analiza el proceso de configuración de las autoridades territoriales y cómo los poderes representativos se legitimaron como quienes reciben los derechos a través de procesos de constante negociación.

\section{La caja de derechos de tenencia como instrumento para comprender la complejidad de los derechos y de los titulares de esos derechos}

En el análisis de los procesos de reforma de la tenencia forestal, usamos un enfoque basado en los derechos (Colchester 2008; véase también Cronkleton en esta colección). Entendemos por tenencia forestal un conjunto de derechos que determina "quién puede utilizar qué derechos, de qué forma, por cuánto tiempo y en qué condiciones, así como quién puede transferir derechos a otros y cómo” en los bosques (Larson 2010: 80). Estos conjuntos de derechos incluyen los derechos del usuario (acceso, uso) y derechos de toma de decisiones (manejo, exclusión y enajenación). El acceso se refiere a la posibilidad de ingresar a un área forestal. Los derechos de uso, extracción y retiro representan la posibilidad de obtener leña, palma o cualquier otro producto forestal maderable o no maderable de los bosques. Los derechos de manejo se refieren a la toma de decisiones sobre el recurso (mantenimiento del recurso, momento de la corta, regular quién usa qué recurso y cómo lo usa). Los derechos de exclusión se refieren a la capacidad de evitar que cualquier individuo o grupo ingrese a los bosques y extraiga recursos de ellos. Por último, los derechos de enajenación se refieren a la posibilidad de transferir derechos, incluyendo el derecho de venta o arrendamiento. En las áreas forestales, estos derechos son potestad de una gama de actores, incluyendo los usuarios comunitarios del bosque, las entidades del Estado o individuos (Barry y Meinzen-Dick 2012). Barry y Meinzen-Dick (2012) argumentan que la desagregación de derechos en estas categorías permite examinar los cambios en los derechos en más detalle.

El trabajo empírico en el que se basa este artículo se centra en la aplicación de una herramienta conceptual, "la caja de derechos de tenencia", para interpretar la tenencia como un "conjunto de derechos". Visualizamos el conjunto de derechos como una matriz 


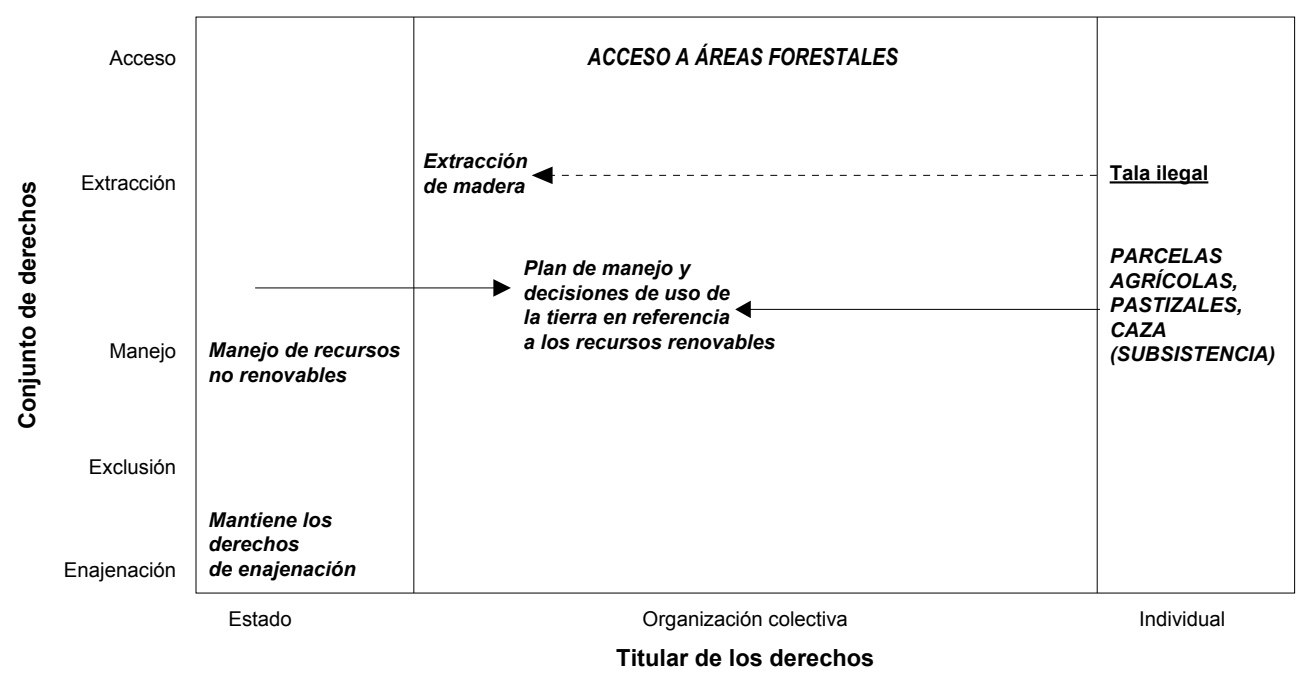

\begin{tabular}{|l|l|}
\hline "Base regulatoria & \multicolumn{1}{|c|}{ Flechas } \\
\hline de jure & $\begin{array}{l}\text { Indica la dirección del derecho, ya sea transferido del Estado al } \\
\text { manejo colectivo o del manejo individual al colectivo }\end{array}$ \\
\hline DE FACTO & $\begin{array}{l}\text { Indica la formalización de una actividad ilegal al titular } \\
\text { colectivo de los derechos }\end{array}$ \\
\hline Acción ilegal & $\ldots \ldots \ldots$ \\
\hline
\end{tabular}

Figura 1. Mapeo: Tendencias en la transferencia de derechos en las reformas de tenencia forestal

Fuente: Adaptado de Barry y Meinzen-Dick 2012

[Figura 1] donde los ejes "se han ampliado", permitiendo una descripción más específica tanto de los tipos de derechos en el conjunto de derechos como de sus titulares. En la caja de tenencia, las flechas indican el recorrido del derecho, ya sea si el Estado lo ha transferido a la colectividad, lo ha individualizado o si se ha dado la situación inversa. Los diferentes tipos de letras utilizados (por ejemplo, normal y cursiva) en los derechos implican que la base reglamentaria estableció ya sea derechos formales de jure, identificados en letra redonda minúscula en el caso de las normas nacionales, o derechos informales de facto, identificados en letras MAYÚSCULAS, reconocidos por el titular colectivo de los derechos. Por último, las acciones ilegales (subrayadas) no son reconocidas por ninguno de los grupos. Una desagregación de los titulares de los derechos en actores específicos permite realizar una mayor diferenciación de las instituciones, organizaciones y entidades que tienen o dejan de tener estos derechos. Esto facilita un mejor entendimiento de la distribución de los derechos entre los actores.

Asimismo, es importante entender los cambios que han tenido lugar en toda la gama de instituciones sociales de los que tienen o han perdido los títulos sobre estos múltiples derechos para evaluar las ventajas y desventajas así como los posibles conflictos. Los recursos forestales son muchos y los sistemas internos (dentro del perímetro del terreno forestal titulado) para administrar esos derechos son con frecuencia invisibles a terceros, incluso al Estado. Estos sistemas pueden ir desde instituciones consuetudinarias definidas 
con claridad hasta normas culturales o religiosas, o simplemente aquellas construidas alrededor de patrones repetidos de dependencia de recursos naturales. Durante el proceso en que las reivindicaciones se convierten en derechos, es importante registrar las diferencias entre los titulares a nivel individual, grupal o colectivo de los diferentes derechos con reivindicaciones sobre los diferentes recursos del bosque, ya que algún tipo de estructura social interna será reconocida y se convertirá en el interlocutor con el Estado. El acto de titulación en sí mismo deberá reconocer una estructura colectiva o exigir la creación de una nueva para poder proceder a la transferencia de estos derechos.

\section{Aspectos metodológicos}

Las actividades de investigación en Guatemala se llevaron a cabo entre el 2007 y el 2008. Para recabar información en todas las escalas pertinentes, la recolección y el análisis de datos se realizó en tres niveles. A nivel nacional, se recabó información relativa a las normas y a los procesos políticos que favorecen una reforma de la tenencia forestal. En el ámbito regional, mediante una revisión de la bibliografía se recolectó información sobre las tendencias políticas y económicas importantes en el área de influencia de la Reserva de la Biosfera Maya en Petén, específicamente la zona de uso múltiple. Por último, recabamos información a nivel de las comunidades locales y las organizaciones concesionarias $^{3}$, incluyendo concesiones miembros y no miembros. Se identificaron los grupos relevantes involucrados en la configuración del modelo de concesión en Petén y se usaron diferentes técnicas para recopilar información.

Nuestra investigación combinó entrevistas semiestructuradas, grupos focales y talleres para recabar información y promover la participación de actores locales en la discusión sobre los orígenes, la naturaleza y los resultados de la reforma de tenencia forestal en Petén. En total se llevaron a cabo 65 entrevistas ${ }^{4}$. Los grupos meta de la investigación incluyeron funcionarios gubernamentales y representantes de organizaciones no gubernamentales que trabajan o trabajaron a nivel local y regional. Las entrevistas se estructuraron con la intención de reunir la percepción de las condiciones actuales y cuestiones relativas a las organizaciones concesionarias, los cambios y los desafíos del sistema de concesiones. También se recabó información relativa a los aspectos vinculados con el papel de las instituciones gubernamentales y las normas existentes referidas a las concesiones. Se identificaron los principales grupos de usuarios (de productos maderables y no maderables) y se incluyeron preguntas relativas a los factores que influyen en el éxito del modelo concesionario comunitario. Durante las entrevistas, se les solicitó a los participantes identificar a los actores relevantes que ellos consideraban debían participar en el debate. Esto permitió verificar la coherencia interna de la selección de actores para asegurar la representación de las perspectivas existentes. También se obtuvo una gran cantidad de información detallada de la observación participante.

Si bien se recabó información a nivel local de las 12 organizaciones concesionarias comunitarias (véase el Cuadro 1), se recolectó información detallada de dos organizaciones 
Cuadro 1. Características generales de las concesiones comunitarias en la Reserva de la Biosfera Maya

\begin{tabular}{|c|c|c|c|c|}
\hline $\begin{array}{l}\text { Concesión } \\
\text { comunitaria }\end{array}$ & $\begin{array}{l}\text { Organización concesionaria } \\
\text { (entidad jurídica) }\end{array}$ & $\begin{array}{l}\text { Extensión } \\
\text { (ha) }\end{array}$ & $\begin{array}{l}\text { Número de } \\
\text { miembros } \\
\text { (familias) }\end{array}$ & $\begin{array}{l}\text { Ubicación (residente } \\
\text { o no residente) }\end{array}$ \\
\hline Suchitecos & $\begin{array}{l}\text { Sociedad Civil Impulsores } \\
\text { Suchitecos (SCIS) }\end{array}$ & 12173 & 50 & No residente \\
\hline Laborantes & $\begin{array}{l}\text { Sociedad Civil Laborantes } \\
\text { del Bosque }\end{array}$ & 19390 & 96 & No residente \\
\hline Uaxactún & $\begin{array}{l}\text { Sociedad Civil Organización, } \\
\text { Manejo y Conservación }\end{array}$ & 83558 & 225 & Residente \\
\hline $\begin{array}{l}\text { Custodios } \\
\text { de la Selva }\end{array}$ & $\begin{array}{l}\text { Sociedad Civil Custodios de } \\
\text { la Selva }\end{array}$ & 21176 & 96 & No residente \\
\hline El Esfuerzo & Sociedad Civil El Esfuerzo & 25386 & 41 & No residente \\
\hline Árbol Verde & Sociedad Civil Árbol Verde & 64974 & 344 & No residente \\
\hline La Colorada & $\begin{array}{l}\text { Asociación Forestal Integral } \\
\text { La Colorada }\end{array}$ & 22067 & 40 & Residente \\
\hline $\begin{array}{l}\text { Cruce a la } \\
\text { Colorada }\end{array}$ & $\begin{array}{l}\text { Asociación Forestal Integral } \\
\text { Cruce a La Colorada }\end{array}$ & 22469 & 65 & Residente \\
\hline $\begin{array}{l}\text { San Miguel } \\
\text { La Palotada }\end{array}$ & $\begin{array}{l}\text { Asociación Forestal San } \\
\text { Miguel La Palotada }\end{array}$ & 7170 & 30 & Residente \\
\hline La Pasadita & $\begin{array}{l}\text { Sociedad Civil Productores de } \\
\text { La Pasadita }\end{array}$ & 18817 & 74 & Residente \\
\hline Carmelita & Cooperativa Carmelita & 53797 & 88 & Residente \\
\hline San Andres & $\begin{array}{l}\text { Asociación Forestal Integral } \\
\text { San Andrés }\end{array}$ & 51940 & 178 & No residente \\
\hline
\end{tabular}

Fuente: Monterroso 2007

concesionarias a fin de poder analizar los cambios en los derechos de tenencia. La elección de estas dos organizaciones se basó en la ubicación de los asentamientos comunitarios, dentro o fuera de la unidad de manejo forestal. Dicha unidad establece el perímetro del contrato de concesión donde los concesionarios tienen derechos. En seis casos (de las 12 organizaciones) las unidades de manejo se encuentran dentro del mismo perímetro donde viven las comunidades. En el resto, los concesionarios pertenecen a comunidades ubicadas fuera de la unidad de manejo forestal. En su estudio sobre los regímenes de tenencia comunal en Sudáfrica, Cousins (2007: 293) destaca la importancia de analizar las estructuras sociales vigentes para comprender cómo funcionan los sistemas de tenencia en la práctica. En el caso de las concesiones comunitarias, hemos podido observar el surgimiento de un conjunto de nuevas relaciones sociales. Una que se deriva del estatus de miembro de una organización colectiva “de concesión comunitaria”. Este nuevo grupo de actores influye en las relaciones entre individuos y la comunidad, por un lado, y entre 
la colectividad y el Estado, por el otro. La relación entre la organización de concesión comunitaria y la organización del Estado se caracteriza por el reconocimiento y la distribución de derechos y también por el cumplimiento de normas que son importantes en términos de esquemas de gobernanza.

\section{Resultados y análisis}

Esta sección combina los principales resultados de nuestro trabajo de investigación y los divide en dos partes. La primera describe las características más importantes del modelo de reforma de tenencia. Analizamos el origen y la naturaleza de las concesiones comunitarias, destacamos elementos del contexto político y revelamos cambios en las reivindicaciones de los recursos forestales para entender su desarrollo como mecanismos de manejo sostenible en las áreas protegidas. Luego analizamos las características de las concesiones comunitarias como modelos de reforma de tenencia, así como la evolución de los usos y usuarios del bosque. La segunda parte se enfoca en los cambios en la redistribución de derechos entre los titulares de los derechos. Concluimos esta sección analizando el proceso por el cual las reivindicaciones se convierten en derechos y examinando las fuentes de legitimidad. Este análisis se centra en los procesos de autorización, adquisición y mantenimiento de los derechos. En la última parte de esta sección, distinguimos entre los elementos internos y externos que sustentan la legitimidad.

\section{Origen y naturaleza de las concesiones comunitarias}

La región de Petén en Guatemala abarca el 35\% de la superficie del país y el $75 \%$ de sus bosques (IARNA et al. 2006), incluyendo las extensiones más grandes de sus bosques latifoliados tropicales. Esta región, altamente diversa en términos ecológicos y culturales, fue durante muchos años el área geográfica y política más aislada del país (Schwartz 1990). Su historia ha estado moldeada por la competencia por el control de los recursos naturales, incluyendo la madera (en especial las maderas tropicales preciosas como la caoba, Swietenia macrophila y el cedro, Cederela odorata), los productos forestales no maderables (PFNM) (como el chicle, Manikara zapota, las hojas de palma, Chamaedorea sp. y la pimienta gorda, Pimenta dioica) y los recursos no renovables. La primera institución del Estado con presencia física en la región, la Empresa Nacional de Fomento y Desarrollo de Petén (FYDEP), fue creada en 1959 por el Gobierno central. Esta entidad, que funcionó hasta 1989, tenía dos objetivos: colonizar la región y distribuir derechos de usufructo, principalmente para la extracción de madera.

A finales de la década de 1980, la creciente preocupación internacional por la conservación y el fuerte apoyo de donantes internacionales (Gómez y Méndez 2005) promovieron la expansión de las áreas protegidas de la región y permitieron el establecimiento de la Reserva de la Biosfera Maya en 1990, con una superficie de más de 2 millones de hectáreas, lo que la convierte en el área más grande en el país bajo un régimen de protección (CONAP 2001). El plan maestro para la reserva la divide en tres zonas de manejo. El área más grande (más del 40\%) se estableció como zona de uso múltiple para promover actividades sostenibles pero sin presencia de asentamientos humanos. Para mediados de 
la década de 1990, cuando la guerra llegaba a su fin y en el marco de la suscripción de los Acuerdos de Paz, el Gobierno de Guatemala enfrentó un conflicto nuevo e impredecible. En una región que, en términos generales, carecía de canales normales de comunicación entre los Gobiernos locales, regionales y centrales y mecanismos mínimos de gobernanza (para informar, discutir, deliberar, etc.), las oficinas gubernamentales del área protegida de creación reciente hicieron pocos esfuerzos para llegar a las comunidades alejadas y atomizadas en una vasta superficie forestal (Sundberg 1998, 2002). Esto generó una fuerte reacción de las comunidades residentes que habían dependido del bosque durante mucho tiempo.

En 1994, el Gobierno de Guatemala legalizó un sistema formal de concesiones comunitarias dentro de la zona de uso múltiple. El resultado fue el reconocimiento de los derechos, tanto ancestrales como recientes, de los asentamientos de las comunidades existentes. Al mismo tiempo, se abordó también la lógica subyacente de la agenda de conservación forestal y de la biodiversidad y se evitó una enajenación total del sector maderero. La justificación de esta decisión era que el otorgamiento de estas grandes áreas forestales a las concesiones forestales comunitarias podrían satisfacer los intereses en competencia de todas los partes: la industria, la conservación y las comunidades. Se reconocieron los derechos de acceso y asentamiento comunitarios y se otorgaron derechos de manejo sobre la base de un esquema, altamente regulado, de producción certificada e independiente de especies de madera de alto valor, transformando así un paisaje forestal antes caracterizado por el conflicto.

\section{Evolución de las reivindicaciones de los recursos forestales en Petén}

Entender la evolución de las reivindicaciones de los recursos forestales en Petén requiere comprender el rol que el Estado guatemalteco cumple definiendo los usos de los bosques y la tierra, así como las estrategias usadas para establecer la autoridad. En este estudio, analizamos los mecanismos de territorialización como ejemplo de posibles formas de legitimación sobre la base de dos momentos históricos relevantes en la construcción social del espacio en Petén en relación con los usos forestales. El Cuadro 2 muestra cómo los intereses y la percepción sobre los bosques en esta región han cambiado con el tiempo, principalmente debido a la existencia de mandatos diferentes en las instituciones del Gobierno central con autoridad sobre los bosques de la región durante los últimos 50 años: el FYDEP y el Consejo Nacional de Áreas Protegidas (CONAP).

El FYDEP se creó en 1959 con el objetivo de incorporar Petén en la dinámica socioeconómica del país (Schwartz 1990). Lejos de cumplir un mandato de conservación, llevó a cabo su misión estableciendo un programa de colonización agrícola y asignando derechos de usufructo sobre recursos mediante la organización de las actividades de extracción de madera (principalmente a través de concesiones para la tala rasa). A finales de la década de los ochenta, y respondiendo a un giro político hacia intereses de conservación, el FYDEP fue reducido y reemplazado por el CONAP, recientemente creado. Este giro en el rol de la entidad estatal en Petén hacia la conservación y la 
Cuadro 2. Principales actores del Estado relacionados con los bosques en Petén

\begin{tabular}{|c|c|c|c|c|}
\hline & $\begin{array}{l}\text { Entidad del } \\
\text { Estado }\end{array}$ & Principales funciones & $\begin{array}{l}\text { Mecanismos de } \\
\text { territorialización } \\
\text { usados para establecer } \\
\text { la autoridad }\end{array}$ & $\begin{array}{l}\text { Otros usuarios } \\
\text { forestales } \\
\text { relevantes }\end{array}$ \\
\hline 1959 & $\begin{array}{l}\text { Empresa } \\
\text { Nacional de } \\
\text { Fomento y } \\
\text { Desarrollo de } \\
\text { Petén (FYDEP) }\end{array}$ & $\begin{array}{l}\text { Colonización agrícola } \\
\text { de las tierras bajas. } \\
\text { Administración de los } \\
\text { recursos naturales. } \\
\text { Distribución } \\
\text { de las tierras y } \\
\text { establecimiento de las } \\
\text { comunidades en Petén. }\end{array}$ & $\begin{array}{l}\text { Llevó a cabo la } \\
\text { titulación de tierras } \\
\text { (privadas y colectivas). } \\
\text { Creó una } \\
\text { reserva forestal. } \\
\text { Estableció concesiones } \\
\text { industriales a } \\
\text { corto plazo. } \\
\text { Promovió } \\
\text { incentivos para la } \\
\text { producción agrícola. } \\
\text { Llevó a cabo actividades } \\
\text { de colonización. }\end{array}$ & $\begin{array}{l}\text { Madereros. } \\
\text { Grupos } \\
\text { extractivos } \\
\text { (chicleros y } \\
\text { recolectores de } \\
\text { palma xate). } \\
\text { Comunidades. }\end{array}$ \\
\hline 1990 & $\begin{array}{l}\text { Consejo } \\
\text { Nacional de } \\
\text { Áreas Protegidas } \\
\text { (CONAP) }\end{array}$ & $\begin{array}{l}\text { Detener movimientos } \\
\text { de migración } \\
\text { espontánea. } \\
\text { Establecer el sistema } \\
\text { de áreas protegidas } \\
\text { en Petén. } \\
\text { Promover la } \\
\text { conservación de la } \\
\text { biodiversidad y el uso } \\
\text { sostenible de recursos. } \\
\text { Crear mecanismos } \\
\text { para aumentar la } \\
\text { participación social } \\
\text { en la gestión de las } \\
\text { áreas protegidas. }\end{array}$ & $\begin{array}{l}\text { Canceló las concesiones } \\
\text { madereras industriales. } \\
\text { Expulsó a las } \\
\text { comunidades locales de } \\
\text { las áreas protegidas. } \\
\text { Llevó a cabo el } \\
\text { proceso de titulación, } \\
\text { restringido a la región } \\
\text { sur de Petén. } \\
\text { Estableció un sistema } \\
\text { de concesiones } \\
\text { comunitarias/ } \\
\text { industriales. }\end{array}$ & $\begin{array}{l}\text { Concesiones } \\
\text { industriales. } \\
\text { Grupos } \\
\text { extractivos. } \\
\text { Comunidades } \\
\text { organizadas. }\end{array}$ \\
\hline
\end{tabular}

preservación de los bosques modificó la lógica que sustentaba la presencia del Estado en el bosque y desafió los derechos de facto de los habitantes del bosque. También permitió que se diera un cambio en las reivindicaciones de los bosques y las estrategias usadas por los grupos sociales para garantizar el acceso a los recursos forestales (véase el Cuadro 3). Las percepciones dominantes de Petén cambiaron: pasó de ser una zona salvaje, controlada para obtener beneficio económico, a ser un importante reservorio de biodiversidad y flora y fauna silvestres que debía ser protegido. El giro hacia los intereses de conservación se dio gracias a un momento político clave a mediados de los noventa, cuando concluían las negociaciones de los Acuerdos de Paz relativos a los derechos de tierras. Estos acuerdos estipulaban que las decisiones de los nuevos Gobiernos sobre los recursos naturales debían garantizar una mayor participación de las comunidades en las áreas protegidas. 
Cuadro 3. Evolución de los reclamantes y las reivindicaciones de los bosques después del establecimiento del Área Protegida en Petén

\begin{tabular}{|c|c|c|c|}
\hline \multirow[t]{2}{*}{ Periodo } & \multicolumn{2}{|c|}{$\begin{array}{c}\text { Reivindicaciones de los bosques y estrategias } \\
\text { utilizadas por los reclamantes }\end{array}$} & \multirow{2}{*}{$\begin{array}{l}\text { Elementos relevantes } \\
\text { del contexto politico y } \\
\text { económico }\end{array}$} \\
\hline & $\begin{array}{l}\text { Actor de la sociedad } \\
\text { civil (recibe } \\
\text { los derechos) }\end{array}$ & $\begin{array}{l}\text { Elementos del contexto } \\
\text { del actor del Estado } \\
\text { (otorga los derechos) }\end{array}$ & \\
\hline \multirow{8}{*}{$\begin{array}{l}\text { Creación del } \\
\text { Área Protegida } \\
\text { (1989-1994) }\end{array}$} & $\begin{array}{l}\text { Confrontaciones abiertas } \\
\text { (a veces violentas). }\end{array}$ & $\begin{array}{l}\text { Detener la tasa de } \\
\text { deforestación. }\end{array}$ & \multirow{3}{*}{$\begin{array}{l}\text { Disolución de la } \\
\text { Empresa Nacional de } \\
\text { Fomento y Desarrollo } \\
\text { de Petén (la única } \\
\text { entidad del Gobierno } \\
\text { central con presencia } \\
\text { en la región) }\end{array}$} \\
\hline & Aprovechamiento ilegal. & $\begin{array}{l}\text { Controlar las } \\
\text { actividades ilegales. }\end{array}$ & \\
\hline & \multirow{2}{*}{$\begin{array}{l}\text { Falta de concientización } \\
\text { (y luego falta de } \\
\text { conocimiento) del } \\
\text { perímetro del área } \\
\text { protegida. }\end{array}$} & \multirow{2}{*}{$\begin{array}{l}\text { Reforzar la presencia } \\
\text { del Estado (autoridad) } \\
\text { aumentando la cantidad } \\
\text { de guardabosques. }\end{array}$} & \\
\hline & & & \multirow{4}{*}{$\begin{array}{l}\text { Creacion de la Consejo } \\
\text { Nacional de Áreas } \\
\text { Protegidas (CONAP). } \\
\text { Dependencia de } \\
\text { economías extractivas } \\
\text { (extracción de chicle y } \\
\text { hojas de palma). }\end{array}$} \\
\hline & $\begin{array}{l}\text { Extracción ilegal de } \\
\text { productos del bosque }\end{array}$ & $\begin{array}{l}\text { Cancelación de los } \\
\text { contratos madereros.* }\end{array}$ & \\
\hline & $\begin{array}{l}\text { y ocupación ilegal de } \\
\text { la zona. }\end{array}$ & \multirow{2}{*}{$\begin{array}{l}\text { Cancelación de } \\
\text { los procesos de } \\
\text { regularización de } \\
\text { tierras en los parques } \\
\text { nacionales y la zona de } \\
\text { uso múltiple. }\end{array}$} & \\
\hline & $\begin{array}{l}\text { Agresión a } \\
\text { guardabosques del } \\
\text { Estado (oficina del área } \\
\text { protegida). }\end{array}$ & & \\
\hline & $\begin{array}{l}\text { Deseo de garantizar } \\
\text { el reconocimiento de } \\
\text { derechos ancestrales } \\
\text { de acceso y uso } \\
\text { sobre los bosques del } \\
\text { área protegida. }\end{array}$ & $\begin{array}{l}\text { Expulsión de } \\
\text { comunidades } \\
\text { establecidas dentro del } \\
\text { área protegida. }\end{array}$ & \\
\hline \multirow{9}{*}{$\begin{array}{l}\text { Establecimiento } \\
\text { del sistema de } \\
\text { concesiones } \\
\text { en la zona de } \\
\text { uso múltiple } \\
\text { (1994-2002) }\end{array}$} & \multirow{3}{*}{$\begin{array}{l}\text { Promover la acción } \\
\text { colectiva mediante } \\
\text { la formalización } \\
\text { de organizaciones } \\
\text { comunitarias. }\end{array}$} & $\begin{array}{l}\text { Detener la tasa de } \\
\text { deforestación. }\end{array}$ & \multirow{9}{*}{$\begin{array}{l}\text { Suscripción de los } \\
\text { Acuerdos de Paz } \\
\text { en } 1996 . \\
\text { Reconocimiento de } \\
\text { los reclamantes como } \\
\text { quienes deben recibir } \\
\text { los derechos. }\end{array}$} \\
\hline & & Reforzar la presencia & \\
\hline & & Controlar las actividade & \\
\hline & \multirow{2}{*}{$\begin{array}{l}\text { Establecimiento de } \\
\text { una organización de } \\
\text { segundo nivel. }\end{array}$} & ilegales. & \\
\hline & & $\begin{array}{l}\text { Resolver las } \\
\text { confrontaciones }\end{array}$ & \\
\hline & \multirow{2}{*}{$\begin{array}{l}\text { Sensibilización en } \\
\text { relación con las } \\
\text { organizaciones } \\
\text { del Estado. }\end{array}$} & violentas. & \\
\hline & & \multirow{3}{*}{$\begin{array}{l}\text { Establecer mecanismos } \\
\text { nuevos (concesiones) } \\
\text { para permitir actividades } \\
\text { de manejo dentro } \\
\text { de la Reserva de la } \\
\text { Biosfera Maya. }\end{array}$} & \\
\hline & $\begin{array}{l}\text { Asegurar el } \\
\text { reconocimiento legal } \\
\text { de los derechos de uso } \\
\text { y manejo deproductos } \\
\text { forestales maderables y } \\
\text { no maderables. }\end{array}$ & & \\
\hline & $\begin{array}{l}\text { Mejorar los medios } \\
\text { de vida. }\end{array}$ & & \\
\hline
\end{tabular}


Cuadro 3. Continuado

\begin{tabular}{|c|c|c|c|}
\hline \multirow[t]{2}{*}{ Periodo } & \multicolumn{2}{|c|}{$\begin{array}{c}\text { Reivindicaciones de los bosques y estrategias } \\
\text { utilizadas por los reclamantes }\end{array}$} & \multirow{2}{*}{$\begin{array}{l}\text { Elementos relevantes } \\
\text { del contexto politico y } \\
\text { económico }\end{array}$} \\
\hline & $\begin{array}{l}\text { Actor de la sociedad } \\
\text { civil (recibe } \\
\text { los derechos) }\end{array}$ & $\begin{array}{l}\text { Elementos del contexto } \\
\text { del actor del Estado } \\
\text { (otorga los derechos) }\end{array}$ & \\
\hline \multirow[t]{5}{*}{$\begin{array}{l}\text { Consolidación } \\
\text { del sistema de } \\
\text { concesiones } \\
\text { en la zona de } \\
\text { uso múltiple } \\
\text { (2002-presente) }\end{array}$} & $\begin{array}{l}\text { Sensibilización en } \\
\text { relación con las } \\
\text { organizaciones } \\
\text { nacionales e } \\
\text { internacionales. }\end{array}$ & $\begin{array}{l}\text { Detener la tasa de } \\
\text { deforestación. } \\
\text { Controlar actividades } \\
\text { ilegales. }\end{array}$ & \multirow[t]{5}{*}{$\begin{array}{l}\text { Nuevos conflictos } \\
\text { vinculados al } \\
\text { surgimiento de } \\
\text { intereses externos } \\
\text { sobre el petróleo y el } \\
\text { turismo. }\end{array}$} \\
\hline & Fortalecer las & \multirow{3}{*}{$\begin{array}{l}\text { Promover las empresas } \\
\text { forestales comunitarias. } \\
\text { Cumplimiento de } \\
\text { la normativa. }\end{array}$} & \\
\hline & $\begin{array}{l}\text { capacidades de } \\
\text { ordenamiento forestal. }\end{array}$ & & \\
\hline & $\begin{array}{l}\text { Control y vigilancia } \\
\text { del perímetro de la } \\
\text { concesión para evitar } \\
\text { ocupaciones de terceros. }\end{array}$ & & \\
\hline & Mejorar medios de vida. & & \\
\hline
\end{tabular}

* Los contratos madereros son acuerdos para la tala rasa por 5 años entre el Estado y la industria local.

Como resultado de constantes negociaciones en medio de estos cambios políticos, entre 1994 y 2001, se firmaron un total de 12 contratos de concesión comunitaria (para superficies de 7000 a $85000 \mathrm{ha}$ ) con grupos comunitarios locales de residentes y no residentes (un total de 390000 ha, Cuadro 1). Se firmaron dos contratos más con industrias para la producción de madera (140 000 ha). Todos los contratos de concesión requerían una organización colectiva y una extracción de recursos basada en planes de manejo aprobados por el CONAP. Durante los últimos 10 a 15 años, las organizaciones comunitarias han creado sus propios sistemas de gobernanza local sobre la base de un conjunto ampliado de derechos sobre los recursos forestales. Esto incluye la organización y el financiamiento de la protección constante del perímetro de la concesión como parte de sus responsabilidades.

\section{Principales características de la reforma de la tenencia forestal en Petén}

Las reformas de la tenencia forestal tienden a tener un carácter complejo, dadas las múltiples funciones que los recursos naturales desempeñan en la provisión de bienes y servicios, y la amplia gama de actores que comparten derechos sobre los recursos comunes (Larson et al. 2010b). Ciertas características hacen que el modelo de concesión sea único en comparación con otras reformas de tenencia en la región. En primer lugar, es importante destacar que se trata de una reforma reciente que todavía se está llevando a cabo (1985-presente). En segundo lugar, debido a que se produjo en un área protegida, la lógica que sustenta la concesión es resultado de los intereses de conservación y no 
de la descentralización forestal o las reformas de las políticas forestales en sí. Asegurar resultados para la conservación era el objetivo principal de la reforma, y el manejo forestal sostenible se convirtió en uno de los vehículos para lograr esta meta. En tercer lugar, el Estado sigue teniendo una fuerte influencia en la regulación de los derechos de acceso. Las concesiones son temporales, otorgadas por períodos de 25 años, a través de contratos renovables entre el Estado y un grupo comunitario organizado que transfieren a este último la capacidad para usar y administrar los productos forestales maderables y no maderables de la zona de uso múltiple. Los derechos de enajenación, así como los derechos sobre el subsuelo, es decir, los derechos de manejo, extracción y usufructo de los recursos no renovables (por ejemplo, el petróleo, la minería y el gas), son propiedad del Estado guatemalteco. Las áreas otorgadas a las concesiones comunitarias, con el tiempo, podrían estar sujetas a la extracción petrolera, dado que el $95 \%$ del petróleo encontrado en el país se encuentra en Petén.

En cuarto lugar, la reforma forestal se centró más en la distribución de los derechos de tenencia sobre los recursos naturales que en la tierra (como en el caso de la reforma agraria). Los recursos forestales, incluyendo los productos forestales maderables y no maderables, principalmente los bienes y servicios relacionados con la provisión, representan el objetivo principal de esta reforma. En quinto lugar, los que reciben los derechos son por lo general entidades colectivas creadas por los miembros de las comunidades locales 5 por lo que la acción colectiva se convierte en un catalizador importante de la reforma de la tenencia. Por último, existen entes específicos (organizaciones concesionarias) que regulan el acceso y uso de los recursos, y que fueron reconocidos como los que deben recibir los derechos.

\section{Evolución de los usuarios y los usos del bosque en Petén}

Los productos forestales en Petén han sido usados tanto para la subsistencia como para el mercado. Los recursos más valorados en el mercado son las maderas duras y los PFNM, como el chicle, la pimienta gorda y las hojas de palma. Las extracciones con fines de subsistencia incluyen la leña, los recursos medicinales y ciertas actividades de caza. Aunque se desarrolla la agricultura y producción ganadera ${ }^{6}$ a pequeña escala en las zonas de gestión del área protegida, estas son importantes actividades económicas que se desarrollan con más frecuencia fuera de las áreas protegidas. Durante mucho tiempo, la región de Petén fue considerada la última frontera agrícola del país. Algunos asentamientos históricos se encuentran dentro de las áreas protegidas, por ello, entre los usuarios del bosque se incluyen personas que viven tanto dentro como fuera de las áreas protegidas. Históricamente, otros grupos migraron a esta zona forestal durante la época de extracción de chicle. Algunos de ellos se asentaron en esta área, mientras que otros retornaron a sus lugares de origen.

La extracción de chicle era la actividad más importante antes de la creación del FYDEP en Petén. Las primeras normas para aumentar los impuestos públicos de su extracción aparecieron en 1977, cuando el Gobierno central aprobó la ley de extracción de chicle. Durante el mismo período, la recolección de hojas de palma y de pimienta gorda se 
convirtió en una importante actividad, pero no estaba regulada. El aprovechamiento de PFNM se organizó en pequeños campamentos itinerantes. La extracción de madera se organizó al principio en concesiones madereras a corto plazo sin ninguna obligación de manejo. Para cuando se suscribieron los contratos de concesión, la mayor parte de las áreas ya habían sido aprovechadas para obtener caoba y cedro rojo, una madera de alto valor.

\section{Cambios después del reconocimiento y redistribución de los derechos forestales entre los diferentes titulares de los derechos}

Esta sección analiza los principales cambios ocurridos en el proceso de reconocimiento de derechos y su redistribución entre los diferentes titulares después de la suscripción de los contratos de concesión. Un elemento de este análisis se refiere la diferenciación efectuada entre el estatus de residente y no residente de los grupos que integran las concesiones comunitarias. Por lo general, las comunidades residentes están alejadas de los centros socioeconómicos y políticos de Petén. Estas comunidades, con una base social en los hogares y los lazos de parentesco, definen sus derechos sobre la tierra y los recursos a través de acuerdos informales. En el caso de los no residentes, la relación entre el miembro individual (de la concesión) y la comunidad es diferente, como lo es también la relación entre el miembro concesionario y el bosque. Seis de las 12 concesiones comunitarias son de residentes del bosque mientras que el resto son de no residentes (véase el Cuadro 1). Los miembros de las concesiones de no residentes pueden estar distribuidos en más de una comunidad y tener propiedades privadas fuera de la zona de uso múltiple, que contiene tierras agrícolas o pastizales.

En las concesiones comunitarias, tanto de residentes como no residentes, dos procesos pueden generar cambios en las dinámicas internas de la comunidad y, por lo tanto, en sus derechos. El primer proceso importante surge de la creación de una organización colectiva formal. Los modelos concesionarios "se abren" o permiten el reconocimiento de una entidad colectiva en grandes áreas forestales. Este nuevo marco legal que apoya a las comunidades exige la existencia de una entidad colectiva reconocida legalmente que sustituya a las empresas industriales que antes tenían acceso al bosque a través de las concesiones. La organización concesionaria que tiene los derechos de concesión se convierte en quien asigna y administra esos derechos. El peso de esta nueva organización en la comunidad es mayor en las concesiones residentes, especialmente a medida que el número de miembros dentro de la comunidad aumenta. El segundo proceso importante vinculado a la nueva organización concesionaria es la relación entre individuos de la comunidad y la nueva organización que otorga a estos individuos el estatus de miembros. Esta relación es importante, ya que transfiere los derechos de toma de decisiones del Estado a la colectividad o, en este caso particular, del Estado guatemalteco a los miembros de las organizaciones concesionarias. Cuando estos miembros provienen de una sola comunidad y residen en el bosque, el vínculo con la comunidad es mucho más sólido que cuando la organización concesionaria está conformada por individuos de distintas comunidades no residentes. 


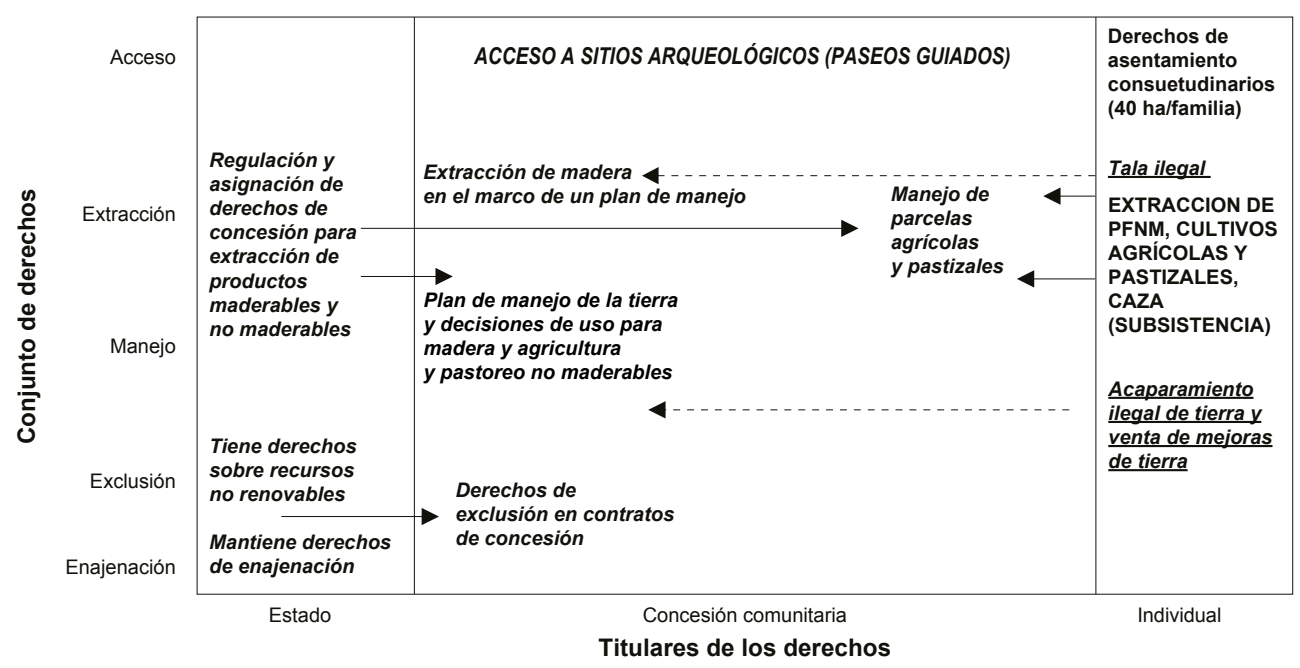

\begin{tabular}{|l|l|}
\hline *Base regulatoria & \multicolumn{1}{|c|}{ Flechas } \\
\cline { 1 - 1 } de jure & $\begin{array}{l}\text { Indica la dirección del derecho, ya sea transferido del } \\
\text { Estado al manejo colectivo o del manejo individual } \\
\text { al colectivo }\end{array}$ \\
\hline DE FACTO & $\begin{array}{l}\text { Indica la formalización de una actividad ilegal al titular } \\
\text { colectivo de los derechos }\end{array}$ \\
\hline Acción ilegal & \\
\hline
\end{tabular}

Figura 2. Distribución del conjunto de derechos en una concesión comunitaria

Fuente: Elaboración propia basada en trabajo de campo

Los principales cambios en la distribución de derechos entre usuarios forestales en las concesiones se presentan en la Figura 2. Como ya se mencionó, esta figura muestra que las comunidades tienen derechos, reconocidos formalmente, de acceso, uso, manejo y exclusión, lo que significa una transferencia de estos derechos desde el Estado hacia la colectividad. Los derechos de enajenación son conservados por el Estado, es decir, los concesionarios no tienen el derecho de arrendar o vender la tierra dentro de las unidades de manejo forestal. Asimismo, el Estado mantiene todos los derechos sobre los recursos del subsuelo, como el petróleo, incluso cuando estos se encuentran dentro de las concesiones.

La distribución de estos derechos es variada. Los derechos de acceso para las familias que viven en las áreas de las concesiones residentes son reconocidos como derechos consuetudinarios tanto en el caso de los miembros concesionarios como de los no miembros (CONAP 2004). Los contratos de concesión ratifican estos derechos y delegan la toma de decisiones, global o general, relativa a la planificación del uso de la tierra a la organización de gobierno local y al comité de desarrollo comunitario, que representa las reivindicaciones de los miembros y no miembros de la organización concesionaria. 
No obstante, en la práctica, la toma de decisiones comunitarias sobre el uso de la tierra alrededor de las zonas residenciales, las áreas de cultivo agrícola y de crianza de animales todavía se hace a través de acuerdo de facto [Figura 2] entre individuos y familias.

Diferentes subgrupos, como los chicleros (como se conoce a quienes se dedican a la extracción de chicle) o los recolectores de palma que vivían dentro o fuera del área de la concesión, presentaron reivindicaciones relativas al acceso a los PFNM. Anteriormente, los derechos de uso de los PFNM de valor comercial se asignaban a contratistas de manera informal. Esto se debe en parte al hecho que, con excepción de algunas normas para la extracción de chicle — principalmente impuestos de comercialización-, los otros PFNM aún no estaban regulados legalmente. Recientemente, el reconocimiento de este vacío normativo obligó al Gobierno a regular el acceso y el manejo de los PFNM, con normas y reglas similares a las de la madera. Esto exigió también la elaboración de planes de manejo y esquemas de certificación específicos para los PFNM. Lo mismo será válido para la agricultura y los pastizales, aunque las normas no se han puesto en práctica aún. Mientras que anteriormente las decisiones relativas a que áreas utilizar para estas actividades se tomaban en el hogar, ahora las concesiones residentes están organizando planes de uso de la tierra más extensos a nivel de paisaje $\mathrm{e}^{7}$.

La planificación y el manejo de recursos forestales específicos, como la palma xate, la pimienta gorda y el chicle, así como las actividades de turismo, están permitidos para los subgrupos dentro de la membresía más amplia de la concesión. El Estado elaboró reglas formales para los recursos de valor comercial, principalmente para la madera y el chicle, pero sin tomar en cuenta su relación con otros recursos forestales. No se les dio importancia a las formas en que los derechos de uso de un grupo podrían afectar los derechos de otros. Por ejemplo, la ley nacional de chicle (1977) estipula que todos los ciudadanos de Guatemala tienen derecho a extraer chicle dentro de los límites del país. Al mismo tiempo, los contratos de concesión comunitarios otorgan a la cooperativa derechos de exclusión a las concesiones, consideradas como la base de la responsabilidad adicional para defender sus perímetros, lo que permite el manejo forestal sostenible dentro de la unidad de manejo. Para mantener la certificación forestal, se deben cumplir estrictas reglamentaciones ambientales, lo que significa que es necesario controlar el acceso externo. Una serie de conflictos surge de esta contradicción en las leyes, ya que un gran número de chicleros no pertenecen a las concesiones comunitarias. Más bien, migran durante la temporada de extracción y no cumplen las reglamentaciones formales o informales establecidas por la cooperativa o el contrato de concesión.

En el caso de algunas concesiones, se han dado algunas respuestas informales a este conflicto, como las asociaciones entre los recolectores migrantes, y recolectores y contratistas comunitarios. Algunas concesiones han tratado de ampliar su sistema informal de reglamentaciones que tiene como objetivo controlar quién está extrayendo chicle, dónde y cómo. Lo hacen proporcionando avales o garantías, un permiso escrito que determina el campamento donde se organizarán las actividades y la cantidad de días que el recolector permanecerá allí. Si bien las reglamentaciones informales como los avales funcionan también para la recolección de palma xate y aunque las prácticas actuales todavía se organizan con base en normas de facto, ya se está llevando a cabo 
un proceso de formalización. Sin embargo, en la mayor parte de las organizaciones no residentes, los usuarios tradicionales que no pertenecen a la organización concesionaria y que anteriormente extraían PFNM a través de acuerdos de facto en estas áreas han perdido sus derechos.

Una diferencia importante en el caso de los concesionarios no residentes es el hecho de que, sin el contrato de concesión, estos miembros no hubieran tenido acceso a los derechos de usufructo o de manejo de los productos forestales maderables y no maderables. Debido a que no son residentes del bosque, no se permiten actividades agrícolas o de pastoreo. Desde que los concesionarios han tomado "posesión" legal de las áreas de manejo, se han reducido las condiciones de acceso abierto que favorecían las actividades ilegales, incluyendo el aprovechamiento ilegal y el saqueo de sitios arqueológicos. Las organizaciones concesionarias han invertido importantes recursos, tiempo y dinero en el patrullaje y la expulsión de transgresores, asegurando así los derechos de tenencia. Las organizaciones concesionarias deben, conforme lo estipula el contrato, denunciar cualquier transgresión a las entidades del Gobierno. Sin embargo, debido a la falta de instrucciones en el Código Penal que sancionen comportamientos delictivos en materia ambiental, estos esfuerzos quedan impunes. Muy raramente llega a los tribunales un caso relacionado con un tema ambiental.

\section{Transformando los reclamos en derechos: estrategias y objetivos de legitimación}

\section{El proceso de autorizar un derecho: el proceso de obtener la legitimidad del que otorga los derechos}

En esta sección, abordamos las estrategias de legitimación utilizadas por el Estado guatemalteco para validar su autoridad en Petén. Lo hacemos examinando las interacciones entre el Estado y otros actores sociales que intervienen en los procesos de autorización de las reivindicaciones de acceso. La configuración de la Reserva de la Biosfera Maya como un mecanismo de ordenación espacial implicó dos cambios importantes. Uno fue "reservar" grandes áreas forestales destinadas a la conservación estricta, quedando las zonas aledañas bajo estrictas normas de uso de tierra y recursos. El otro cambio fue la expansión física del Estado en este territorio. Luego de una historia de aparente ausencia de las instituciones del Estado hasta finales de la década de los cincuenta, el establecimiento de áreas protegidas representó un giro en las agencias estatales en las regiones forestales, y el Gobierno supuso que esto sería suficiente para validar su autoridad dentro de las zonas de manejo (Clark 2000). El establecimiento de una entidad del Estado específica responsable de regular las áreas protegidas y la disolución de las antiguas instituciones del Estado — vinculadas más bien a programas de colonización de tierras- demandó una mayor presencia del Gobierno en el lugar. Aunque su función principal fue la de resguardar las áreas protegidas, sancionar a los transgresores y controlar la evolución del bosque, esta entidad con el tiempo reconoció que su autoridad provenía más bien del rol de acompañante y mediador de la concesión comunitaria, la industria y otros actores de la región forestal. 
Según Tschinkel (com. pers. 2007), la falta de claridad y la lentitud de los procesos de aprobación de normas concesionarias demoraron el proceso de asignación entre 1994 y 1998 (solo tres concesiones comunitarias fueron otorgadas durante este período). Otras agencias importantes del Gobierno, por ejemplo, el Servicio Forestal, así como instituciones de turismo, historia y arqueología, tenían poca presencia en el área. Además, el Gobierno municipal local participó poco o nada en el proceso de definición de la Reserva de la Biosfera Maya y las concesiones, a pesar del importante papel que hubieran podido desempeñar en la mediación de los conflictos locales. Aunque no se aborda en detalle aquí, otros autores (Sundberg 1998) han analizado la influencia de las organizaciones de asistencia externa, como la Agencia de los Estados Unidos para el Desarrollo Internacional (USAID) y varias importantes organizaciones no gubernamentales $(\mathrm{ONG})$ internacionales de conservación, en el rol de los actores gubernamentales. El diseño y la dirección del proyecto estuvieron a cargo principalmente de USAID y las ONG asociadas.

Nuestros resultados coinciden con trabajos anteriores (Gómez y Méndez 2005) que analizan el papel clave desempeñado por las instituciones externas, como la USAID, para movilizar considerable financiamiento y canalizarlo a la región en un período relativamente corto de tiempo. El objetivo de estos esfuerzos fue cambiar por completo la lógica del uso de las tierras, y así la región pasaría de ser una alejada región agrícola a un centro nacional de conservación. El diseño de la USAID aplicó el modelo creando una institución totalmente nueva (el CONAP) y prestando poca atención a las agencias e instituciones existentes. Las organizaciones establecidas recientemente no demostraron prácticamente ningún conocimiento de cómo las comunidades se habían asentado, vivían y trabajaban en la región forestal. En última instancia, consideramos que la USAID y sus ONG asociadas reemplazaron a las instituciones guatemaltecas y así dejaron de lado la opción de establecer una autoridad más local y sólida, una mayor legitimidad y la capacidad de una gobernanza a largo plazo junto con las comunidades.

\section{El proceso de adquirir el derecho: legitimación de las reivindicaciones de acceso}

Entre las estrategias empleadas por los concesionarios para adquirir y mantener la legitimidad se incluyen la formalización de sus estructuras organizativas a través de la creación de entidades legales para obtener el estatus de "concesiones comunitarias", el cumplimiento de los criterios de certificación forestal y los procesos de producción (normas del Consejo de Manejo Forestal), y la formalización de sus estrategias de acceso y reglamentaciones relativas a los PFNM. Las comunidades deben cumplir estas normas y las relativas a la producción de madera y la extracción de chicle (sobre una base anual) para renovar sus derechos de concesión. Las normas forestales son sumamente complejas, costosas, y demandan mucho tiempo. Esto se hace más problemático debido a que la experiencia organizativa y técnica de algunos grupos de concesiones comunitarias es limitada. Por otra parte, cuando la situación requiere de todo el apoyo de la colectividad, las comunidades necesitan más tiempo para poder llegar a un consenso (en comparación, 
por ejemplo, con la industria privada de la madera). Esto es más relevante en el caso de los requisitos para exportar caoba y obtener las evaluaciones de certificación anual, sin mencionar que las intenciones de exportar PFNM requieren procedimientos separados para cada producto (para la certificación y para el diseño de los planes de manejo y los planes operativos anuales).

Las organizaciones comunitarias han creado sus propios sistemas de gobernanza, basados en un conjunto ampliado de derechos de acceso, uso y toma de decisiones sobre sus recursos forestales. Esto incluye la organización y el pago de vigilancia y patrullaje del perímetro de las concesiones como parte de sus responsabilidades. Mientras que la mayoría ha logrado estabilizar las ocupaciones ilegales y las actividades de extracción ilegal, aunque con considerable inversión, las dinámicas de deforestación han sido más agresivas en las concesiones comunitarias con historia de establecimiento reciente (Bray et al. 2008).

\section{El proceso de mantener el derecho}

Las concesiones comunitarias de Petén son sistemas de tenencia que resultan de la negociación entre una serie de actores, incluyendo las autoridades de conservación, los concesionarios comunitarios, la industria de la madera y el Gobierno local. Aquí diferenciamos las estrategias de legitimación de las reivindicaciones internas de las externas.

\section{La legitimación externa de las reivindicaciones}

Para poder mantener reivindicaciones legítimas sobre los recursos de la zona de uso múltiple, las concesiones comunitarias deben probar que se ha alcanzado el objetivo principal para el cual fueron creadas. En el caso de Petén, los objetivos son los de asegurar la conservación del bosque y crear sistemas sólidos de gobernanza forestal (servir de interlocutor para el Estado). A pesar de las incursiones y los posteriores cambios en el uso de la tierra en varias concesiones comunitarias, en particular aquellas donde los primeros bosques habían sido seriamente degradados $^{8}$, el éxito relativo de la mayoría de ellas destaca los resultados positivos del sistema de concesiones comunitarias en términos de los objetivos de conservación. Como prueba de que las concesiones comunitarias han logrado estabilizar las dinámicas de cambio de uso de tierra dentro de la Reserva de la Biosfera Maya, comparamos el cambio en el uso de la tierra (en hectáreas) entre los sistemas de concesiones comunitarias y las tres zonas de manejo (zona de uso múltiple, zona de amortiguamiento y zona núcleo, o sea, parques nacionales) de la Reserva de la Biosfera Maya entre 1990 y 2005.

La Figura 3 muestra que entre 1990 y 2005, la tasa de cambio de uso de tierra en las zonas de manejo analizadas es mayor, tanto en la zona de amortiguamiento (donde se pierden entre 4000 y 12000 ha al ańo) como en los parques nacionales (donde se pierden entre 2000 y 6000 ha al año), en comparación con la zona de uso múltiple (donde se 


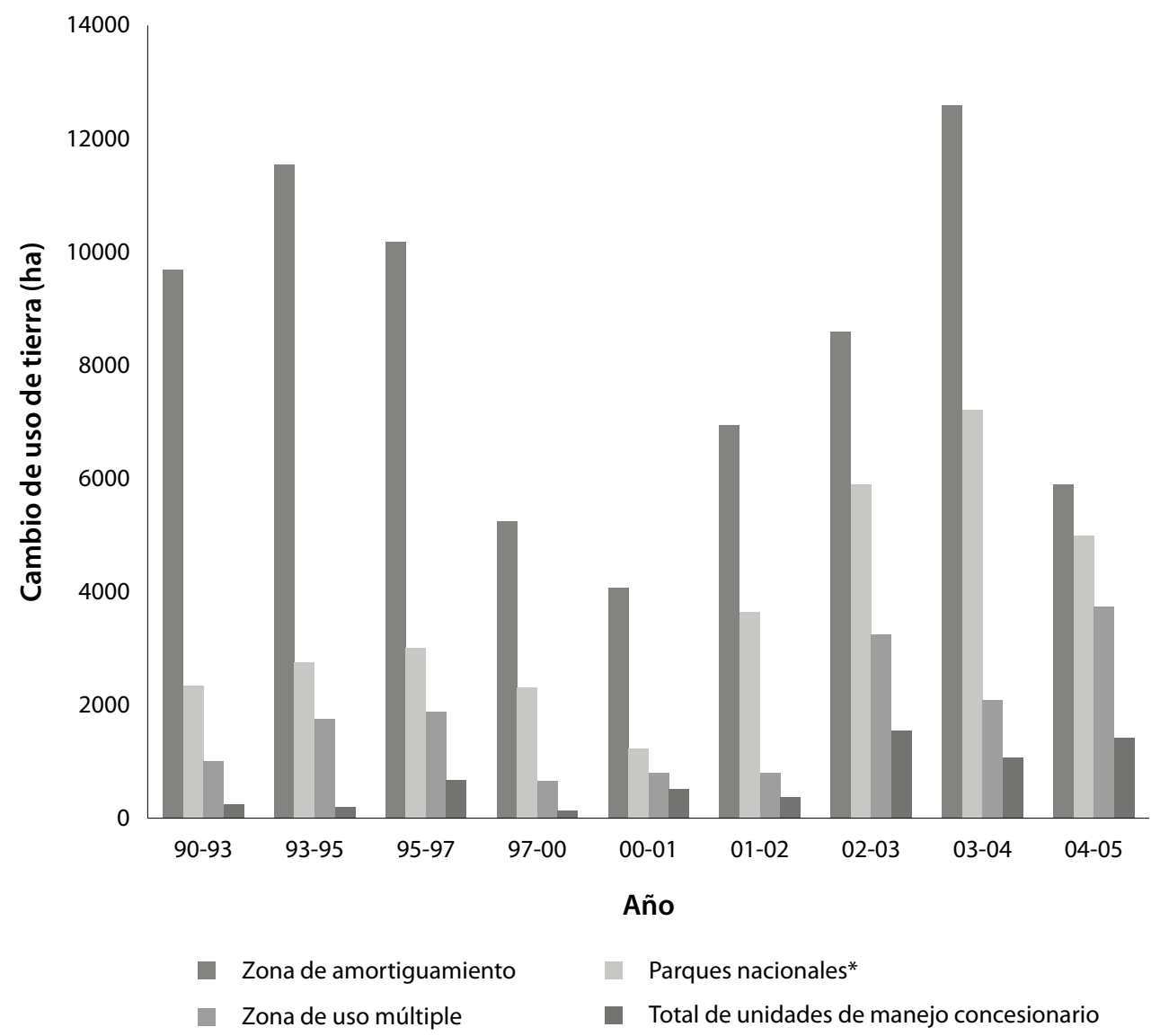

Figura 3. Cambio de uso de tierra (ha): comparación de dinámicas en la zona de amortiguamiento, los parques nacionales y la zona de uso múltiple (1990-2005)

\footnotetext{
* "Los Parques Nacionales en el análisis incluyen Lagua de Tigre y Sierra de Lacandon que juntos representan cerca del $65 \%$ de la zona núcleo (más de 450,000 ha)

+ Datos de la Zona de Uso Múltiple se basan sobre las áreas totales mientras que el Total de unidades de manejo concesionario incluyen datos para las concesiones industriales y comunitarias"
}

Fuente: WCS, CONAP, FIPA 2002, 2003, 2004, 2005

mantienen tasas por debajo de las 2000 ha al año). Los parques nacionales estudiados, Sierra del Lacandón y Laguna del Tigre, representan más del 65\% de la zona núcleo. Adicionalmente, la condiciones estables de la cobertura de bosque en las concesiones comunitarias han sido corroboradas por series temporales de imágenes Landsat y mapas de la Reserva de la Biosfera Maya de este período comparado con el período anterior a las concesiones comunitarias (WCS, CONAP y FIPA 2002, 2003, 2004, 2005). En vista de que las tasas de deforestación de las comunidades con estatus de residente y no residente cambian, este factor se ha vuelto particularmente relevante para aquellas comunidades con una historia de residencia. Este resultado ha sido corroborado por otros trabajos que examinan las dinámicas de deforestación en Guatemala y México (Radachowsky et al. 2012; Bray et al. 2008). 


\section{Legitimidad interna de las reivindicaciones}

Un conjunto diferente de factores define la legitimidad interna de los reclamantes o de los concesionarios comunitarios. El elemento más importante para legitimar los derechos sobre los recursos es si estos generan o no beneficios para las propias comunidades. Aunque la generación de beneficios se relaciona generalmente con los ingresos, nuestra investigación en estas concesiones demuestra que existen por lo menos otras cinco maneras en las que las organizaciones concesionarias pueden generar beneficios para sus miembros: por medio de la condición de miembro, de la reinversión en la empresa comunitaria, de la distribución de los ingresos de las ventas (de madera) a miembros individuales/familiares, de la generación de empleo y, por último, de inversiones sociales en las comunidades, como clínicas, escuelas, caminos, etc. Esto significa que existen por lo menos dos tipos de estructuras sociales que se deben tomar en cuenta al analizar la generación y distribución de beneficios, una asociada a la membresía y otra relacionada con la residencia. La relación entre concesionarios y sus comunidades puede analizarse en términos de creación de empleos y mediante la observación de las inversiones de las organizaciones concesionarias dentro de la comunidad en general.

Los beneficios relacionados con los ingresos pueden ser obtenidos directamente, ya sea a través de la generación de empleo o por medio de la distribución de los ingresos de las ventas de madera y de la comercialización de PFNM. Mientras que la primera comprende beneficios para miembros y no miembros, los ingresos de las ventas de madera se distribuyen ólo entre los miembros de la organización concesionaria. En el análisis de 12 organizaciones concesionarias, Monterroso y Barry (2007) determinaron que las actividades de manejo de madera generan más de 50000 puestos de trabajo en la región al año e involucran directamente a 2000 familias e indirectamente a más de 3000 beneficiarios individuales. En el caso de la extracción de PFNM, consideramos que la generación de empleo es más relevante en las concesiones de residentes. Estas proporcionan un flujo constante de ingresos a través de salarios y jornales, mientras que las otras implican una distribución de ganancias a fin de año.

Los concesionarios comunitarios han aumentado los ingresos de los hogares notablemente, ya que disfrutan los beneficios de las ganancias compartidas de la venta de madera (más del $33 \%$ de aumento en ingresos derivados de la madera, incluidos el cedro y la caoba) y especies menos conocidas en el mercado internacional (más del 60\% de aumento en beneficios comparados con la situación existente anterior a la concesión). Los ingresos procedentes de las ventas colectivas de madera se distribuyen entre los miembros, se reinvierten o se invierten en infraestructura social anualmente, y el porcentaje distribuido varía en función de las normas internas que cada grupo ha generado. La relación entre la comunidad y la empresa comunitaria no es siempre clara, especialmente en los casos en que la organización concesionaria está conformada por individuos que no son miembros residentes de los bosques y provienen de varias comunidades. Esto genera en ocasiones problemas en la toma de decisiones respecto de cómo se utilizan los ingresos, y forma parte fundamental del debate relativo a la participación, la rendición de cuentas y, en última instancia, la distribución de beneficios. Este último punto señala los fundamentos de la legitimidad interna de las concesiones. 
Este análisis demuestra que influyen múltiples mecanismos en la distribución de beneficios de los recursos naturales entre los actores sociales. Es importante reconocer a nivel comunitario qué otros elementos entran en juego cuando se aborda la legitimidad, ya que estos elementos pueden socavar la seguridad de la tenencia. Estos derivan especialmente de la capacidad de las organizaciones no solo de incrementar los beneficios económicos en términos de ingresos y generación de empleo, sino también de la capacidad de crear mecanismos de rendición de cuentas que aseguren la distribución de los beneficios económicos y sociales entre los diferentes grupos, incluyendo miembros y no miembros de la entidad concesionaria colectiva.

\section{Cuestiones y recomendaciones para los profesionales}

Otro tema importante es la falta de coherencia en el respeto y la defensa de los derechos de exclusión de las concesiones comunitarias por parte del Estado. Los derechos de exclusión se defienden en dos niveles: la defensa física contra la intromisión de terceras partes y la defensa política de los titulares de los derechos o concesionarios. En el primer nivel es importante anotar que las agencias del Gobierno (el CONAP, por ejemplo) todavía tienen una presencia, desempeñando un papel clave en el diseño y la aplicación del marco reglamentario, influyendo en la ejecución diaria tanto de la agenda ambiental (de conservación) como de las actividades de producción forestal. Sin embargo, el Estado, como el que otorga derechos, no ha cumplido a cabalidad su rol de apoyar los derechos de exclusión de los concesionarios, ya que todavía carece de un sistema de aplicación de sanciones y penalizaciones contra transgresores. En la práctica, esto modifica la carga de protección contra las incursiones en las comunidades. El costo de combatir el ingreso de terceras partes (madereros, traficantes, colonos, etc.) es alto, pues requiere el despliegue constante de mano de obra en los bosques para perseguir y capturar a los transgresores. Lo que es peor aún, hemos observado que hay poco seguimiento y acción legal por parte del Estado cuando se denuncia la existencia de actividades ilegales.

En segundo lugar, en lo que respecta a la defensa política de los derechos de exclusión, las organizaciones concesionarias frecuentemente encuentran la necesidad de llevar a cabo actividades de incidencia ante el Gobierno central en defensa de sus derechos contra las incursiones del Estado o el sector privado en sus áreas forestales. Los intereses arqueológicos y de turismo ecológico promovidos a través de empresas conjuntas (del Estado y del sector privado) han llevado a debilitar y erosionar el poder de toma de decisiones de la concesión comunitaria. La ampliación de la infraestructura para prospección y explotación petrolera en sus terrenos forestales también puede dañar seriamente el bosque y socavar la autoridad tanto de las concesiones comunitarias como de la agencia ambiental del Gobierno.

Dado lo alejado de la región y la sobreposición e incongruencia de las leyes y reglamentaciones de las agencias gubernamentales, las organizaciones forestales locales deben estar constantemente alerta, expresar sus necesidades abiertamente y ser defensoras activas del cumplimiento de sus derechos. Aquí surge el tema de la legitimidad otra 
vez; cuanto más se considera la conservación como la prioridad del Estado, como la lógica que fundamente la legitimidad externa, mayores son las posibilidades de que los derechos comunitarios prevalezcan frente a otros. Esto destaca la necesidad de que tanto las comunidades como las organizaciones de conservación defiendan de manera conjunta sus intereses comunes frente a las presiones ejercidas por otros sectores. Entre otras opciones se podría incluir la búsqueda de un enfoque más integrado del uso del bosque que podría contemplar diferentes tipos de turismo, pero solo sobre la base del respeto de los derechos de las concesiones comunitarias y su legitimidad como interlocutores válidos en el diseño de planes para la región forestal.

Para los profesionales, los costos que implican ambos niveles de defensa de los derechos de exclusión son altos, dependiendo del grado de competencia de los intereses en la región forestal, los que por lo general se subestiman. Por un lado, el despliegue físico de miembros comunitarios para que patrullen las áreas de su concesión debe y puede ser calculado e incorporado a los costos de producción, o si fuera el caso, a los costos de mitigación. Por otro lado, los costos relacionados con la defensa política de sus derechos son incluso más altos, difíciles de predecir y, sin embargo, vitales para la seguridad de sus derechos de tenencia. El desplazamiento a la capital del país para asistir a reuniones con funcionarios del Gobierno, la participación en las numerosas reuniones en la región forestal, el seguimiento de las inversiones financieras en la región (públicas y privadas), las campańas de información pública y las continuas negociaciones que generan financiamiento para reuniones internas que permiten compartir y formular posiciones dentro de las comunidades pueden ser abrumadores. No sólo tiene esto un costo financiero sino que también demanda recursos humanos cada vez más especializados a nivel de las organizaciones comunitarias.

\section{Conclusiones}

En este documento, hemos argumentado que el mantenimiento y la seguridad de los derechos a los bosques en el tiempo dependen de la manera en que se establece la legitimidad en el proceso a través del cual una reivindicación se convierte en un derecho. Para ello analizamos la naturaleza del proceso de reforma de la tenencia forestal en la zona de uso múltiple de la Reserva de la Biosfera Maya, donde en los últimos 20 años el Estado guatemalteco ha creado una nueva serie de reglamentaciones y transferido un conjunto de derechos sobre los recursos forestales a grupos comunitarios organizados. Esto permitió el surgimiento de un sistema de concesiones forestales comunitarias que abrió oportunidades para obtener beneficios y mejorar los medios de vida.

Los resultados indican que, para sostener el proceso de reforma de la tenencia forestal en el tiempo, es importante comprender cómo los regímenes de tenencia funcionan en la realidad (o en su contexto), y cómo los elementos que sustentan la legitimidad y aquellos que definen la autoridad intervienen en el proceso. Evaluamos la naturaleza y la evolución de las reivindicaciones de los recursos forestales, cómo se reconocieron (autorizaron) y se convirtieron en derechos. A su vez, observamos cómo "el que otorga los derechos" 
podía establecer también su autoridad mediante el reconocimiento por parte de los que los reciben. Nuestros resultados evidencian que este proceso tiene lugar en un ambiente de constante disputa y negociación. Exploramos las estrategias utilizadas para adquirir y mantener la legitimidad, dentro y fuera del modelo concesionario. A nivel interno, estas estrategias están vinculadas a las posibilidades de asegurar mejores medios de vida y la evolución de instituciones que garanticen beneficios a los miembros de las concesiones (que reciben los derechos). A nivel externo, los fundamentos de la legitimidad están íntimamente relacionados con garantizar el logro de los objetivos de conservación del Estado guatemalteco (que otorga los derechos) dentro del área protegida.

Por último, argumentamos que es necesario entender la base de la legitimidad de las reformas de la tenencia forestal para identificar formas en las que estos procesos sean viables y puedan funcionar realmente. Por ello, para tener éxito, las reformas de la tenencia forestal requieren de constante respuesta a los objetivos, en desarrollo o cambiantes, de los actores involucrados, para mejorar los resultados tanto del bosque como de los medios de vida. Esto también es importante para diseñar marcos reglamentarios más sólidos que llenen los vacíos y resuelvan las incongruencias en el sistema gubernamental de manejo forestal.

\section{Notas}

1. Las actividades de investigación se realizaron en 30 sitios en América Latina, África y Asia. Los sitios de estudio se encontraban en 10 países: Brasil, Bolivia, Nicaragua, Camerún, Ghana, Burkina Faso, Nepal, Filipinas, India y Laos.

2. Según Sikor y Lund (2009) la territorialización es una forma de legitimación empleada por los Gobiernos para controlar la ordenación espacial y las personas que habitan ese espacio. Aquí argumentamos que las estrategias de territorialización empleadas por el Gobierno de Guatemala tienen como objetivo el establecimiento de formas de control sobre los recursos naturales y las poblaciones que los utilizan.

3. Según las normas nacionales, existen dos tipos de concesiones forestales dentro de un área protegida: las industriales y las comunitarias. Los contratos de concesión comunitaria representan acuerdos legales entre el Estado y un grupo organizado conformado por miembros que viven en una comunidad. En Petén existen dos tipos de concesiones comunitarias. El primer grupo consta de concesiones comunitarias cuyos miembros viven en el mismo lugar dentro del perímetro del área forestal en la zona de uso múltiple. El segundo grupo está formado por concesionarios residentes cuyos miembros pueden pertenecer a uno o más asentamientos comunitarios fuera del perímetro del área forestal en la zona de uso múltiple. En este documento, la comunidad se refiere a un asentamiento rural cuyos miembros comparten ciertas características sociales y culturales.

4. Se elaboraron tres tipos de informes de investigación: uno a nivel regional, dos a nivel de la concesión comunitaria y otro que integra el análisis de los resultados. Los informes están disponibles en http://www.cifor.org/tenure-reform/. 
5. Aunque las organizaciones creadas se definen formalmente como concesiones forestales comunitarias, están integradas tanto por miembros comunitarios que viven en las unidades de manejo forestal como por miembros de lugares ubicados fuera de estas unidades y que pueden representar más de una comunidad.

6. En algunas áreas, la ganadería ilegal ha alcanzado proporciones importantes.

7. Las superficies agrícolas varían dentro de las concesiones residentes; en Carmelita una de las concesiones residentes estudiadas_- cerca del $2 \%$ de su área de manejo tenía este uso de la tierra.

8. Específicamente, nos referimos a las concesiones comunitarias de La Pasadita, San Miguel La Palotada, Cruce a la Colorada, y La Colorada, donde ha tenido lugar el acaparamiento de tierras y ventas ilegales. Según entrevistas de campo y otros documentos (UAESPNN 2004), estos procesos están más relacionados con la expansión del narcotráfico y otras actividades ilegales que con los campesinos sin tierra que expanden las fronteras agrícolas.

\section{Referencias}

Arneson, R. 2003. Debate: Defending the purely instrumental account of democratic legitimacy. The Journal of Political Philosophy 11(1): 122-132.

Barry, D. y R. Meinzen-Dick. 2012. The invisible map. Community tenure rights. En: The social life of forests. (eds. Hecht S., K. Morrison y C. Padoch) Chicago, Estados Unidos: University of Chicago Press.

Benda-Beckmann, F. Von. y K. Von Benda-Beckmann. 1999. A functional analysis of property rights, with special reference to Indonesia. En: Property rights and economic development: Land and natural resources in Southeast Asia and Oceania. (eds. T. Van Meijl y F. Von Benda-Beckmann). Pp. 15-56. Londres: Kegan Paul Publications.

Bohman, J. 1996. Public deliberation: pluralism, complexity and democracy. Cambridge, Estados Unidos: MIT Press.

Bray, D.B., E. Duran, V.H. Ramos, J.F. Mas, A. Velazquez, R.B. McNab, D. Barry y J. Radachowsky. 2008. Tropical deforestation, community forests, and protected areas in the Maya Forest. Ecology and Society 13(2): 56. http://www.ecologyandsociety. org/vol13/iss2/art56. [Consultado el 20 de diciembre del 2010].

Broegaard, R. 2005. Land tenure security and inequality in Nicaragua. Development and Change 36(4): 845-864.

Cashore, B. 2002. Legitimacy and the privatization of environmental governance: How non-state market driven (NSMD) governance systems gain rule-making authority. Governance 15: 503-529.

Clark, C. 2000. Land tenure de-legitimization and social mobility in tropical Petén, Guatemala. Human Organisation 59: 419-427. 
Colchester, M. 2008. Beyond tenure: Rights-based approaches to peoples and forests. Some lessons from the Forest People Programme. Londres: Iniciativa para los Derechos y Recursos (RRI) y Programa para los Pueblos de los Bosques (FPP).

Consejo Nacional de Áreas Protegidas (CONAP). 2001. Plan Maestro de la Reserva de Biosfera Maya. Guatemala: CONAP.

Consejo Nacional de Áreas Protegidas (CONAP). 2004. Politica de asentamientos humanos en áreas protegidas. Proyecto de Fortalecimiento a la Institucionalidad y Politica Ambiental, FIPA. Guatemala: CONAP.

Cousins, B., T. Cousins, D. Hornby, R. Kingwill, L. Royston y W. Smit. 2005. Will formalizing property rights reduce poverty in South Africa's 'second economy'? Questioning the mythologies of Hernando de Soto. Policy Brief No. 18. Sudáfrica: PLAAS.

Cousins, B. 2007. More than socially embedded: The distinctive character of 'communal tenure' regimes in South Africa and its implications for land policy. Journal of Agrarian Change 7(3): 281-315.

Eden, S. 2009. The work of environmental governance networks: traceability, credibility and certification by the Forest Stewardship Council. Geoforum 40: 383-394.

Gómez I. y E. Méndez. 2005. Análisis de contexto: el caso de la organización de comunidades forestales de Petén (ACOFOP). El Salvador: PRISMA.

Habermas, J. 2004. Legitimation crisis. Londres: Polity Press.

Iniciativa para los Derechos y Recursos (RRI) y Organización Internacional de las Maderas Tropicales (OIMT). 2009. Tropical forest tenure assessment: Trends, challenges and opportunities. Trabajo elaborado para la International Conference on Forest Tenure, Governance and Enterprise: New Opportunities for Central and West Africa. Del 25 al 29 de mayo del 2009, Hôtel Mont Fébé, Yaundé, Camerún.

Instituto de Agricultura, Recursos Naturales y Ambiente (IARNA), Universidad Rafael Landivar (URL) y Asociación Instituto de Incidencia Ambiental (IIA). 2006. Perfil ambiental de Guatemala: tendencias y reflexiones sobre la gestión ambiental. Guatemala: IARNA, URL e IIA.

Larson, A. 2010. Making the 'rules of the game': Constituting territory and authority in Nicaragua's indigenous communities. Land Use Policy 27: 1143-1152.

Larson, A.M., D. Barry y G.R. Dahal. 2010a. New rights for forest based communities: understanding processes of forest tenure reform. International Forestry Review 12(1): 78-96.

Larson, A.M., D. Barry, G.R. Dahal y C.J.P. Colfer. (eds.). 2010b. Forests for People: Community Rights and Forest Tenure Reform. Londres: Earthscan.

Lemos, M. y A. Agrawal. 2006. Environmental governance. Annual Review of Environmental Resources 31: 297-325.

Monterroso I. y D. Barry. 2007. Community based forestry and the changes in tenure and access rights in the Mayan Biosphere Reserve. En: Poverty reduction and forests: tenure, market and policy reforms. Organizado por el Centro Regional de Formación Forestal Comunal para Asia y el Pacífico (RECOFTC). Tailandia: RECOFTC. 9 de septiembre del 2007. 
Monterroso, I. 2007. Extracción de xate en la RBM: elementos para su sostenibilidad. Facultad Latinoamericana de Ciencias Sociales (FLACSO) Guatemala. Editorial en Ciencias Sociales. Guatemala.

Nuggehalli, R. y L. Stalker. 2009. Motivating factors and facilitating conditions explaining women's participation in co-management of Sri-Lankan forests. Forest Policy and Economics 11(4): 288-293.

Radachowsky, J., V.H. Ramos, R. McNab, E.H. Baur y N. Kazakov. 2012. Forest concessions in the Mayan Biosphere Reserve: A decade later. Forestry Ecology and Management 268: 18-28.

Schwartz, N. 1990. Forest society: A social history of Petén, Guatemala. Filadelfia, Estados Unidos: University of Pennsylvania Press.

Sikor T. y C. Lund. 2009. Access and property regarding natural resources: A question of power and authority. Development and Change 40(1): 1-22.

SI PETÉN 2002. Centro de Monitoreo y Evaluación de CONAP (CEMEC) Región VIII. Base de Datos. Guatemala.

Sociedad para la Conservación de la Vida Silvestre (WCS), Consejo Nacional de Áreas Protegidas (CONAP) y Programa de Fortalecimiento Institucional en Políticas Ambientales (FIPA). 2002. Estimación de la deforestación en la Reserva de Biosfera Maya, Período 2001-2002. Guatemala: WCS, CONAP y FIPA.

Sociedad para la Conservación de la Vida Silvestre (WCS), Consejo Nacional de Áreas Protegidas (CONAP) y Programa de Fortalecimiento Institucional en Políticas Ambientales (FIPA). 2003. Estimación de la deforestación en la Reserva de Biosfera Maya, Periodo 2002-2003. Guatemala: WCS, CONAP y FIPA.

Sociedad para la Conservación de la Vida Silvestre (WCS), Consejo Nacional de Áreas Protegidas (CONAP) y Programa de Fortalecimiento Institucional en Políticas Ambientales (FIPA). 2004. Estimación de la deforestación en la Reserva de Biosfera Maya, Período 2003-2004. Guatemala: WCS, CONAP y FIPA.

Sociedad para la Conservación de la Vida Silvestre (WCS), Consejo Nacional de Áreas Protegidas (CONAP) y Programa de Fortalecimiento Institucional en Políticas Ambientales (FIPA). 2005. Estimación de la deforestación en la Reserva de Biosfera Maya, Periodo 2004-2005. Guatemala: WCS, CONAP y FIPA.

Suchman, M. 1995. Managing legitimacy: strategic and institutional approaches. The Academy of Management Review 20(3): 571-610.

Sundberg, J. 2002. Conservation as a site for democratization in Latin America: Exploring the contradictions in Guatemala. The Canadian Journal of Latin American and Caribbean Studies 27(53): 73-103.

Sundberg, J. 1998. NGO Landscapes in the Mayan Biosphere Reserve, Guatemala. Geographical review 88(3): 388-412.

Sunderlin, W., J. Hatcher y M. Liddle. 2008. From exclusion to ownership? Challenges and opportunities. En: Advancing forest tenure reform. Washington D.C.: Iniciativa para los Derechos y Recursos (RRI). 
Taylor, P. 2009. Conservation, community, and culture? New organisational challenges of community forest concessions in the Maya Biosphere Reserve of Guatemala. Journal of Rural Studies 26(2): 173-184.

Unidad de Parques Nacionales Naturales de Colombia (UAESPNN). 2004. Estrategia integral y diferencial de gobernabilidad en Áreas protegidas del Petén. Guatemala: Departamento del Interior de los Estados Unidos, DOI, Programa de Fortalecimiento Institucional de Políticas Ambientales (FIPA) de la Agencia de los Estados Unidos para el Desarrollo Internacional (USAID) y Consejo Nacional de Áreas Protegidas (CONAP).

White, A. y A. Martin. 2002. Who owns the world's forests? Washington, D.C.: Forest Trends.

Weber, M. 1921. Economy and society. Nueva York: G. Roth, C. Wittich, Bedminster Press. 


\title{
De bosques comunales a áreas protegidas
}

\author{
Las implicaciones de los cambios de la tenencia en el manejo de los recursos \\ naturales en Guatemalai
}

Silvel Elíasii

\section{Resumen}

En ocasiones, las iniciativas de áreas protegidas han provocado conflictos con la población indígena cuyos medios de vida dependen de los bosques. En este artículo se examinan los esfuerzos para promover la protección de los bosques comunales en el altiplano guatemalteco. Se analizan los mecanismos institucionales utilizados para crear áreas protegidas en el contexto de una historia de profunda desigualdad y de la nueva legislación de Guatemala que reconoce por primera vez la existencia de tierras comunales. En lugar de apoyar las instituciones comunitarias y los derechos a la tierra, los esfuerzos de conservación han fortalecido el papel de los gobiernos municipales, provocando cambios fundamentales en la gobernanza local y las estrategias de medios de vida, y desplazando la participación de la comunidad en el manejo de los recursos naturales. El presente artículo responde a las siguientes preguntas: ¿Cuál es la relación entre el discurso de conservación y las demandas de los pueblos indígenas? ¿Cómo se han modificado las prácticas cotidianas de acceso y uso de los recursos naturales con la creación de áreas protegidas? ¿Qué repercusiones tienen estos procesos en las instituciones locales de administración territorial? Y, ¿cómo se pueden diseñar mecanismos de conservación para fortalecer los derechos de los pueblos indígenas?

\section{Introducción}

Es innegable que la creación de áreas protegidas ha contribuido significativamente a detener o reducir la degradación de los recursos naturales y el deterioro de la biodiversidad en muchas partes del mundo. No obstante, el aumento de áreas protegidas también ha sido cuestionado. Su periodo principal de expansión, de 1985 a 1995, coincidió con el auge de políticas económicas neoliberales, y en la actualidad las áreas protegidas son parte

i Este artículo es una traducción del original, que apareció en inglés en la revista Conservation and Society, en la edición especial sobre Reformas de tenencia forestal (eds. Anne M. Larson y Ganga Ram Dahal). La cita original completa es: Elías, S. 2012 From Communal Forests to Protected Areas: The Implications of Tenure Changes in Natural Resource Management in Guatemala. Conservation and Society 10(2): 151-160. El artículo cuenta con una licencia de Creative Commons de Atribución 3.

ii Facultad de Agronomía, Universidad de San Carlos, Ciudad de Guatemala, Guatemala silvelelias@yahoo.com. 
importante de las estrategias de globalización de las políticas ambientales. Con todo, las áreas protegidas han generado conflictos y tenido impactos sociales y económicos que afectan principalmente a las poblaciones —en particular las de los pueblos indígenasque habitan en bosques y dependen de ellos, quienes han visto limitadas sus oportunidades de medios de vida (Brockington et al. 2008; Zimmerer 2006).

La conservación en áreas indígenas presenta dos dilemas íntimamente relacionados. En primer lugar, los esfuerzos para apoyar la conservación no solo deberían tener en cuenta los derechos de los pueblos indígenas, sino que también deberían garantizarlos, especialmente los derechos de tenencia de la tierra y de autodeterminación (OIT 1989; Sunderlin et al. 2008). En segundo lugar, la conservación debe garantizar el acceso a actividades de subsistencia, sobre todo el de la población más pobre; es decir, la conservación debería ser considerada como un mecanismo para reducir la pobreza. Esto significa que los proyectos, independientemente de que su objetivo principal sea o no la conservación o el desarrollo, o incluso la mitigación o adaptación al cambio climático, deberían adoptar un enfoque integrado. Es decir, la lucha contra la pobreza debe enmarcarse en el contexto de la conservación, y la conservación debe contemplarse en el contexto de la lucha contra la pobreza. Los proyectos también deberían garantizar el reconocimiento de los derechos humanos de la población que vive en los bosques y depende de ellos (Fisher et al. 2008; Seymour 2008). Muchas importantes organizaciones de conservación de todo el mundo empiezan a reconocer poco a poco la necesidad de replantear sus conceptos y crear mecanismos para la creación de Áreas de Conservación Comunitarias e Indígenas (ACCI), con el fin de reconocer los derechos de los pueblos indígenas a controlar y manejar sus propios territorios (UICN [Unión Internacional para la Conservación de la Naturaleza] 2003; Borrini et al. 2004).

El manejo colectivo de los recursos naturales ha sido abordado en la "teoría de los comunes", basada en las ideas de Ostrom (Ostrom 1990) y otros autores que, desde 1990, han refutado la influyente tesis de Hardin "la tragedia de los comunes" (Hardin 1968). Hardin argumentó que los recursos de propiedad común están condenados al fracaso, ya que los individuos buscan maximizar sus beneficios hasta agotarlos, porque son de acceso libre. Hardin propuso que la nacionalización y privatización de los recursos de propiedad común son las mejores formas de evitar la tragedia. Ostrom, por el contrario, demostró que los recursos de propiedad común son regulados por principios de autogestión que a lo largo del tiempo han ayudado a conservar la naturaleza.

No obstante, la teoría de Hardin continúa influenciando las políticas y acciones de conservación en muchas partes del mundo. Los bosques comunales del altiplano de Guatemala, por ejemplo, son objeto de un creciente interés conservacionista debido a su importancia estratégica al ser los últimos remanentes de biodiversidad en una región caracterizada por la pobreza y una alta densidad de población. Para abordar la presión sobre los recursos naturales, la principal propuesta ecológica del gobierno y de organismos ambientales es declarar estos bosques áreas protegidas. Pero esta política está siendo cuestionada, ya que la creación de áreas protegidas implica crear nuevas normas que limitan el acceso de la población —especialmente la más pobre— a los medios de vida. 
Los pueblos indígenas representan el 80 por ciento de la población de esta región de Guatemala (INE 2002). Están firmemente arraigados a sus territorios ancestrales, y su cohesión social en torno a organizaciones tradicionales es fuerte. En este aspecto, la tenencia comunitaria es un sistema de manejo colectivo del territorio y los recursos naturales, ha sido fundamental para el cuidado de los bosques y la distribución de los beneficios forestales. Los derechos de acceso, uso y exclusión son ejercidos a través de instituciones indígenas locales que se encargan de regular la cosecha y el mantenimiento de los recursos, generalmente siguiendo normas creadas por las propias comunidades (Elías 2005; Wittman y Geisler 2005; Elías y Wittman 2005).

La contribución de los pueblos indígenas u originarios al manejo de los recursos naturales ha obligado a revisar la "tragedia de los comunes" y, de hecho, ha dirigido la atención hacia la necesidad de entender, documentar y reforzar la coexistencia de pueblos indígenas y sus espacios naturales (Chapin 1995). No obstante, en los últimos veinte años, los territorios indígenas de Guatemala han experimentado cambios en la tenencia de la tierra y nuevas dinámicas económicas, en forma de programas de colonización agrícola, industrias madereras, explotación de petróleo, minas a cielo abierto, grandes autopistas, saqueo de la biodiversidad, imposición de áreas protegidas, y otros proyectos que excluyen igualmente a las poblaciones originales. En respuesta, muchas comunidades del altiplano occidental están haciendo un esfuerzo para mantener el control y la regulación de sus territorios con el fin de equilibrar las áreas de acceso colectivo e individual.

La práctica de establecer áreas protegidas en territorios indígenas está muy extendida, especialmente en países en desarrollo. Las políticas de conservación y de tierras se unen para facilitar las reformas de la tenencia y los cambios institucionales requeridos (Ho y Spoor 2006), pero con frecuencia no reconocen los derechos de la población indígena, la cual es desplazada de sus territorios o se le restringe el uso de recursos naturales (Colchester 2003).

Este artículo se basa en los resultados de un estudio de campo realizado por el autor, que incluyó entrevistas con poblaciones indígenas en el altiplano guatemalteco. Se funda en particular en un estudio regional y cuatro estudios de caso sobre derechos de tenencia y medios de vida, llevados a cabo como parte de un proyecto de investigación más amplio financiado por el Centro para la Investigación Forestal Internacional (Elías et al. 2009; Larson y Dahal en este volumen), así como en un estudio sobre manejo y conservación de recursos naturales en tierras comunales (Elías 2008). El artículo analiza los mecanismos institucionales empleados para convertir bosques comunales en áreas protegidas y responde a las siguientes preguntas: ¿Cuál es la relación entre el discurso de conservación y las demandas de los pueblos indígenas? ¿Cómo se han modificado las prácticas cotidianas de acceso y uso de los recursos naturales con la creación de las áreas protegidas? ¿Qué repercusiones tienen estos procesos en las instituciones locales de administración territorial? Y, ¡cómo se pueden diseñar mecanismos de conservación para fortalecer los derechos de los pueblos indígenas? 


\section{La importancia ecológica de los bosques comunales del altiplano}

El paisaje forestal del altiplano occidental guatemalteco, una región que comprende los departamentos de Huehuetenango, San Marcos, Quetzaltenango, Totonicapán, Quiché y Sololá, está dominado por coníferas (Pinus, Abies Cupressus), árboles latifoliados (Quercus, Alnus, Arbutus), y bosques mixtos. Más del 80 por ciento de la cobertura forestal se halla en tierras colectivas, de tenencia comunitaria o municipal (Elías 2008). Los bosques comunales de esta región son espacios únicos en los que se ha mantenido la biodiversidad, gracias a los esfuerzos de las comunidades por crear sus propias instituciones de autogobierno para administrar su patrimonio colectivo. No obstante, los pueblos indígenas creen que la biodiversidad y los recursos naturales en general forman parte de espacios territoriales más amplios y, por lo tanto, no deben ser considerados aisladamente, sino como parte de un todo interrelacionado.

Los bosques del altiplano tienen una importancia estratégica para las comunidades locales y la población en su conjunto, debido a su ubicación en las zonas altas de las cuencas hidrológicas que contribuyen al mantenimiento de las fuentes de agua, un aspecto que está adquiriendo mayor interés y relevancia a la vista de la disminución de los recursos hídricos. Como consecuencia de la presión demográfica, los sistemas de agricultura a pequeña escala y la pobreza, el paisaje forestal se compone de bosques pequeños y fragmentados, pero su contribución a la conservación de la biodiversidad y al manejo de los recursos forestales ha sido reconocida por organizaciones forestales y conservacionistas (Elías 2008, 2009). La región también contiene ecosistemas únicos con gran cantidad de especies endémicas, como el abeto de Guatemala o pinabete (Abies guatemalensis Rehder; UICN 2010).

Aunque estos bosques son pequeños, tienen la función estratégica fundamental de proporcionar bienes y servicios a la población, en particular leńa, plantas medicinales y agua, todos ellos cruciales para los medios de vida y las estrategias de supervivencia de los habitantes locales. Además, tienen un valor simbólico irreemplazable en la espiritualidad indígena como ubicación de lugares sagrados y de veneración.

Estos ecosistemas se caracterizan por el lento crecimiento de la biomasa debido a las bajas temperaturas, los intensos vientos y las heladas. Por ello, son muy sensibles a presiones sociales como los cambios de uso del suelo, la deforestación y los incendios forestales, así como a fenómenos derivados del cambio climático, particularmente las sequías prolongadas y las lluvias irregulares.

No obstante, a pesar de la presión social, la tasa de deforestación es algo inferior al 1 por ciento anual, es decir, por debajo del 1,46 por ciento de la media nacional (UVG - INAB CONAP 2006). Esta cifra tan baja se debe a las comunidades locales que supervisan su regulación y protección. Otros estudios llevados a cabo por el autor, (Elías 1997, 2008, 2009), demuestran que los bosques del altiplano han sido conservados gracias a la tradición de tenencia forestal colectiva en esta región. Los resultados de estos estudios también indican que los objetivos de conservación se logran en la medida en que las 
comunidades se benefician de los productos y servicios que estos bosques ofrecen para la subsistencia familiar. Además, se ha visto que los esfuerzos locales de conservación están mejor organizados cuando las comunidades son capaces de diseñar sus propias reglas de uso y acceso, formas de autogobierno y mecanismos de monitoreo y control.

Sin embargo, desde la perspectiva de la conservación, varios estudios realizados en las últimas dos décadas han advertido de los riesgos de deforestación en esta región, causados en particular por la alta presión demográfica, el consumo de leña y la necesidad de tierra agrícola para la población que vive cerca de los bosques (Utting 1993; Valenzuela 1991; Greenpeace 1992). Basándose en estos estudios, varias organizaciones nacionales e internacionales vinculadas a intereses conservacionistas han propuesto que declarar áreas protegidas en los bosques remanentes ayudaría a conservarlos, ya que se regularía el uso y acceso, reduciendo así la presión sobre los recursos naturales. De hecho, muchas personas siguen argumentando que las principales causas del deterioro ambiental, y especialmente de la deforestación, son el uso de leña, que representa el 35 por ciento del volumen total extraído de los bosques del país (IARNA-URL-IIA 2006), y la creación de pastizale. Por eso, la conservación de los bosques comunales involucraría necesariamente limitar el uso de leña (la principal fuente de energía del 90 por ciento de los hogares de la región), y el pastoreo de ovejas. Aunque esta última actividad ha disminuido, todavía juega un papel importante en las estrategias de supervivencia de las familias rurales más pobres.

\section{Los bosques comunales como parte integrante de la territorialidad indígena}

Los bosques comunales son una expresión de la planificación espacial del territorio comunitario, por lo que no pueden ser contemplados aisladamente ni centrándose solo en unos cuantos de sus atributos naturales o ecológicos. Los territorios indígenas son puntos de referencia para la identidad colectiva; ellos permiten la expresión de pertenecer a un grupo y una cultura determinados. Los territorios indígenas tienen dimensiones históricas, culturales, económicas y políticas. Como espacio histórico, el territorio simboliza las relaciones afectivas con los ancestros y también el espacio vivido que lleva las huellas dejadas por las relaciones entre los miembros de la comunidad. En su dimensión cultural, el territorio es el principal punto de referencia simbólico para la relación con la madre naturaleza y la reproducción de la cultura, a través de la memoria y el patrimonio colectivos (Grünberg 2003). En su dimensión económica, el territorio indígena es un espacio para la apropiación, como fuente de bienes y recursos para beneficio individual o colectivo, sujeto a distintas formas de ocupación, producción y transformación. En su dimensión política, el territorio indígena es un espacio para el ejercicio de relaciones de poder, movilización social y reivindicaciones étnicas.

Los pueblos indígenas ejercen la territorialidad para defender y mantener el control de sus espacios vitales. La larga historia de la construcción social y simbólica de los territorios indígenas convierte a estos espacios en patrimonio colectivo, transmitiendo de generación en generación los bienes, conocimientos, organizaciones y relaciones (tierras, bosques, fuentes de agua, lugares sagrados y gobierno) que son fundamentales para los medios de vida locales. 


\section{Políticas de tierras y derechos de tenencia}

Los bosques de las regiones indígenas de Guatemala son los últimos reservorios de naturaleza existentes, gracias a iniciativas locales para mantener sistemas de conservación indígenas, particularmente en forma de bosques comunales. La mayoría de estas formas alternativas de protección no están incluidas en el Sistema Guatemalteco de Áreas Protegidas (SIGAP, Elías 2008). No obstante, varios bosques están siendo convertidos en áreas protegidas por iniciativa de organizaciones de conservación. Las normas respectivas de las áreas protegidas oficiales reducen el acceso a los medios de vida, especialmente de las familias más pobres (Elías et al. 2009).

Los cambios de tenencia que se han observado en los bosques del altiplano guatemalteco tienen sus raíces en las políticas de tierras y conservación implementadas en las dos últimas décadas en Guatemala y otros lugares del mundo. Promovidas por organismos internacionales como el Banco Mundial, las políticas de tierras se han diseñado para contribuir al crecimiento económico y a la reducción de la pobreza (Deininger 2003), pero están basadas en un modelo neoliberal que defiende la privatización como condición sine qua non para estimular el desarrollo de economías de mercado en países en desarrollo (Ho y Spoor 2006). Estas políticas incluyen una serie de reformas del sistema de tenencia de la tierra que utiliza mecanismos como la certeza jurídica para formalizar los derechos de propiedad, los registros de tierras para mejorar la administración de la tierra, y la activación de un mercado de tierras para estimular el acceso y la redistribución.

No obstante, luego de dos décadas de experimentar con estas políticas, se ha hecho muy poco para transformar la profunda desigualdad de la distribución territorial de Guatemala, una de las más desiguales del continente. El programa de mercado de tierras, instituido en los ańos noventa, ha sido un completo fracaso y está muy lejos de desencadenar cambios significativos en una estructura agraria excesivamente polarizada y todavía dominada por la herencia colonial (Van Dam 1999; Carrera 2000; Merlet y Annalisa 2003).

Respecto a fortalecer la seguridad de la tenencia mediante el registro y la titulación de tierras, solo ahora empieza a haber progresos. Como parte de los compromisos de los Acuerdos de Paz que finalizaron el conflicto armado interno que afectó al país durante más de tres décadas, el Decreto 41-2005, de la Ley del Registro de Información Catastral (RIC), fue aprobado en 2005 para ayudar a resolver problemas agrarios y sentar una base sólida para la seguridad formal de la tenencia de tierra. Al mismo tiempo, el gobierno está facilitando el acceso a tierras según el modelo de reforma agraria apoyado por el mercado. Ambos están siendo implementados siguiendo el enfoque de política de tierras promovido por el Banco Mundial en países en desarrollo. De hecho, el Banco Mundial ha concedido al gobierno guatemalteco un préstamo de 62 millones de dólares estadounidenses para llevar a cabo el catastro en siete departamentos.

Gran parte de las tierras a evaluar y registrar son comunales, pero las comunidades indígenas y campesinas por lo general no tienen documentación legal que demuestre sus derechos, lo que pone en peligro su reconocimiento. Por este motivo, organizaciones indígenas y campesinas han insistido en que se cumpla el artículo 65 de la ley del RIC, 
que establece que: "Si durante el proceso de establecimiento catastral se determina la propiedad, posesión o tenencia comunal de tierras, el RIC reconocerá y hará la declaratoria administrativa de tierra comunal y emitirá las certificaciones para lo que sea conducente y, en su caso, ordenar el registro". Aunque el RIC ha aprobado recientemente un Reglamento de Tierras Comunales tras más de dos años de debate, las comunidades casi no lo conocen y, por sí mismo, no es suficiente para garantizar derechos colectivos a tierras comunales. Es importante señalar que la necesidad del catastro también surgió de las demandas de las organizaciones de base, que trataron de conseguir los documentos necesarios para regular la tenencia, revertir la apropiación indebida, resolver conflictos agrarios y recuperar las tierras expoliadas a comunidades indígenas.

\section{Los bienes comunales frente al discurso conservacionista}

Motivados por acuerdos internacionales, entre ellos el Convenio sobre la Diversidad Biológica (CDB), organizaciones ambientales y organismos del gobierno han asumido el compromiso de aumentar el número de áreas protegidas. En Guatemala existen hasta el momento 241 áreas protegidas con una superficie de 34000 kilómetros cuadrados, lo que equivale al 32 por ciento del país (CONAP 2009a) ${ }^{1}$. Las áreas protegidas más importantes - la Reserva de la Biosfera Maya (véanse Barry y Monterroso en este volumen) y la Reserva de la Biosfera Sierra de las Minas - se encuentran al norte del país, y fueron creadas a principio de la década de los noventa. Durante su creación, no se tuvieron mucho en cuenta los derechos de acceso y uso que muchas comunidades y usuarios a título personal poseían antes de su declaración, ni las dinámicas económicas preexistentes (aprovechamiento tradicional de productos forestales maderables y no maderables, pesca y caza), lo que dio lugar a una serie de conflictos y dificultades de gestión que aún perduran. Más adelante hubo un rápido aumento de declaraciones de áreas protegidas en lugares donde las condiciones naturales evidenciaban un significativo interés en la conservación (Sundberg 1998).

Las principales propuestas para declarar áreas protegidas en el altiplano occidental de Guatemala surgieron de grupos de conservación nacionales e internacionales que, basándose en un discurso bien intencionado sobre la necesidad de proteger la naturaleza, se dedicaron a identificar tales espacios, bien sea por su valor paisajístico, biológico o natural. Muchas de las áreas protegidas fueron creadas sin el consentimiento previo, libre e informado de las comunidades interesadas. Para ilustrar estas circunstancias, a continuación se presentan tres casos emblemáticos [Figura 1].

El primer caso se refiere a la creación en 1997, mediante el Decreto Ley 40-97, de la Reserva de la Biosfera Visís Cabá en las 45000 hectáreas que forman parte del territorio ancestral del pueblo maya ixil de la municipalidad de San Gaspar Chajul, en el norte del departamento de Quiché. La Reserva de la Biosfera Visís Cabá fue creada por grupos conservacionistas de Ciudad de Guatemala, revelando su control sobre territorios indígenas a través del marco político e institucional del país. Las comunidades afectadas expresaron sus objeciones y exigieron que el decreto fuese derogado, argumentando que no habían sido consultadas y, por lo tanto, creían que estaban siendo despojadas de sus 


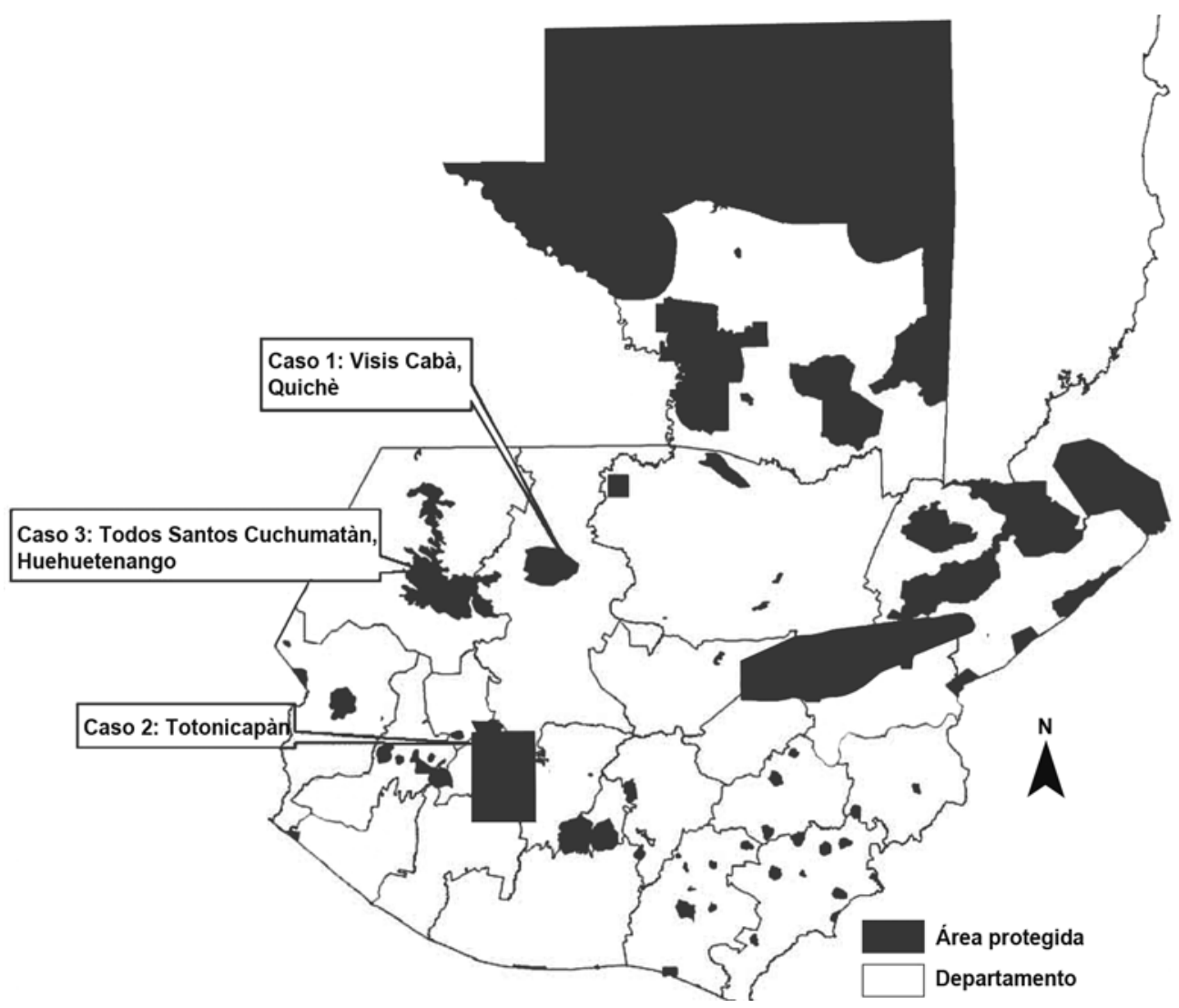

Figura 1. Estudios de caso en el altiplano de Guatemala

Fuente: CONAP 2009a

derechos de control, acceso y uso de su propio territorio ancestral. Estas comunidades demostraron que la conservación existente en la zona era el producto del esfuerzo invertido por ellas durante muchos años, y que la montaña en cuestión es un espacio del que dependen para sus medios de vida. Desde su punto de vista, la categoría propuesta para el área protegida por los conservacionistas no solo infringía sus medios de vida, sino que también transfería el control del bosque a entidades externas a la comunidad, a las cuales estarían sometidas. Después de un intenso conflicto, la población ixil de Chajul fue escuchada finalmente por entidades del gobierno y ONG ecologistas y, aunque no han conseguido que se revoque la declaración de área protegida, han progresado en sus reivindicaciones de derechos colectivos como pueblos indígenas.

El segundo caso es la transformación en 1996 de 16000 hectáreas del bosque comunal de Totonicapán en el Parque Municipal Regional Los Altos de San Miguel Totonicapán, en el territorio ancestral de la población maya quiché. Desde el punto de vista ambiental, este bosque es importante para la conservación de Abies guatemalensis, una especie de abeto amenazada e incluida en la lista roja de CITES (Convención sobre el Comercio 
Internacional de Especies Amenazadas de Fauna y Flora Silvestres), para la cual se ha diseñado una estrategia de protección muy restrictiva, que incluso limita su uso a las comunidades que poseen los bosques comunales en los que crece la especie. Por el contrario, para las comunidades el bosque tiene valor simbólico porque contiene muchos lugares sagrados; tiene importancia hidrológica porque en él se encuentran la fuente de más de 900 arroyos que suministran agua a las comunidades; y tiene relevancia económica porque los bosques proporcionan madera para fabricar muebles, una actividad que durante muchos ańos fue la estrategia de medios de vida más importante de las comunidades de Totonicapán (Veblen 1978; Elías 1997; Tiu y García 2002). La estrategia de área protegida le dio al gobierno municipal un papel protagónico en la administración del área protegida, aunque la protección y el manejo habían estado en manos de las organizaciones tradicionales representadas en el Comité de los 48 Cantones. No obstante, las organizaciones ambientales presionaron para crear una organización comunitaria ad hoc, que denominaron Ulew Che Ja' (que significa tierra, árbol y agua en lengua k'iche'), una entidad compuesta por líderes indígenas locales, pero con un modelo operativo muy diferente al de las organizaciones tradicionales de las comunidades indígenas. Por ejemplo, la nueva organización fue constituida legalmente y tuvo que aprobar estatutos escritos oficiales, lo que le confirió un carácter más formal que agradó al Estado y a los interesados externos, pero no tanto a las propias comunidades. Ulew Che $J a$ ' recibió el apoyo de la comunidad durante un tiempo, pero su vulnerabilidad frente a grupos poderosos, especialmente su subordinación al gobierno municipal y los partidos políticos, fue pronto evidente. Esto minó su credibilidad hasta el punto que la propia población indígena decidió disolverla, tras llegar a la conclusión de que respondía más a intereses externos que locales.

El tercer caso se refiere a la protección formal de las 7068 hectáreas del bosque comunal de Todos Santos Cuchumatán, situado en el territorio del pueblo maya man, en el departamento de Huehuetenango, que han ocupado desde la época prehispánica. Este territorio tiene una distribución espacial en la que cada comunidad reclama la porción de tierra de su área de influencia como tierra comunal. Aunque no hay establecida formalmente una delimitación física del área de influencia de cada comunidad, cada una de ellas reconoce los límites que la separan de las otras. En 2001, tras grandes esfuerzos liderados por organizaciones medioambientales nacionales e internacionales, el área protegida fue creada como reserva forestal municipal mediante un acuerdo con el Consejo Municipal de Todos Santos Cuchumatán y fue reconocida por el Consejo Nacional de Áreas Protegidas (CONAP) en 2004. Para administrar el área protegida, el gobierno municipal creó una infraestructura institucional con el apoyo de ONG ambientales, que consistió principalmente en un nuevo mecanismo regulatorio para acceder a la reserva y hacer uso de ella. Así el gobierno municipal adquirió un rol protagónico que no había tenido con anterioridad, ya que el cuidado de los bosques había sido responsabilidad de las poblaciones locales que viven en las inmediaciones. Algunas comunidades se opusieron a la aplicación de las nuevas normas, especialmente porque ahora se limitaba el uso de los recursos forestales y se reducían las zonas de pastoreo de ovejas, actividad que había sido durante muchos años la fuente principal de medios de vida para las comunidades locales, en particular las mujeres más pobres (Elías et al. 2009). 


\section{Cambios institucionales y de tenencia}

La conversión de estos bosques comunales en áreas protegidas ha requerido establecer una serie de mecanismos institucionales, como reformas legales y de políticas, y asistencia técnica. Ninguno de estos aspectos se explicita en los instrumentos técnicos y legales para las áreas protegidas; más bien son acuerdos tácitos promovidos en las organizaciones comunitarias para asegurar la conservación de sus recursos naturales. El cambio de lo consuetudinario a lo formal ha servido para obtener el apoyo técnico y financiero disponible para organizaciones de base, principalmente las ONG involucradas en estos procesos. En este aspecto, los principales cambios institucionales observados son los siguientes:

\section{Fortalecimiento del papel de los gobiernos municipales}

El surgimiento del liderazgo municipal en la gestión de recursos naturales es muy reciente; fue solo en 1999 que se reformó el Código Municipal, asignando al gobierno municipal la función de supervisar íntegramente su jurisdicción, y preservar su patrimonio natural y cultural. Esto ayudó a asegurar que el discurso de conservación fuese bien recibido por los gobiernos municipales, que habían visto en estas propuestas una revalorización de su rol en el control y regulación del territorio. De esta manera, muchos gobiernos municipales obtuvieron o recuperaron el control de varias áreas consideradas tradicionalmente tierras comunales (Totonicapán, Todos Santos Cuchumatán en Huehuetenango, Tecpán), gracias al apoyo que recibieron de ONG de conservación para convertir esas tierras comunales en áreas protegidas. Paralelamente, los gobiernos municipales reforzaron sus capacidades institucionales para asumir las nuevas responsabilidades requeridas para su incursión en el tema de la conservación. Este rol municipal también es apoyado por las funciones que la Ley Forestal de 1996, Decreto Legislativo 101-96, asignó a los gobiernos municipales en la administración forestal (Wittman y Geisler 2005). Ambos factores facilitaron la creación de oficinas forestales municipales, así como departamentos de áreas protegidas en varias municipalidades del país; desde entonces estas oficinas han atraído fondos de programas de incentivos forestales y de la cooperación internacional. No obstante, el aspecto más importante ha sido la confirmación del papel protagónico de los gobiernos municipales en la administración de los recursos naturales.

Aunque la mayor parte de la población del altiplano es indígena, en la práctica las municipalidades responden a una estructura oficial que opera uniformemente en todo el país, tal como lo establece el Código Municipal; esto significa que no actúan como estructuras de gobierno indígena, incluso si todos los miembros del gobierno son indígenas. Sin embargo, en la mayoría de las municipalidades del altiplano también existen estructuras tradicionales indígenas conocidas como los alcaldes indígenas. $\mathrm{El}$ propósito principal de estas entidades es mantener la cohesión territorial, regular el uso de los recursos naturales y resolver conflictos mediante el derecho consuetudinario. Cuando los bosques comunales se convirtieron en áreas protegidas, las normas formales establecidas por la Ley de Áreas Protegidas estipulaban que quedaban bajo la jurisdicción y el control de la municipalidad, mientras que las normas consuetudinarias y el papel de los gobiernos indígenas tradicionales desaparecían gradualmente. Incluso en municipalidades 
donde todos los miembros del consejo son indígenas, estos gobiernos locales se someten a las leyes oficiales y los objetivos del Estado, que con frecuencia son contrarios a las expectativas y las metas de los pueblos indígenas. Además, la cooperación extranjera y las organizaciones de conservacionistas nacionales e internacionales prefieren trabajar con estos gobiernos municipales, precisamente porque son entidades formales, mientras que a los gobiernos indígenas se los deja con muy poco apoyo técnico y financiero.

\section{Creación de áreas protegidas}

Las principales categorías de áreas protegidas que han sido promovidas son: Reservas Forestales Municipales (pertenecientes a la categoría III de la UICN), Parques Regionales Municipales y Reservas Ecológicas Municipales (ambas pertenecientes a la categoría IV de la $\mathrm{UICN})^{2}$. Estas categorías, cuya única diferencia real es el nombre, han sido promovidas en el altiplano occidental desde 1996 por varias ONG nacionales e internacionales, que apoyan la capacitación técnica, financiera y administrativa de los gobiernos municipales. Estas ONG también coordinan esfuerzos con las comunidades y los gobiernos locales para facilitar el registro de bosques comunales y municipales en esa categoría de manejo. Esto incluye la creación de conciencia y actividades educativas a fin de fomentar la aprobación municipal de mecanismos e instrumentos para la administración del área protegida, entre los cuales destacan: acuerdos para crear el parque, establecimiento de un Departamento de Áreas Protegidas y Medio Ambiente (DAPMA), asignación del presupuesto y del personal correspondiente, y aprobación de las ordenanzas respectivas.

Estos modelos conllevan una transformación sustancial de los mecanismos de manejo de recursos naturales en espacios forestales colectivos. La transformacipon se hace evidente en cuatro ámbitos: primero, un cambio en las acciones, roles y derechos de los interesados respecto al uso y manejo de los recursos naturales; segundo, el establecimiento del aparato administrativo y la implementación de normas que regulen los recursos comunales, desde el nivel comunal hasta el estatal; tercero, una nueva relación entre las comunidades y las entidades del Estado, específicamente el CONAP y el Instituto Nacional de Bosques (INAB), para la administración de las áreas; y cuarto, la presencia de nuevos agentes externos vinculados a la cooperación técnica y financiera.

Según CONAP, desde 1996 se han creado 46 áreas protegidas en el país bajo la responsabilidad de gobiernos municipales, de las cuales 31 son parques regionales municipales, 3 son reservas forestales municipales y 1 es una reserva ecológica municipal [Cuadro 1]. Estas áreas abarcan un total de 48688 hectáreas (CONAP 2009b).

\section{Innovaciones institucionales}

La creación deáreas protegidas ha elevado el perfil de los gobiernos municipales en el manejo de los recursos naturales, principalmente en la administración de las áreas que todavía eran de acceso colectivo. Los gobiernos municipales cada vez están más involucrados en la formulación de políticas y la gestión del patrimonio natural, pero también están involucrados en esfuerzos para desarrollar las capacidades de las instituciones, como la creación de los Departamentos de Áreas Protegidas y Medio Ambiente a modo de áreas 
Cuadro 1. Áreas protegidas en tierras municipales y comunales en Guatemala

\begin{tabular}{lcc}
\hline Categoría de manejo & Cantidad & Extensión (ha) \\
\hline Parque regional municipal & 42 & 39938 \\
Reserva forestal municipal & 3 & 7226 \\
Reserva ecológica & 1 & 1524 \\
Total & 48 & 48688 \\
\hline
\end{tabular}

Fuente: CONAP 2009b

técnicas y administrativas en sus respectivos gobiernos municipales. Uno de los aspectos más notables es el acceso a fondos de incentivos forestales nacionales, principalmente los destinados a la protección del bosque y la reforestación, y la cooperación nacional e internacional ofrecida a los gobiernos municipales con este fin. Esto ha obligado a la creación de nuevas normas para regular el uso y acceso a los recursos naturales que, en la mayoría de los casos, responden a los requisitos establecidos por CONAP. Algunos ejemplos de las nuevas normas son: la administración de las nuevas áreas protegidas quedan bajo el control exclusivo de los gobiernos municipales, limitación en el aprovechamiento de productos forestales maderables y no maderables por parte de los usuarios tradicionales del bosque, prohibición de las actividades tradicionales de pastoreo en áreas protegidas, y formalización de las normas de uso y las sanciones para los infractores [Cuadro 2].

El reglamento interno del uso del bosque de Totonicapán brinda un ejemplo concreto de las nuevas normas. El artículo 4 estipula: "Régimen de manejo forestal municipal: la Municipalidad, junto con la asociación, autoriza la tala de un árbol en un área determinada después del estudio técnico, del pago de la tasa fijada y el acuerdo para reforestar la zona asignada. Está prohibido el transporte de leña en vehículos y de árboles vivos". El artículo 5 establece tres tipos de sanciones: "primera: una llamada de atención y registro escrito del caso...; segunda: suspensión de servicios de abastecimiento de agua al infractor durante un mes y multa de cincuenta quetzales (50 GTQ equivalen a unos USD 6,50); tercera: pérdida definitiva del derecho a agua potable" (Ulew Che Ja' 1999).

El propio CONAP ha creado una unidad de apoyo al gobierno municipal llamada Unidad de Enlace Municipal, cuya función es apoyar e involucrar a los gobiernos municipales en el manejo de las áreas protegidas.

\section{Impacto en la población local y el manejo colectivo}

La transformación de bosques comunales en áreas protegidas ha supuesto un cambio significativo en el manejo de los recursos naturales. Existe una contradicción evidente entre las formas tradicionales de gobernanza de los bosques comunales y la administración oficial de las áreas protegidas. Esto está debilitando el ámbito de los derechos de uso tradicionales, la institucionalidad local, la participación local en el manejo colectivo, la economía local y los sistemas de gobernanza de los recursos y el territorio. 
Cuadro 2. Comparación de normas tradicionales y oficiales en las nuevas áreas protegidas

\begin{tabular}{|c|c|c|}
\hline Tipo de norma & Norma tradicional & Norma oficial \\
\hline $\begin{array}{l}\text { Acceso para el } \\
\text { aprovechamiento de } \\
\text { productos maderables }\end{array}$ & $\begin{array}{l}\text { Los miembros de la comunidad } \\
\text { pueden cortar ramas o recolectar } \\
\text { leña de árboles caídos; según } \\
\text { las necesidades de la persona } \\
\text { solicitante y sus servicios a la } \\
\text { comunidad, las autoridades } \\
\text { comunitarias pueden permitirle } \\
\text { el aprovechamiento de } \\
\text { árboles vivos. }\end{array}$ & $\begin{array}{l}\text { La cosecha debe estar autorizada } \\
\text { por funcionarios del área } \\
\text { protegida; está prohibido } \\
\text { aprovechar árboles vivos. }\end{array}$ \\
\hline Monitoreo y supervisión & $\begin{array}{l}\text { La comunidad elige a un grupo } \\
\text { de guardabosques anualmente, } \\
\text { quienes ofrecen sus servicios a la } \\
\text { comunidad ad-honorem. }\end{array}$ & $\begin{array}{l}\text { La oficina del área protegida } \\
\text { contrata a un grupo de "guardas } \\
\text { de los recursos", quienes trabajan } \\
\text { por un salario. }\end{array}$ \\
\hline Sanciones & $\begin{array}{l}\text { Las autoridades comunitarias } \\
\text { tratan de conseguir la conciliación } \\
\text { y la reparación o corrección del } \\
\text { daño ocasionado basándose en el } \\
\text { derecho consuetudinario. }\end{array}$ & $\begin{array}{l}\text { La oficina del área protegida } \\
\text { multa a los infractores. }\end{array}$ \\
\hline $\begin{array}{l}\text { Mantenimiento } \\
\text { (viveros de árboles, } \\
\text { reforestación, control } \\
\text { de incendios forestales) }\end{array}$ & $\begin{array}{l}\text { Se pide a los miembros de la } \\
\text { comunidad que contribuyan al } \\
\text { mantenimiento del bosque con } \\
\text { un número determinado de días } \\
\text { de trabajo. }\end{array}$ & $\begin{array}{l}\text { La oficina del área protegida paga } \\
\text { los salarios de las personas que } \\
\text { trabajan en el mantenimiento de } \\
\text { las áreas protegidas. }\end{array}$ \\
\hline
\end{tabular}

Nota: En lugares donde los bosques comunales aún son gestionados por los gobiernos indígenas, las normas tradicionales son totalmente vigentes en la actualidad. En contraste, donde los bosques han sido declarados áreas protegidas, las normas oficiales están siendo impuestas rápidamente. No obstante, aún se pueden encontrar algunas normas tradicionales en la práctica, debido principalmente a las demandas de derechos y acceso hechas por usuarios de bosques comunitarios. Por este motivo, en los tres casos estudiados, las normas tradicionales todavía pueden ser opciones parciales y viables para garantizar el manejo sostenible de las nuevas áreas protegidas.

El establecimiento de un área protegida supone nuevas normas para el manejo de los recursos naturales, la mayoría de las veces limitando usos tradicionales como el pastoreo y la extracción de productos maderables y no maderables, ya que normalmente estas actividades se consideran incompatibles y por lo tanto no están incluidas en los correspondientes planes de manejo.

Luego, los mecanismos de control, supervisión y regulación del uso de los recursos naturales que anteriormente utilizaban las comunidades están en declive, debido a que el sistema local de normas ha sido reemplazado gradualmente por nuevos reglamentos municipales establecidos específicamente para el manejo de áreas protegidas. Por ello, la población local participa menos en la administración de los recursos naturales. Por ejemplo, el papel conciliador que desempeñaban los principales o ancianos en el caso de infracciones ha sido sustituido por multas o por la suspensión de los servicios de agua, tal como imponen las municipalidades. 
Además, en muchos casos, las economías locales basadas en el uso de recursos naturales han sido alteradas. En Todos Santos Cuchumatán y Totonicapán, las actividades de pastoreo de ovejas practicadas especialmente por mujeres pobres se han reducido significativamente. En esas localidades se han establecido parcelas para la regeneración natural de Abies guatemalensis; su principal característica es obstaculizar el paso de ganado. En consecuencia, las familias que poseen ovejas han tenido que reducir el tamaño de sus rebaños debido a la escasez de zonas de pastoreo y, aunque se ha promovido la cría de ovejas en estabulación, esta práctica no ha sido ampliamente adoptada porque la población tampoco tiene tierra para cultivar alimento para el ganado.

Para finalizar, han surgido conflictos socioambientales provocados por la restricción del acceso al uso y administración de los recursos naturales a comunidades que no han sido incluidas en los nuevos planes de gobernanza (Elías y Wittman 2005). Algunos de esos conflictos acarrean disputas entre grupos de interesados dentro de las propias comunidades (Elías et al. 2009); en otros, las comunidades se enfrentan a los gobiernos municipales (Prado 2007; Durocher 2002; Wittman y Geisler 2005); mientras que en otros casos se expresa el rechazo de las decisiones impuestas desde el nivel central (Ferroukhi 2003).

\section{Conservación en bosques comunales: hacia un nuevo paradigma basado en la cosmovisión visión del mundo y los conocimientos tradicionales de los pueblos indígenas}

La preocupación de los conservacionistas sobre los efectos de las presiones sociales en la degradación de los bosques comunales es legítima, en el sentido de que requieren intervenciones inmediatas para evitar un daño irreversible a la biodiversidad y al medio ambiente en general. El problema, sin embargo, son los mecanismos utilizados para promover la conservación. En muchas partes del mundo, la creación de áreas protegidas ha implicado cambios en la tenencia que han sido contraproducentes tanto para las comunidades como para los objetivos de conservación.

¿Cómo podemos acercarnos a un nuevo paradigma de conservación que incluya a los usuarios tradicionales del bosque? Las experiencias del autor en el altiplano de Guatemala sugieren seis propuestas fundamentales, que surgen de la manera en la que los pueblos indígenas entienden la conservación.

\section{Reconocimiento de los derechos territoriales y de tenencia de los pueblos indígenas}

En la concepción indígena del mundo, la naturaleza representa el espacio vital en el cual los pueblos indígenas son una parte. Por ello, conservar la naturaleza significa también proteger los derechos de los pueblos indígenas, en particular los derechos al territorio, la organización y la autodeterminación. No obstante, este doble sentido de conservación no está siempre en los programas conservacionistas, que generalmente se centran en elementos biológicos o paisajísticos, definidos como "áreas de interés para la 
conservación”. Un enfoque de conservación nuevo debe tener como punto de partida el reconocimiento de los derechos colectivos de los pueblos indígenas y de sus esfuerzos para proteger la naturaleza. En ese sentido, tanto el Convenio 169 de la Organización Internacional del Trabajo (de 1989) como la Declaración de las Naciones Unidas sobre los Derechos de los Pueblos Indígenas (de 2007) apoyan la necesidad de basar las políticas y acciones de conservación en los derechos colectivos de los pueblos indígenas.

\section{Gobernanza basada en organización comunitaria}

La protección de los recursos por parte de las comunidades es ejercida a través de sus instituciones locales, es decir, sus propias normas y formas de gobierno. Por lo tanto, en lugar de presionar a las comunidades indígenas y a la población local para que reestructuren sus organizaciones y las hagan compatibles con mecanismos propuestos por ONG, las organizaciones existentes deben ser reconocidas y reforzadas, porque ellas son la base para acciones de conservación más dinámicas, sin desencadenar conflictos en las comunidades.

\section{Proporción entre costos y beneficios}

Los costos de supervisar y mantener los recursos naturales en zonas comunales generalmente son compensados mediante los beneficios individuales y colectivos recibidos por las familias y las comunidades, de tal manera que esto se convierte en una especie de incentivo para la acción colectiva. Por lo general, los proyectos de conservación introducen el dinero, que es necesario para algunas actividades de mantenimiento, pero que con frecuencia termina reemplazando las responsabilidades individuales o generando incertidumbre y disputas internas sobre el control de los fondos.

\section{Fortalecimiento de los conocimientos tradicionales}

Dada su larga relación con la naturaleza, los pueblos y comunidades indígenas han desarrollado sistemas de conocimiento que pueden servir de base de apoyo para proyectos de conservación. No obstante, este conocimiento no solo está en peligro por los procesos de cambio cultural, sino que también está siendo aprovechado para objetivos comerciales, sin que la población indígena tenga acceso a la distribución de beneficios. ${ }^{3}$ En el altiplano guatemalteco se ha demostrado que la gran riqueza de biodiversidad agrícola es debida al aporte de los pueblos indígenas al conocimiento local, pero que este conocimiento está siendo seriamente amenazado por la introducción de nuevas prácticas basadas en el uso de semillas mejoradas, productos agroquímicos y cultivo comercial. Por este motivo, urge la necesidad de iniciativas de conservación que respeten y fortalezcan los conocimientos tradicionales.

\section{Respeto a la dimensión simbólica y cultural de la naturaleza}

Para los pueblos indígenas, la naturaleza tiene un valor simbólico y sagrado que rara vez es comprendido o siquiera incluido en el discurso de la conservación. Los lugares sagrados, por ejemplo, tienen un valor incalculable en la cultura indígena, por lo que 
son necesarios nuevos planteamientos para su conservación. En Guatemala, un proyecto de ley sobre lugares sagrados debatido en el Congreso aún no ha recibido suficiente respaldo legislativo para su aprobación, porque condiciona algunos derechos de tenencia en manos privadas.

\section{Fortalecimiento del manejo forestal comunitario}

Hay algunas iniciativas incipientes que ofrecen apoyo directo a las comunidades para manejo forestal y conservación, como el Proyecto de Fortalecimiento Forestal Municipal y Comunal (BOSCOM) del INAB, y los programas de iniciativa forestal que han estado en marcha desde 1995. Trabajan con comunidades sin necesidad de obligarlas a que declaren sus bosques áreas protegidas. Algunas ONG están promoviendo iniciativas similares para ayudar a las comunidades a mejorar y fortalecer sus mecanismos de manejo forestal y conservación.

\section{Conclusiones}

La conversión de bosques comunales en áreas protegidas se basa en un discurso dominante sobre la necesidad de asegurar que las diversas presiones no aceleren la destrucción de los recursos naturales. Este argumento es bien recibido por los gobiernos municipales, que ven en estas iniciativas un mecanismo para afirmar el control sobre la administración de los recursos naturales en su jurisdicción y como una oportunidad para acceder a los fondos disponibles.

No obstante, la creación de áreas protegidas ha restringido derechos tradicionales sobre estos espacios; provocando cambios fundamentales en la gobernanza local y las estrategias de medios de vida, que han desplazado o limitado la participación de la comunidad en el manejo de los recursos naturales.

Si existe interés alguno en promover la conservación en territorios indígenas, es esencial que la población indígena tenga el derecho a mantener cierto grado de control sobre esos recursos a través de sus instituciones de manejo territorial colectivo ya existentes. Esto requiere diseñar nuevos esquemas de gobernanza basados en la participación local y el reconocimiento de los derechos colectivos de las comunidades.

En la actualidad existe un amplio debate sobre la necesidad de replantear los programas oficiales de áreas protegidas para hacerlos más pertinentes a las necesidades y prácticas de los pueblos indígenas. Esto podría suponer la inclusión de aspectos de manejo colectivo, conocimiento local, cosmovisión, lugares sagrados y medios de vida en los mecanismos de gestión y planificación de las áreas protegidas, bosques, cuencas hidrológicas, fuentes de agua y otros espacios en los que el manejo sostenible es importante para el conjunto de la sociedad. Además, la contribución de los sistemas indígenas de conservación de la naturaleza a los esfuerzos globales para afrontar el cambio climático está siendo cada vez más reconocida a nivel mundial. 


\section{Agradecimientos}

Agradezco a Judy Butler y Anne Larson por su apoyo en la traducción de la versión original de este artículo del español al inglés. Asimismo, estoy agradecido con Anne Larson por su orientación durante la investigación y por motivarme para escribir este artículo.

\section{Notas}

1. http://conap.gob.gt:7778/conap/areas-protegidas/sigap/listado-areas-protegidas/

2. Ni la Ley de Áreas Protegidas (Decreto Legislativo 4-89) ni el reglamento para su aplicación (Acuerdo Gubernativo 759-90) hacen referencia explícita a las categorías de áreas protegidas de la UICN, pero se presume que las seis categorías incluidas en el reglamento se refieren a las de la UICN.

3. Los grupos de trabajo del CDB debaten actualmente una propuesta de Acceso y Participación en los Beneficios (APB, o ABS en inglés - Access and Benefit Sharing) para los usos de la biodiversidad con conocimientos tradicionales.

\section{Referencias}

Borrini, G., A. Kothari y G. Oviedo. 2004. Indigenous and local communities and protected areas towards equity and enhanced conservation guidance on policy and practice for co-managed protected areas and community conserved areas. IUCN - The World Conservation Union.

Brockington, D., R. Duffy y J. Igoe. 2008. Nature unbound: Conservation capitalism and the future of protected areas. Londres: Earthscan.

Carrera, J. 2000. El mercado de tierras en Guatemala. Serie Desarrollo Productivo. Santiago, Chile: Comisión Económica para América Latina y el Caribe.

Chapin, M. 1995. La lucha por la tierra en la última frontera centroamericana. Mesoamérica 29: xvi-xxviii.

Colchester, M. 2003. Naturaleza cercada. Pueblos indígenas, áreas protegidas y conservación de la biodiversidad. Ginebra: Instituto de Investigación de las Naciones Unidas para el Desarrollo Social.

Deininger, K. 2003. Land policies for growth and poverty reduction. A World Bank Policy Research Report. Washington, DC: The World Bank.

Durocher, B. 2002. Los dos derechos de la tierra: la cuestión agraria en el país ixil. Serie Dinámicas Agrarias 3. Guatemala: Facultad Latinoamericana de Ciencias Sociales, Misión de las Naciones Unidas para Guatemala, Comisión Presidencial para la Resolución de Conflictos de Tierra.

Elías, S. 1997. Autogestión comunitaria de recursos naturales. El caso de Totonicapán. Facultad Latinoamericana de Ciencias Sociales, Guatemala.

Elías, S. 2005. La lucha por la tierra y la autonomía indígena en Guatemala. Asuntos Indigenas 4: 30-35. 
Elías, S. (ed.). 2008. Diagnóstico de la conservación y manejo de recursos naturales en tierras comunales. Guatemala: Consejo Nacional de Áreas Protegidas/Serviprensa.

Elías, S. (ed.). 2009. Estrategia nacional para conservación y manejo de recursos naturales en tierras comunales. Guatemala: Consejo Nacional de Áreas Protegidas/Serviprensa.

Elías, S. y H. Wittman. 2005. The state, forest and community: Decentralization of forest administration in Guatemala. En: The politics of descentralization: Forests, power and people. (eds. Colfer, C.J.P. y D. Capistrano). Pp. 282-295. Indonesia: CIFOR.

Elías, S., A. Larson y J. Mendoza. 2009. Bosques, tenencia y medios de vida en el Altiplano de Guatemala. Guatemala: Centro para la Investigación Forestal Internacional, Iniciativa de Derechos y Recursos, Facultad de Agronomía de la Universidad de San Carlos de Guatemala.

Ferroukhi, L. (ed.). 2003. La Gestión Forestal Municipal en América Latina. Bogor: Centro para la Investigación Forestal Internacional, Centro de Investigación de Desarrollo Internacional.

Fisher, R., S. Maginnis, W. Jackson, E. Barrow y S. Jeanrenaud. 2008. Linking conservation and poverty reduction: Landscapes, people and power. Londres: Earthscan/ James \& James.

Greenpeace. 1992. Los bosques de Totonicapán. Guatemala: Ediciones Don Quijote.

Grünberg, G. 2003. Tierras y Territorios Indigenas en Guatemala. Col. Dinámicas Agrarias 1. Guatemala: Facultad Latinoamericana de Ciencias Sociales (FLACSO).

Hardin, G. 1968. The tragedy of commons. Science 162: 1243-1248.

Ho, P. y M. Spoor. 2006. Whose land? The political economy of land titling in transition economies. Land Use Policy 23(4): 580-587.

Instituto de Agricultura, Recursos Naturales y Ambiente-Universidad Rafael LandivarInstituto de Incidencia Ambiental (IARNA-URL-IIA). 2006. Perfil Ambiental de Guatemala: Tendencias y reflexiones sobre la gestión ambiental. Guatemala: Instituto de Agricultura, Recursos Naturales y Ambiente (IARNA), Universidad Rafael Landivar (URL), Instituto de Incidencia Ambiental (IIA).

Instituto Nacional de Estadística (INE). 2002. XI Censo de Población y VI Habitación. Guatemala: Instituto Nacional de Estadística.

International Union for Conservation of Nature (IUCN). 2010. Red list of threatened species. Version 2010.4. Unión Internacional para la Conservación de la Naturaleza. htpp://www.iucnredlist.org. Consultado el 1 de diciembre de 2010.

International Union for Conservation of Nature (IUCN). 2003. WPC Recommendation 26 community conserved areas. World Parks Congress; Unión Internacional para la Conservación de la Naturaleza. http://www.danadeclaration.org/pdf/ recommendations26eng.pdf. Consultado el 30 de noviembre de 2010.

Merlet, M. y M. Annalisa. 2003. Acceso a la tierra y reconocimiento de los derechos de tenencia de la tierra en Guatemala. Guatemala: Institut de Recherches et d'Applications des Méthodes de Développement.

Consejo Nacional de Áreas Protegidas (CONAP). 2009a. Listado de áreas protegidas de Guatemala.http://conap.gob.gt:7778/conap/areas-protegidas/sigap/listado-areasprotegidas. Consultado el 3 de octubre de 2010. 
Consejo Nacional de Áreas Protegidas (CONAP). 2009b. Parques Regionales Municipales de Guatemala. Una estrategia de Manejo y Conservación de la Diversidad Biológica y el Agua. Guatemala: Consejo Nacional de Áreas Protegidas.

Organización Internacional del Trabajo (OIT). 1989. Convenio sobre pueblos indígenas y tribales en paises independientes. Convenio 169. Ginebra: Organización Internacional del Trabajo.

Ostrom, E. 1990. Governing the commons. The evolution of institutions for collective action. Nueva York: Cambridge University Press.

Prado, P. 2007. Conservation by cultivation: Linkages between an endangered endemic fir (Abies guatemalensis Rehder) and peasant economies in the western highlands of Guatemala. Universidad de Copenhague, Facultad de Ciencias de la Vida.

Seymour, F. 2008. Climate change, and human rights: Managing risks and trade-offs. Bogor: Centro para la Investigación Forestal Internacional.

Sundberg, J. 1998. NGO landscapes: Conservation and communities in the Maya Biosphere Reserve, Petén, Guatemala. The Geographical Review 88(3): 388-412.

Sunderlin, W., J. Hatcher y M. Liddle. 2008. From exclusion to ownership? Challenges and opportunities in advancing forest tenure reform. Washington: Rights and Resources Iniciative.

Tiu, R. y P. García. 2002. Los Bosques comunales de Totonicapán, Historia, situación jurídica y derechos indígenas. Guatemala. Facultad Latinoamericana de Ciencias Sociales, Misión de las Naciones Unidas para Guatemala, Comisión Presidencial para la Resolución de Conflictos de Tierra.

Ulew Che Ja. 1999. Reglamento de la Asociación Ulew Che Ja. Totonicapán, Guatemala.

Utting, P. 1993. Trees, people, power: Social dimensions of deforestation and forest protection in Central America. Londres: Instituto de Investigación de las Naciones Unidas para el Desarrollo Social, Earthscan.

Universidad del Valle de Guatemala, Instituto Nacional de Bosques, Consejo Nacional de Áreas Protegidas (UVG - INAB - CONAP). 2006. Dinámica de la Cobertura Forestal de Guatemala durante los años 1991, 1996 y 2001. Fase II. Guatemala. Universidad del Valle de Guatemala, Instituto Nacional de Bosques, Consejo Nacional de Áreas Protegidas.

Valenzuela, I. 1991. La dinámica social de la deforestación en Totonicapán. Guatemala: Instituto de Investigación de las Naciones Unidas para el Desarrollo Social.

Van Dam, C. 1999. La tenencia de la tierra en América Latina. El estado del arte de la discusión en la región. Santiago: Unión Internacional para la Conservación de la Naturaleza.

Veblen, T. 1978. Forest preservation in the western highlands of Guatemala. The Geographical Review 68: 417-434.

Wittman, H. y C. Geisler. 2005. Negotiating locality: Decentralization and communal forest management in the Guatemalan highlands. Human Organization 64(1): 62-74.

Zimmerer, K. (ed.). 2006. Globalization and new geographies of conservation. Chicago: University of Chicago Press. 



\title{
Las reformas de las políticas públicas y la gobernanza forestal indígena
}

\author{
El caso del pueblo Yuracaré en Boliviai
}

Rosario Leónnii, Patricia Uberhuagai", Jean Paul Benavidesii, Krister Andersson ${ }^{\text {iii }}$

\section{Resumen}

El reciente auge en los esfuerzos para reformar la gobernanza forestal, tanto a través de la descentralización como de las reformas de la tenencia, se ha visto acompañado por un aumento en los estudios empíricos que evalúan las virtudes y limitaciones de los nuevos regímenes. Sin embargo, a pesar de la creciente literatura, todavía existe un conocimiento limitado sobre los efectos de estas reformas en los indígenas y sus instituciones de gobernanza forestal. Este estudio pretende contribuir a la literatura empírica mediante el análisis de cómo las reformas políticas en Bolivia han incidido en un territorio indígena, sus habitantes, su régimen de derechos de propiedad de facto y los esfuerzos resultantes para gobernar sus recursos forestales. El estudio de caso, relativo a las decisiones de uso de los bosques y las acciones del pueblo Yuracaré en las tierras bajas de Bolivia, es un ejemplo de lo que las sociedades indígenas amerindias enfrentan en términos de las oportunidades y limitaciones relacionadas con la aplicación de los derechos de jure formalizados sobre los bosques. Prestamos especial atención a los efectos de las reformas forestales de 1996 en las condiciones institucionales para gobernar los recursos forestales comunes. El estudio se basa en datos de campo primarios que se obtuvieron antes y después de la ejecución de las reformas. Determinamos que la introducción de los derechos formales ha llevado a una mayor seguridad de los derechos de tenencia y a la aparición de más oportunidades para diversificar las fuentes de ingresos para el pueblo Yuracaré. Pero también hay costos significativos asociados con el logro de estos beneficios. Las reformas indujeron al pueblo Yuracaré a integrarse con las economías públicas y privadas que lo rodeaban, pero observamos que estas interacciones han deteriorado los sistemas tradicionales de gobernanza.

\footnotetext{
i Este artículo es una traducción del original, que apareció en inglés en la revista Conservation and Society, en la edición especial sobre Reformas de tenencia forestal (eds. Anne M. Larson y Ganga Ram Dahal). La cita original completa es: León, R., Uberhuaga, P., Benavides, J.P. and Andersson, K. 2012 Public Policy Reforms and Indigenous Forest Governance: The Case of the Yuracaré People in Bolivia. Conservation and Society 10(2): 195-207. El artículo cuenta con una licencia de Creative Commons de Atribución 3.

ii Centro de Estudios de la Realidad Económica y Social (CERES), Cochabamba, Bolivia.

iii UniversityofColoradoatBoulder,Boulder,Colorado,EstadosUnidos-Krister.Andersson@ colorado.edu.
} 


\section{Introducción}

Pocos sectores públicos en el mundo en desarrollo han sido objeto de tantas reformas de las políticas públicas como el sector forestal. En los últimos 20 años, una serie de reformas destinadas a cambiar la tenencia de los bosques y el grado de descentralización en la toma de decisiones han ayudado a transformar la manera en que la administración pública gobierna los bosques, al menos en el papel. Una de las conclusiones principales de la investigación sobre la gobernanza forestal local es que las reformas políticas no siempre cambian la forma en que realmente se hacen las cosas en el sitio (Gibson et al. 2005; Lindsay 1998; Bruce 1998; Alston et al. 2000).

Sin embargo, sobre la base de las cifras que presentan los Gobiernos mismos, hay una mayor tenencia forestal en proceso de transición, por la cual más y más bosques del mundo son controlados por comunidades rurales y grupos indígenas (White y Martin 2002). Esta transición es, en parte, debida a las reformas agrarias dirigidas por los Gobiernos por las que reconocen los derechos de los pueblos indígenas sobre sus tierras ancestrales. Estas reformas conceden, en diversos grados, la propiedad de estas tierras a sus custodios históricos (White y Martin 2002). La distribución cambiante de los terrenos forestales ha sido bien recibida no solo por los propios indígenas, sino también por los estudiosos de políticas y profesionales preocupados por la infravaloración de los recursos forestales, asociada a los derechos de tierras inseguros. Algunos estudios recientes muestran, sin embargo, que los países que han realizado reformas agrarias han obtenido resultados dispares en lo que respecta a dar una mayor seguridad de tenencia para las poblaciones rurales pobres que dependen de los bosques (Meinzen Dick y Mwangi 2008; Larson et al. 2008, 2010). La formalización de los derechos, al parecer, es un primer paso importante hacia una tenencia forestal más segura, pero no parece ser suficiente para lograr mejores resultados en materia de gobernanza. Esta observación plantea la pregunta de qué condiciones institucionales —además de los derechos de propiedad de jure - conducen a resultados de gobernanza forestal socialmente justos, económicamente viables y ecológicamente sostenibles. En última instancia, esa es la pregunta que motiva este estudio.

Hay un incremento y existe más literatura que examina cómo las reformas de las políticas forestales a nivel central de gobierno afectan, o no afectan, la toma de decisiones sobre los bosques a nivel local. Sin embargo, es sorprendente la poca investigación empírica y sistemática que hay para evaluar el impacto de las reformas en las poblaciones indígenas y su gobernanza de los recursos forestales. Los estudiosos que tratan de abordar este vacío de conocimiento se encuentran con varios desafíos metodológicos. Uno de los problemas más espinosos se relaciona con la dificultad de atribuir los patrones observados del usuario en el campo al establecimiento de la reforma agraria específica. Parte del problema de establecer la causalidad se debe a la falta de datos pertinentes relativos al comportamiento y la toma de decisiones antes que las reformas fueran aprobadas; el interés en la evaluación de los efectos de una política en particular a menudo surge después que la política haya estado en vigor durante algún tiempo. Como resultado, los 
analistas políticos y los responsables políticos todavía desconocen no solo los resultados de las reformas, sino también las modificaciones más adecuadas para que las políticas cumplan sus objetivos.

Este estudio espera contribuir a la literatura empírica contemporánea mediante el análisis de cómo las reformas forestales han incidido en los usuarios forestales indígenas a nivel local. Se presentan los resultados de un estudio de caso longitudinal detallado de un territorio indígena, sus habitantes y sus esfuerzos para gobernar sus recursos forestales. El estudio se basa en datos de campo primarios que fueron recogidos antes y después de la aplicación de las reformas públicas, lo que nos permite verificar algunas de las hipótesis principales sobre los efectos de estas reformas en las poblaciones indígenas y sus sistemas de gobernanza.

El estudio de caso que aquí se presenta se basa en el Programa de Investigación sobre Recursos e Instituciones Forestales Internacionales (IFRI, por sus siglas en inglés), que investigó estas comunidades en dos ocasiones (en 1996 y 2007), reuniendo datos cualitativos y cuantitativos que se pueden combinar y comparar en el tiempo y espacio. En cada una de las comunidades estudiadas, organizamos reuniones con la mayoría de los habitantes locales y recopilamos datos sobre las interacciones de la población con el bosque. También obtuvimos las genealogías de los principales líderes locales del pueblo Yuracaré y realizamos entrevistas detalladas y semiestructuradas con los líderes de la comunidad. En las visitas de 1996 y 2006 se estudiaron y encuestaron las mismas áreas forestales. ${ }^{1}$

El estudio es sobre el pueblo Yuracaré, cuyo territorio ancestral se encuentra en las tierras bajas tropicales de Bolivia. Este estudio de caso constituye un ejemplo de lo que las sociedades indígenas amerindias enfrentan en cuanto a oportunidades y limitaciones relacionadas con la aplicación de las reformas del sector forestal, que en este caso implican las reformas paralelas de tenencia y descentralización. Nuestro análisis presta especial atención a cómo las reformas (en especial las normas para el manejo forestal) han influido en las condiciones institucionales para hacer frente a un conjunto de problemas de acción colectiva que son inherentes a todos los esfuerzos locales relativos a la gestión de los recursos comunes.

Comenzamos el artículo con una revisión de la literatura contemporánea sobre el tema de la gobernanza local de los bosques y las sociedades indígenas. Tomando como referencia la base común de recursos de literatura, seleccionamos una serie de variables que describen las condiciones propicias para una acción colectiva eficaz y, sobre la base de nuestras observaciones de estas variables, evaluamos los efectos de las reformas forestales. Procedemos a describir las propias reformas y luego la sociedad Yuracaré. Concluimos el artículo con una evaluación del grado en que los principios de las condiciones institucionales persistentes que son extraídos de la literatura sobre propiedad común contribuyen a explicar la forma en que el pueblo Yuracaré respondió a las reformas del sector forestal. 


\section{Investigaciones previas}

La literatura sobre los derechos de propiedad ha tratado mayormente sobre los tipos de tenencia relacionados con mejores condiciones forestales. Una de las principales conclusiones del análisis institucional con respecto a el manejo de los recursos de propiedad común es que los límites bien definidos (en cuanto a dónde empiezan los derechos de una persona y dónde terminan los de otra) facilitan la gobernanza eficaz de esos recursos (Ascher 1995; Baland y Platteau 1996; Dietz et al. 2003; Gibson et al. 2005; Meinzen-Dick et al. 2002; Ostrom 1999), al aumentar la probabilidad de mantener la acción colectiva local (Gibson et al. 2000; Meinzen-Dick et al. 2002; Ostrom 2003).

Otro resultado fundamental de un trabajo empírico reciente es que el tipo de tenencia no es tan importante como la seguridad de la tenencia (Gibson et al. 1998; Tucker 1999). Asimismo, McKean (2000) sostiene que la propiedad común es el tipo de tenencia más adecuado para el manejo forestal, ya que mantener los bosques como un bien común disminuye muchos de los riesgos y los factores externos que supone el manejo de los bosques fragmentados.

Gran parte de las investigaciones previas sobre la reforma forestal en los países en desarrollo se centra en cómo las reformas de políticas públicas inciden en las decisiones y acciones del Gobierno en los distintos niveles de gobernanza, especialmente en el caso de las reformas de descentralización (Ferroukhi 2003; Kaimowitz et al. 2001; Larson 2002; Andersson 2003; Pacheco 2002). Pocos estudios abordan específicamente cómo las instituciones indígenas se ven influenciadas por estas reformas (Pacheco 2008; Larson et al. 2008; Andersson y Pacheco 2006 tratan este tema). En la actualidad se reconoce, sin embargo, que los grupos de usuarios a nivel local desempeñan un papel crucial en la elaboración y aplicación de las normas de gobernanza forestal (Becker y León 1999; Gibson et al. 2000).

Agrawal y Ostrom (2001) señalan la importancia de considerar el papel de los grupos de usuarios locales en el análisis de cómo la descentralización y las políticas de reforma agraria influyen en los resultados en materia de bosques. En una comparación entre las comunidades forestales del norte de la India y Nepal, los autores concluyen que las comunidades locales que han recibido derechos formales de propiedad más amplios a través del proceso de reforma tienden a estar más motivadas para gobernar los bosques y, en general, lo hacen con más eficacia. Agrawal y Ostrom (2001) sugieren además que las reformas probablemente no contribuirán a mejorar las condiciones para el autogobierno de los bosques, a menos que las comunidades forestales locales sean reconocidas como propietarias de los bosques que utilizan. En este trabajo, partimos del enfoque desarrollado por Agrawal y Ostrom (2001) y estudiamos cómo un esfuerzo dirigido por el Gobierno para reformar el sector forestal en Bolivia ha tenido un impacto en un determinado grupo local de usuarios, sus regímenes de derechos de propiedad y su lucha para gobernar los extensos terrenos forestales. De este modo, buscamos combinar los conocimientos obtenidos a partir de la literatura sobre los derechos de propiedad y la gobernanza de los recursos naturales. 
El papel de las instituciones indígenas de propiedad común en los regímenes locales de gobernanza forestal no está exento de controversia. Ribot (2001: 22), por ejemplo, sugiere que las autoridades consuetudinarias no son "necesariamente representativas, legítimas o incluso deseadas por las poblaciones locales”. La presencia de hombres fuertes locales o dictadores corporativistas es otro aspecto de los retos organizacionales que enfrentan muchas instituciones indígenas (Baland y Platteau 1996). Otros problemas son la manera en que las grandes organizaciones indígenas pueden seguir tomando decisiones por consenso, la forma de complementar las pequeñas comunidades con las comunidades más grandes para tener éxito en la prestación de importantes servicios a gran escala y la medida en que las organizaciones de gobernanza local son capaces de concordar con las preferencias de los diversos actores de las comunidades más pequeñas (Chandra 2001; Coleman 1990; Ostrom et al. 1993).

Lo que estos estudios señalan muy claramente son los múltiples desafíos organizacionales que en la actualidad enfrentan las organizaciones sociales indígenas en los países en desarrollo. A medida que los Gobiernos nacionales comienzan a aprobar reformas que reconocen el estatus político y social de los grupos indígenas, es importante que los estudios evalúen el grado en que dichas reformas inciden en la capacidad organizativa de estos grupos. Asimismo, dado que las instituciones indígenas se han convertido en actores cada vez más importantes en muchos regímenes de gobernanza forestal nacional, como es el caso de Bolivia, es importante examinar en qué medida las reformas han modificado las formas en que se toman las decisiones de gobernanza forestal.

\section{Antecedentes: Bolivia y el pueblo Yuracaré}

Las tierras bajas de Bolivia representan un área de estudio apropiado para el estudio de la relación entre las reformas de políticas y la gobernanza forestal indígena por al menos tres razones. En primer lugar, el país es ampliamente considerado como un líder en América Latina en lo que respecta al reconocimiento de los derechos territoriales de las poblaciones indígenas (BID 2004). En segundo lugar, desde el año 1994 se ha realizado un amplio proceso de descentralización política, con el objetivo de mejorar el desempeño del servicio público llevando el Gobierno más cerca a la gente. En tercer lugar, la mayoría de los territorios indígenas están en áreas bajo bosque, y las poblaciones indígenas de las tierras bajas administran múltiples productos forestales, que son fuentes importantes de sus medios de vida. Las tierras comunales indígenas en Bolivia abarcan una superficie de hasta 20 millones de hectáreas, lo que representa alrededor de un tercio del total de las tierras bajas de Bolivia y una gran proporción de las áreas forestales del país.

El pueblo Yuracaré vive en un territorio de 247165 ha. Este se encuentra en dos municipios (Chimoré y Villa Tunari) y en dos departamentos (Cochabamba y Beni), que están en disputa sobre quién tiene jurisdicción sobre esta área. El pueblo Yuracaré fue uno de los primeros grupos en Bolivia en adquirir un plan de manejo forestal aprobado por el Gobierno, por medio del cual se le otorgaron oficialmente los derechos formales de utilizar los bosques para satisfacer sus necesidades domésticas y usos comerciales. 
Este logro le dio un "conjunto de derechos" bastante completo (Larson y Puhlin en esta colección; Cronkleton en esta colección) con respecto a su uso de los bosques. Este proceso fue apoyado por el Centro de Estudios de la Realidad Económica y Social (CERES) de Bolivia, que se ha dedicado a realizar actividades de investigación en colaboración con el pueblo Yuracaré desde 1993 hasta la actualidad. Las referencias relativas a la sociedad Yuracaré en este artículo son el resultado de la investigación de campo en dos períodos: uno entre 1994 y 1996, y otro entre 2005 y 2008, cuando se repitió el estudio.

\section{Las reformas forestales bolivianas}

A partir de 1986, Bolivia comenzó a poner en marcha una serie de reformas para "modernizar" el Estado y cumplir con los criterios establecidos en los Programas de Ajuste Estructural apoyados por el Banco Mundial y el Fondo Monetario Internacional. Posteriormente, se iniciaron una serie de reformas de "segunda generación" con el fin de mitigar los impactos negativos sociales y ambientales de este tipo de programas. Entre estos se incluían la Ley de Participación Popular (1994), la Ley del Servicio Nacional de Reforma Agraria (1996) y la Ley Forestal (1996). La formulación de estas normas fue influenciada por varias fuentes, incluyendo acuerdos y convenios internacionales, demandas locales sin resolver por una mayor autonomía, nuevas estrategias de los partidos políticos que respondían a los intereses locales, así como un nuevo orden constitucional nacional (Urioste y Pacheco 2001; O’Neill 2003). En Bolivia, las reformas del sector forestal se caracterizaron por los esfuerzos para democratizar el proceso de las políticas públicas y la revisión del marco regulatorio forestal anterior, que se consideraba anticuado y cada vez menos pertinente (Pacheco 2004). De estas tres leyes, solo la Ley Forestal (1996) se centró explícitamente en los temas forestales. Además, se podrían agregar a esta lista (de Jong 2004) la Ley de Descentralización Administrativa (1995) y la Ley de Municipalidades (1994), pero estas leyes fueron diseñadas como complementos de las tres primeras leyes mencionadas.

A continuación ofrecemos una breve explicación cronológica de cada una de estas leyes, identificando su importancia y su relación con el sector forestal, así como el posible efecto de cada ley en la tenencia de tierras de las comunidades indígenas.

La Ley de Participación Popular (1994) fue, en esencia, una ley de descentralización municipal. Creó los Gobiernos municipales, tanto en zonas rurales como urbanas, con autoridades de elección popular, a las que se les concedió el poder de administrar las finanzas del Gobierno local. La fuente más importante de financiamiento del Gobierno local en Bolivia proviene de las transferencias del Gobierno central, pero los Gobiernos locales también tienen la autoridad para reunir pequeñas cantidades de dinero de las tasas e impuestos. Otra característica importante de este proceso fue la creación de los Comités de Vigilancia, compuestos por representantes de la sociedad civil presentes en el municipio, contempladas en la ley como Organizaciones Territoriales de Base. Estas se encargan de participar en el proceso de planificación municipal, que en esencia significa identificar las necesidades en el área de influencia de cada grupo. La Ley de Participación Popular (1994), sin embargo, hace poco para dirigir la gestión de los bosques y ofrece pocas facultades específicas para hacerlo. 
La Ley del Servicio Nacional de Reforma Agraria (1996) ratifica los derechos de facto obtenidos por los pueblos indígenas en las movilizaciones del año 1990, que reconocían a las tierras indígenas como Tierras Comunitarias de Origen (TCO). El mayor efecto de esta reforma ha sido el proceso de titulación de las tierras indígenas, donde los grupos indígenas exigieron el 29\% de la superficie nacional como TCO. Para el año 2003, las demandas de 51 TCO abarcaron entre 17,5 y 19,5 millones de hectáreas en las tierras bajas (Cronkleton y Albornoz 2004; Pacheco 2008), pero hasta el 2008 solo el 4,2\% había sido efectivamente titulado (Pacheco 2008: 17).

Por último, la Ley Forestal (1996) especifica el método de acceso y uso de los recursos forestales. De este modo, se cambia radicalmente la estructura de incentivos para los usuarios de los bosques (Contreras-Hermosilla y Vargas 2002), con el objetivo de promover el uso sostenible de estos. Por ejemplo, los concesionarios forestales ahora pagan al Gobierno una tarifa fija por hectárea de tierra de concesión, en lugar de pagar la tarifa por volumen extraído, como solía ser el caso durante el antiguo régimen (Pacheco y Kaimowitz 1998). La Ley Forestal reconoce los derechos exclusivos de los pueblos indígenas para la extracción de los recursos forestales de sus TCO. En virtud de la Ley Forestal de 1996, todos los usuarios de los bosques, sin embargo, están formalmente obligados a desarrollar un plan de manejo forestal antes de que pueda darse cualquier actividad de extracción comercial. Esto implica problemas organizativos y tecnológicos para los usuarios locales de los bosques que, por ejemplo, de acuerdo con la ley, no están autorizados a usar motosierras, pero están obligados a utilizar otro tipo de tecnología moderna (que es menos accesible a los grupos locales).

Posiblemente, la característica más llamativa de las reformas fue la transferencia de los derechos de propiedad de los bosques a los pueblos indígenas, que ahora tienen estos derechos sobre los territorios indígenas en regímenes de propiedad común. En el sector forestal, el Gobierno central transfirió algunas responsabilidades de gobierno y poder de decisión a los Gobiernos municipales. Los Gobiernos locales tienen a menudo dificultades para llevar a cabo su mandato descentralizado debido a la falta de fondos y de recursos humanos calificados. Además, con frecuencia hay problemas de jurisdicción entre los municipios y los grupos indígenas, que pueden producir una gran cantidad de tensión local entre estos grupos (Hernáiz y Pacheco 2000).

\section{Transferencia de derechos de propiedad a los pueblos indígenas}

Desde su fundación en 1825, el Gobierno de Bolivia ha tratado de reivindicar el control sobre sus grandes extensiones poco pobladas de bosques y tierras. La población indígena ha sido históricamente desplazada y echada de sus tierras ancestrales. Hasta hace poco, los pueblos indígenas de Bolivia poseían menos derechos formales que los ciudadanos no indígenas, lo que reflejaba los prejuicios que persistían y se plasmaban en las políticas hasta finales del siglo XX (Van Cott 2000). De acuerdo con el pensamiento dominante de finales del siglo XIX y principios del siglo XX, la mayor parte de las tierras bajas no estaba habitada, sino "mal habitada" (Fawcett 1910). 
El Convenio no 169 de la Organización Internacional del Trabajo, que fue ratificado por Bolivia en 1996, tuvo un efecto importante en las cuestiones relativas a la tenencia indígena de la tierra del país. Este convenio trata sobre los derechos de tierras como parte de los derechos humanos fundamentales de los pueblos indígenas y tribales en los países miembros de las Naciones Unidas. El convenio obliga a los países firmantes a reconocer los derechos de propiedad de las poblaciones indígenas sobre los terrenos forestales como propiedad común, en áreas que previamente habían sido consideradas como de acceso público o abierto. En cumplimiento de los requisitos del convenio, la Ley del Servicio Nacional de Reforma Agraria de Bolivia (1996), reconoció los territorios indígenas como propiedad indígena común a través de un proceso de regularización de títulos en todo el país. Esto incluyó los derechos sobre los bosques y las tierras y ofreció nuevas oportunidades a las comunidades indígenas para el manejo de los bosques, aunque muchas de estas comunidades aún no han logrado capitalizar estas oportunidades (para conocer un caso similar, véase Cronkleton en esta colección). A través de este proceso, se les ha concedido a las comunidades indígenas derechos de acceso a la tierra, extracción, gestión y exclusión (pero no los derechos de enajenación). Por otra parte, la legislación reconoce los derechos sociales, culturales y económicos de los pueblos indígenas, y permite a estos grupos confiar en sus instituciones de gobierno tradicionales y sus derechos consuetudinarios.

\section{La sociedad indígena Yuracaré}

El pueblos Yuracaré es uno de los 32 pueblos indígenas de Bolivia y está ubicado en la cuenca del río Chapare. El río constituye una frontera natural entre las provincias de Chapare y Carrasco, ambas en Cochabamba y tiene más de $300 \mathrm{~km}$ de largo. Esta cuenca es una zona mayormente inexplorada de bosques y pastizales húmedos naturales, con un poco de petróleo crudo y gas natural, y una red vial deficiente. El único acceso vial es a través de una pequeña carretera al puerto de entrada de la zona, Puerto Cochabamba. El pueblo Yuracaré ha estado, durante siglos, a lo largo de la región del Chapare, sin embargo, el proceso de colonización los ha trasladado a su actual asentamiento. De esta manera, el actual territorio Yuracaré, con una extensión de 247165 ha es solo una pequeña parte de la superficie que ha ocupado históricamente el pueblo Yuracaré. Esta área se ha reducido progresivamente, al ir apareciendo otros asentamientos (Becker y León 2000).

El pueblo Yuracaré está en un proceso de cambio de sus patrones tradicionales de uso de los terrenos forestales: de hogares con alta movilidad en grandes superficies de bosques a asentamientos más permanentes. Sin embargo, el pueblo Yuracaré todavía vive en las orillas del río y sigue cazando, pescando, recolectando productos del bosque, plantando cultivos de subsistencia y extrayendo madera y productos no maderables del bosque, como sus principales medios de vida. Hoy en día, esta sociedad indígena tiene contacto con redes de mercado y, a través de ellas, con otras partes de la sociedad occidental. Su estilo de vida está experimentando un rápido proceso de cambio, en el que se adaptan a la dinámica socioeconómica del trópico boliviano moderno. Ellos también se ven afectados por una importante producción ilegal de hoja de coca, que está estrechamente relacionada con la economía internacional (Uberhuaga 2001: 46). 
Hoy en día, la población Yuracaré es alrededor de 3000 habitantes, que viven en 18 comunidades a lo largo del río Chapare. ${ }^{3}$ La unidad principal de la institución social de los Yuracaré es el clan —una población consanguínea - que constituye la unidad más baja de toma de decisiones. En la antigüedad, cada clan estaba ubicado en un asentamiento llamado puerto, ya que el río era la característica ecológica principal en la organización territorial de esta población. En un nivel superior de organización, el pueblo Yuracaré se divide en "corregimientos", que son grupos de familias extensas y nucleares que tienen derechos sobre un territorio más amplio y que eligen a sus representantes generalmente por consenso. Como se ilustra en la Figura 1, en el más alto nivel de organización, existe un Consejo Yuracaré, que consiste en un cacique mayor y ocho secretarios (CERES 1997: 14-15). ${ }^{4}$

El territorio Yuracaré se encuentra en una zona inundable, en diferentes etapas de sucesión formadas por diferentes cauces antiguos del río Chapare, que forman áreas potenciales para la reproducción de peces y fauna en general. El territorio posee una diversidad biológica sumamente alta, y las zonas de asentamiento corresponden a los bosques de cauces situados en las zonas de terrazas altas donde se desarrollan las prácticas agroforestales (Uberhuaga 2001: 46). La gestión de esta zona es a través de ciclos de rotación mínimos de parcelas agrícolas llamadas chacos y barbechos. ${ }^{5}$

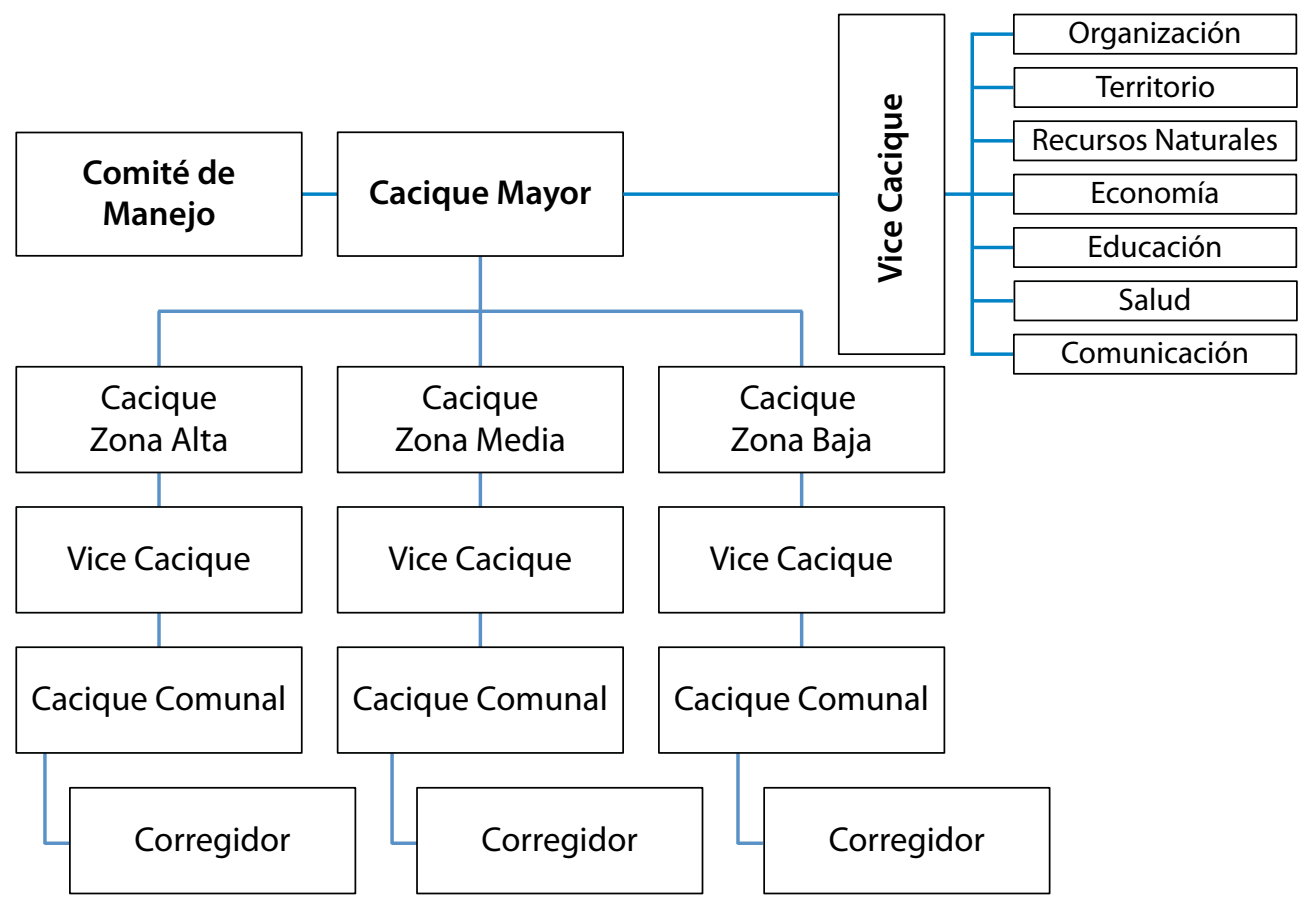

Figura 1. Estructura de la autoridad

Fuente: Elaboración de los autores en base a las observaciones de campo 1996-2009 
La población Yuracaré se basa principalmente en las prácticas agrícolas estacionales y depende de los bosques como la principal fuente de alimento. De los bosques obtienen carne de caza y pescado, frutas y semillas para la alimentación y la medicina, cosechas de arroz, yuca y plátanos, materiales para construir sus viviendas y productos derivados de la madera para vender en el mercado. Así, su economía se basa en el suministro de productos forestales, los cuales están sujetos a la dinámica de la demanda de mercado interna y externa.

La población Yuracaré también interactúa con la sociedad occidental, como resultado de la interacción con el mercado. Los esfuerzos del pueblo Yuracaré para insertarse en la sociedad boliviana fueron motivados por una combinación del objetivo de generar mayores ingresos por la venta de la madera y el deseo de adquirir el reconocimiento legal y los derechos formales de propiedad de sus tierras y recursos naturales.

\section{Evaluación de los efectos de las reformas en la gobernanza forestal local}

Una gobernanza forestal sólida requiere instituciones locales fuertes porque los bosques son recursos comunes que hacen que la exclusión de potenciales usuarios externos sea difícil y costosa (Ostrom 1999; Gibson et al. 2000). Los bosques tienen externalidades importantes en lo que respecta a los servicios atmosféricos, hidrológicos y biológicos. Además, el crecimiento de los bosques (y sus subsistemas asociados) toma mucho más tiempo que los períodos de gobierno de parlamentarios o presidentes. Los bosques son complejos, ya que pueden generar productos múltiples, por ejemplo, madera para construcción y/o combustible, flora y fauna silvestres, agua, hojas, frutas, forrajes, semillas, paja, sombra, suelo fértil, piedras, etc. Estos productos pueden ser o no ser para el consumo, madurar a ritmos diferentes y tener las características de los bienes de propiedad común, privada o pública, brindando servicios ecosistémicos a regiones, países y continentes. En otras palabras, los bosques son recursos complejos y, como tales, no admiten soluciones simples de políticas (Andersson y Ostrom 2008).

Cualquier evaluación sistemática de los efectos de las reformas políticas debe desarrollar un conjunto de criterios e indicadores aplicables que reflejen los objetivos de las reformas políticas. Para evaluar el grado en que el conjunto de reformas ha incidido en las actividades forestales de las comunidades indígenas, nos basamos en investigaciones previas realizadas por Ostrom (1999), que ponen de relieve los principios que caracterizan a instituciones de recursos de propiedad común que han perdurado. Sostenemos que los efectos de las reformas de las políticas públicas en estas instituciones indígenas dependen del grado en que dicho proceso ayuda a la creación de condiciones institucionales que apoyan más a las instituciones sólidas de autogobierno. A partir de una selección de los principios de diseño institucional de Ostrom, evaluamos cómo las reformas han influido en estas condiciones para un autogobierno efectivo (Ostrom 1990, 1992, 1999). 
Prevemos que con las reformas se obtengan resultados de gobernanza positivos para los pueblos indígenas cuando las condiciones locales para el desarrollo de instituciones locales sólidas sean apoyadas, en lugar de cuestionadas (Dietz et al. 2003). Según los principios de diseño institucional de Ostrom (1990), estas condiciones incluyen: normas que sean congruentes con las condiciones ecológicas, límites claramente definidos de recursos y grupos de usuarios, mecanismos de rendición de cuentas para el monitoreo, la aplicación de sanciones graduales en casos de infracciones, mecanismos de resolución de conflictos de bajo costo, la inclusión de las partes interesadas en los debates informados sobre las normas, la posibilidad de una gobernanza adaptable a múltiples niveles y el empleo de mezclas de tipos institucionales.

Elegimos utilizar los principios de diseño de Ostrom como nuestros principales criterios para evaluar el autogobierno porque muchos de los principios de diseño de Ostrom, si no todos, han sido corroborados por un gran número de estudios empíricos. Entre estos estudios se han incluido trabajos experimentales (Ostrom et al. 1994; Ostrom 2003; Cárdenas 2000; Janssen et al. 2010), estudios cuantitativos (Gibson et al. 2000, 2005; Agrawal y Chhatre 2006; Chhatre y Agrawal 2009; Van Laerhoven 2010), estudios de caso comparativos (Andersson y Pacheco 2006) y análisis espaciales (Nagendra 2007; Ostrom y Nagendra 2006). Por lo tanto, existe una fuerte justificación teórica y empírica para usarlos como criterios de evaluación del autogobierno.

Nuestro análisis del autogobierno forestal compara las condiciones institucionales para una gobernanza eficaz para el pueblo Yuracaré antes y después de las reformas políticas, en particular, el impacto de la reforma forestal de 1996. Estimamos que algunos de los principios se vean más influidos que otros por las reformas institucionales, las transformaciones de las organizaciones y la asignación de nuevos derechos y responsabilidades. El Cuadro 1 resume los resultados de la comparación intertemporal.

\section{Cuadro 1. Comparación entre los indicadores de gobernanza antes y después de las reformas de 1996}

\begin{tabular}{lll}
\hline Indicador & Antes & Después \\
\hline $\begin{array}{l}\text { Congruencia de } \\
\text { las normas con las } \\
\text { condiciones ecológicas }\end{array}$ & $\begin{array}{l}\text { Alta: sistema flexible que se } \\
\text { adaptaba a las necesidades y a } \\
\text { las preferencias productivas de } \\
\text { las familias }\end{array}$ & $\begin{array}{l}\text { Baja: imposición de normas } \\
\text { de arriba hacia abajo que } \\
\text { son idénticas para todos, } \\
\text { independientemente del } \\
\text { contexto institucional local }\end{array}$ \\
$\begin{array}{lll}\text { Claridad en los límites } \\
\text { Moderada: no siempre se } \\
\text { respetan las reglas de acceso } \\
\text { Rendición de cuentas } \\
\text { de los responsables del } \\
\text { monitoreo }\end{array}$ & $\begin{array}{l}\text { Alta: derechos de propiedad } \\
\text { de jure y título otorgado por } \\
\text { espacialmente extensivo sin } \\
\text { apoyo externo }\end{array}$ & $\begin{array}{l}\text { Baja: monitoreo formalizado y } \\
\text { actividades de control limitadas al } \\
\text { área que corresponde al plan de } \\
\text { manejo forestal }\end{array}$ \\
\hline
\end{tabular}


Cuadro 1. Continuado

\begin{tabular}{|c|c|c|}
\hline Indicador & Antes & Después \\
\hline $\begin{array}{l}\text { Aplicación de } \\
\text { sanciones graduales }\end{array}$ & $\begin{array}{l}\text { Activa: sistema autoorganizado } \\
\text { que dependía de la presión social }\end{array}$ & $\begin{array}{l}\text { Inactiva/emergente: el sistema } \\
\text { formalizado sí tiene sanciones } \\
\text { graduales, pero no se hacen } \\
\text { cumplir en el ámbito local }\end{array}$ \\
\hline $\begin{array}{l}\text { Mecanismos de bajo } \\
\text { costo para la resolución } \\
\text { de conflictos }\end{array}$ & $\begin{array}{l}\text { Disponible: menor necesidad de } \\
\text { intervención externa, ya que la } \\
\text { mayoría de conflictos eran pocos } \\
\text { y localizados }\end{array}$ & $\begin{array}{l}\text { Menos disponible-mayor } \\
\text { demanda de intervenciones } \\
\text { externas debido a una mayor } \\
\text { cantidad de conflictos sobre el } \\
\text { uso de la tierra y transacciones de } \\
\text { mercado }\end{array}$ \\
\hline $\begin{array}{l}\text { Participación de las } \\
\text { partes interesadas en la } \\
\text { creación de normas }\end{array}$ & $\begin{array}{l}\text { Moderada/alta en el caso de } \\
\text { los miembros yuracaré: los } \\
\text { sistemas de normas no reconocen } \\
\text { actores externos }\end{array}$ & $\begin{array}{l}\text { Baja: imposición de arriba hacia } \\
\text { abajo de la nueva legislación } \\
\text { sin considerar el contexto } \\
\text { institucional local }\end{array}$ \\
\hline $\begin{array}{l}\text { Gobernanza adaptable } \\
\text { a múltiples niveles }\end{array}$ & $\begin{array}{l}\text { Moderada/baja: autorregulación } \\
\text { con mínima intervención externa }\end{array}$ & $\begin{array}{l}\text { Moderada: normas y regulaciones } \\
\text { aplicadas de forma centralizada } \\
\text { con cierta coproducción de } \\
\text { monitoreo y aplicación }\end{array}$ \\
\hline $\begin{array}{l}\text { Combinaciones de tipos } \\
\text { institucionales }\end{array}$ & $\begin{array}{l}\text { Estructura social diversa y } \\
\text { compleja }\end{array}$ & $\begin{array}{l}\text { Sistemas institucionales más } \\
\text { homogéneos impuestos } \\
\text { desde arriba }\end{array}$ \\
\hline
\end{tabular}

\section{Elaboración de normas que sean congruentes con las condiciones ecológicas}

En el sector forestal las reformas legales formales impusieron normas en lo que respecta al manejo forestal que no consideraron las tradiciones locales, los conocimientos ni los sistemas de gobernanza de los pueblos Yuracaré. La expectativa de la agencia forestal del Gobierno central fue que los Yuracaré adoptaran un modelo científico occidental de manejo forestal, que era muy diferente de su propio enfoque tradicional. No es de extrañar que se hayan producido muchos problemas cuando el pueblo Yuracaré comenzó a administrar los bosques de acuerdo con estas nuevas reglas de juego. Después de tratar, durante unos tres ańos, de ejecutar una operación de manejo forestal formal según todas las reglas y normas detalladas del plan de manejo forestal, decidieron dejar de hacerlo debido a una serie de problemas relacionados con el funcionamiento del aserradero, dificultades para la comercialización, la complejidad de la organización y la limitada aceptación por parte de la mayoría de las personas. Sus actividades formales de manejo forestal se iniciaron en 1997 y terminaron en el 2000. Al final del tercer ańo, la comunidad decidió interrumpirlas porque, en esencia, el manejo forestal formal parecía haberse vuelto demasiado costoso para el grupo (véase Larson y Pulhin en esta colección).

Así como Holt (2005: 212) abogó por un retorno a las estrategias de conservación centradas en las personas, que permitan el aprendizaje social "de una manera culturalmente 
respetuosa”, nuestro análisis sugiere que, para que funcione el manejo sostenible de los bosques en el territorio Yuracaré y en los otros territorios indígenas, los regímenes jurídicos deben ser flexibles al contexto local. Sin embargo, las reformas forestales bolivianas no permitieron esta flexibilidad, sino que indujeron al pueblo Yuracaré a modificar su sistema de elección colectiva y su sistema de gobierno constitucional para dar cabida a las nuevas normas operativas, a aprender nuevos procesos tecnológicos y a adaptarse a los nuevos procesos de producción.

Antes de las reformas, individuos o familias Yuracaré poseían derechos de facto para llevar a cabo la extracción forestal comercial. La extracción formaba parte de un patrón altamente móvil en el que las actividades de aprovechamiento se extendían a lo largo de los grandes terrenos forestales del territorio Yuracaré. Una de las implicaciones de este sistema de gestión tradicional en su conjunto es que permitió a los participantes adquirir un conocimiento profundo del sistema ecológico forestal y sus complejidades (Becker y León 2000). Para el año 1992, el pueblo Yuracaré había organizado una asociación forestal que recibió un permiso anual de aprovechamiento del Gobierno del Centro de Desarrollo Forestal, la agencia forestal nacional en ese momento. En la asociación, cada Yuracaré negoció la cantidad de madera que se extraería individualmente, de acuerdo a las necesidades y preferencias de los individuos participantes y sus familias.

Las normas para las prácticas forestales durante esta época anterior a la reforma eran más bien de carácter general y permitieron la adaptación local del pueblo Yuracaré. Por otra parte, las actividades de monitoreo y aplicación del Centro de Desarrollo Forestal fueron muy irregulares e ineficaces, por lo que el régimen de jure fue menos relevante para las actividades locales de gobernanza forestal. Por ejemplo, antes de las reformas, no había normas técnicas específicas para la tala de árboles (en términos de tamaño). El pueblo Yuracaré tenía su propio sistema de gobierno indígena para la extracción de madera; cada persona autorizada internamente a cosechar productos tenía que atenerse al sistema Yuracaré de clasificación del bosque y a las normas relacionadas con la madurez del producto. El principio fundamental que guió todo el uso del bosque era "usar sin agotar" (León 1993: 10). Esta regla general reforzó el conocimiento del grupo sobre el territorio en su conjunto. De acuerdo con los usuarios de los recursos y los forestales profesionales que conjuntamente llevaron a cabo las actividades de medición de los bosques durante nuestra primera visita al lugar (entre 1994 y 1996), los bosques del territorio Yuracaré tenían condiciones ecológicas sanas, mejores que los bosques adyacentes a su territorio. En el momento de nuestra segunda visita, unos diez años más tarde, las condiciones del bosque se mantenían estables en todo el territorio Yuracaré. Al comparar los valores de área basal y la diversidad de especies entre 1996 y 2007, no se encontraron diferencias estadísticamente significativas en ninguna de estas variables.

Sin embargo, lo que había cambiado durante este período eran las condiciones institucionales para una gobernanza forestal eficaz. Nuestras observaciones de campo durante la segunda visita, 10 años después de las reformas, reveló que gran parte del patrón anterior de la gobernanza forestal, en efecto, había cambiado. La Ley del Servicio Nacional de Reforma Agraria de 1996 (Ley INRA, n 1715), junto con las reformas 
de descentralización forestal de 1996 (esbozadas en la Ley Forestal nº 1700), no solo reconoció los derechos territoriales de los pueblos Yuracaré y les otorgó títulos de propiedad, sino que también le dio al grupo la oportunidad de formalizar su sistema de gestión y de cumplir con las nuevas normas de manejo forestal establecidas en la Ley Forestal (1996). Las leyes de la reforma forestal promovieron el aprovechamiento comercial de madera en las sociedades indígenas y ofrecieron incentivos fiscales para esta actividad. Sin embargo, era necesario tener planes formales de manejo forestal para llevarla a cabo.

El pueblo Yuracaré desarrolló un plan de manejo forestal y compró un aserradero para comenzar la producción, tal como establecía su plan. Se contrató a un ingeniero forestal y la extracción de madera se llevó a cabo en períodos de tres meses, con una cuidadosa medición de la madera extraída. Durante los primeros tres períodos (de tres meses), la extracción de madera aumentó, de 8700 a 11000 y 36000 pies tablares, respectivamente, y se envió a la ciudad de Cochabamba por camiones madereros.

Antes de la ejecución de su plan de manejo forestal, era difícil estimar la cantidad de madera extraída, ya que la extracción era llevada a cabo en pequeńas cantidades por grupos familiares, y la madera solo se vendía a nivel local. Por lo general, las cosechas de madera de familias individuales, antes de la introducción del plan de manejo forestal formal, no eran suficientemente grandes como para requerir el uso de camiones madereros (Freddy Cruz com. pers. 12 de marzo de 2007).

Como resultado de la Ley Forestal (1996), el pueblo Yuracaré ya no impone sus propias normas operativas de manejo forestal sobre el terreno, sino que estas son dadas por la agencia del gobierno central para el sector forestal (la Superintendencia Forestal). Estas nuevas reglas operativas se basan únicamente en criterios técnicos y con poca consideración por las normas locales o escasos conocimientos del sistema ecológico.

Siguiendo las reglas del nuevo plan formal de manejo forestal del pueblo Yuracaré, que fue aprobado oficialmente por el Gobierno nacional en 1998 (el primero en Bolivia), ya no tuvo sentido que el pueblo Yuracaré llevara a cabo actividades forestales en grandes extensiones, como antes de las reformas. Más bien, su plan de manejo forestal definió de manera muy precisa las áreas en que los productos iban a ser cosechados y estas zonas representaron, por razones prácticas, una pequeña fracción de la superficie a la que antes se accedía para la extracción. El plan de manejo forestal también determinó los volúmenes exactos de cada especie que los miembros de la comunidad estaban autorizados a extraer de cada unidad de extracción, todo ello de acuerdo con el volumen de madera en pie calculado en el censo forestal del plan. Las exigencias del plan de manejo forestal elevaron los costos y redujeron los beneficios del manejo forestal formal para el pueblo Yuracaré.

Estas observaciones apuntan a una posible contradicción: si las reformas produjeron modificaciones en las condiciones institucionales para el autogobierno forestal específicamente, recetas externas que llevaron a la intensificación de las actividades de aprovechamiento en una zona geográficamente más concentrada—, ¿por qué estos 
efectos institucionales no se tradujeron en diferencias observables en las condiciones de los bosques? Hay varias razones por las que no se observaron cambios significativos en las condiciones entre los dos períodos. En primer lugar, la cantidad de tiempo que el pueblo Yuracaré llevó a cabo el manejo forestal formal solo fue de tres años, de 1997 al 2000, un período de tiempo relativamente corto. En segundo lugar, la técnica de extracción utilizada fue la tala selectiva de un número limitado de especies comercialmente viables. Esto significa que el volumen de madera extraída durante este período representó una pequeña fracción de la población total de árboles, incluso dentro de la zona de gestión de la madera, relativamente pequeña. En tercer lugar, nuestra evaluación de las condiciones de los bosques después de la reforma se llevó a cabo varios años después de que las actividades formales de gestión habían terminado, lo que permitió que las zonas afectadas se regeneren hasta cierto punto. Por último, nuestra evaluación del estado de los bosques se basó en mediciones de árboles que se realizan en parcelas de muestreo distribuidas en una superficie mucho mayor que el área relativamente pequeña de gestión de la madera. De ahí que los datos de las parcelas de muestreo que están dentro del área de gestión de la madera se mezclan con los datos de la totalidad de los terrenos forestales Yuracaré, que son muchas veces más grandes que la zona de donde se extrajo la madera entre 1997 y 2000. Por estas razones, se requeriría una gran perturbación en los bosques para que nuestras medidas cuantitativas del estado de los bosques indiquen una diferencia estadísticamente significativa entre las dos fechas.

\section{Límites claramente definidos de recursos y grupos de usuarios}

Uno de los efectos más notables de las reformas ha sido el reconocimiento de los derechos de propiedad de la tierra de los pueblos indígenas (reforma agraria), lo que incluye los derechos de acceso, extracción, gestión y exclusión (reforma forestal). En la Ley Forestal (1996) se otorgaron derechos parciales de enajenación que están supeditados a las normas formales de manejo forestal. Las poblaciones indígenas en Bolivia son ahora las propietarias de al menos una parte de sus tierras ancestrales, pero no de los bosques que crecen sobre ellas, ya que el Estado boliviano ha retenido la propiedad formal de estos bosques. El conjunto actual de derechos está en marcado contraste con la situación anterior a la reforma. Por ejemplo, durante nuestra primera visita al territorio en 1993, Juan Rojas (com. pers.), uno de los líderes Yuracaré nos dijo:

\footnotetext{
"Estamos cansados de que entren extraños en nuestras comunidades y nuestro territorio para cazar y pescar. Están maltratando a los animales, utilizando dinamita para pescar, y los peces se están muriendo... Esta gente no respeta nada y cuando los hemos enfrentado solo nos dicen: 'muéstrennos sus papeles' y ‘ ¿ustedes piensan que son dueños de estas tierras o qué?'... Es por eso que queremos aprender cómo podemos conseguir que el Gobierno reconozca nuestro territorio como nuestra propiedad, como lo ha hecho con otros grupos como nosotros. Creo que la ley apoya nuestra causa."
}

En 1998, el pueblo Yuracaré recibió el título de su tierra, y desde entonces puede tomar medidas legales para proteger su integridad territorial y excluir o controlar las actividades de terceros en su territorio. 
Otro impacto importante de la aclaración de los límites en la propiedad colectiva indígena es que ha reforzado la seguridad de la tenencia de los bosques. El aumento de la seguridad, a su vez, ha inducido a una extracción más intensiva de la madera. Antes de la titulación, los bosques eran considerados como recursos para ser utilizados en situaciones de emergencia - actuando más como una cuenta de ahorros- al convertir estos recursos en efectivo a través de la venta de madera. La ley, sin embargo, reconoció sus derechos de usos tradicionales, pero no les dio ningún poder para vender la madera. No obstante, ahora las normas limitan la explotación de los bosques sin un plan de manejo forestal. Por ejemplo, el pueblo Yuracaré puede utilizar la madera con fines personales, pero no pueden venderla por dinero en efectivo o en casos de emergencia como solían hacer antes de la titulación. Para vender la madera, sobre la que tienen derechos exclusivos, tuvieron que poner en marcha un plan de manejo forestal que estableciera la producción a gran escala de acuerdo con la Ley Forestal de 1996.

El territorio Yuracaré, no obstante, está en un proceso de fragmentación interna, en tres secciones diferentes. Las causas de la división son muchas y difíciles de explicar. Una de las razones, sin embargo, es la aplicación de la Ley de Participación Popular (1994), que obliga a los asentamientos a ser legalizados como Organizaciones Territoriales de Base para que ser incluidos en la planificación municipal. Cada organización de base reivindicó un área territorial, lo que llevó a la fragmentación del territorio indígena original. Al final del proceso, este estaba dividido en 11 asentamientos reconocidos oficialmente - a diferencia de la anterior entidad territorial única-, cada uno con el reconocimiento legal del Estado y con representantes políticos. Además, como los 11 asentamientos se agruparon naturalmente en tres subgrupos con características ecológicas relativamente similares, estos últimos se convirtieron en las tres subunidades principales del nuevo régimen de gobernanza, incluyendo el nuevo plan de manejo forestal (zona superior, zona media y zona baja). Cada una de estas áreas se rige por un sistema de gobernanza independiente. Esta fragmentación interna de los grupos hace que los límites de los derechos de cada grupo sobre los recursos sean menos claros para todos, incluidos tanto los actores internos como los externos.

\section{Monitoreo local y rendición de cuentas de los responsables del monitoreo}

Antes de la Ley Forestal (1996), el monitoreo de los bosques era mayormente una empresa colectiva en el territorio, que se organizaba en torno a las observaciones personales de los individuos que se desplazaban por todo el territorio para cazar, pescar y realizar actividades de extracción de madera. Esta era una tarea organizada por la Asociación Forestal y sus socios, a los que los responsables del monitoreo informaban las infracciones que observaban.

Después de la Ley Forestal (1996), el monitoreo local, se limitó principalmente a las reducidas áreas de cosecha establecidas en el plan de manejo forestal. Además, este control se circunscribió a las personas con más conocimientos sobre las reglas operativas y la estructura del plan de manejo forestal formal. Dado que el plan incluye la prohibición 
expresa de entrada a algunas de las áreas administradas, estas tierras no han sido vigiladas regularmente después de las reformas. Gran parte de las actividades de monitoreo posteriores a la reforma se encuentran en manos de los profesionales del sector forestal, que el Gobierno exige que los titulares de planes de manejo forestal utilicen para las evaluaciones periódicas.

La desventaja de este sistema es que la población indígena ya no participa de manera tan activa en el monitoreo de las actividades de extracción, por lo que se pierden muchos observadores potenciales a través del territorio, menos ojos para observar significa una detección menos eficaz de las infracciones a las reglas. El cambio de responsabilidades de monitoreo y control de los habitantes de la zona a los ingenieros forestales debilita el sistema interno de rendición de cuentas.

\section{Aplicación de sanciones graduales por infracciones}

Antes de las reformas, las sanciones en el pueblo Yuracaré se basaban en sus costumbres sociales y normas establecidas, lo que implicaba que debían adaptarse a la situación de la infracción, y, por regla general, el castigo debía ser incrementado de acuerdo con la gravedad y la frecuencia del acto de incumplir normas específicas. En general, las reformas no han producido cambios en estas formas de sanción. Las funciones de control social son todavía muy importantes. Las sanciones por infracciones de las normas eran de carácter gradual (desde advertencias iniciales hasta la suspensión permanente de los derechos de extracción), de acuerdo con las reglas de la asociación forestal Yuracaré. El cumplimiento de estas reglas era relativamente alto, dada la amenaza creíble de sanciones sociales. Si un individuo violaba una norma (como la extracción en un lugar prohibido, con una motosierra, o la venta de madera ilegal), las autoridades locales en general hablaban con la persona y le exigían el cese inmediato de estas actividades. La segunda vez que era capturado el mismo individuo, la infracción se convertía en un tema de debate en la siguiente asamblea comunal, lo que potencialmente podía limitar los derechos de acceso a los recursos forestales. La amenaza de perder prestigio y reputación personal frente a la autoridad de la comunidad funcionó muy bien; durante nuestras primeras visitas de campo (1994-1996), el equipo no encontró pruebas de que la asamblea de la comunidad haya tenido que negar el acceso a los bosques a algún miembro de la comunidad.

Desde que se iniciaron las reformas, sin embargo, todavía no se ha formulado ni aplicado un diseño formal de sanciones graduales a las infracciones de las nuevas normas de gestión. Debido a que el nuevo proceso de gobernanza aún está en proceso de consolidación, las normas colectivas y su cumplimiento todavía están emergentes y solo vagamente definidas. En la actualidad, no existe un sistema formal de sanciones graduales. La regla general es que todos tienen que seguir las especificaciones del plan de manejo forestal y que cualquier infracción de la norma implica la pérdida de tales derechos. Sin embargo, existe la aplicación informal de sanciones sociales para regular las actividades ilegales de los Yuracaré. Esta aplicación continúa en su mayoría a través del funcionamiento de los clanes familiares, incluso durante el período posterior a la introducción del plan de manejo forestal. En la actualidad, se está gestionando una nueva definición de los 
requisitos formales del sistema de gestión con el Gobierno liderado por Morales. Esta redefinición es probable que también incida en el sistema Yuracaré de control social y de sanciones.

\section{Establecimiento de mecanismos de bajo costo para la resolución de conflictos}

El pueblo Yuracaré tradicionalmente ha resuelto los conflictos en su territorio aplicando su sistema consuetudinario, lo que significa que todos los problemas se discuten en la asamblea comunal hasta alcanzar, en la medida de lo posible, un consenso sobre las acciones a tomar para la gestión o la resolución de la disputa. La finalidad de las deliberaciones de la asamblea es de llegar a una solución en consenso, aunque los líderes reconocen que un consenso total a veces no es posible y que entonces se necesita llegar a un acuerdo mutuo. Los mecanismos para resolver los conflictos varían en función de la naturaleza e intensidad del conflicto, así como de quiénes toman parte en él. A menudo estas diferencias se resuelven en una asamblea comunal, pero hay algunas excepciones en las que se han presentado casos ante un juez externo para tomar una decisión acorde con las leyes nacionales. Sin embargo, los costos del uso del sistema judicial estatal boliviano son bastante altos. Esto se debe a la dificultad de movilizar a todas las partes interesadas de las comunidades a lo largo del extenso territorio para llegar a una postura unificada.

No obstante, hay un número cada vez mayor de situaciones de conflicto en el que los mecanismos tradicionales de resolución de conflictos ya no son adecuados. Notamos que después de las reformas, el papel de los agentes externos en los asuntos de la comunidad se volvió más prominente, incluyendo las relaciones con los representantes de la Superintendencia Forestal, las autoridades elegidas de los Gobiernos municipales y el Instituto Nacional de Reforma Agraria (INRA). En la época posterior a la reforma, hay más conflictos con las partes externas debido a un aumento general en el número de interacciones con actores que no son indígenas Yuracarés. Esta nueva realidad impone nuevas demandas sobre el sistema consuetudinario de resolución de conflictos, y nuestras observaciones de campo sugieren que los foros tradicionales para la resolución de conflictos ya no son capaces de responder eficazmente a estas demandas. Aunque, en teoría, podría tener sentido para el pueblo Yuracaré aumentar su confianza en el sistema judicial estatal para una mejor gestión de los conflictos con los extraños - ya que las partes no Yuracarés en el conflicto puede que no reconozcan la legitimidad de las decisiones de la asamblea comunitaria-, en la práctica, este cambio todavía no representa una alternativa viable debido a los altos costos de transacción asociados con dicho cambio.

\section{Participación de las partes interesadas en las discusiones sobre las normas}

Antes de 1996, los clanes familiares tomaban las decisiones acerca de cómo y dónde extraer productos forestales, de acuerdo con la asociación forestal y las autoridades locales (asamblea comunal). Estas reglas evolucionaron durante un tiempo muy largo y estaban estrechamente relacionadas con las normas de jerarquía establecidas y otras formas de 
estructuras comunitarias. Estas reglas fueron bien entendidas por todos los miembros de la comunidad, y el proceso de toma de decisiones permitió posibles enmiendas. El sistema local de gobierno incluía definir los momentos adecuados para el marcado de los árboles para la extracción y determinar la práctica de la cosecha en sí. Todas estas restricciones se establecieron en función de las temporadas de sequía y lluvia, pero había flexibilidad en la toma de decisiones para que cada individuo pudiera definir el momento exacto de la cosecha, para que tuviera sentido con el sistema de producción más amplio de cada familia.

Después de las reformas, sin embargo, el proceso de manejo forestal adquirió otros mecanismos de ejecución de las normas dictadas por la Superintendencia Forestal. Así, para el aprovechamiento forestal, solo el técnico forestal transmite información sobre las normas y reglamentos a los miembros de la comunidad, sin intercambios ni mayor respeto por las formas locales de toma de decisiones. Este es un proceso de arriba hacia abajo que ignora, en gran medida, los conocimientos locales, las necesidades locales y las formas consuetudinarias de gobernanza territorial. Además, el modelo de manejo forestal formal que se introdujo con el paquete de reformas de 1996 se basa en la falsa premisa de que los sistemas de producción indígenas son de carácter colectivo. Por lo tanto, en las normas para el plan de manejo forestal formal se preveía que los grupos indígenas solo quieren cosechar los bosques de forma colectiva, no individual, pero la cosecha individual ha sido típica en el caso de muchos Yuracarés. Como resultado de esta visión de gestión forestal colectiva, se le presentó al pueblo Yuracaré la idea de formar una empresa forestal para organizar una cadena vertical de producción industrializada a pequeña escala, incluyendo el funcionamiento de un aserradero móvil. Las decisiones técnicas asociadas a esta idea no implicaron una amplia participación de los pueblos indígenas que se dedican a la extracción de madera, y por lo tanto, las normas para la extracción de madera no tuvieron en cuenta que los Yuracaré, además de otros grupos étnicos, estaban acostumbrados a cortar madera en áreas de fácil acceso para cada familia. En el marco del nuevo sistema, el plan de manejo forestal establecía un enfoque más restrictivo, en el que la extracción legal tenía que ser llevada a cabo por todos en un área específicamente designada.

\section{Permitir la gobernanza adaptable a múltiples niveles}

El sistema anidado de manejo forestal de los Yuracaré está en crisis debido a la incongruencia entre los cambios exógenos y la respuesta institucional local. Grandes modificaciones tecnológicas a nivel operativo han producido cambios en la organización de las decisiones colectivas. Estos cambios han dado lugar a una pérdida de claridad entre los diferentes niveles de toma de decisiones. Por ejemplo, los cambios se impusieron a través de la aprobación de la Ley Forestal (nivel constitucional) y su aplicación por parte de los actores políticos locales (nivel de elección colectiva) de acuerdo con las especificaciones técnicas (normas operativas), todas las cuales son ajenas a las costumbres y tradiciones locales relacionadas con la gobernanza forestal. Los cambios operativos han modificado los patrones tradicionales de acceso a los bosques, limitando la gestión de la extracción de madera a una forma colectiva, bajo esquemas y calendarios rígidos. Estas 
modificaciones no han permitido la creación de oportunidades de acceso alternativas para los habitantes que emprenden actividades madereras comerciales a pequeña escala, lo que hace más difícil que las familias cosechen en casos de emergencia, lo que solía ser la costumbre antes.

\section{Uso de diferentes diseños institucionales}

Las relaciones entre los líderes Yuracarés y las organizaciones gubernamentales externas solían ser muy diversas. Estas se desarrollaron lentamente durante un largo período de tiempo y respondieron a una lógica de articulación indígena. En el territorio Yuracaré, un intenso proceso de negociación entre las organizaciones locales y externas movilizó tanto al capital interno como al social del pueblo Yuracaré. Estas estrategias de formación de relaciones, sin embargo, se han vuelto menos diversificadas, como resultado de las reformas. La Figura 2 ilustra cómo ha evolucionado la configuración de las relaciones en el tiempo.

Como se observa en la Figura 2, las relaciones de hoy en día responden a articulaciones más individualistas, con pocas relaciones apropiadas para la articulación de las demandas generales del territorio Yuracaré. Las relaciones se han vuelto particularizadas, y las reformas no han logrado crear una estructura de gobernanza que se adapte al contexto

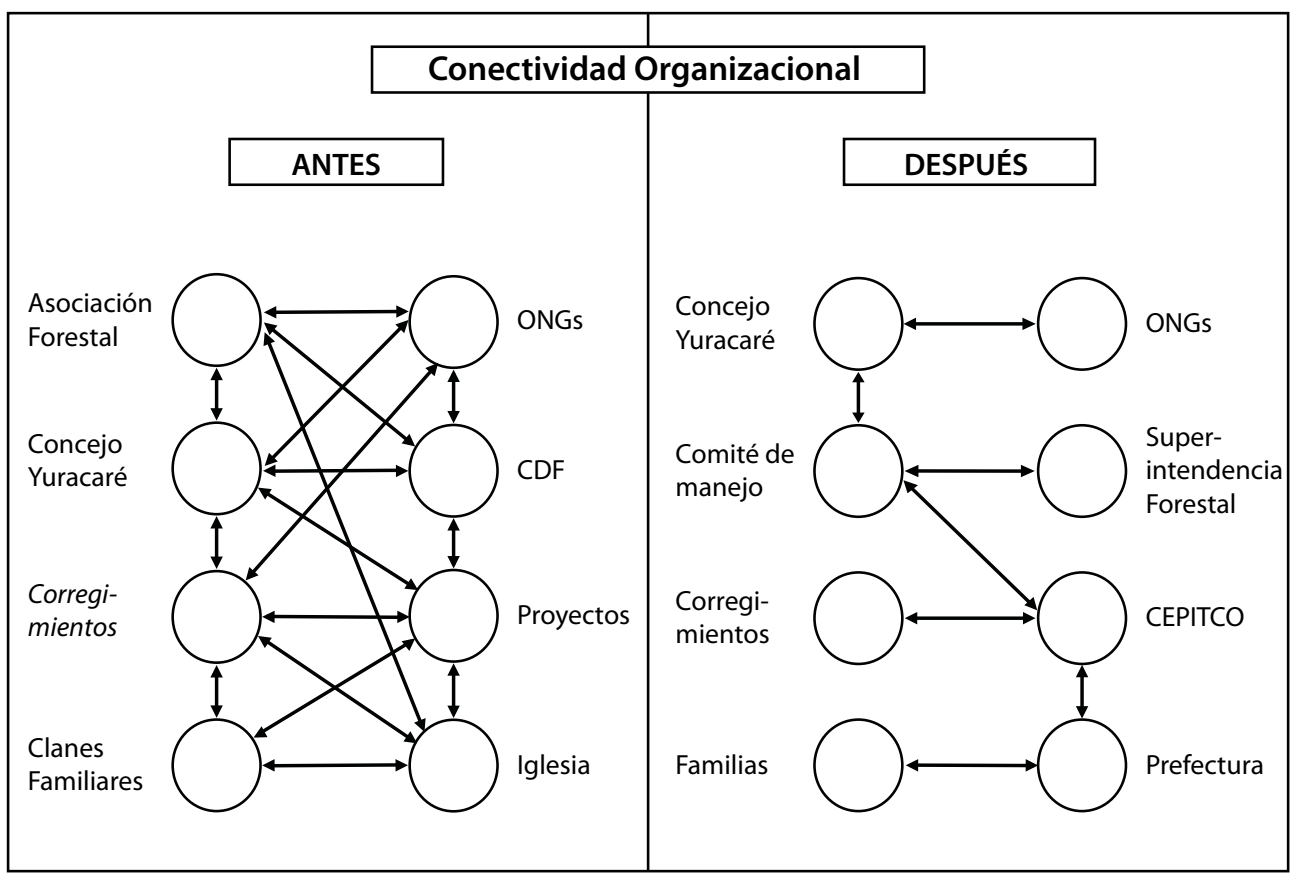

Figura 2. Relaciones institucionales antes y después de las reformas

Fuente: Elaboración propia en base a las observaciones de campo 1996-2009 
institucional Yuracaré. Primero, la mayoría de las familias indígenas no pueden participar en las elecciones municipales democráticas, porque no tienen la documentación para votar. En segundo lugar, las jurisdicciones de los municipios se superponen con el territorio indígena de una forma contenciosa, no complementaria. En tercer lugar, los colonos vecinos tienen envidia de las poblaciones indígenas Yuracaré, ya que consideran su territorio demasiado grande para ser administrado por pocas familias indígenas. Nuestras observaciones de campo nos llevan a concluir que las reformas forestales, en gran parte, no han podido crear la combinación adecuada de competencias complementarias entre los sistemas institucionales a diferentes escalas.

\section{Conclusión}

Este análisis del caso Yuracaré muestra que aunque las reformas forestales favorecieron la seguridad de la tenencia indígena de los bosques mediante la concesión a los grupos indígenas del acceso legal y la titularidad de sus tierras ancestrales, el mismo proceso implicó adaptaciones institucionales que han sido problemáticos para el pueblo Yuracaré. Además, otros grupos indígenas de las tierras bajas de Bolivia, 16 años después de las reformas, aún no tienen plenos derechos de enajenación debido a los lentos procedimientos burocráticos para la obtención de tales derechos.

Las reformas del sector forestal dieron lugar a un reconocimiento de los derechos consuetudinarios de los pueblos indígenas que fue bien recibido. El problema de las reformas, sin embargo, fue que se ignoró casi por completo el contexto institucional local, como se ve en los supuestos sobre los esquemas colectivos de manejo, que eran poco realistas. Otro problema fue la eliminación de sus sistemas de monitoreo previamente establecidos — todos los poderes de monitoreo y control oficiales se concedieron a un profesional forestal—, lo cual debilitó el papel de las instituciones de administración indígenas. Más aun, las normas de manejo forestal impusieron tecnologías para cortar y procesar la madera de una manera que, de hecho, socava el reconocimiento de los derechos consuetudinarios indígenas (para obtener un análisis más detallado de este fenómeno, véase Larson y Pulhin en esta colección).

Al final, la introducción de las reformas produjo una gran tensión interna entre el pueblo Yuracaré. El ejemplo Yuracaré muestra que la transición de la subsistencia a la producción excedentaria a través del mercado puede ser un proceso difícil de atravesar (como se muestra en Pacheco en esta colección). A pesar de un comienzo difícil, el pueblo Yuracaré ha tenido cierto éxito en hacer que esto suceda. Aunque es imposible saber lo que hubiera pasado en ausencia de las reformas, la mayor parte del pueblo Yuracaré no quiere volver a como eran las cosas antes de que obtuvieran su título legal.

Una de las lecciones más generales que podemos recoger de la experiencia Yuracaré hasta ahora es que la formalización de los derechos es un paso importante hacia un mayor control y seguridad de la tenencia forestal, pero para lograr mayores beneficios de la gobernanza de los bosques, una serie de otros factores también deben tenerse en cuenta. 
Muchas otras características institucionales — tanto internas como externas - también influyen en la capacidad del grupo para tomar ventaja de las nuevas oportunidades de inversión y producción que conlleva una mayor seguridad de la tenencia.

\section{Agradecimientos}

Estamos en deuda con varias personas por sus aportes en esta investigación. Anne Larson, Ashwin Ravikumar, Elinor Ostrom, Glenn Wright, Hetal Hariya y un revisor anónimo dieron valiosas sugerencias sobre los borradores iniciales de este artículo. Agradecemos a los muchos miembros de la comunidad Yuracaré que nos han ayudado en nuestro trabajo de campo; sin su apoyo, este estudio no hubiera sido posible. Agradecemos el apoyo financiero de la Fundación Nacional de Ciencias (National Science Foundation) (SES-648447, DEB-11 14984 y BCS 0.527.165-) y al Programa de Apoyo a la Investigación Colaborativa de Agricultura Sostenible y Manejo de Recursos Naturales de la Agencia de los Estados Unidos para el Desarrollo Internacional (USAID SANREM CRSP).

\section{Notas}

1. El Programa de Investigación sobre Recursos e Instituciones Forestales Internacionales (IFRI, por sus siglas en inglés) y su centro de investigación colaborativa, el Centro de Estudios de la Realidad Económica y Social (CERES), han llevado a cabo investigaciones de campo en las comunidades forestales de Bolivia desde 1993. Uno de los primeros estudios del IFRI en Bolivia se llevó a cabo en el territorio Yuracaré, y se tituló "Current Situation of Forest Management" (Situación actual del manejo forestal). Tuvo el objetivo de apoyar las demandas territoriales de la población local para esta zona y ayudar a las comunidades locales en la elaboración de un plan de manejo forestal.

2. La colonización llevó gente desde los Andes hasta las tierras bajas. Esto comenzó con la Reforma Agraria de 1952 y continuó hasta la década de 1970 (Uberhuaga 2001: 38).

3. El plan de manejo forestal Yuracaré indica que 385 familias se distribuyen por todo el territorio, el $51 \%$ en el norte, el $15 \%$ en la parte central y el $34 \%$ en el sur (CERES-CONIYURA 1988: 84).

4. El ordenamiento territorial se basa en tres formas de "orden", todos los cuales están relacionados con normas específicas. Estos están a su vez dentro de un sistema más amplio de gobernanza para todo el territorio. Hay dos niveles básicos de gobernanza: los corregimientos y el territorio (CERES 1997: 14).

5. Los chacos son parcelas agrícolas (plátano, arroz, yuca y maíz), generalmente ubicados alrededor de las casas familiares con extensiones entre 0,5 ha y 5 ha (CERES-CONIYURA 1998: 88). Los barbechos son tierras que se usan para actividades agrícolas por alrededor de 15 a 25 ańos, donde los residentes plantan productos perennes (café, naranja y especies forestales). 


\section{Referencias}

Agrawal, A y A. Chhatre. 2006. Explaining success on the commons: Community forest governance in the Indian Himalayas. World Development 34(1): 149-166.

Agrawal, A. y E. Ostrom. 2001. Collective action, property rights, and decentralization in resource use in India and Nepal. Politics and Society 29(4): 485-514.

Agrawal, A. y J. Ribot. 1999. Accountability in decentralization: A framework with South Asian and West African cases. The Journal of Developing Areas 33: 473-502.

Alston, L.J., G.D. Libecap y B. Mueller. 2000. Land reform policies, the sources of violent conflict, and implications for deforestation in the Brazilian Amazon. Journal of Environmental Economics and Management 39(2): 162-188.

Andersson, K. 2003. What motivates municipal governments? Uncovering the institutional incentives for municipal governance of forest resources in Bolivia. Journal of Environment and Development 12(1): 5-27.

Andersson, K. 2004. Who talks with whom? The role of repeated interactions in decentralized forest governance. World Development 32(2): 233-249.

Andersson, K. 2006. Understanding decentralized forest governance. Sustainability: Science, Practice \& Policy 2(1): 25-35.

Andersson, K. y D. Pacheco. 2006. Turning to forestry for a way out of poverty: Is formalizing property rights enough? En: Linking the formal and informal economy: concepts and policies (eds. Guha-Khasnobis, B., R. Kanbur y E. Ostrom). Pp. 195-211. Oxford, Reino Unido: Oxford University Press.

Andersson, K. y E. Ostrom. 2008. Analyzing decentralized natural resource governance from a polycentric perspective. Policy Sciences 41(1): 1-23.

Ascher, W. 1995. Communities and sustainable forestry in developing countries. San Francisco, Estados Unidos: ICS Press.

Baland, J.M. y J.P. Platteau. 1996. Halting degradation of natural resources: Is there a role for rural communities? Oxford, Reino Unido: Clarendon Press.

Banana, A.Y., N.D. Vogt, J. Bahati y W. Gombya-Ssembajjwe. 2007. Decentralized governance and ecological health: Why local institutions fail to moderate deforestation in Mpigi district of Uganda. Scientific Research and Essay2 (10): 434-445.

Banco Interamericano de Desarrollo (BID) 2004. Territorial rights (Program of indigenous populations and communal development). Washington D.C.: BID.

Barton, D. 2002. Adaptive management, organizations and common property management: Perspectives from the community forests of Quintana Roo, Mexico. Trabajo presentado en Community Forestry in Mexico: Concordance and Contradiction between Institutions, Policies and Economies.

Becker, D. y R. León. 2000. Indigenous forest management in the Bolivian amazon: Lessons from the Yuracaré people. En: People and forests: communities, institutions and governance (eds. Gibson, C.C., M. McKean y E. Ostrom). Cambridge, Estados Unidos: MIT Press. 
Beneria-Surkin, J. 2003. Decentralization questioned: The structuring and articulation of Guarani participation in conservation and development in Izozog, Bolivia. Tesis doctoral. University of California, Los Angeles, Los Ángeles, Estados Unidos.

Bigombe Logo, P. 2002. Forest management decentralization and social conflicts in Cameron: Rethinking intergenerational access to forest and its resources in Southeastern Cameroon. Trabajo presentado en 2002 IASCP Conference en Harare, Zimbabue.

Bowen, J. 2000. Should we have a universal concept of indigenous people's rights? Anthropology Today 16(4): 12-16.

Bruce, J. 1998. Legal bases for the management of forests as common property. Roma: Organización de las Naciones Unidas para la Alimentación y la Agricultura (FAO).

Cárdenas, J.C. 2000. How do groups solve local commons dilemmas? Lessons from experimental economics. Environment. Development and Sustainability 2(3-4): 305-322.

Centro para el Estudio de la Realidad Económica y Social (CERES).1997. Manejo Actual de los Recursos del Territorio Indígena Yuracaré: Bases para un Plan de Manejo. Cochabamba, Bolivia: Centro para el Estudio de la Realidad Económica y Social.

Centro para el Estudio de la Realidad Económica y Social (CERES) y Consejo Indígena Yuracaré (CONIYURA). 1998. Plan de Manejo de Bosques del Territorio Indígena Yuracaré. Cochabamba, Bolivia: Centro para el Estudio de la Realidad Económica y Social.

Chandra, K. 2001. Ethnic bargains, group instability, and social choice theory. Politics and Society 29(3): 337-362.

Chhatre, A. y A. Agrawal. 2008. Forest commons and local enforcement. Proceedings of the National Academy of Sciences 105(36): 13286-13291.

Chhatre, A. y A. Agrawal. 2009. Trade-offs and synergies between carbon storage and livelihood benefits from forest commons. Proceedings of the National Academy of Sciences 106(42): 17667-17670.

Coleman, J.S. 1990. Foundations of social theory. Cambridge, Estados Unidos: Belknap Press of Harvard University Press.

Contreras-Hermosilla, A. y M.T. Vargas. 2002. Las Dimensiones Sociales, Ambientales y Económicas de las reformas a la politica forestal en Bolivia. Washington D.C.: Forest Trends.

Cronkleton, P. y M. Albornoz. 2004. Forestería Comunitaria en Bolivia: Abriendo Horizontes para Nuevos Actores. En Memória: Fórum sobre Florestas, Gestão e Desenvolvimento, Belém 2003. Belém, Brasil: Centro para la Investigación Forestal Internacional (CIFOR).

Cronkleton, P. y P. Pacheco. 2008. Communal tenure policy and the struggle for forest lands in the Bolivian Amazon. Cheltenham, Reino Unido. $12^{\text {th }}$ Biennial Conference of the International Association for the Study of the Commons.

De Jong, W. (ed.). 2004. Retos y Perspectivas del Nuevo Régimen Forestal en el Norte Amazónico Boliviano. Bogor, Indonesia: Centro para la Investigación Forestal Internacional (CIFOR). 
Dietz, T., P.C. Stern y E. Ostrom. 2003. Struggling the commons. Science 302: 1907-1012. Fawcett, P.H. 1910. Explorations in Bolivia. Geographical Journal 35(5): 513-529.

Ferroukhi, L. 2003. La Gestión Forestal Municipal en América Latina. Bogor, Indonesia: Centro para la Investigación Forestal Internacional (CIFOR).

Gibson, C.C., E. Ostrom y M.A. MacKean. 2000. Forests, people, and governance: Some initial theoretical lessons. En: People and forests: Communities, institutions and governance (eds. Gibson, C.C., M. McKean y E. Ostrom). Cambridge, Estados Unidos: MIT Press.

Gibson, C.C., J.T. Williams y E. Ostrom. 2005. Local enforcement and better forests. World Development 33(2): 273-284.

Groenfeldt, D. 2003. The future of indigenous values: Cultural relativism in the face of economic development. Futures 35: 917-929.

Hernáiz, I. y D. Pacheco. 2000. La Ley INRA en el espejo de la historia: dos siglos de reformas agrarias en Bolivia. La Paz: Fundación TIERRA.

Hirtz, F. 2003. It takes modern means to be traditional: On recognizing indigenous cultural communities in the Philippines. Development and Change 34(5): 887-914.

Holt, L. 2005. The catch-22 of conservation: Indigenous peoples, biologists, and cultural change. Human Ecology 33(2): 199-215.

Janssen, M.A., R. Holahan, A. Lee y E. Ostrom. 2010. Lab experiments for the study of social-ecological systems. Science 328(5978): 613-617.

Kaimowitz, D., P. Pacheco, R. Mendoza y T. Barahona. 2001. Municipal governments and forest management in Bolivia and Nicaragua. En: World forests, markets and policies (eds. Palo, M., J. Uusivuori y G. Mery). Finlandia: Kluwer Academic Publishers.

Larson, A.M. 2002. Natural resources and decentralization in Nicaragua: Are local governments up to the job? World Development 30(1): 17-31.

Larson, A.M. 2003. Decentralization and forest management in Latin America: Toward a working model. Public Administration and Development 23(3): 211-226.

Larson, A.M., D. Barry, G.R. Dahal y C.J.P. Colfer (eds.). 2010. Forests for people: Community rights and forest tenure reform. Londres: Earthscan.

Larson, A.M., P. Cronkleton, D. Barry y P. Pacheco. 2008. Tenure rights and beyond: Community access to forest resources in Latin America. CIFOR Occasional Paper No. 50. Bogor, Indonesia: Centro para la Investigación Forestal Internacional (CIFOR).

León, R. 1993. Territorios invisibles: Los Yuracarés. Documento de trabajo. Cochabamba, Bolivia: Centro de Estudios de la Realidad Económica y Social (CERES) y Programa Bosques, Árboles y Comunidades Rurales (FTPP).

Lindsay, J.M. 1998. Designing legal space for community-based management. Trabajo presentado en el International Workshop on Community-based Natural Resource Management. Washington D.C.: Banco Mundial. Del 10 al 14 de mayo de 1998. 
Loomis, T.M. 2002. Indigenous populations and sustainable development: Building on indigenous approaches to holistic, self-determined development. World Development 28(5): 893-910.

McDaniel, J.M. 2003. History and the duality of power in community-based forestry in Southeast Bolivia. Development and Change 34(2): 339-356.

McGinnis, M. 1999. Introduction. En: polycentric governance and local public economies: Readings from the workshop in political theory and policy analysis (ed. McGinnis, M.). Ann Arbor, Estados Unidos: University of Michigan Press.

McKean, M. 2000. Common property: What is it, what is it good for, and what makes it work? En: People and forests: Communities, institutions and governance (eds. Gibson, C.C., M.A. MacKean y E. Ostrom). Cambridge, Estados Unidos: MIT Press.

Meinzen-Dick, R., A. Knox, F. Place y B. Swallow. 2002. Innovation in natural resource management: The role of property rights and collective action in developing countries. Washington D.C.: Instituto Internacional de Recursos Fitogenéticos (IPGRI).

Meinzen Dick, R. y E. Mwangi. 2008. Cutting the web of interests: Pitfalls of formalizing property rights. Land Use Policy 26(1): 36-43.

Miller, G. 1992. Managerial dilemmas: The political economy of hierarchy. Cambridge, Estados Unidos: Cambridge University Press.

Nagendra, H. 2007. Drivers of reforestation in human-dominated forests. Proceedings of the National Academy of Sciences 104(39): 15218-15223.

Nygren, A. 2005. Community-based forest management within the context of institutional decentralization in Honduras. World Development 33: 639-655.

O'Faircheallaigh, C. 1998. Resource development and inequality in indigenous societies. World Development 26(3): 381-394.

O'Neill, K. 2003. Decentralization as an electoral strategy. Comparative Political Studies 36(9): 1068-1091.

Ostrom, E. 1990. Governing the commons. The evolution of institutions for collective action. Nueva York: Cambridge University Press.

Ostrom, E. 1992. Crafting institutions for self-governing irrigation systems. San Francisco, Estados Unidos: ICS Press.

Ostrom, E. 1999. Self-governance and forest resources. CIFOR Occasional Paper No. 20. Bogor, Indonesia: Centro para la Investigación Forestal Internacional (CIFOR).

Ostrom, E. 2003. How types of goods and property rights jointly affect collective action. Journal of Theoretical Politics 15(3): 139-170.

Ostrom, E., R. Gardner y J. Walker. 1994. Rules, games, and common-pool resources. Ann Arbor, Estados Unidos: University of Michigan Press.

Ostrom, E. y H. Nagendra. 2006. Insights on linking forests, trees, and people from the air, on the ground, and in the laboratory. Proceedings of the National Academy of Sciences 103(51): 19224-19231.

Ostrom, E. y V. Ostrom. 1999. Public goods and public choices. En: Polycentricity and local public economies (ed: Mcginnis, M.). Ann Arbor, Estados Unidos: The University of Michigan Press. 
Ostrom, E., L. Schroeder y S. Wynne. 1993. Institutional incentives and sustainable development. Boulder, Estados Unidos: Westview Press.

Oyono, P.R. 2004. One step forward, two steps back? Paradoxes of natural resources management decentralisation in Cameroon. Journal of Modern African Studies 42(1): 91-111

Pacheco, P. 2002. Contribuye la Descentralización a Mejorar la Gestión Forestal? Las Lecciones Aprendidas del Caso Boliviano. Trabajo presentado en la I Reunión Nacional de Investigación Forestal. Santa Cruz, Bolivia.

Pacheco, P. 2004. Decentralization of forest management in Bolivia: Who benefits and why? Trabajo presentado en Decentralization of federal systems in forestry and national forest programmes. Interlaken, Suiza.

Pacheco, D. 2007. An institutional analysis of decentralization and indigenous timber management in common-property forests of Bolivia's lowlands. Tesis doctoral. Indiana University, Bloomington, Estados Unidos.

Pacheco, P. 2008. Enfoques forestales homogéneos para actores diversos: la encrucijada del manejo de bosques en Bolivia. Informe Temático Sobre Desarrollo Humano en Bolivia PNUD-Bolivia.

Pacheco, P. y D. Kaimowitz. 1998. Municipios y gestión forestal en el trópico boliviano. La Paz y Bogor, Indonesia: Centro de Estudios para el Desarrollo Laboral y Agrario (CEDLA) y Centro para la Investigación Forestal Internacional (CIFOR).

Ribot, J. 2001. Local actors, powers and accountability in African decentralizations: A review of issues. Washington D.C.: Centro Internacional de Investigación para el Desarrollo (CIID).

Ribot, J. 2002. Democratic decentralization of natural resources: Institutionalizing popular participation. Washington D.C.: Instituto de Recursos Mundiales (WRI).

Tucker, C. 1999. Private versus common property forests: Forest conditions and tenure in a Honduran community. Human Ecology 27(2): 201-229.

Uberhuaga, P. 2001. Legal or illegal? Networks and forest regulations in timber commercialization: An analysis of social capital and interfaces among ethnic groups in the tropic of Cochabamba, Bolivia. Tesis de maestría. Wageningen University, Wageningen, Países Bajos.

Urioste, M. y D. Pacheco. 2001. Las Tierras Bajas de Bolivia a Fines del Siglo XX. La Paz: PIEB.

Van Cott, D.L. 2000. Party system development and indigenous populations in Latin America. The Bolivian case. Party Politics 6(2): 155-174.

Van Laerhoven, F. 2010. Governing community forests and the challenge of solving two-level collective action dilemmas-A large-N perspective. Global Environmental Change 20(3): 539-546.

White, A. y A. Martin. 2002. Who owns the world's forests? Forest tenure and public forests in transition. Washington D.C.: Forest Trends y Centro para el Derecho Internacional Ambiental (CIEL). 


Los Documentos de CIFOR contienen resultados de investigación relevantes para la gestion de bosques tropicales. Su contenido es revisado por pares interna y externamente.

En muchos países en desarrollo, pero especialmente en América Latina, los derechos a cerca de 200 millones de hectáreas de bosque se han reconocido o transferido legalmente a comunidades locales y grupos indígenas. Estos cambios en las políticas se han unido para formar lo que hoy entendemos por reformas en la tenencia forestal, similar a las grandes reformas agrarias que tuvieron lugar a mediados del siglo $\mathrm{XX}$, con consecuencias igualmente importantes. Entender esta dinámica emergente exige el análisis sistemático y comparativo de los procesos y resultados asociados con estas reformas así como el desarrollo de marcos y enfoques que faciliten dicha comparación. Esta colección representa los resultados de una investigación preliminar.

La introducción presenta un panorama general de la historia de la reforma y los principales resultados de la investigación. Los siguientes cuatro capítulos temáticos exploran, respectivamente, los problemas que enfrentan los acuerdos de cogestión, las regulaciones como barreras a los derechos, los desafíos de participar en los mercados de madera, y la experiencia y el potencial de las organizaciones de segundo nivel. Tres estudios de caso examinan las concesiones forestales comunitarias del Petén, Guatemala, las áreas protegidas en el altiplano de Guatemala y un territorio indígena en Bolivia. Todos los artículos apuntan a uno de los hallazgos principales del estudio: obtener los derechos en papel no es mas que el punto de partida de un camino largo y difícil.

Esta investigación fue realizada por CIFOR como parte del Programa de Investigación de CGIAR sobre Bosques, Árboles y Agroforestería. El objetivo del programa es mejorar el manejo y uso de los bosques, la agroforestería y los recursos genéticos de los árboles a lo largo del paisaje, desde bosques hasta plantaciones. CIFOR dirige el programa de colaboración en asociación con Bioversity International, CIRAD, el Centro Internacional de Agricultura Tropical y el Centro Mundial de Agroforestería

\section{IDRC * CRDI}

\section{Center for International Forestry Research}

CIFOR impulsa el bienestar humano, la conservación ambiental y la equidad mediante investigación orientada hacia políticas y prácticas que afectan a los bosques de los países en vías de desarrollo. CIFOR es un centro de investigación del Consorcio CGIAR. La sede principal de CIFOR se encuentra en Bogor, Indonesia. El centro también cuenta con oficinas en Asia, África y Sudamérica.

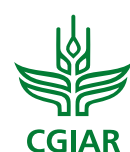

